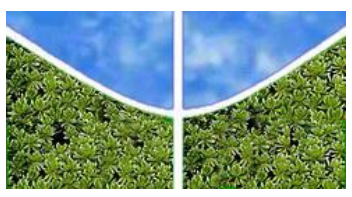

UNIVERSIDADE DE BRASÍLIA

INSTITUTO DE CIÊNCIAS HUMANAS

DEPARTAMENTO DE GEOGRAFIA

PROGRAMA DE PÓS-GRADUAÇÃO EM GEOGRAFIA

LABORATÓRIO DE SISTEMAS DE INFORMAÇÕES ESPACIAIS

\title{
INTEGRAÇÃO DE MODELOS HIDROLÓGICO E ECONÔMICO PARA A AVALIAÇÃO DOS CUSTOS INTERNOS DA EROSÃO NA AGRICULTURA EM BACIAS HIDROGRÁFICAS
}

THIAGO AVELAR CHAVES

ORIENTADOR: PROF.DR. OSMAR ABÍLIO DE CARVALHO JÚNIOR CO-ORIENTADOR: DR. JORGE ENOCH FURQUIM WERNECK LIMA 


\section{INTEGRAÇÃO DE MODELOS HIDROLÓGICO E ECONÔMICO PARA A AVALIAÇÃO DOS CUSTOS INTERNOS DA EROSÃO NA AGRICULTURA EM BACIAS HIDROGRÁFICAS}

Tese de Doutorado submetida ao Departamento de Geografia da Universidade de Brasília, como parte dos requisitos necessários à obtenção do Grau de Doutor em Geografia, linha de pesquisa "Geoprocessamento".

ORIENTADOR: PROF.DR. OSMAR ABÍLIO DE CARVALHO JÚNIOR CO-ORIENTADOR: DR. JORGE ENOCH FURQUIM WERNECK LIMA

Brasília 29 de Fevereiro de 2016 


\section{DEFESA DE DOUTORADO}

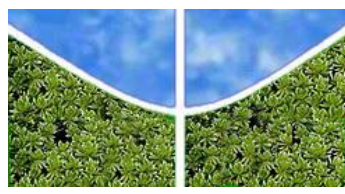

BRASÍLIA

FEVEREIRO/2016

PROGRAMA DE PÓS-GRADUAÇÃO EM GEOGRAFIA

LABORATÓRIO DE SISTEMAS DE INFORMAÇÕES ESPACIAIS

\section{INTEGRAÇÃO DE MODELOS HIDROLÓGICO E ECONÔMICO PARA A AVALIAÇÃO DOS CUSTOS INTERNOS DA EROSÃO NA AGRICULTURA EM BACIAS HIDROGRÁFICAS}

\section{THIAGO AVELAR CHAVES}

Defesa de Doutorado aprovada pela Banca Examinadora, constituída por:

Prof. Dr. Osmar Abílio de Carvalho Júnior - Universidade de Brasília (Orientador)

Prof. Dr. - Ricardo Tezini Minoti (Examinador - Universidade de Brasília)
Dr. Jorge Enoch Furquim Werneck Lima

- Embrapa (Co-orientador)

Prof $^{a}$. Dr ${ }^{\mathrm{a}}$. - Conceição de Maria Albuquerque Alves (Examinadora Universidade de Brasília)

Prof. Dr. - Abelardo Antônio de Assunção Montenegro (Examinador Universidade Federal Rural de Pernambuco)

Brasília, 29 de Fevereiro de 2016 


\section{FICHA CATALOGRÁFICA}

\section{CHAVES, THIAGO AVELAR}

Integração de modelos hidrológico e econômico para a avaliação dos custos internos da erosão na agricultura em bacias hidrográficas, 140 p., 297mm, (UnB-IH-GEA-LSIE, Doutorado, 2016).

Tese de Doutorado - Universidade de Brasília. Departamento de Geografia.

1 - Custo Econômico da Erosão

2 - SWAT

3 - Modelagem Hidrológica

4 - Calibração e Verificação

5 - Custos de Reposição de Nutrientes

\section{REFERÊNCIA BIBLIOGRÁFICA}

CHAVES, Thiago Avelar. Integração de modelos hidrológico e econômico para a avaliação dos custos internos da erosão na agricultura em bacias hidrográficas. Tese de Doutorado, Curso de Pós-Graduação em Geografia, Universidade de Brasília, 2016, 140 p.

\section{CESSÃO DE DIREITOS}

NOME DO AUTOR: Thiago Avelar Chaves

TÍTULO DA TESE: INTEGRAÇÃO DE MODELOS HIDROLÓGICO E ECONÔMICO PARA A AVALIAÇÃO DOS CUSTOS INTERNOS DA EROSÃO NA AGRICULTURA EM BACIAS HIDROGRÁFICAS

GRAU/ ANO: Doutor/ 2016

É concedida à Universidade de Brasília permissão para reproduzir cópias desta dissertação e emprestar ou vender tais cópias somente para propósitos acadêmicos e científicos. O autor reserva outros direitos de publicação e nenhuma parte desta tese de doutorado pode ser reproduzida sem a autorização por escrito do autor. 


\section{AGRADECIMENTOS}

Aos meus pais, Dóris Magna Avelar de Oliveira (in memorian) e Rubens Chaves de Oliveira , exemplos de vida e superação para toda a família. Meus irmãos Arthur Avelar Chaves, pelas horas de descontração com nossas partidas e análises de jogos, filmes e séries, e Igor Avelar Chaves, mesmo estando literalmente do outro lado do mundo, sempre esteve presente.

Aos professores Roberto Arnaldo Trancoso Gomes, Osmar Abílio de Carvalho Júnior, Renato Fontes Guimarães, Éder de Souza Martins e Jorge Enoch Furquim Werneck Lima pelos anos de dedicação, amizade, confiança e aprendizado.

Aos colegas do Laboratório de Sistemas de Informações Espaciais, Wátila, Sandro, Míriam, Nicolas, Verônica, Vinícius, e Marcus Fábio pelas discussões, debates, sugestões e críticas que contribuíram significativamente para o desenvolvimento da tese.

Ao corpo docente do Departamento de Geografia da UnB.

Aos meus amigos Tunico e Marina pela compreensão, dado que minha ausência foi constante.

Agradeço também ao Laboratório de Hidrometria, Laboratório de Química de Água, e Laboratório de Biofísica Ambiental da Embrapa Cerrados pelo apoio logístico nos trabalhos de campo e pelos dados necessários para a modelagem hidrológica na tese.

Em especial, agradeço à Adriana Dias por todo o companheirismo, carinho e apoio dado durante o desenvolvimento da tese.

Por fim, agradeço à CAPES pelo apoio financeiro por meio de bolsa de estudo. 


\section{RESUMO}

As perdas de solo e nutrientes por meio de processos erosivos constituem um fator importante na redução da capacidade produtiva do solo, podendo provocar impactos econômicos em diversas escalas. Nesse sentido, trabalhos que visem integrar modelos de base física com métodos de valoração econômica podem representar importante ferramenta de gestão do espaço geográfico, uma vez que esta integração pode reduzir o grau de incerteza na avaliação econômica ambiental. Este trabalho possui como objetivo realizar a integração de modelos hidrológico e econômico para estimar os custos internos provocados pela erosão na agricultura. Para tal, foi utilizado o modelo SWAT (Soil and Water Assessment Tool) - para estimar a perda de solos; a perda de nutrientes e corretivos como nitrogênio $(\mathrm{N})$, fósforo $(\mathrm{P})$, potássio $(\mathrm{K})$, cálcio $(\mathrm{Ca})$ e magnésio $(\mathrm{Mg})$; e a produtividade nas áreas de agricultura associado com o método de Custo de Reposição de Nutrientes para estimar quais os impactos econômicos da reposição de nutrientes no valor da produção. A abordagem metodológica utilizada foi aplicada na bacia experimental do córrego Sarandi - DF, abrangendo o período entre 2012 e 2014, contribuiu para a análise do custo interno da erosão em área agrícola com um menor grau de incerteza. Os resultados indicam que a área de estudo apresenta baixos níveis de perda de solos e nutrientes, refletindo nos custos de reposição de nutrientes, que apresentaram variação de 75,97 a 240,87 R $\$ . h^{-1}$ em 2012, de 86,51 e 212,81 R $\$ . h^{-1}$ em 2013, e de 87,81 e 447,05 R $\$ . h^{-1}$ em 2014, representando, na maior parte da bacia, menos de $2 \%$ do valor da produção.

Palavras-chave: Custo Econômico da Erosão; SWAT; Modelagem hidrológica; Calibração e Verificação; Custos de Reposição de Nutrientes 


\begin{abstract}
Soil and nutrient loss due to erosive processes is an important factor to soil productive capacity loss, incurring in economic impacts on many scales. In this sense, research that aim to integrate physical based models with economic valuation methods may represent an important tool of geographical space management, since this integration may reduce uncertainties in environmental economic valuation. This thesis aims to integrate hydrological and economic models to estimate on-site costs of erosion in agriculture areas. To achieve this, SWAT model (Soil and Water Assessment Tool) - used to estimate soil loss; nutrient losses of nitrogen (N), phosphorus $(\mathrm{P})$, potassium $(\mathrm{P})$, calcium $(\mathrm{Ca})$ and magnesium $(\mathrm{Mg})$; and crop productivity in the area of study - was integrated with the Nutrient Replacement Costs method to evaluate the economic impacts of nutrient replacement on production value. The methodological approach was applied in the Sarandi river experimental basin - DF, in a period between 2012 and 2014, which contributed to reduce uncertainty levels in assessing internal erosion costs in agricultural areas. Results show that the area has low levels of soil and nutrient losses, reflecting on nutrient replacement low costs, which varied from 75,97 a $240,87 \mathrm{R} \$$.ha-1 in 2012 , 86,51 e 212,81 R \$.ha-1 in 2013, and 87,81 e 447,05 R \$.ha-1 in 2014, representing on the majority of the area, less than $2 \%$ of production value.
\end{abstract}

Keywords: Economic costs of erosion; SWAT; Hydrologic model; Calibration and Verification; Nutrient Replacement Costs 
SUMÁRIO

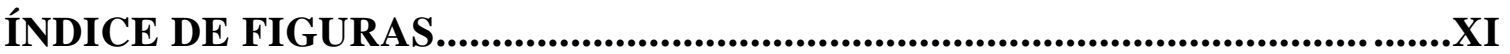

ÍNDICE DE TABELAS...........................................................................XIV

LISTA DE ABREVIATURAS..................................................................

1.0 - INTRODUÇÃO 20

1.1 - OBJETIVOS 22

1.1.1 - OBJETIVO GERAL 22

1.1.2 - OBJETIVOS ESPECÍFICOS 22

1.2 - HIPÓTESESS 23

2.0 - REFERENCIAL TEÓRICO 24

2.1 - CONCEITOS GEOGRÁFICOS APLICADOS À ANÁLISE 24 ECONÔMICA AMBIENTAL

2.1.1 - ESPAÇO E PAISAGEM 25

2.1.2 - PAISAGEM E SISTEMAS 30

2.1.3 - ECONOMIA AMBIENTAL 33

2.1.3.1 - Vertentes da Economia Ambiental 33

2.1.3.2 - Técnicas de Valoração Ambiental 34

2.1.4 - ESPAÇO, PAISAGEM E ECONOMIA AMBIENTAL 35

2.2 - EROSÃO NA AGRICULTURA 42

2.3 - MODELOS HIDROLÓGICOS 45

2.3.1 - MODELOS HIDROLÓGICOS ASSOCIADOS AO 46

GEOPROCESSAMENTO

2.4- O MODELO SWAT

2.4.1 - BALANÇO HÍDRICO 48

2.4.1.1 - Escoamento Superficial 49

3.0 - MATERIAIS E MÉTODOS 52

3.1 - ÁREA DE ESTUDO 
3.3 - APLICAÇÃO DO MODELO SWAT

3.3.1 - DADOS DE ENTRADA DO SWAT

$\begin{array}{lr}\text { 3.3.1.1 - Análise Morfométrica } & 57\end{array}$

3.3.1.2 - Análise do Uso e Cobertura da Terra 58

$\begin{array}{lr}\text { 3.3.1.3 - Base Pedológica } & 59\end{array}$

$\begin{array}{ll}\text { 3.3.1.4 - Dados Climáticos } & 60\end{array}$

3.3.1.5 - Práticas de Manejo na Área de Estudo 62

3.3.1.5.1 - Mapeamento da Produção $\quad 62$

3.3.1.5.2-Base de Fertilizantes $\quad 62$

3.3.1.5.3 - Práticas de Irrigação $\quad 63$

3.3.2 - ANÁLISE DE SENSIBILIDADE $\quad 64$

3.3.3 - CALIBRAÇÃO, VERIFICAÇÃO DO MODELO E ANÁLISE 71 ESTATÍSTICA

3.3.3.1 - Calibração e Verificação pela Vazão 72

3.3.3.2 - Calibração e Verificação pela Qualidade da Água 73

$\begin{array}{ll}\text { 3.3.3.2.1 - Sedimentos } & 73\end{array}$

3.3.3.2.2-Nutrientes $\quad 74$

3.3.4 - ANÁLISE DA PERDA DE SOLOS E PRODUÇÃO DE 75 SEDIMENTOS

3.3.5 - ANÁLISE DA PERDA DE NUTRIENTES 77

$\begin{array}{ll}\text { 3.3.5.1 - Perdas de N e P } & 77\end{array}$

$\begin{array}{ll}\text { 3.3.5.2 - Perdas de Ke Ca+Mg } & 78\end{array}$

3.4 - ANÁLISE DO CUSTO DE REPOSIÇÃO 78

3.5 - ANÁLISE DO IMPACTO ECONÔMICO DA REPOSIÇÃO DE 81 NUTRIENTES NA PRODUÇÃO

3.5.1 - CÁLCULO DA PRODUTIVIDADE 81

3.5.2 - CÁLCULO DO VALOR DA PRODUÇÃO 81

4.0 - RESULTADOS 
4.1 - ANÁLISE MORFOMÉTRICA 85

4.2 - MAPADE USO E COBERTURA DA TERRA 86

4.3 - MAPEAMENTO DA PRODUÇÃO NA ÁREA DE ESTUDO 88

4.4 - VALOR DE NPK APLICADO NAS HRUS DA ÁREA DE ESTUDO 90

4.5 - - DEFINIÇÃO DAS UNIDADES DE RESPOSTAS HIDROLÓGICAS 91 (HRUS)

4.6 - ANÁLISE DE SENSIBILIDADE 92

4.6.1 - VAZÃO 92

4.6.2 - SEDIMENTOS 93

4.6.3 - NUTRIENTES 95

4.7 - CALIBRAÇÃO E VERIFICAÇÃO DO MODELO SWAT 96

4.7.1 - SIMULAÇÃO DA VAZÃO 96

4.7.1.1 - Simulação do Balanço Hídrico na Bacia 100

4.7.2 - CALIBRAÇÃO E VERIFICAÇÃO DO MODELO SWAT PELO 101 SEDIMENTO

4.7.3 - CALIBRAÇÃO E VERIFICAÇÃO DO MODELO SWAT PELOS 106 NUTRIENTES

4.8 - ANÁLISE DA PERDA DE SOLOS 109

4.9 - ANÁLISE DA PERDA DE NUTRIENTES NA BACIA 113

4.8.1 - PERDAS DE N E P 113

4.8.2 - PERDAS DE K E Ca+Mg 116

4.10 - ANÁLISE DO CUSTO DE REPOSIÇÃO DE FERTILIZANTES 119

4.11 - IMPACTOS DA PERDA DE NUTRIENTES NO VALOR DA 121 PRODUÇÃO

5.0 - CONSIDERAÇÕES FINAIS 126

REFERÊNCIAS BIBLIOGRÁFICAS 128

$\begin{array}{ll}\text { ANEXOS } & 139\end{array}$ 


\section{ÍNDICE DE FIGURAS}

Figura 1 - Perfil esquemático demonstrando como a paisagem se insere dentro da 29 totalidade do espaço geográfico

Figura 2 - Principais relações entre os elementos formadores da paisagem, 31 representado por ampulheta (Fonte: Martins et al., 2004)

Figura 3 - Complexidade, Escala de Benefícios, e Provável Importância de uma 38 paisagem em diferentes escalas ecológicas (MITSCH E GOSSELINK, 2000)

Figura 4 - Valor global de uma porção adicional da paisagem em determinada 39 região em função da população humana próxima

Figura 5 - Representação gráfica do método de Custo de Reposição para 44 levantamento dos custos internos da erosão na agricultura (BARBIER, 1998)

Figura 6 - Metodologia adotada

Figura 7 - Localização da área de estudo em relação ao território do Distrito 55 Federal em imagem SPOT de 2003. No detalhe, Imagem da região da Bacia Experimental do Córrego Sarandi proveniente de ortofotos obtidas em $2010 \mathrm{com}$ resolução espacial de $1 \mathrm{~m}$, disponibilizadas pela Companhia Imobiliária de Brasília (TERRACAP, 2010).

Figura 8 - Fluxograma do Modelo SWAT (adaptado de Castro, 2013) 57

Figura 9 - Mapa de Solo em escala 1:30.000 (LIMA, 2013) 60

Figura 10 - Série de chuva (mm) entre jan/2012 a dez/2014. A) CPAC_Principal; 61 B) CPAC-Chapada (Dados cedidos pelo Laboratório de Biofísica Ambiental da Embrapa Cerrados)

Figura 11 - Série de vazão na Estação Jusante (Dados cedidos pelo Laboratório 73 de Hidrometria da Embrapa Cerrados)

Figura 12 - Série de sedimentos na Estação Jusante (Dados cedidos pelo 74 Laboratório de Hidrometria da Embrapa Cerrados)

Figura 13 - Série de NO3 (kg) na Estação Jusante (Dados cedidos pelo 75 Laboratório de Química de Água da Embrapa Cerrados)

Figura 14 - Modelo Digital de Terreno da Área de Estudo 85

Figura 15 - Declividade da Área de Estudo 86

Figura 16 - Mapa de Uso e Ocupação da Terra na Bacia do Sarandi em escala 88 1:25.000

Figura 17 - Mapa de Produção na bacia do córrego Sarandi 
Figura 18 - Mapa de HRUs geradas na interface ArcSWAT 92

Figura 19 - Valores de t-stat e p-value dos parâmetros relacionados à vazão 93

Figura 20 - Valores de t-stat e p-value dos parâmetros relacionados aos 94 sedimentos

Figura 21 - Valores de t-stat e p-value dos parâmetros relacionados aos nutrientes 95

Figura 22 - Comparação entre dados simulados com dados observados de vazão 96 e de chuva sem calibração

Figura 23 - Comparação entre dados simulados com dados observados de vazão 98 e de chuva após a calibração

Figura 24 - Gráfico de dispersão dos dados de vazão observados e simulados no 99 período de 2012 a 2014 sem calibração

Figura 25 - Gráfico de dispersão dos dados de vazão observados e simulados no 100 período de 2012 a 2014 após a calibração

Figura 26 - Ciclo Hidrológico Simulado pelo SWAT - todas as unidades em mm 101 (Figura gerada pelo aplicativo SWAT-Check)

Figura 27 - Comparação entre dados simulados com dados observados de 102 sedimentos e de chuva sem calibração

Figura 28 - Comparação entre dados simulados com dados observados de 104 sedimentos e de chuva após a calibração

Figura 29 - Gráfico de dispersão dos dados de sedimentos observados e simulados 105 no período de 2012 a 2014 sem calibração

Figura 30 - Gráfico de dispersão dos dados de sedimentos observados e simulados 105 no período de 2012 a 2014 após a calibração

Figura 31 - Comparação entre dados simulados com dados observados de NO3 e 106 de chuva sem calibração

Figura 32 - Comparação entre dados simulados com dados observados de NO3 e 108 de chuva após a calibração

Figura 33 - Gráfico de dispersão dos dados de NO3 observados e simulados no 109 período de 2012 a 2014 sem calibração

Figura 34 - Gráfico de dispersão dos dados de NO3 observados e simulados no 109 período de 2012 a 2014 sem calibração

Figura 35 - Erosão anual durante o período de jan/2012 a dez/2014 por HRU 
Figura 36 - Total de sedimento transportado no canal principal no período de 112 2012-2014 (toneladas.dia-1) comparados com os dados de precipitação registrado na Estação CPAC-Principal (mm)

Figura 37 - Perdas de N simulados pelo SWAT na área de produção agrícola da 114 bacia experimental do córrego Sarandi

Figura 38 - Perdas de P simulados pelo SWAT na área de produção agrícola da 115 bacia experimental do córrego Sarandi

Figura 39 - Perdas de K estimadas a partir das taxas de erosão laminar na área 117 de produção agrícola da bacia experimental do córrego Sarandi

Figura 40 - Perdas de Ca+Mg estimadas a partir das taxas de erosão laminar na 118 área de produção agrícola da bacia experimental do córrego Sarandi

Figura 41 - Custos de reposição de fertilizantes na área de produção agrícola da 120 bacia experimental do córrego Sarandi

Figura 42 - Produtividade simulada pelo SWAT

Figura 43 - Valor Presente Líquido da produção (R\$.ha-1) na área de estudo

Figura 44 - Custos relativos da reposição de nutrientes em relação ao VPL da 125 produção 


\section{ÍNDICE DE TABELAS}

Tabela 1 - Classificação das diversas paisagens culturais 32

Tabela 2 - Variáveis Utilizadas pelas Diferentes Técnicas de Valoração 36

Tabela 3 - Características de Sistemas Gerais, Sistema da Paisagem e Sistema 37 Econômico

Tabela 4 - Perdas econômicas internas e externas provocadas pela erosão 43

Tabela 5 - Balanço hídrico anual em pequenas bacias hidrográficas do Distrito Federal 49

Tabela 6 - Características dos Grupos Hidrológicos 51

$\begin{array}{ll}\text { Tabela } 7 \text { - Valores de CN2 Utilizados } & 59\end{array}$

Tabela 8 - Valores de NPK para cada tipo de produção existente na área de estudo 63

Tabela 9 - Quantidade de água aplicada durante as operações de irrigação na área de 64 estudo

Tabela 10 - Classificação de Sensibilidade dos Parâmetros do Modelo SWAT 65

Tabela 11 - Parâmetros identificados, por meio de análise de sensibilidade, como os 66 mais importantes na simulação da vazão em diversos trabalhos utilizando o modelo SWAT no Brasil

Tabela 12 - Variação dos parâmetros de vazão para análise de sensibilidade 68

Tabela 13 - Variação dos parâmetros de sedimentos para análise de sensibilidade 69

Tabela 14- Variação dos parâmetros de nutrientes para análise de sensibilidade 70

Tabela 15 - Valores Iniciais de CP utilizados 76

Tabela 16 - Classes de Perda de Solos 76

Tabela 17 - Custos de Aplicação e Preços dos Fertilizantes $\quad 80$

Tabela 18 - Coeficientes técnicos de conversão de nutrientes em fertilizantes 81

Tabela 19 - Custo de Implantação e Manutenção para Agricultura Irrigada, Pivô 83 Central e Agricultura de Sequeiro

Tabela 20 - Receitas geradas na Agricultura Irrigada, Pivô Central e Agricultura de 84 Sequeiro

Tabela 21 - Área ocupada pelas diversas culturas produzidas na bacia 90

Tabela 22 - Valores médios de NPK aplicados às operações de fertilização 91 
Tabela 23 - Comparação entre a variação de valores inicial e final utilizada no modelo 97 SWAT para parâmetros de vazão

Tabela 24 - Valores de ENS obtidos em simulações de vazão com o modelo SWAT no 98 Distrito Federal

Tabela 25 - Comparação entre a variação de valores inicial e final utilizada no modelo 102 SWAT para parâmetros de sedimentos

Tabela 26 - Valores de ENS obtidos em simulações de sedimentos com o modelo SWAT 103 no Distrito Federal

Tabela 27 - Comparação entre a variação de valores inicial e final utilizada no modelo 107 SWAT para parâmetros de qualidade da água

Tabela 28 - Valores de ENS obtidos em simulações de qualidade de água com o modelo 107 SWAT no Distrito Federal

Tabela 29 - Comparação dos resultados obtidos com os de Lima et. al. (2012) para o 110 período analisado 


\section{LISTA DE ABREVIAÇÕES}

SWAT

ADJ_PKR

AGNPS

Ahru

ALPHA-BF

ANION_EXCL

ANSWERS

BIOMIX

BLAI

C

Ca

Ca

CANMX

CDN

CFRG

CH_COV1

CH_COV2

CH-K2

CH-N2

CI

Cm

CMN

CN

CN1

CN2
Soil and Water Assessment Tool

Fator de ajuste de pico de sedimentos nos canais tributários (adimensional)

Agricultural Non-Point Source Pollution Model

Área da HRU (ha)

Constante de recessão do fluxo de base (dias)

Espaço vazio em que os ânions são excluídos

Areal Non-Point Source Watershed Environmental Response Simulation

Eficiência de mistura biológica (adimensional)

Índice de área foliar máxima

Cobertura superficial ou uso/ manejo (adimensional)

Cálcio

Custo de aplicação dos fertilizantes $\left(\mathrm{R} \$ \cdot \mathrm{ha}^{-1}\right)$

Capacidade máxima de armazenamento de água no dossel (mm.H2O)

Coeficientes da taxa exponencial da denitrificação (adimensional)

Fragmentos grosseiros $(\%)$

Fator de erodibilidade do canal (adimensional)

Fator de cobertura do canal (adimensional)

Condutividade hidráulica efetiva do canal $\left(\mathrm{mm} \cdot \mathrm{h}^{-1}\right)$

Coeficiente "n" de Manning para o canal principal

Custo de reposição de nutrientes $\left(\mathrm{R} \$ . \mathrm{ha}^{-1}\right)$

Custo de manutenção ou replantio da cultura

Fator de mineralização de húmus orgânico (adimensional)

Número da curva para um dia. Esse parâmetro é função da permeabilidade e uso da terra e da umidade que tem o solo antes de ocorrer a precipitação.

Representa a umidade do solo no ponto de murcha permanente, assim como o menor valor que o $\mathrm{CN}$ pode assumir em condições secas

Representa a umidade média do solo 
CN2

CN3

Co

CPAC

$\mathrm{Cr}$

DEEPST

DF

Ea

Embrapa

ENS

EPIC

ESCO

FRT_SURFACE Fração de fertilizante aplicado aos primeiros $10 \mathrm{~mm}$ da camada superficial do solo

GPS

GWDELAY

GW-QMN

GWREVAP

HRU

$\mathbf{I}_{\mathbf{a}}$

IBGE

K

K

L

LAT_SED

MDT

Mg

Curva número na condição II (adimensional)

Representa a umidade do solo em sua capacidade de campo

Investimento inicial do empreendimento

Centro de Pesquisas Agropecuárias do Cerrado

Custo de reposição de nutrientes na HRU

Altura inicial da água no aquífero profundo (mm)

Distrito Federal

Evapotranspiração total no dia i (mm H2O)

Empresa Brasileira de Pesquisas Agropecuárias

Coeficiente de Nash-Sutcliffe

Erosion Productivity Impact Calculator

Fator de compensação de evaporação do solo (adimensional)

Sistema de Posicionamento Global (Global Positioning System)

Tempo de retardo da água subterrânea (dias)

Limiar da profundidade da água no aquifero superficial para o fluxo de retorno ocorrer (mm)

Coeficiente revap, que determina a percolação da água no aquífero profundo para o raso (adimensional)

Unidade de resposta hidrológica - (Hydrologic Response Unit)

Perdas iniciais do escoamento, tais como acumulação superficial, interceptação e infiltração (mm)

Instituto Brasileiro de Geografia e Estatística

Potássio

erodibilidade do solo (ton.ha.h.hs ${ }^{-1}$.(MJ.mm) ${ }^{-1}$ )

comprimento de rampa (m)

Concentração de sedimento no fluxo lateral e subsuperficial (mg. $\left.\mathrm{L}^{-1}\right)$

Modelo Digital de Terreno

Magnésio 
MUSLE

$\mathbf{N}$

Nload

NO3

NPERCO

NPK

OV_N

$\mathbf{P}$

$\boldsymbol{P}$

$\mathbf{P}$

p-factor

Pn

PRF_BSN

Qgw

QI

Qn

qp

$\mathbf{Q}_{\text {surf }}$

$\mathbf{r}$

R

$\mathbf{R}^{2}$

RCN

$\mathbf{R}_{\text {day }}$

REVAPMN

r-factor

RSDCO
Equação universal de perda de solos modificada (Modified Universal Soil Loss Equation)

Nitrogênio

Quantidade de NO3 carreado pelo escoamento superficial (kg N.dia ${ }^{-1}$ )

Concentração de nitrato $\left(\mathrm{mg} . \mathrm{L}^{-1}\right)$

Coeficientede percolação de nitrogênio (adimensional)

Proporção entre a quantidade de Nitrogênio, Fósforo e Potássio presentes no fertilizante $\left(\mathrm{kg} \cdot \mathrm{ha}^{-1}\right)$

Coeficiente de rugosidade de Manning do escoamento superficial (adimensional)

Fósforo

Paisagem

práticas conservacionistas (adimenisonal)

Representa o quanto os dados observados encontram-se dentro da curva de incerteza

Preço dos fertilizantes $\left(\mathrm{R} \$ . \mathrm{kg}^{-1}\right)$

Fator de ajuste de pico dos sedimentos no canal (adimensional)

Quantidade de água que retorna ao curso de água no dia i por meio de escoamento sub-superficial

Lâmina de escoamento superficial (mm.ha-1)

Quantidade de fertilizantes carreados por processos erosivos (kg.ha-1)

Vazão de pico $\left(\mathrm{m}^{3} . \mathrm{s}-1\right)$

Quantidade e escoamento superficial no dia i (mm H2O)

Taxa de juros privado

Valor de mercado do produto final

Coeficiente de determinação

Concentração de N na chuva (mg N.L $\left.{ }^{-1}\right)$

Quantidade de chuva precipitada no dia i (mm H2O)

Profundidade do aquífero em que ocorre o revap (mm)

Espessura da curva de incerteza

Coeficiente de decomposição de resíduos (adimensional) 
SDNCO

Sed

SHALLST

SHALLST_N

SIG

SLSUBBSN

SOL_NO3

SOL_ORGN

SOL-ALB

SOL-AWC

SPCON

SPEXP

SPOT

SURLAG

Swo

$\mathbf{S W}_{\mathbf{t}}$

TERRACAP

USLE

USLE_C

USLE_K

USLE_P

VPL

$\mathbf{W}_{\text {seep }}$

$\boldsymbol{\alpha}$ parâmetro de retenção (mm)

gradiente de declividade (\%)

Limiar da quantidade de água para denitrificação (adimensional)

Produção de sedimentos diária (toneladas)

Altura inicial da água subterrânea $(\mathrm{mm})$

Concentração de nitrato existente na água subsuperficial contribuindo para a vazão na sub-bacia (mg N.L ${ }^{-1}$ )

Sistema de Informações Geográficas

Tamanho médio do comprimento de rampa (m)

Concentração inicial de NO3 nas camadas de solo (mg.kg-1)

Concentração inicial de $\mathrm{N}$ orgânico nas camadas de solo $\left(\mathrm{mg} \cdot \mathrm{kg}^{-1}\right)$

Albedo do solo (adimensional)

Capacidade de água disponível no solo $\left(\mathrm{mm} \cdot \mathrm{mm}^{-1}\right)$

Parâmetro linear para cálculo da quantidade máxima de sedimento que pode ser "reentrained" durante o "routing" do sedimento do canal (adimensional)

Parâmetro exponencial para cálculo da quantidade de sedimento que pode ser "reentrained" durante o "routing" do sedimento do canal (adimensional)

Satelite Pour l'Observation de la Terre

Coeficiente de lag do escoamento superficial

Quantidade inicial de água no solo no dia i (mm H2O)

Quantidade final de água no solo $(\mathrm{mm} \mathrm{H} 2 \mathrm{O})$

Companhia Imobiliária de Brasília

Equação universal de perda de solos

Fator C da MUSLE (adimensional)

Fator K da MUSLE (adimensional)

Fator P da MUSLE (adimensional)

Valor presente líquido

Quantidade de água percolada entre a camada simulada para a camada inferior no dia i (mm H2O)

Processos de transformação da paisagem 


\section{0 - INTRODUÇÃO}

Os processos de tomadas de decisão em políticas públicas espaciais, em geral, possuem um alto grau de subjetividade, uma vez que existe uma carência de métodos que possam mensurar, de forma quantitativa e qualitativa, problemas relacionados aos serviços ecossistêmicos, dado que os custos provocados por impactos ambientais diversos normalmente não são considerados nestas políticas.

Nesse contexto, a integração de modelos hidrológicos e econômicos podem contribuir, a partir de análises que ocorrem na paisagem, para reduzir esses níveis de subjetividade. Assim, esta abordagem metodológica pode fornecer uma forma de quantificar e qualificar custos econômicos ambientais, contribuindo, dessa maneira, para a gestão ambiental e espacial como importante ferramenta de apoio a tomadas de decisão.

Desde meados da década de 1980, o foco das políticas de planejamento rural, se tornou mais abrangente, passando a considerar uma maior ênfase nas características da paisagem, incluindo a fauna e a flora entre estas características (WHATERN, 1986). Essa ênfase se dá pela necessidade de aliar o desenvolvimento econômico à qualidade ambiental, em especial da produção agrícola, uma vez que há uma demanda crescente frente ao aumento da população mundial, à salubridade alimentar e ao crescimento econômico baseado na agricultura.

Essa demanda fez com que, no Brasil, a agricultura tivesse um peso significativo na balança comercial, contribuindo para a geração de empregos, aumento das exportações, e dinamização da economia nacional (VIANA, 2004), sendo que, nesse cenário, a produção agrícola e florestal no país vem aumentando tanto pelo avanço fronteira agrícola como pelo aprimoramento dos sistemas produtivos (MINOTI, 2006). Porém, esse desenvolvimento em grande escala se correlaciona diretamente com mudanças na paisagem, acarretando em custos ambientais (Embrapa, 2003).

Nesse sentido, os efeitos das mudanças ambientais na paisagem e sua influência na economia devem ser considerados no estabelecimento de uma medida para a realocação dos recursos escassos (DRAKE, 1999), uma vez que o desenvolvimento econômico sustentável deve contemplar tanto a expansão e modernização dos diversos setores da economia como a manutenção da qualidade da paisagem, exigindo uma interação econômica, social e ambiental (HAMMOND et. al., 1995; HEINZE, 2002). 
Um exemplo dessas mudanças ambientais são os processos erosivos provocados pelas atividades antrópicas, cuja aceleração afeta a segurança alimentar mundial por meio da redução de terras agricultáveis disponíveis ao redor do globo. Os estudos e dados medidos acerca das dimensões e extensões da erosão do solo são escassos e concentrados em alguns locais do globo, sendo a estimativa para a perda de solos, em escala global é de 26 bilhões Mg ano-1 (DEN BIGGELLAR et. al., 2003).

A perda de solos por meio da erosão tende a aumentar o preço da produção em médio e longo prazos por meio da perda de nutrientes, ocasionando um aumento da demanda por fertilizantes e maior eficiência operacional do maquinário (SCHICK ET. al., 2000). Estes fatores levam a redução da capacidade produtiva do solo, que eventualmente levará a uma desvalorização da terra (TELLES et. al., 2011).

Assim, a perda de solo possui impactos ambientais tais como perda de nutrientes, alteração da estrutura do solo, e perda de matéria orgânica, afetando propriedades rurais, onde a carga de sedimentos e nutrientes alteram a qualidade de águas superficiais, além de afetar negativamente as funções dos serviços ambientais (BENNET, 1933; COHEN et. al. 2006; CHAVES, 2011; TELLES et. al., 2011).

A identificação dessas alterações na paisagem é geralmente baseada em diversos dados, tais como cartas topográficas, imagens de sensoriamento remoto, estudos geodésicos e morfométricos, lista de espécies originais, dados estatísticos, etc. Tais análises também devem considerar alterações ocorridas no tempo, tomando o estado em que a paisagem se encontra como ponto de referência (BENDER et al., 2005).

Nesse contexto, estudos econômicos ambientais que incorporam, do ponto de vista quantitativo, atributos espaciais, analisando os efeitos de determinado impacto, tanto a montante quanto à jusante de uma propriedade rural são relativamente escassos (TELLES et. al., 2011). Assim, há uma carência de métodos e modelos que associam medições de parâmetros ambientais feitas por modelos ecológicos, hidrológicos, e físicos, e modelos de valoração econômica (ANDRADE e ROMEIRO, 2013).

Com base no exposto, existe uma necessidade de trabalhos que visem integrar modelos de base física com métodos de valoração econômica para que haja uma redução no grau de incerteza na avaliação econômica ambiental, aumentando, assim, o número de ferramentas disponíveis para gestores e tomadores de decisão na distribuição de recursos para a promoção do desenvolvimento sustentável e econômico. 
Diante do exposto, neste trabalho é apresentada uma abordagem metodológica para a integração de modelos hidrológico e econômico objetivando a análise de custos internos da erosão em áreas agrícolas em bacias hidrográficas. Este processo visa reduzir o nível de incerteza e subjetividade na definição de custos ambientais e, consequentemente melhoria na mensuração do valor econômico ambiental, favorecendo a tomada de decisão e na avaliação de alternativas referentes à gestão espacial.

\section{1 - OBJETIVOS}

\subsection{1 - OBJETIVO GERAL}

Integrar modelos hidrológico e econômico para avaliar os custos internos provocados pela erosão em uma bacia hidrográfica ocupada por agricultura.

\subsection{2 - OBJETIVOS ESPECÍFICOS}

a. Avaliar a aplicabilidade do modelo SWAT na simulação da vazão, da perda de solos, da produção de sedimentos e do fluxo de nutrientes (NPK, $\mathrm{Ca}$ e $\mathrm{Mg}$ ) em uma bacia hidrográfica agrícola no Bioma Cerrado;

b. Integrar os resultados do modelo SWAT com um modelo de avaliação dos custos da erosão de forma espacialmente distribuída em uma bacia hidrográfica agrícola no Bioma Cerrado;

c. Avaliar a aplicabilidade do enfoque de integração dos modelos hidrológico e econômico em uma bacia hidrográfica agrícola do Bioma Cerrado;

d. Aplicação dos conceitos geográficos para a economia ambiental. 


\section{2 - HIPÓTESES}

a) A utilização de conceitos como espaço geográfico e paisagem se aplicam, conceitualmente, na integração de modelos hidrológicos e econômicos;

b) A integração de modelos hidrológico e econômico pode reduzir o grau de incerteza e subjetividade na valoração econômica ambiental;

c) Os custos internos da erosão possuem maior impacto no valor de produção de pequenas propriedades. 


\section{0 - REFERENCIAL TEÓRICO}

\section{1 - CONCEITOS GEOGRÁFICOS APLICADOS À ANÁLISE ECONÔMICA AMBIENTAL}

A totalidade do espaço geográfico é formada por diversas instâncias, entre elas, a paisagem. Uma característica fundamental a todas as paisagens é que estas estão sempre em transformação. Com o aumento da pressão sobre os recursos da paisagem, tais como: terra, água, minérios, entre outros, estas transformações se intensificam (HEIDE, et al., 2008).

Assim, existe a necessidade de aperfeiçoar as demandas sobre o uso da paisagem e de seus diversos elementos. O foco das políticas de planejamento, em especial, as de desenvolvimento rural (difundidas desde meados da década de 1980), enfatiza as características da paisagem, incluindo a fauna e a flora (WHATERN, 1986). Nesse sentido, os efeitos das mudanças ambientais na paisagem e sua influência na economia devem ser levados em conta para estabelecer uma medida para a realocação dos recursos escassos (DRAKE, 1999). Um exemplo disso é o fato de que, em nível localizado, a geração, manipulação e descarte de resíduos e efluentes recebem atenção de diversos países por meio de políticas defensivas, envolvendo, cada vez mais recursos econômicos e financeiros (MUELLER, 2007). Outro exemplo que podemos citar são os impactos causados pela degradação do solo e a retirada de seus nutrientes na agricultura, que provoca sérios problemas para a economia de diversos países. Tal degradação dos recursos da paisagem ameaça o crescimento econômico e o bemestar da população, afetando principalmente os indivíduos de baixa renda (BARBIER, 1998).

De acordo com Veiga e Ehlers (2003), a promoção de práticas conservacionistas é um vetor de dinamização de áreas rurais permitindo alavancar o crescimento econômico ao invés de prejudicá-lo. Bennet (1929) já apontava para esta questão ao chamar a atenção para os custos provocados pela erosão do solo na agricultura. Estes custos são provocados pela interferência das atividades econômicas na paisagem, que consistem nos fluxos de matéria, energia, e informação dos estoques de capital ${ }^{1}$ natural que combinam o capital manufaturado e humano para produzir um estado de bem-estar social (CONSTANZA et al., 1997). Os serviços ambientais fornecem o suporte necessário para a manutenção das funções da paisagem (ORTIZ,

\footnotetext{
${ }^{1}$ Constanza et al. (1997) consideram capital como um estoque de materiais ou informações que existem em determinado tempo, descrevendo suas categorias como: A) O capital natural é composto pelos elementos do meio ambiente, tais como minerais, ecossistemas, atmosfera, etc.; B) O capital manufaturado consiste no maquinário e edificações, e; C) O Capital humano consiste nos recursos humanos disponíveis.
} 
2003). Porém, tais serviços ambientais não são incorporados completamente ao mercado, assim como não são adequadamente quantificados em termos de serviços econômicos e capital manufaturado, recebendo pouco peso no contexto das decisões políticas, vindo a comprometer a sustentabilidade do crescimento econômico (CONSTANZA et al., 1997, FISHER et al., 2009). Além disso, os autores consideram importante a estimativa de valores marginais dos serviços ambientais, estimando a taxa de alteração do valor entre o ambiente natural e o alterado.

Para analisar tais mudanças, não devemos nos basear apenas nos aspectos econômicos dos serviços ambientais, mas também na dinâmica ambiental dos diferentes ecossistemas para não incorrer no erro de inferir que devemos substituir uma paisagem com maior valor econômico por outra de menor valor econômico, tal como fez Constanza et al. (1997). As mudanças podem ser analisadas a partir de um grande leque de dados, tais como: cartas topográficas, imagens de sensoriamento remoto, dados estatísticos, entre outros. Tais análises de mudanças devem considerar o estado em que a paisagem se encontra como ponto de referência (BENDER et al., 2005).

\subsection{1 - ESPAÇO E PAISAGEM}

Ao longo da história da humanidade, a compreensão acerca do tema do espaço geográfico e da paisagem foi influenciada pelo desenvolvimento da filosofia, religião, política, ciência, busca pela estética, entre outros aspectos (MAXIMIANO, 2004).

O conceito Gêneros de Vida (LA BLACHE, 2005) traz a noção de como as diferentes sociedades humanas são influenciadas pelo meio em que vivem. Porém, para o autor, o homem é considerado um agente passivo em relação ao ambiente. Este conceito trouxe grandes implicações para os estudos regionais dentro da ciência geográfica.

Ao abordar a importância da forma de como vivem os homens, La Blache (1954) afirma que as áreas são influenciadas pelos gêneros de vida que ali estão, ou seja, um gênero de vida constituído implica em uma ação metódica e contínua no meio, que age sobre a natureza das áreas. Essas associações (Homem-Natureza) vivem juntas e têm interesses recíprocos, uns beneficiando-se da presença dos outros. Nesse contexto, podem ser observadas adaptações das 
plantas e animais ao homem (por meio da domesticação) e do homem ao meio (adaptações físicas, culturais, alimentação, comportamento, construção, transporte etc.).

Por outro lado, Hartshorne (1959) apresenta um método menos empírico e um raciocínio mais dedutivo no trato das questões geográficas de sua época. Para o autor, a Geografia teria sua forma própria de analisar a realidade, não isolando os elementos da análise, mas sim trabalhando com suas inter-relações.

Um dos conceitos mais importantes encontrados na sua obra é o de Área, formada por múltiplos processos que deveriam ser considerados (HARTSHORNE, 1959). Esse conceito permitiu a análise de um só lugar considerando seus vários elementos integrados diversas vezes através do conhecimento profundo do local.

Já os autores contemporâneos enfatizam a importância e a interferência do capitalismo na realidade das cidades e as consequências desse fato. Harvey (2011) analisa a crise econômica do ano de 2008 a partir de uma abordagem marxista, enfatizando que o capitalismo não é capaz de superar suas contradições, ou seja, o que ele faz é contorná-la sucessivas vezes.

Após citar diversos ciclos de crises econômicas até culminar na crise das hipotecas dos bancos americanos, o autor argumenta que as cidades, enquanto alternativas para a superação de crises (provendo trabalho etc.), são a expressão do capitalismo. Uma situação interessante levantada pelo autor é a ideia de que os governos, com o objetivo de tentar resolver problemas de desemprego nas cidades, investem em infraestrutura, gerando emprego e renda, especialmente durante a fase de obras que tais atividades demandam.

Essa prática é chamada pelo autor de ciclo do capitalismo, uma vez que, cada vez mais as cidades aumentam com a implantação de obras que, seguramente pretendem melhorar a qualidade de vida dos habitantes, mas que, por outro lado, aumentam as áreas urbanas estimulando um aumento da população. Nesse sentido, o autor afirma que o sistema capitalista requer um processo contínuo de investimentos em urbanização/reurbanização para gerar emprego e renda, alimentando, assim, o mercado.

Carlos (2011) corrobora a ideia de Harvey (2011) ao abordar a questão do capitalismo e a cidade, e emenda o pensamento ao afirmar que as transformações no espaço geográfico devem ser acompanhadas pelo pensamento geográfico.

Com base no exposto, este trabalho irá se basear nas ideias de Santos (1996) - dado a sua abrangência na literatura da geografia brasileira - que afirma que o espaço geográfico é um 
"sistema de objetos e de ações", onde, por objeto, o autor entende que estes são os objetos geográficos, que dão forma, possuem uma estrutura e que as ações são as temporalidades, as funções e, através destas, os objetos geográficos adquirem processos específicos em sua existência produzindo assim, o espaço.

Dentro deste conceito mais geral, Santos (1996) conduz o leitor a uma intuição epistemológica deste sistema de objetos e ações através das diversas categorias do espaço geográfico, em que, inicialmente, desenvolve um raciocínio demonstrando que este sistema é o próprio espaço geográfico em si, caracterizado por possuir intencionalidades, que criam espaço através da interação entre objetos e ações. Estas intencionalidades resultantes de eventos específicos, em que ação e objeto são inseparáveis, podem ser conceituadas como:

\begin{abstract}
"O resultado de um feixe de vetores, conduzido por um processo, levando uma nova função ao meio pré-existente. Mas o evento só é identificável quando ele é percebido, isto é, se perfaz e se completa. E o evento somente se completa quando integrado ao meio. Somente aí há o evento, não antes. (...) se aquele feixe de vetores pudesse ser parado no caminho, antes de se instalar, não haveria evento. A ação não se dá sem que haja um objeto. E, quando exercida, acaba por se redefinir como ação e por redefinir o objeto. Por isso os eventos (dotados de intencionalidade) estão dotados no próprio coração da interpretação geográfica dos fenômenos sociais” (SANTOS, 1996, p. 95).

"A ideia de forma-conteúdo une o processo e o resultado, a função e a forma, o passado e o futuro, o objeto e o sujeito, o natural e o social” (SANTOS, 1996, p. 66).
\end{abstract}

Nesse sentido, o espaço geográfico é a totalidade, ou seja, é "a especificação do todo social" (SANTOS, 1996, p. 120).

Além disso, Santos (1996) considera necessário a distinção entre a Paisagem e o Espaço:

\footnotetext{
"A paisagem é o conjunto de formas que, num dado momento, exprimem as heranças que representam as sucessivas relações localizadas entre homem e natureza. $O$ espaço são essas formas mais a vida que as anima” (SANTOS, 1996, p. 103).
}

De acordo com Martinelli e Pedrotti (2001) e Rocha (2007), que realizaram extensa revisão bibliográfica sobre o tema, a humanidade utiliza a paisagem como expressão de vivência desde seus primórdios, mas, é somente a partir de pensadores como Aristóteles, que este conceito passa a ser refletido, visualizando-o como um composto de elementos naturais e construídos. 
O termo paisagem é aplicado como conceito geográfico durante a primeira metade do séc. XIX com o trabalho do naturalista Alexander Von Humbold, que se baseia na fisionomia da vegetação como critério essencial para a caracterização de uma paisagem. O conceito passa, a partir deste momento, por uma série de modificações que seguem até os dias de hoje (HOLZER, 1999; MARTINELLI e PEDROTTI, 2001; ROCHA, 2007).

Rocha (2007) coloca que, o marco para o desenvolvimento do pensamento geográfico se dá com o estabelecimento da discussão em torno das culturas. A partir das ideias de Sauer, "a paisagem é referenciada não mais apenas como uma cena contemplada por um observador, mas da percepção de diversas cenas individuais" (ROCHA, 2007, p. 24). Nesse sentido, a paisagem possui, ao mesmo tempo uma individualidade e se relaciona com outras paisagens.

Nesse sentido, Martinelli e Pedrotti (2001), dizem que as escalas temporais e espaciais são fundamentais para o discernimento de diferentes paisagens, já que:

\footnotetext{
"Sua adequação tem a ver com a categoria de estudo, (...) compativel com a resolução dos fenômenos nela enquadrados, os quais por sua vez demandam certo tempo para a sua organização, e com a consequente manifestação espacial característica. Porém, esses fenômenos não acontecem apenas de forma sucessiva, mas também de maneira simultânea. (...) a categoria espacial e, concomitantemente, temporal de interesse estaria inserida numa sequência hierarquizada de escalas temporo-espaciais, a qual escalonaria as ordens de grandeza, os respectivos relacionamentos ou contradições de natureza física, biológica ou social (...)" (MARTINELLI e PEDROTTI, 2001, p.41).
}

Já Maximiano (2004) entende a paisagem como uma manifestação do espaço geográfico, sendo o produto das interações entre elementos de origem natural e humana, em um determinado espaço, que se organizam de maneira dinâmica, ao longo do tempo e do espaço. Tal processo resulta na formação de feições dinâmicas, diferenciadas ou repetidas, permitindo a sua classificação.

Martins et al. (2004) partem de uma abordagem multidisciplinar para apresentar a noção de que a paisagem se insere em um conjunto de sistemas e ações. Apesar de possuir uma abordagem diferenciada de Santos (1996), estes autores se aproximam das ideias deste quando afirmam que:

\footnotetext{
"As imagens de ação estão se tornando mais importantes que as imagens de objeto. O estudo das transformações torna-se o foco das pesquisas (da Ecologia das Paisagens), uma vez que as transformações humanas da paisagem tornaram-se preponderantes diante dos processos naturais. Os objetos não são mais estáticos. As
} 
estruturas que suportam os aspectos dinâmicos de uma paisagem não são estáticas. Apenas apresentam ciclos mais longos que os aspectos que estão sendo estudados“(MARTINS et al., 2004, p. 16).

Os autores supracitados concordam sobre a noção de totalidade do espaço geográfico, onde tempo e espaço são indissociáveis. Além disso, concordam que os processos internos da paisagem são formados por diversos elementos, compostos por fatores ambientais (geologia, geomorfologia, clima, solos, vegetação, fauna e intervenções antrópicas).

Podemos elaborar tal afirmação com o seguinte exemplo, ilustrado na Figura 1: uma paisagem $P_{1}$ se transforma em paisagem $P_{2}$ dentro de um tempo $t_{1}$ por meio de seus processos internos $\alpha_{1}$, posteriormente, $P_{2}$ se transforma em $P_{3}$ dentro de um tempo $t_{2}$ por meio de seus processos internos $\alpha_{2}$, e assim por diante até $P_{n}$, dentro de um tempo $t_{n}$ por meio de processos $\alpha_{n}$, onde a totalidade destes processos formam o espaço geográfico.

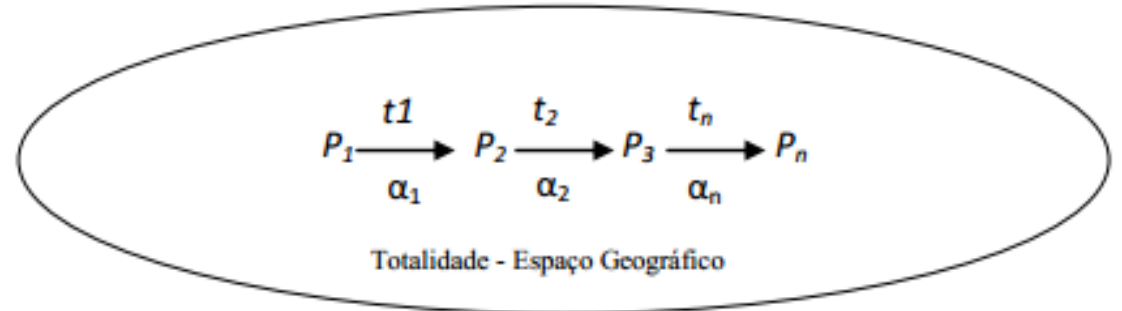

\section{Figura 1 - Perfil esquemático demonstrando como a paisagem se insere dentro da totalidade do espaço geográfico}

Assim, podemos visualizar os feixes de vetores colocados por Santos (1996), as funções que cada elemento da paisagem possui, e, quando estas se transformam, a paisagem também se transforma. Maximiano (2002) coloca que estas transformações ocorrem pelo caráter dinâmico dos elementos da paisagem.

Por fim, Martins et al. (2004) sugere a noção de temporalidade, convergindo com as ideias de Santos (1996) de que "a paisagem é um conjunto de formas em um dado momento", porém, para chegar a este momento, ocorreram processos dinâmicos que moldaram a paisagem.

Assim, pode-se afirmar que os padrões da paisagem surgem a partir de diversos processos e respostas entre seus elementos, onde estes atuam em dinâmicas espaciais e temporais distintos envolvendo sua agregação e classificação em entidades ecologicamente interpretáveis (BOLLINGER, 2005). 


\subsection{2 - PAISAGEM E SISTEMAS}

No geral, as diversas abordagens científicas buscam compreender o funcionamento de um sistema a partir do comportamento de entrada e saída de matéria e energia. Assim, são estudados os fenômenos que ocorrem entre o sistema e o seu meio circundante, ou seja, o estado de um sistema é como ele se apresenta externamente, como, por exemplo, na abordagem da termodinâmica (MARTINS et al., 2004).

É importante lembrar também, dentro deste contexto, a noção definida por Faissol (1973) de que os sistemas são formados por:

- Um conjunto de elementos identificados aos quais atribuímos ou percebemos características não necessariamente similares;

- Um conjunto de relações entre as características - atributos destes elementos objetivos;

- $\quad$ Um conjunto de relações entre este conjunto de elementos com seu ambiente externo.

Conforme Christofoletti (2004) pode-se considerar dois tipos de sistemas: os sistemas simples ou sistema linear, onde "os componentes são relacionados conjuntamente e agindo um sobre os outros conforme determinadas leis"; e os sistemas dinâmicos complexos definidos como "um conjunto de grande quantidade de elementos interligados, com capacidade de trocar informações com seu entorno condicionante, possuindo também a capacidade de adaptar sua estrutura interna como sendo consequências ligadas a tais interações".

A primeira lei da termodinâmica - Lei de Conservação de Energia - diz que um sistema, quando sofre transformação, esta possui implicações nos fluxos de matéria e energia. Já a segunda lei da termodinâmica - lei da Entropia - regula tais transformações, ao assegurar que a energia e, em alguns casos, parte da matéria transformada não retornem ao sistema, ou seja, alguns impactos ambientais podem provocar alterações na paisagem de forma que seu estado original não pode ser restaurado por meios naturais.

Conforme Martins et al. (2004), os fatores ambientais que formam os elementos da paisagem possuem propriedades emergentes que, quando relacionadas entre si, não são apenas a soma de suas partes, dado que possuem processos e dinâmicas distintos. Sendo que, estes 
últimos são os indicadores primários para o funcionamento de sistemas ambientais, em que a compreensão de seus ciclos individuais indica como os mesmos atuam e como se interrelacionam na paisagem em duas escalas diferentes: a escala temporal e a escala espacial.

A primeira se mostra nos ciclos de formação destes fatores, na seguinte ordem: rocha, clima, formas de relevo, solos e organismos. Já na segunda escala, os fatores são relacionados de forma hierárquica, onde uma unidade homogênea possui diversas unidades homogêneas dos fatores posicionados em hierarquia inferior - por exemplo, uma única litologia apresenta diferentes formas de relevo; uma única forma de relevo pode comportar diferentes tipos de solo, etc. (MARTINS et al., 2004). Estas escalas são demonstradas na Figura 2.

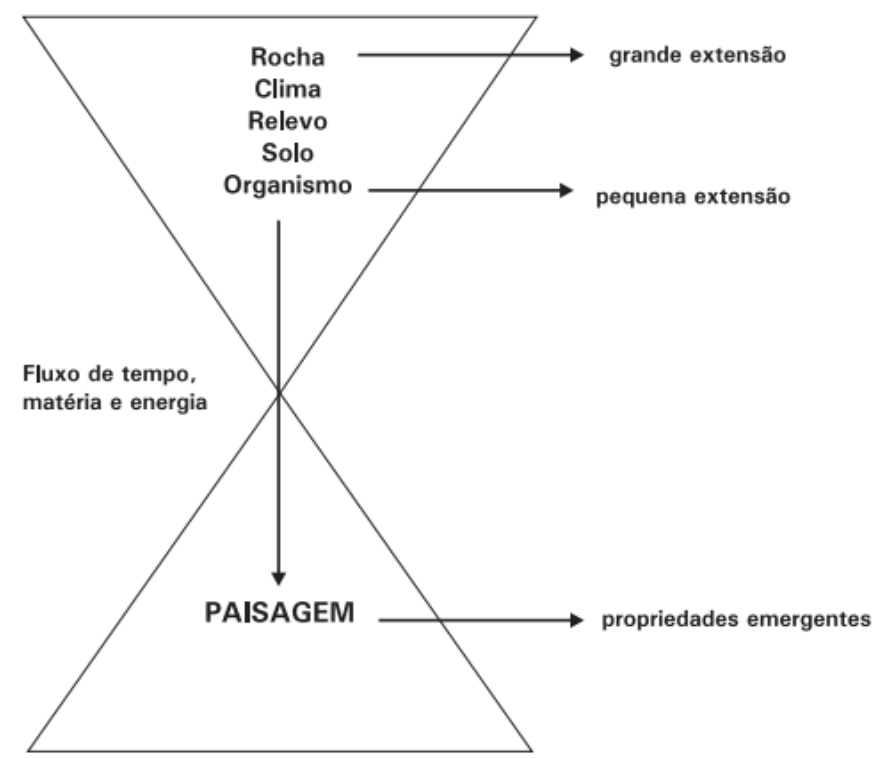

Figura 2 - Principais relações entre os elementos formadores da paisagem, representado por ampulheta (Martins et al., 2004)

Além da paisagem natural, formada pelos elementos descritos na Figura 2, existe a paisagem cultural. Stigliano et al. (2011) define paisagem cultural como a relação entre uma comunidade, abrangendo determinadas preferências culturais, e as características naturais da paisagem; podendo ser analisada tanto como um sistema físico como um sistema econômico por meio da entrada e saída de energia e/ ou capital, por meio da relação entre as atividades antrópicas e os fatores ambientais da paisagem. Tendo como base a taxa de importação e exportação de energia, a paisagem cultural pode ser dividida em local, regional e globalizada, conforme é apresentado na Tabela 1 (TAPPEINER et al., 1998; MARTINS et al., 2004; BENDER et al., 2005; MUELLER, 2007). 
Tabela 1 - Classificação das diversas paisagens culturais

\begin{tabular}{|c|c|c|c|}
\hline $\begin{array}{l}\text { Paisagem } \\
\text { Cultural }\end{array}$ & Descrição & Nível tecnológico & $\begin{array}{c}\text { Taxa de } \\
\text { importação e } \\
\text { exportação de } \\
\text { energia e } \\
\text { matéria } \\
\end{array}$ \\
\hline Local & $\begin{array}{l}\text { - Produto de longa interação do homem com } \\
\text { o ambiente; } \\
\text { - Possui tendência no equilíbrio no balanço } \\
\text { de matéria e energia; } \\
\text { - Tendência de ser sustentável no longo } \\
\text { prazo. }\end{array}$ & $\begin{array}{l}\text { Tecnologia que não } \\
\text { depende da utilização } \\
\text { externa à paisagem }\end{array}$ & Baixa \\
\hline Regional & $\begin{array}{l}\text { - Antecede a tendência de globalização; } \\
\text { - Fluxos ocorrem entre os centros urbanos e } \\
\text { meio rural; } \\
\text { - O intercâmbio entre regiões aumenta, de } \\
\text { forma progressiva, até chegar à nível } \\
\text { global. }\end{array}$ & & \\
\hline Globalizada & 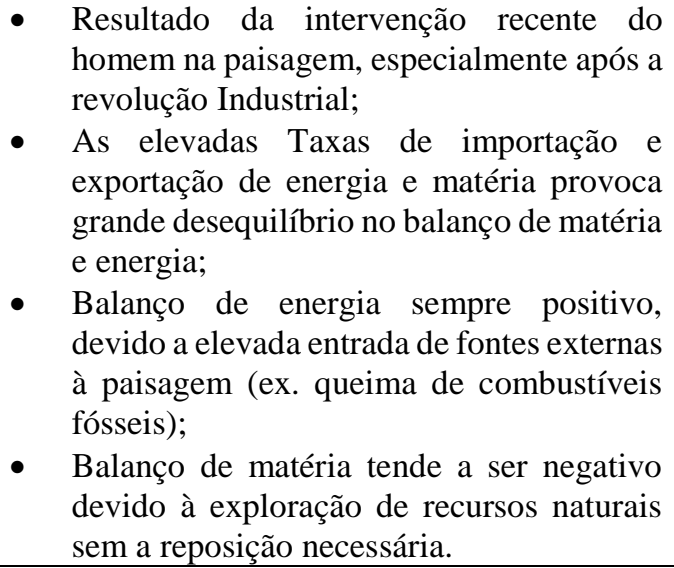 & $\begin{array}{l}\text { Tecnologia que } \\
\text { depende da entrada de } \\
\text { energia externa ao } \\
\text { sistema. }\end{array}$ & Elevada \\
\hline
\end{tabular}

Fonte: Adaptado de Martins et al. (2004). 


\subsection{3 - ECONOMIA AMBIENTAL}

\subsubsection{1 - Vertentes da Economia Ambiental}

A economia ambiental se propõe a apresentar soluções de atividades potencialmente poluidoras ou que possam provocar impactos ambientais a partir da aplicação de instrumentos econômicos, estabelecendo soluções econômicas para o gerenciamento ambiental em conjunto com instrumentos jurídicos (NETO e PETERS, 2005). Nesse contexto, a economia ambiental se divide em duas principais vertentes: a economia ambiental neoclássica e a economia ecológica.

A economia ambiental neoclássica possui o seu foco nos problemas ambientais de economias de mercado, com base em epistemologia mecanicista, considerando, portanto, um meio ambiente neutro e passivo, onde os impactos ambientais provocados pelo sistema econômico podem ser revertidos. Nesse sentido, esta vertente considera a existência de uma poluição ótima que representa o equilíbrio entre a satisfação do indivíduo perante os benefícios da produção e consumo de determinado bem ou serviço com o mal-estar provocado por estes (MUELLER, 2007).

Como exemplo, Barbier (1998) argumenta que, do ponto de vista econômico, a conservação do solo implica em criar um determinado "estoque" para uso futuro. Por outro lado, um fazendeiro pode escolher intensificar a produção, aumentando, dessa maneira, a pressão sobre o recurso ao custo de maiores taxas de erosão, provocando um esgotamento do recurso e inviabilizando o uso futuro. Neste contexto, o autor coloca que, do ponto de vista econômico, a conservação significa redistribuição de determinado recurso em taxas de uso visando ação futura, enquanto o termo esgotamento significa a redistribuição dos recursos para um uso no tempo presente. Assim, dentro dessa abordagem econômica, o manejo da erosão não deve ter o objetivo de anular os processos erosivos ou até mesmo atingir taxas de erosão ideais, mas deve buscar uma situação em que os benefícios marginais para a conservação do solo sejam iguais aos seus custos.

Já a economia ecológica considera que o sistema econômico provoca alterações, por vezes irreversíveis, ao interagir com os elementos da paisagem. Rejeitando assim, a ideia de que o meio ambiente é passivo, com capacidade ilimitada de fornecer recursos naturais e absorver os resíduos e efluentes gerados pelas atividades do sistema econômico, e, mesmo considerando a resiliência do meio ambiente, esta pode vir a ser comprometida dependendo do 
tamanho do impacto. Assim, esta vertente do pensamento considera o sistema econômico como uma entidade dotada de vida, que troca matéria e energia com seu meio externo, onde os limites do sistema econômico assim como a natureza de seus impactos merecem destaque (MUELLER, 2007). Por fim, esta vertente busca a definição desses limites, dentro dos princípios da precaução ${ }^{2}$, para a produção e consumo total de bens e serviços ambientais, onde, com este conhecimento, os incentivos econômicos através do mercado podem atuar de maneira significativa na alocação do consumo desses bens e serviços (ROMEIRO, 2003).

\title{
2.1.3.2 - Técnicas de Valoração Ambiental
}

Conforme Ortiz (2003), todo recurso ambiental possui um valor intrínseco, ou seja, o seu valor próprio, interior, inerente ou peculiar, que reflete seu direito de existência e interesses de espécies de fauna, flora e elementos abióticos. Porém, o autor destaca que, apesar da existência de métodos para determinar o valor intrínseco dos recursos naturais, o valor econômico destes recursos é aquele diretamente relacionado ao bem-estar social. Em relação à valoração econômica, o autor coloca que:

\begin{abstract}
“O principal objetivo da valoração econômica ambiental é estimar os custos sociais de se usar recursos ambientais escassos ou, ainda, incorporar os benefícios sociais advindos do uso desses recursos. Os economistas estimam valores ambientais em termos monetários de maneira a tornar esse valor comparável com outros valores de mercado, de forma a permitir a tomada de decisões envolvendo recursos ambientais. Ou seja, o que desejamos é a inclusão dos benefícios (e custos) ambientais na análise de custo/ benefício envolvendo recursos ambientais. Dessa forma, a valoração econômica ambiental é fundamental para a gestão de recursos ambientais, bem como para a tomada de decisões que envolvam projetos de grande impacto ambiental. Além disso, permite inserir de forma mais realista, o meio ambiente nas estratégias de desenvolvimento econômico, sejam estas locais, regionais ou nacionais" (ORTIZ, 2003, p. 82)
\end{abstract}

As técnicas de valoração se dividem em métodos indiretos e diretos. Os primeiros são os métodos que se baseiam diretamente nos preços e valores de mercado ou em alterações na produção provocadas por determinado impacto ambiental, além disso, buscam estimar o valor econômico do recurso natural com base nas mudanças provocadas no valor de bens

\footnotetext{
${ }^{2} \mathrm{O}$ princípio da precaução tem como objetivo "tratar de situações em que é necessário considerar legítima a adoção por antecipação de medidas relativas a uma fonte potencial de danos sem esperar que se disponha de certezas científicas quanto às relações de causalidade entre a atividade em questão e o dano temido" (ROMEIRO, 2003, p. 21)
} 
complementares e/ ou bens substitutos. Os métodos diretos são aqueles que, tendo por base os valores de mercado, buscam inferir as preferências individuais por bens ou serviços ambientais a partir de aplicação de questionários (ORTIZ, 2003; MUELLER, 2007).

A Tabela 2 apresenta exemplos das principais técnicas de valoração econômica, sendo importante destacar que não é objetivo deste trabalho discorrer sobre cada técnica ou discutir a sua validade e implicações éticas. Porém, é possível notar que, em todas elas existem elementos geográficos que podem acabar se tornando secundárias dentro de uma análise econômica, como impactos físicos, uso do solo, condições ambientais, habitats, alteração da paisagem, entre outros.

Quando aplicamos os conceitos geográficos discutidos anteriormente, podemos visualizar de forma mais clara a afirmação de Constanza et al. (1997), de que o exercício para estimar o valor de serviços ambientais consiste em determinar que sutis mudanças possam provocar no bem-estar humano.

\subsection{4 - ESPAÇO, PAISAGEM E ECONOMIA AMBIENTAL}

A configuração da paisagem, com seus atributos espaciais e distribuição de seus elementos, são influenciados pela sua forma e como seu planejamento é feito (HEIDE et al., 2008). Nesse sentido, para que a estimativa do valor econômico de um recurso natural seja mais eficiente, é preciso analisar a sua dimensão espacial e temporal, evitando que ele não seja analisado apenas como um bem econômico puro, mas sim como um bem que faz parte do espaço e da paisagem de determinada área, incorporando, dessa maneira, novas variáveis aos modelos econômicos existentes, como, por exemplo, carga de sedimentos, erosão, pluviosidade, fragmentação de vegetação, etc. (CHAVES, 2011). 
Tabela 2 - Variáveis Utilizadas pelas Diferentes Técnicas de Valoração

\begin{tabular}{|c|c|c|}
\hline Método & $\begin{array}{l}\text { Técnica de } \\
\text { Valoração } \\
\end{array}$ & Variáveis Utilizadas \\
\hline \multirow{9}{*}{ Indireto } & $\begin{array}{l}\text { Método do Custo de } \\
\text { Oportunidade }\end{array}$ & $\begin{array}{l}\text { Preços de mercado; } \\
\text { Valor de emprego de um recurso de dada maneira; } \\
\text { Valor de formas alternativas de uso }\end{array}$ \\
\hline & $\begin{array}{l}\text { Método da Mudança } \\
\text { de produtividade }\end{array}$ & $\begin{array}{l}\text { Impactos físicos da exploração econômica de recurso ambiental ao } \\
\text { longo do tempo; } \\
\text { Valor presente da perda de produção }\end{array}$ \\
\hline & $\begin{array}{l}\text { Método do Capital } \\
\text { Humano }\end{array}$ & $\begin{array}{l}\text { Fluxo de rendimentos esperados de cada indivíduo; } \\
\text { Probabilidade do indivíduo sobreviver em cada ano futuro após a } \\
\text { implementação de determinado projeto. }\end{array}$ \\
\hline & $\begin{array}{l}\text { Método do Custo de } \\
\text { Restauração }\end{array}$ & $\begin{array}{l}\text { Valor de restauração das condições ambientais após a ocorrência de } \\
\text { impacto ambiental }\end{array}$ \\
\hline & $\begin{array}{l}\text { Método do Preço de } \\
\text { Propriedade }\end{array}$ & $\begin{array}{l}\text { Preço de residências; } \\
\text { Característica das residências ( } \mathrm{n}^{\text {o }} \text { de cômodos, qualidade do material } \\
\text { utilizado, localização, estado de conservação da paisagem, etc.); } \\
\text { Técnicas estatísticas para isolar a contribuição das condições ambientais } \\
\text { na composição do preço da residência. }\end{array}$ \\
\hline & $\begin{array}{l}\text { Método do Diferencial } \\
\text { de Salários }\end{array}$ & $\begin{array}{l}\text { Salários pagos; } \\
\text { Local de trabalho; } \\
\text { Vantagens não-salariais oferecidas pela empresa; } \\
\text { Condições de transporte; } \\
\text { Acesso à moradia; } \\
\text { Qualidade do meio ambiente nos locais de trabalho; } \\
\text { Técnicas estatísticas para isolar a contribuição das condições ambientais } \\
\text { na diferença de salários de trabalhadores. }\end{array}$ \\
\hline & $\begin{array}{l}\text { Método do Custo de } \\
\text { Viagem }\end{array}$ & $\begin{array}{l}\text { Despesas de indivíduos ou famílias para chegar a estes locais, partindo } \\
\text { de seu local de residência; } \\
\text { Despesa com o ingresso à área de recreação (quando houver); } \\
\text { Custo de oportunidade do tempo dos viajantes; } \\
\text { Excedente do consumidor para as visitas dos indivíduos de cada área; } \\
\text { Excedente consumidor Total. }\end{array}$ \\
\hline & Preços Hedônicos & $\begin{array}{l}\text { Valor do bem de mercado; } \\
\text { Características ambientais que determinam o preço de mercado }\end{array}$ \\
\hline & Gastos Defensivos & $\begin{array}{l}\text { Gastos em bens substitutos para não alterar a quantidade consumida ou } \\
\text { qualidade do recurso natural }\end{array}$ \\
\hline \multirow[b]{2}{*}{ Direto } & $\begin{array}{l}\text { Valoração } \\
\text { Contingente }\end{array}$ & $\begin{array}{l}\text { Pesquisa amostral para determinar, em termos monetários, as } \\
\text { preferências individuais em relação a quantidade e/ ou qualidade de um } \\
\text { recurso natural. }\end{array}$ \\
\hline & $\begin{array}{l}\text { Ranqueamento } \\
\text { Contingente }\end{array}$ & $\begin{array}{l}\text { Pesquisa amostral para determinar, em termos monetários, as } \\
\text { preferências individuais em relação a quantidade e/ ou qualidade de um } \\
\text { recurso natural dentro de uma ordem de preferência de situações pré- } \\
\text { determinadas }\end{array}$ \\
\hline \multirow{3}{*}{$\begin{array}{l}\text { Análise } \\
\text { Custo- } \\
\text { Benefício }\end{array}$} & Valor de uso & $\begin{array}{l}\text { Valor presente do benefício líquido que os usuários do meio ambiente } \\
\text { não afetado por determinado projeto estimam usufruir dele. }\end{array}$ \\
\hline & Valor de Opção & $\begin{array}{l}\text { Valor presente do benefício líquido do meio ambiente preservado para } \\
\text { os indivíduos em sociedade que, em dado momento usufruem dele, mas } \\
\text { desejam fazer também uso futuro deste bem. }\end{array}$ \\
\hline & Valor de Existência & $\begin{array}{l}\text { Valor atribuído pela sociedade para a existência de uma área preservada } \\
\text { ou de uma reserva natural }\end{array}$ \\
\hline
\end{tabular}

Fonte: Adaptado de Ortiz (2003) e Mueller (2007). 
Barbier (1994) afirma que a valoração de um ambiente significa dar valor às características do sistema. Assim, qualquer sistema, seja natural ou antrópico, pode ser caracterizado dentro de três conceitos-chave: estoque, fluxo, e organização desses estoques e fluxos. Essas três características possuem equivalência tanto na paisagem ${ }^{3}-$ componentes estruturais, funções ambientais, e diversidade cultural e paisagística; como na economia taxação de serviços e atributos ${ }^{4}$. A Tabela 3 resume esta ideia relacionando os aspectos da paisagem e sistema econômico.

Assim, a avaliação ecológica é utilizada em diversas situações quando se trata do planejamento de paisagens, uso do solo e conservação. Em escalas regionais, as técnicas de valoração são utilizadas para estimar o valor relativo de diferentes localizações dentro de uma determinada área. Em alguns estudos, o resultado da avaliação ecológica é apenas um dos diversos dados de entrada para elaborar planos de uso e conservação do solo, ou para determinar a importância de uma determinada área (WHATERN et al., 1986).

Tabela 3 - Características de Sistemas Gerais, Sistema da Paisagem e Sistema Econômico

\begin{tabular}{|c|c|c|}
\hline $\begin{array}{c}\text { Característica Geral } \\
\text { do Sistema }\end{array}$ & $\begin{array}{c}\text { Características do Sistema } \\
\text { da Paisagem }\end{array}$ & $\begin{array}{c}\text { Características do } \\
\text { Sistema Econômico }\end{array}$ \\
\hline Estoques & Componentes Estruturais & Taxas \\
\hline Fluxos & Funções ambientais & Serviços \\
\hline Organização & $\begin{array}{c}\text { Diversidade cultural e } \\
\text { paisagística }\end{array}$ & Atributos \\
\hline
\end{tabular}

Fonte: BARBIER (1994)

Um exemplo da relação intrínseca entre os conceitos geográficos e a economia ambiental é demonstrado por Mitsch e Gosselink (2000). Neste trabalho realiza-se a valoração econômica de campos pantanosos do centro oeste dos E.U.A., considerando os seguintes princípios: 1) os campos pantanosos são um sistema com diversos valores; 2) Os serviços ambientais de maior valor dos campos pantanosos são os que advêm do seu valor de uso e existência; 3) A relação entre as áreas de campos pantanosos e seu valor marginal é complexa; 4) Os valores comerciais possuem limites, enquanto os campos pantanosos oferecem serviços durante a sua existência; 5) A comparação entre o benefício imediato de um uso da paisagem

\footnotetext{
${ }^{3}$ Barbier (1994), assim como outros autores (Constanza et al., 1997; Barbier, 1998; Ortiz, 2003; Romeiro, 2003, Mueller, 2007, entre outros), utilizam, em alguns casos, termos como "ecologia", "diversidade biológica", "ambiente", etc., para se referir a elementos e funções da paisagem.

${ }^{4}$ Os atributos são definidos como a "diversidade biológica, característica ou herança cultural única, etc., que possuem valor econômico por induzirem atividades econômicas ou por possuir valor por si mesmo" (BARBIER, 1994, p. 156).
} 
em relação ao benefício em longo prazo da conservação dos campos pantanosos não é adequada; e 6) Os valores são influenciados por fatores culturais e econômicos.

A partir desses seis princípios, os autores consideram alguns fenômenos da paisagem e de escala para criar generalizações acerca dos campos pantanosos que tornam a valoração um exercício complexo, que podem ser extrapoladas para outras formas de paisagem.

O primeiro fenômeno é o Princípio da Escala, onde, dependendo da escala ecológica analisada, a complexidade, os benefícios e a sua provável importância, alteram as estimativas de valor (Figura 3).

\section{Complexidade Benefícios $\begin{gathered}\text { Provável } \\ \text { Importância }\end{gathered}$}
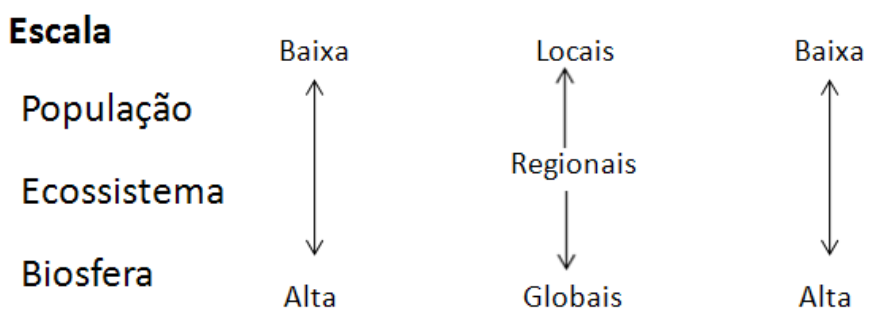

Figura 3 - Complexidade, Escala de Benefícios, e Provável Importância de uma paisagem em diferentes escalas ecológicas (MITSCH E GOSSELINK, 2000)

O segundo fenômeno é o Paradoxo do Valor Marginal, em que uma menor disponibilidade de áreas de paisagem natural não implica, necessariamente, um maior valor, considerando que a população humana sobrecarregou as funções de determinada paisagem natural, ou seja, em situações em que existe ausência de vida humana ou situações em que a densidade populacional é tão alta que anula as funções da paisagem, o valor desta é muito baixo ou até mesmo nulo, dado que o valor é atribuído a partir da percepção humana (Figura 4). 


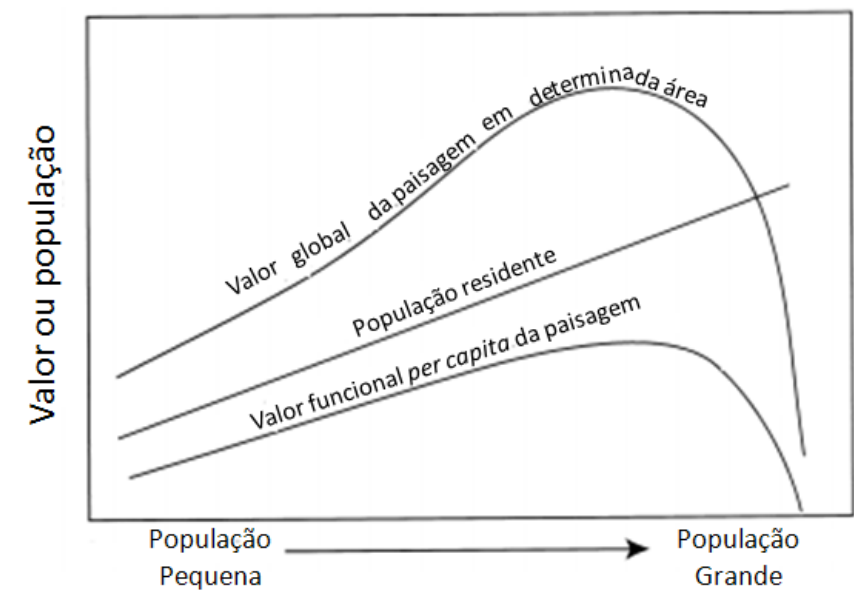

Figura 4 - Valor global de uma porção adicional da paisagem em determinada região em função da população humana próxima. $O$ valor global é o produto da multiplicação entre a população e o valor funcional per capita. $O$ valor funcional marginal per capita da paisagem inicialmente aumenta conforme a população cresce, dado que a disponibilidade dos recursos da paisagem é reduzida. Porém, a partir do momento em que a população cresce a um certo nível, as funções da paisagem são taxadas com diversos impactos ambientais, reduzindo assim, o valor funcional marginal é reduzido de forma abrupta com o aumento da população a partir deste ponto (MITSCH E GOSSELINK, 2000)

Outro fenômeno é o Princípio Hidrogeomórfico, em que o regime hídrico e a movimentação de sedimentos em determinada paisagem possuem funções reguladoras, tais como: áreas de inundação, áreas de acumulação de sedimento, áreas mais propensas a formação de erosão, áreas propensas a formações florestais, arbustivas ou campestres e, a disponibilidade de recursos hídricos à montante e à jusante, entre outros.

Por fim, o fenômeno do Paradoxo da Substituição de Ecossistemas, em que, a análise econômica segue uma lógica na qual diferentes valores são atribuídos a diferentes paisagens, substituindo a paisagem de menor valor por uma de maior valor. Mas como essa substituição é, em muitos casos, fisicamente impossível, dado as características geológicas, climáticas, geomorfológicas e pedológicas de determinada paisagem, esta visão estritamente econômica coloca uma limitação na análise econômica ambiental justamente por não haver uma contextualização espacial de determinado recurso ambiental, como feito em diversos trabalhos econômicos (CONSTANZA et al, 1997; MAY et al., 2003; MUELLER, 2007; FORTES et al., 2010).

Por outro lado, é importante destacar outros trabalhos que incorporam elementos e conceitos geográficos: 
- Barbier (1994) faz uma análise de custo-benefício na conservação e alteração de áreas pantanosas em ambientes tropicais a partir do custo de oportunidade advindo com a redução das áreas de campo natural, demonstrando que um nível menor de alteração destas seria uma situação mais benéfica. Além disso, o autor discute os limites da função de produção aproximada das características destas áreas que não possuem valor de mercado.

- Barbier (1998) considera a taxa de erosão dentro de uma determinada propriedade para estimar o custo da erosão no processo produtivo in-site, deixando implícito que as escolhas feitas pelos produtores para conservar ou não o solo são fortemente influenciadas pela cultura local de produção agrícola;

- Drake (1999) faz uma análise por método direto, a partir da valoração contingente para estimar o valor da paisagem agrícola na Suécia, utilizando como parâmetros as preferências dos indivíduos e características econômicas, sugerindo algumas políticas para mitigar os problemas identificados, tais como redução de terras agricultáveis, redução de elementos cênicos da paisagem e redução da biodiversidade.

- Heide et al. (2008) apresentou um método para auxiliar o planejamento espacial que combina a eficiência econômica com instrumentos de gestão participativa a partir do conceito de "disposição a pagar" na região norte dos Países Baixos, no distrito de Frisian Lake, aumentando assim, a colaboração mais ativa dos atores envolvidos na dinâmica espacial, de uma maneira a auxiliar os gestores a criar cenários no processo de planejamento e design.

- Constanza et al. (1997) argumentam que os serviços ecossistêmicos representam uma porção considerável do bem-estar humano. Os benefícios oferecidos pelos serviços ecossistêmicos para o bem-estar humano podem variar de serviços simples a serviços mais complexos. Os autores exemplificam uma floresta que oferece desde lenha até solo e umidade, criando microclimas. Porém, ao sugerir que um tipo de paisagem com maior valor econômico deve substituir um de menor valor, os autores não consideraram que esta imposição pode, no longo prazo, provocar diversos impactos ambientais negativos ocasionando, assim, um desequilíbrio nos serviços ecossistêmicos prestados pela paisagem.

- Nelson et al. (2009) se utiliza de modelagem espacial baseado em funções de produção para analisar diversos cenários de uso e cobertura da terra, quantificando alterações em diversos serviços ambientais em escala de paisagem para cada cenário e demonstrando 
as variações que podem ocorrer na valoração dos serviços ambientais em cada um dos cenários simulados.

- Um exemplo prático da aplicação da discussão desse trabalho é o Zoneamento Ecológico Econômico, regulamentado no Brasil pelo Decreto $\mathrm{n}^{\circ}$ 4.294, de 10 de Julho de 2002, sendo definido pelo mesmo documento em seus artigos $2^{\circ}$ e $3^{\circ}$ como "instrumento de organização do território" tendo como objetivo "organizar, de forma vinculada, as decisões dos agentes públicos e privados quanto a planos, programas, projetos e atividades que, direta ou indiretamente, utilizem recursos naturais, assegurando a manutenção do capital e serviços ambientais dos ecossistemas” levando em conta as características dos diversos ecossistemas existentes no território nacional. Para detalhes sobre estudos e discussões acerca do ZEE, ver AB'SÁBER (1989); CREPANI et. al. (1996); ACSELRAD, (2000); CREPANI et. al. (2001); DI FREITAS et. al. (2005); STEINBERGER (2006); VASCONCELOS et. al. (2013) entre diversos outros.

Por fim, Gómez-Baggethun et al. (2010), demonstram, a partir de uma análise do desenvolvimento do conceito de serviços ambientais, que o foco da valoração monetária e regimes de pagamento influenciaram para atrair apoio político para ações conservacionistas, porém, contribuiu para a comoditização de diversos serviços ambientais reforçando assim os paradigmas da economia neoclássica e reproduzindo a lógica do mercado na forma de intervenção em problemas ambientais, uma vez que, se o valor recebido não for alto o suficiente para compensar os custos de oportunidade de determinado serviço ambiental, então esta ação, dentro desse paradigma, pode ser considerado ineficiente.

Para contrapor esta visão, os conceitos geográficos de espaço e paisagem vêm a contribuir para tornar esta análise mais objetiva, com melhores critérios de análise, tendo como base as diferentes paisagens em diversos espaços geográficos formados ao longo do tempo. Assim, uma discussão, tal como a valoração de serviços ambientais, (que, conforme de Groot et al. (2010), faltam dados empíricos, teria um aporte de conceitos e tipologias para os serviços, valores e benefícios gerados por ações conservacionistas. 


\section{2 - EROSÃO NA AGRICULTURA}

A erosão afeta diretamente os meios de subsistência rurais, além de afetar de forma indireta, os recursos hídricos, dinâmica hidrossedimentológica, ciclo de carbono global, biodiversidade aquática e terrestre, e serviços ecossistêmicos, sendo que das terras cultiváveis do mundo, entre 30 e $50 \%$ se encontram substancialmente impactados pela perda de solo (COHEN et. al., 2006). Bennet $(1923,1929)$ já apontava para esta questão ao chamar a atenção para os custos provocados pela erosão do solo na agricultura.

Este impacto está associado a uma gama de questões ambientais, sociais e econômicas, sendo reconhecido como um grande obstáculo na segurança alimentar e uma questão preocupante no que tange ao desenvolvimento sustentável. Apesar da interferência de tecnologias para renovar recursos naturais para o uso, se determinados processos não forem interrompidos, podem comprometer, de forma irreversível, a capacidade produtiva de áreas agricultáveis (PIMENTEL et. al., 1995; TELLES et. al., 2011).

Além disso, a erosão dos solos acarreta custos internos, relacionados a perdas na eficiência da produção agrícola, e externos, relacionados à degradação de recursos naturais fundamentais para a manutenção da produção agrícola (ex. assoreamento dos recursos hídricos), cujas despesas não são incorporadas aos custos privados do produtor (BENNET, 1933; HUFSCHMIDT et al. 1983; BARBIER, 1990; BARBIER, 1994; MARQUES, 1998, BARBIER, 1998; DANTAS e MONTEIRO, 2010).

A partir de extensa revisão da literatura acerca dos custos econômicos da erosão, Telles et. al. (2011) listam uma série de efeitos negativos que a erosão provoca tanto na propriedade (custos internos) como para a sociedade (custos externos), conforme apresentado na Tabela 4. 
Tabela 4 - Perdas econômicas internas e externas provocadas pela erosão

\begin{tabular}{|c|c|}
\hline Perdas econômicas internas provocadas pela erosão & Perdas econômicas externas provocadas pela erosão \\
\hline $\begin{array}{l}\text { - Perda de solo; } \\
\text { - Perda de nutrientes; } \\
\text { - Perda de matéria orgânica no solo; } \\
\text { - } \quad \text { Redução da fertilidade química, física e biológica } \\
\text { - do solo; } \\
\text { - } \quad \text { Pueda na produção agrícola; } \\
\text { - Redução da área agricultável disponível; } \\
\text { - } \quad \text { Redução da renda. }\end{array}$ & 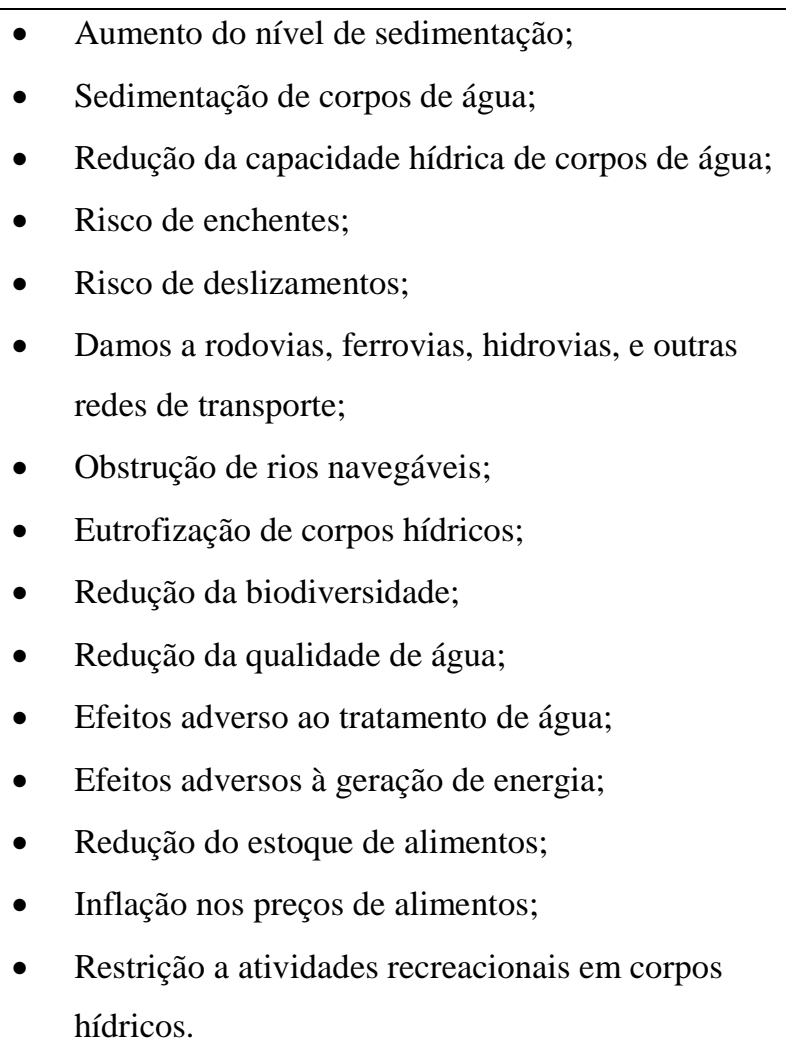 \\
\hline
\end{tabular}

Fonte: TELLES et. al. (2011)

Tradicionalmente, a implementação de práticas de conservação ambiental em áreas agrícolas é percebida como uma dificuldade ou até mesmo um fator de redução de lucros. Porém, com incentivos financeiros para a aplicação dessas práticas, o rendimento da produção pode chegar a aumentar, tornando a prática de manejo de erosão um custo de oportunidade para o produtor (VEIGA e EHLERS, 2003; MCCONNELL e BURGER, 2011). Dessa maneira, o produtor, como agente econômico racional irá determinar o quanto é necessário investir na prevenção de custos internos provocados pela erosão para que a sua produção seja sustentável no longo prazo.

Rodrigues (2005) realizou estudos comparativos entre produção de milho e soja em ambiente de cerrado demonstrando a maior eficácia do método de plantio direto para reduzir os efeitos internos e externos associados à erosão do solo.

Dantas e Monteiro (2010) aplicaram o método do custo de reposição na produção de soja do cerrado piauiense nas safras 2000/2001 e 2007/2008, demonstrando que a perda de 
nutrientes e sua reposição representa aproximadamente $2,9 \%$ do valor da produção naquele estado.

Sarcinelli et. al. (2009) realizou análise de custo-benefício de práticas conservacionistas na bacia do córrego Oriçanguinha (SP), utilizando como base da análise a reposição de nutrientes na bacia, cujos custos variaram entre 86,93 a $120,87 \mathrm{R} \$ \cdot \mathrm{ha}^{-1} \cdot \mathrm{ano}^{-1}$.

Pugliesi et. al. (2011) realizou diversos ensaios para estabelecer os custos associados à reposição de fertilizantes em latossolos vermelhos distroférricos no município de Campinas (SP), demonstrando a eficácia de diferentes tipos de manejo na redução destes custos, que variaram entre 56,76 e $352.46 \mathrm{R} \$ \cdot \mathrm{ha}^{-1}$.

Barbier (1998) descreve o método do custo de reposição como sendo os custos de reposição de nutrientes ou herbicidas associados à erosão, sendo que os custos internos são medidos em termos de redução do valor marginal da produção devido ao aumento do uso de insumos. Este método é representado na Figura 5.

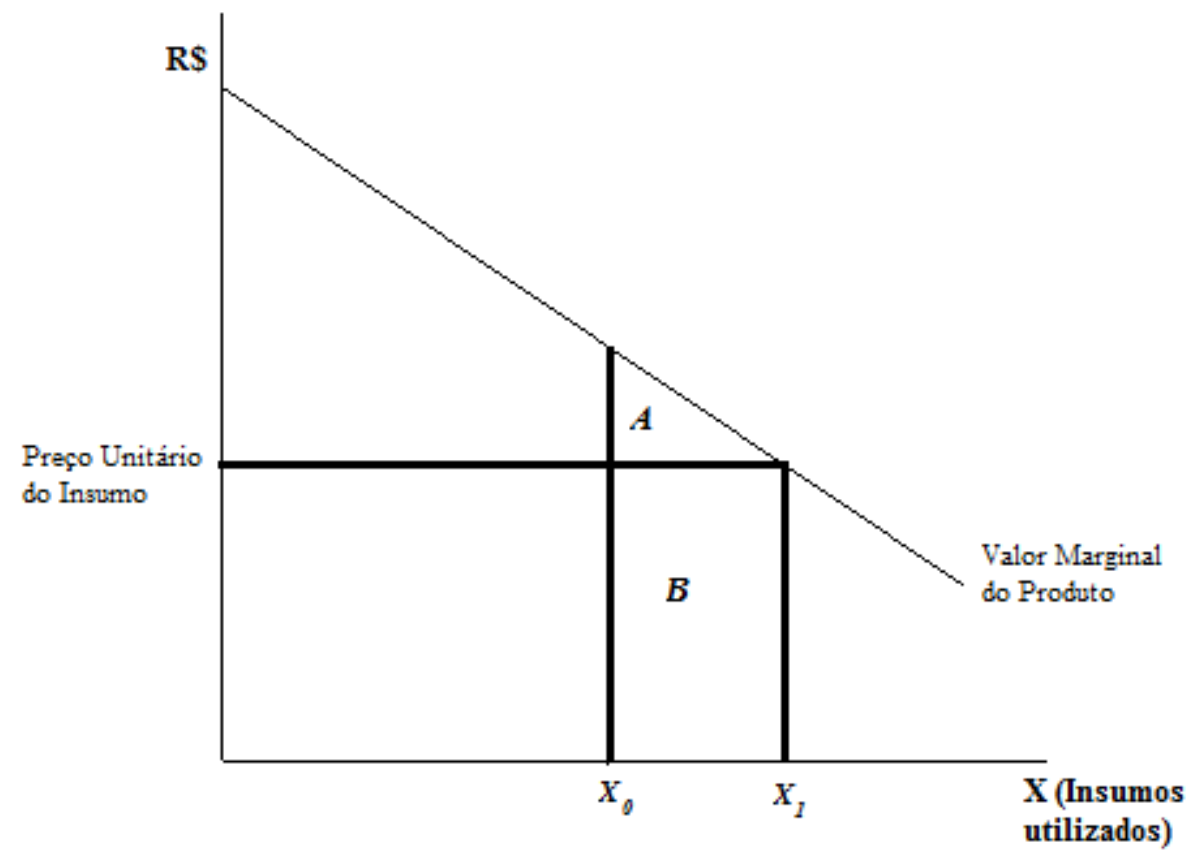

Figura 5 - Representação gráfica do método de Custo de Reposição para levantamento dos custos internos da erosão na agricultura (BARBIER, 1998)

O gráfico assume que o uso de insumos (neste caso, os fertilizantes utilizados) são utilizados de forma em que seu custo se iguala ao valor marginal do produto $\left(X_{l}\right)$. Porém, a 
erosão do solo e o escoamento superficial carregam parte do fertilizante aplicado e, como consequência, somente $X_{0}$ do insumo é aproveitado. Assim, a perda de nutrientes é $X_{1}-X_{0}$; valor do custo dos insumos é a área $B$; a redução do valor de mercado da produção é representado por $A+B$, sendo que $A$ representa as perdas do valor presente causadas pela erosão. Porém, como existe uma dificuldade de se obter as informações sobre o valor marginal dos insumos, a área $B$ é utilizado como uma aproximação de $A$. Nesse sentido, Barbier (1998) destaca que não existem motivos para acreditar que $B$ será uma boa aproximação para se estimar a área $A$ dado que geralmente não há como saber o quanto de $X_{l}$ foi aproveitado na produção.

Nesse contexto, a utilização de modelos hidrológicos (como o SWAT - Soil and Water Assessment Tools) pode contribuir para reduzir os níveis de incerteza de métodos econômicos como do custo de reposição, uma vez que o modelo pode simular tanto as perdas de nutrientes como a quantidade aproveitada pela produção agrícola (NEITSCH, 2011). Neste contexto, Um arranjo metodológico que vise a integração de modelos hidrológicos e econômico permite um afastamento da visão neoclássica uma vez que se aproxima mais da visão de análise proposta pela economia ecológica, por meio de uma contribuição empírica e metodológica.

\section{3 - MODELOS HIDROLÓGICOS}

Para a análise de processos hidrológicos, assim como ferramentas para suporte à gestão e manejo dos recursos hídricos, são necessários estudos de modelagem hidrológica tanto em bacias representativas como em bacias experimentais (LIMA et. al., 2014).

Em razão da relevância e da dificuldade de monitoramento dos impactos provocados por processos erosivos, modelos matemáticos foram desenvolvidos para descrever, predizer, e simular processos erosivos.

A partir da compilação dos dados de perda de solos descritos por Wishmeier e Smith (1962, 1978) foi criada a EUPS - Equação Universal de Perda de Solos, e, a partir deste modelo, vários outros foram desenvolvidos, tais como: ANSWERS (BEASLEY e HUGGINS, 1982); AGNPS (YOUNG et. al., 1987); MUSLE (WILLIAMS, 1975); EPIC (WILLIAMS, 1990); SWAT (ARNOLD e ALLEN, 1996); entre outros.

Os modelos hidrológicos também são usados na construção de cenários para simular mudanças no regime hidrológico tais como capacidade, nível de poluição e seus efeitos, causados por alterações nos atributos da bacia hidrográfica, onde a construção desses modelos 
são baseados nas seguintes premissas: 1) o pressuposto de que processos físicos em uma bacia hidrográfica podem ser representados de forma determinística e que a relação dessas soluções é possível; 2) frequentemente se assume que os dados de entrada, obtidos em campo, estão disponíveis para os cálculos ou que o modelo possa derivar tai parâmetros a partir da manipulação de dados relacionados obtidos em campo; e 3) existe o pressuposto de que os dados de entrada derivados a partir de amostragem seletiva em campo, representam adequadamente a variabilidade espacial e temporal medida em campo. Porém, apesar de muitos modelos conseguirem sintetizar um ou mais parâmetros do balanço hídrico, ainda é necessário um grande esforço para obtenção de dados para a calibração destes modelos. (ARNOLD e ALLEN, 1996).

\subsection{1 - MODELOS HIDROLÓGICOS ASSOCIADOS AO GEOPROCESSAMENTO}

De acordo com Menke (2012), a bacia hidrográfica é uma unidade fundamental para os estudos ambientais, possuindo diversos processos que modificam a paisagem, uma vez que os cursos de água consistem em um dos processos morfogenéticos mais ativos na esculturação da paisagem. Análises envolvendo modelagem hidrológica requerem uma grande quantidade de dados assim como novas formas de integrar estas informações (OLIVEIRA, 2008).

Minoti (2006) aponta a importância para a busca de ferramentas que possam contribuir para uma melhor interpretação de informações acerca dos impactos provocados pelos diversos tipos de uso da terra em corpos hídricos inseridos em bacias hidrográficas, uma vez que a qualidade da água e do solo refletem diretamente na qualidade de vida da população humana.

Nesse contexto, os resultados advindos do uso de geotecnologias em associação com modelos matemáticos permitem prever e minimizar consequências negativas provenientes de impactos ambientais, uma vez que esta associação possibilita uma análise espacialmente distribuída da dinâmica hidrológica da bacia hidrográfica (CORREIA et. al., 2015). Além disso, Oliveira (2008) aponta que estudos de topologia e geometria das redes de drenagem tem contribuído substancialmente para os estudos em hidrologia e geomorfometria, possibilitando até mesmo modelos de evolução de paisagens.

As técnicas de geoprocessamento permitem realizar análises multivariada de dados, análise de clusters e análises geomorfométricas de bacias hidrográficas, consistindo em ferramentas importantes para a gestão de recursos hídricos. A partir dessas análises é possível realizar análises espaciais referentes à amplitudes topográficas, curvatura do relevo, direção de 
fluxo, acumulação de fluxo, índices de circularidade e sinuosidade, densidade de drenagem, etc. (OLIVEIRA, 2008; CHAVES, 2011; MENKE, 2012).

Um dos modelos hidrológicos associados a sistemas de informações geográficas é o SWAT - Soil and Water Assessment Tool, descrito no tópico a seguir.

\section{4 - O MODELO SWAT}

O modelo SWAT foi desenvolvido para simular os impactos causados pelo manejo de água, sedimentos, e componentes químicos utilizados na agricultura em bacias hidrográficas, possuindo a capacidade de elaborar cenários ambientais. (ARNOLD e ALLEN, 1996; MARCHIORO et al., 2011; NEITSCH et. al., 2005).

Nesse contexto, o SWAT parte do ciclo hidrológico associado à MUSLE - Modified Universal Soil Loss Equation (WILLIAMS, 1975) para simular os ciclos do nitrogênio e fósforo (NEITSCH et. al., 2011), calculando, dessa maneira, as perdas de nutrientes em bacias hidrográficas (NEITSCH et. al., 2011, MONSALVE-HERRERA, 2013, ABBASPOUR et. al., 2015), mostrando-se uma ferramenta importante para subsidiar políticas de planejamento e manejo ambiental.

Fan et. al. (2016) realizaram a integração de serviços ecossistêmicos (nível de água, nutrientes orgânicos e inorgânicos, e retenção de sedimento), utilizando o modelo SWAT, tendo como base alterações de uso do solo e mudanças climáticas em uma bacia hidrográfica localizada na região norte de Japão. Os resultados obtidos pelos autores mostram que é possível realizar políticas de manejo e conservação de serviços ecossistêmicos associado ao desenvolvimento econômico na região.

Zhang et. al. (2015) utilizaram o modelo SWAT para analisar mudanças no uso e cobertura do solo e diferentes respostas hidrológicas sob diferentes cenários de mudanças climáticas em uma bacia hidrográfica no noroeste da China. Este estudo demonstrou que, na área estudada, as mudanças climáticas afetam mais os recursos hídricos do que alterações no uso e cobertura da terra.

Koua et. al. (2014) realizou estudos com o modelo SWAT para simular o escoamento superficial em uma região de lagos na França, demonstrando que parâmetros de vazão ligados ao escoamento superficial mostraram-se menos sensíveis que os parâmetros de vazão ligados à água sub-superficial. 
Arnold et. al. (2014) realizou estudos de integração do modelo hidrológico SWAT com análises de custo-benefício de diferentes práticas de manejo em diversas bacias dos Estados Unidos. O estudo demonstra que, ao integrar os dois modelos, aumenta-se a confiança em simulações de impactos econômicos pois utiliza dados e conhecimentos gerados pela validação de modelos hidrológicos nas regiões de estudo.

Pereira et. al. (2014) aplicaram o modelo SWAT em diferentes cenários de desflorestamento na costa leste brasileira, demonstrando que práticas de reflorestamento assegurariam a vazão mínima na região e regularizaria a vazão máxima dos cursos de água.

Machado et. al. (2003) realizaram, na microbacia do ribeirão dos Marins em Piracicaba (SP), uma simulação de cenários alternativos de uso da terra comparando com o modelo SWAT para analisar produção de sedimentos na região, demonstrando a necessidade de tratar a paisagem em bacias hidrográficas de forma global, onde são identificadas áreas mais sensíveis para implantação de práticas de controle erosivos na bacia.

\subsection{1 - BALANÇO HÍDRICO}

O balanço hídrico demonstra a disponibilidade hídrica no solo (TOLEDO et. al., 2002). No modelo SWAT, conforme Neitsch et. al. (2011), o balanço hídrico é calculado da seguinte maneira:

$$
S W_{t}=S W_{o}+\sum_{i=1}^{t}\left(R_{\text {day }}-Q_{\text {surf }}-E_{a}-W_{\text {seep }}-Q_{g w}\right)
$$

Onde $\mathrm{SW}_{\mathrm{t}}$ é a quantidade final de água no solo (mm H2O); $\mathrm{SW}_{\mathrm{o}}$ é a quantidade inicial de água no solo no dia i (mm H2O); t representa o tempo (dias); $\mathrm{R}_{\text {day }}$ representa a quantidade de chuva precipitada no dia i $(\mathrm{mm} \mathrm{H} 2 \mathrm{O}) ; \mathrm{Q}_{\text {surf }}$ é a quantidade de escoamento superficial no dia i (mm H2O); $\mathrm{E}_{\mathrm{a}}$ é a evapotranspiração total no dia i (mm H2O); $\mathrm{W}_{\text {seep }}$ é a quantidade de água percolada entre a camada simulada para a camada inferior no dia i $(\mathrm{mm} \mathrm{H} 2 \mathrm{O})$; e, por fim, $\mathrm{Q}_{\mathrm{gw}}$ representa a quantidade de água que retorna ao curso de água no dia i por meio do escoamento sub-superficial. 
Para a representação do balanço hídrico, Lima (2010) compilou valores para serem utilizados como referência em pequenas bacias hidrográficas no Distrito Federal (Tabela 5). Com base nestes resultados, o autor observa que, no ano mais chuvoso, 3,00 \% da lâmina precipitada foi convertida em escoamento superficial enquanto que, no ano mais seco, 1,42\% da lâmina precipitada foi convertida para escoamento superficial. Em relação à quantidade de chuva convertida para escoamento superficial, o autor mostra que há uma variação de 25,43 a 26,86\%. A vazão no exutório varia de 28,29 a 29,29\% do total precipitado. Por fim, o autor observa que, quando se considera a variação anual da lâmina de água no solo igual a zero, a evapotranspiração representa $70 \%$ do total precipitado.

Tabela 5 - Balanço hídrico anual em pequenas bacias hidrográficas do Distrito Federal

\begin{tabular}{|c|c|c|c|c|c|c|}
\hline Referência & \multicolumn{2}{|c|}{ Silva e Oliveira (1999) } & \multicolumn{2}{|c|}{ Lima (2000) } & \multicolumn{2}{|c|}{ Lima (2010) } \\
\hline Ano Hidrológico & \multicolumn{2}{|c|}{$1996 / 1997$} & \multicolumn{2}{|c|}{$1998 / 1999$} & \multicolumn{2}{|c|}{$2007 / 2008$} \\
\hline Bacia hidrográfica & \multicolumn{2}{|c|}{ Capetinga, DF } & \multicolumn{2}{|c|}{ Capetinga, DF } & \multicolumn{2}{|c|}{ Alto Jardim, DF } \\
\hline Área da bacia $\left(\mathrm{km}^{2}\right)$ & \multicolumn{2}{|c|}{10,0} & \multicolumn{2}{|c|}{10,0} & \multicolumn{2}{|c|}{104,86} \\
\hline Variável & mm.amo-1 & $\%$ & mm.amo-1 & $\%$ & mm.amo-1 & $\%$ \\
\hline Precipitação & 1744,00 & 100,00 & 1058,73 & 100,00 & 1100,00 & 100,00 \\
\hline Escoamento Superficial & 52,50 & 3,01 & 15,08 & 1,42 & 32,33 & 2,94 \\
\hline Escoamento de base & 444,00 & 25,46 & 284,39 & 26,86 & 289,89 & 26,35 \\
\hline Escoamento Total & 496,50 & 28,47 & 299,47 & 28,29 & 322,22 & 29,29 \\
\hline $\begin{array}{l}\text { Variação da lâmina de } \\
\text { água no solo }\end{array}$ & $0,00 *$ & $0,00 *$ & $-71,77$ & 6,78 & $0,00 *$ & $0,00 *$ \\
\hline Evapotranspiração real & 1247,50 & 71,53 & 831,03 & 78,49 & 777,78 & 70,71 \\
\hline
\end{tabular}

*Valor não medido

Fonte: LIMA (2010)

\subsubsection{1 - Escoamento Superficial}

O escoamento superficial é o fluxo de água que ocorre ao longo de uma superfície inclinada (NEITSCH et. al., 2011), calculada no modelo SWAT conforme as equações 2 a 4.

$$
Q_{\text {surf }}=\frac{\left(R_{\text {day }}-I_{a}\right)^{2}}{\left(R_{\text {day }}-I_{a}+S\right)}
$$


Onde $Q_{\text {surf }}$ é o escoamento superficial ou o excesso de chuva $(\mathrm{mm}) ; R_{\text {day }}$ representa a pluviometria $(\mathrm{mm}) ; I_{a}$ representa as perdas iniciais do escoamento tais como a acumulação superficial, interceptação e infiltração $(\mathrm{mm})$; e $S$ representa o parâmetro de retenção $(\mathrm{mm})$.

O parâmetro de retenção é dado pela seguinte equação:

$$
S=25,4\left(\frac{1000}{C N}-10\right)
$$

Onde $C N$ representa o número da curva para um dia. Esse parâmetro é função da permeabilidade e uso da terra e da umidade que tem o solo antes de ocorrer a precipitação. $\mathrm{O}$ $C N$ também é definido de acordo com o tipo hidrológico do solo (Tabela 6).

As perdas iniciais $I_{a}$ geralmente são consideradas como valor de $0,2 S$, de forma que a Equação 2 pode ser reescrita da seguinte maneira:

$$
Q_{\text {surf }}=\frac{\left(R_{d i a}-0,2 S\right)^{2}}{\left(R_{d i a}+0,8 S\right)}
$$

Conforme descrito por Salles (2012), o método Curva-Número (CN) do SCS (1972) define três condições de umidade nos solos:

- CN1 - representa a umidade do solo no ponto de murcha permanente, assim como o menor valor que o $\mathrm{CN}$ pode assumir em condições secas;

- CN2 - representa a umidade média de um solo;

- $\quad \mathrm{CN} 3$ - representa a umidade do solo em sua capacidade de campo. 
Tabela 6 - Características dos Grupos Hidrológicos

\begin{tabular}{|c|c|}
\hline $\begin{array}{c}\text { Grupo } \\
\text { Hidrológico }\end{array}$ & Principais características \\
\hline $\mathbf{A}$ & $\begin{array}{l}\text { - } \quad \text { Solos muito profundos (prof. }>200 \mathrm{~cm}) \text { ou profundos }(100 \mathrm{a} 200 \mathrm{~cm}) ; \\
\text { - } \quad \text { Solos com alta taxa de infiltração e com alto grau de resistência e tolerância à erosão; } \\
\text { - } \quad \text { Solos porosos com baixo gradiente textural }(<1,20) ; \\
\text { - Solos de textura média; } \\
\text { - Solos de textura argilosa ou muito argilosa desde que a estrutura proporcione alta macro- } \\
\text { - } \quad \text { Sorosidade em todo o perfil; } \\
\text { - } \quad \text { Solos com argila baixa }(\mathrm{Tb}), \text { minerais de argila } 1: 1 ; \\
\text { - } \quad \text { A textura dos horizontes superficial e sub-superficial pode ser: média/ média, argilosa/ argilosa } \\
\text { e muito argilosa/ muito argilosa. }\end{array}$ \\
\hline B & $\begin{array}{l}\text { - Solos profundos (100 a } 200 \mathrm{~cm}) \text {; } \\
\text { - Solos com moderada taxa de infiltração, mas com moderada resistência e tolerância a erosão; } \\
\text { - Solos porosos com gradiente textural variando entre } 1,20 \text { e } 1,50 \text {; } \\
\text { - Solos de textura arenosa ao longo do perfil ou te textura média com horizonte superficial } \\
\text { arenoso; } \\
\text { - Solos de textura argilosa ou muito argilosa desde que a estrutura proporcione boa } \\
\text { macroporosidade em todo o perfil; } \\
\text { - Solos com argila de atividade baixa (Tb) e minerais de argila } 1: 1 \text {; } \\
\text { - A textura dos horizontes superficial e subsuperficial pode ser: arenosa/ arenosa, arenosa/ } \\
\text { média, média/ argilosa, argilosa/ argilosa e argilosa/ muito argilosa. }\end{array}$ \\
\hline $\mathbf{C}$ & $\begin{array}{l}\text { - Solos profundos (100 a } 200 \mathrm{~cm}) \text { ou pouco profundos }(50 \text { a } 100 \mathrm{~cm}) \text {; } \\
\text { - Solos com baixa taxa de infiltração e baixa resistência e tolerância à erosão; } \\
\text { - São solos com gradiente textural maior que } 1,50 \text { e comumente apresentam mudança textural } \\
\text { - } \quad \text { Solos associados a argila de atividade baixa }(\mathrm{Tb}) ; \\
\text { - } \\
\quad \text { A textura nos horizontes superficial e subsuperficial pode ser: arenosa/ média e média/ argilosa } \\
\text { apresentando mudança textural abrupta, arenosa/ argilosa e arenosa/ muito argilosa. }\end{array}$ \\
\hline D & $\begin{array}{l}\text { - Solos com taxa de infiltração muito baixa oferecendo pouquíssima resistência à erosão; } \\
\text { - Solos rasos (prof. }<50 \mathrm{~cm} \text { ); } \\
\text { - Solos pouco profundos associados à mudança textural abrupta ou solos profundos } \\
\text { apresentando mudança textural abrupta aliada à argila de alta atividade (Ta), apresentando } \\
\text { minerais de argila } 2: 1 ; \\
\text { - Solos associados à argila de atividade alta (Ta); } \\
\text { - Solos orgânicos }\end{array}$ \\
\hline
\end{tabular}

Fonte: SARTORI et. al. (2005) 


\section{0 - MATERIAIS E MÉTODOS}

Para a estimativa dos custos da erosão na área de estudo foram realizadas as seguintes etapas: A) Preparação dos dados de entrada do modelo SWAT; B) Calibração do modelo SWAT; C) Análise da perda de solos na área de estudo; D) Análise da perda de nutrientes na área de estudo; E) Análise do custo de reposição de nutrientes na área de estudo; F) Análise dos impactos econômicos do custo de reposição no valor da produção. Na Figura 6 é apresentado o fluxograma com os passos metodológicos adotados neste trabalho.

A preparação da base de dados do SWAT consistiu na elaboração do modelo digital de terreno, mapa de uso e cobertura da terra, base pedológica (mapa de solos e parametrização das classes de solo) e dados climáticos da bacia. Após a uma simulação prévia no modelo SWAT, foi feita a calibração e verificação dos resultados com base em dados observados de vazão, sedimento e quantidade de nitrato disponibilizados pela Embrapa Cerrados.

Após a obtenção dos mapas de perdas de solos e perdas de nutrientes, foi feito o cálculo do custo de reposição de nutrientes e o quanto estes custos impactam valor da produção na área de estudo. Todos os passos metodológicos são detalhados ao longo deste capítulo. 


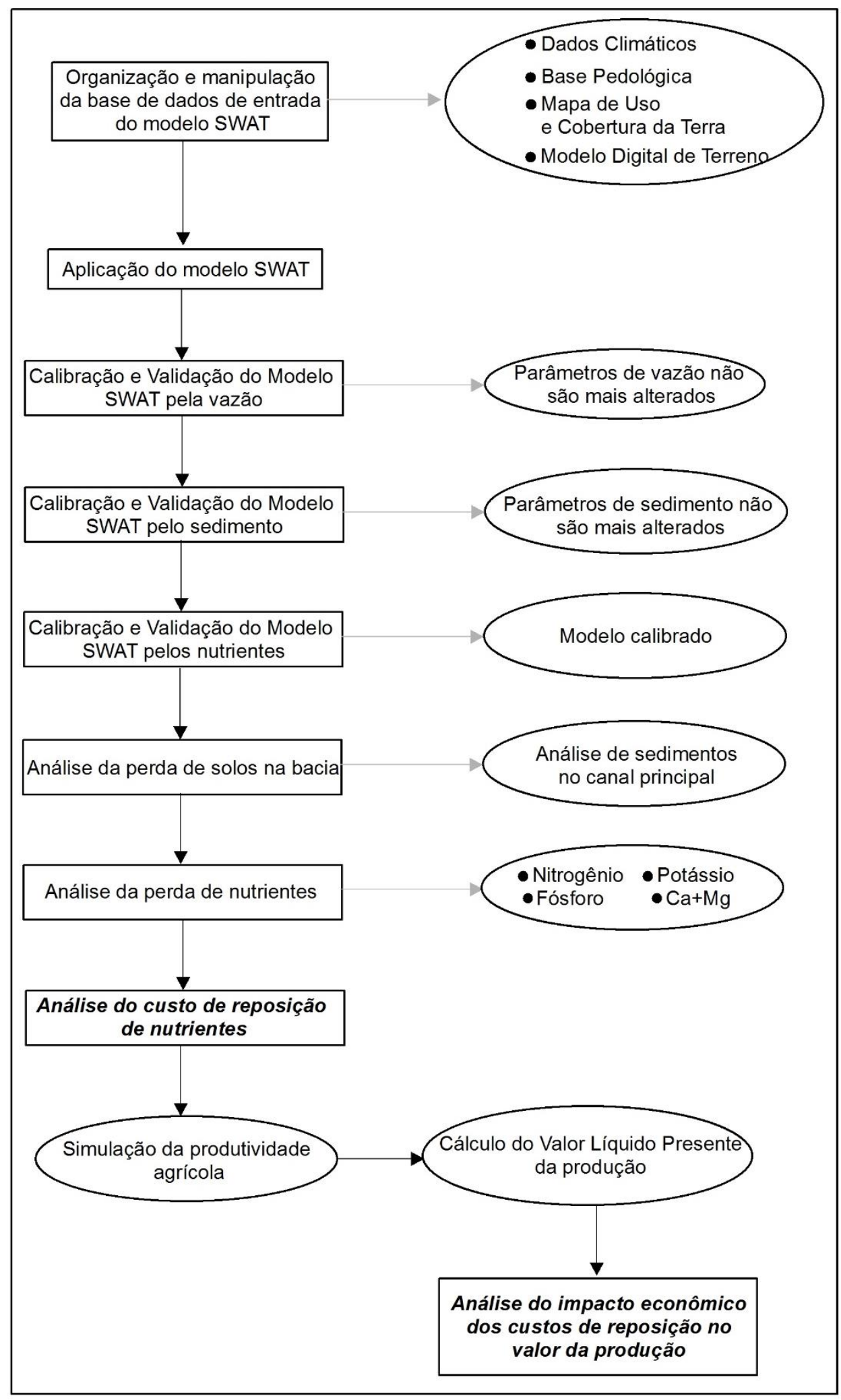

Figura 6 - Metodologia adotada 


\section{1 - ÁREA DE ESTUDO}

A bacia experimental do Córrego do Sarandi, com área de aproximadamente $30 \mathrm{~km}^{2}$ (3025 ha), situa-se na região centro-norte do Distrito Federal, entre as coordenadas $47^{\circ} 47^{\prime} 24^{\prime \prime} \mathrm{W}, 47^{\circ} 41^{\prime} 48^{\prime \prime} \mathrm{W}$ de longitude e $15^{\circ} 34^{\prime} 27^{\prime}$ 'S e $47^{\circ} 46^{\prime} 24^{\prime}$ 'S de latitude, conforme demonstrado na Figura 7. A área foi escolhida dada a sua importância em experimentos agropecuários, já que é nesta bacia que se localiza a Embrapa Cerrados, que realiza trabalhos de monitoramento ambiental na bacia, facilitando o acesso aos dados necessários para aplicar no modelo SWAT.

Além da presença da Embrapa Cerrados, que ocupa quase toda a área compreendida na margem direita do Córrego Sarandi, a União Pioneira da Integração Social - Faculdades Integradas (UPIS) e a Estação Ecológica de Águas Emendadas (ESECAE) são outros dois importantes ocupantes da bacia. Na região ainda há a comunidade do Núcleo Rural Sarandi e diversas chácaras, onde, em algumas delas, são desenvolvidas atividades econômicas como piscicultura, agricultura irrigada, criação de aves, criação de gado e outras. A proximidade de zonas urbanas como as cidades de Planaltina e Sobradinho tem imposto pressão de urbanização na parte alta da bacia, onde já se verifica o parcelamento de terras para o estabelecimento de condomínios horizontais (CHAVES et. al., 2014).

Segundo a classificação de Köppen, o clima da área de estudo é do tipo Aw, caracterizado por possuir duas estações bem definidas, sendo a estação chuvosa se estende de outubro a abril e a estação seca se estende de maio a setembro. A média de precipitação anual na bacia é de aproximadamente $1300 \mathrm{~mm}$. 


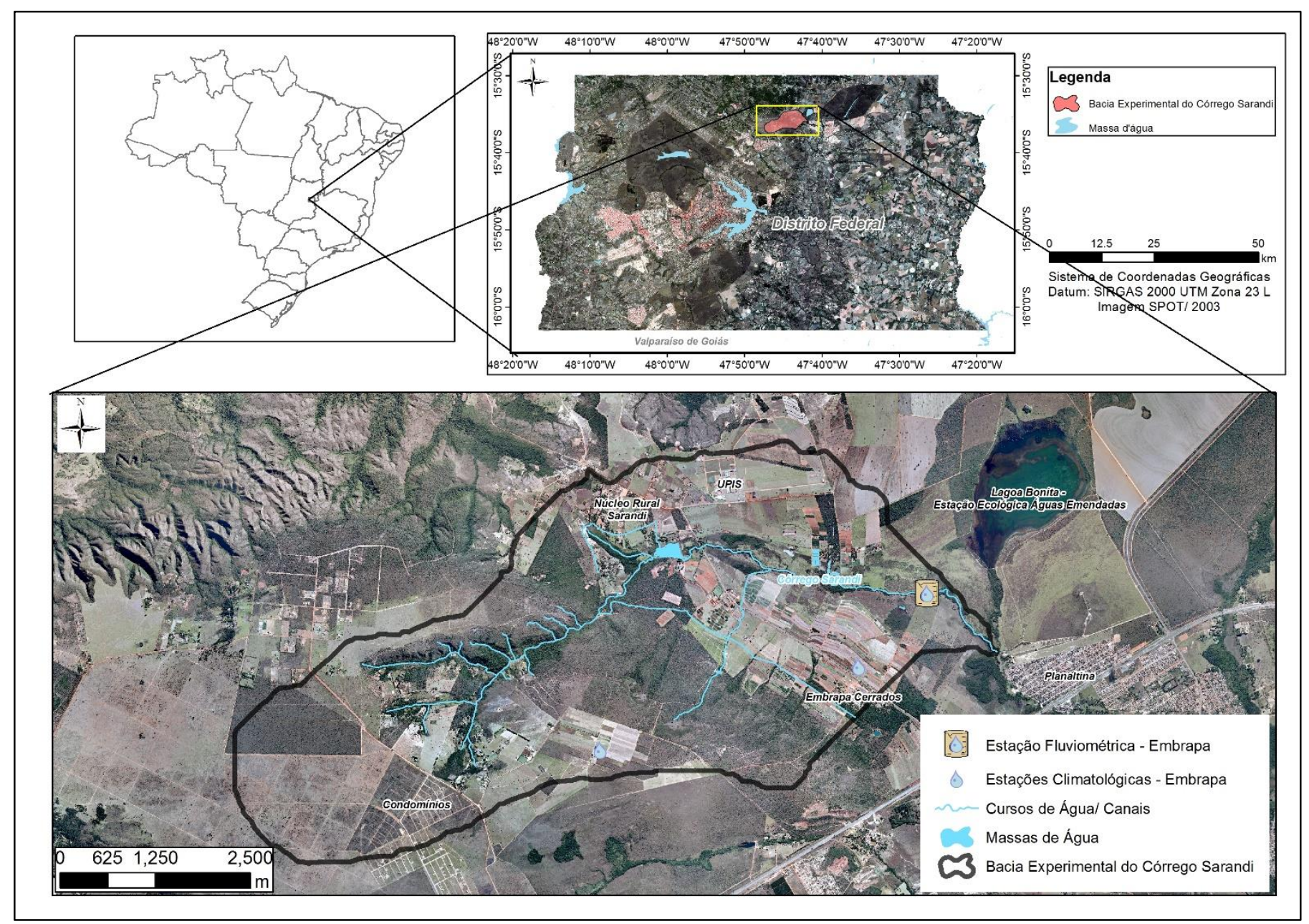

Figura 7 - Localização da área de estudo em relação ao território do Distrito Federal em imagem SPOT de 2003. No detalhe, Imagem da região da Bacia Experimental do Córrego Sarandi proveniente de ortofotos obtidas em 2010 com resolução espacial de 1 m, disponibilizadas pela Companhia Imobiliária de Brasília (TERRACAP, 2010).

\section{2 - PROGRAMAS COMPUTACIONAIS}

- ArcGIS 10.1 - Plataforma SIG para manipulação e edição de dados geográficos;

- ArcSWAT 2012 - Extensão utilizada para aplicar o modelo SWAT no ArcGIS;

- SWAT Check - Ferramenta associada ao ArcSWAT, utilizada para visualizar, de forma resumida, os resultados obtidos na simulação feita no ArcSWAT; 
- SWAT-CUP - Aplicativo para realizar a calibração e verificação dos resultados obtidos do modelo SWAT;

- Executável REV629 - Arquivo executável utilizado para obter os resultados tanto no ArcSWAT como no SWAT-CUP.

\section{3 - APLICAÇÃO DO MODELO SWAT}

A aplicação do modelo SWAT, por meio da interface ArcSWAT exige, como dados de entrada, a utilização de dados de declividade, uso e cobertura do solo, e pedológicos para realizar a simulação (Figura 8). Posteriormente, é necessário que seja feita uma calibração com base em dados observados na bacia para que os resultados simulem um cenário mais próximo da realidade física. A descrição dos dados de entrada e de calibração será feita mais adiante.

No modelo, a bacia é dividida em sub-bacias, que são subdivididas em Unidades de Resposta Hidrológica (HRU - Hydrologic Response Unit), definidas como a menor unidade de escala do SWAT, formada a partir do cruzamento dos mapas de declividade, pedológico, e uso e cobertura do solo (NEITSCH et. al. 2009; ABBASPOUR et. al., 2015). A partir da aplicação do modelo SWAT na bacia experimental do córrego Sarandi, foram geradas 261 HRUs.

Após a definição das HRUs, é feita uma $1^{\mathrm{a}}$ simulação do modelo para definir, empiricamente, o período de aquecimento ${ }^{5}$. A próxima etapa é a análise de sensibilidade, onde são identificados os parâmetros mais sensíveis do modelo com base nos testes $t$ e $p$ estatístico. Uma vez identificados, estes parâmetros são ajustados com o objetivo de gerar, na etapa de calibração, resultados mais próximos da realidade observada e posteriormente validados para gerar os resultados finais do modelo hidrológico (Figura 8).

\footnotetext{
${ }^{5} \mathrm{O}$ período de aquecimento é um período determinado a ser excluído do resultado final. Isso é necessário pois, de acordo com Mellos et. al. (2008), existe um elevado grau de incerteza no modelo devido ao desconhecimento das condições iniciais do sistema analisado, como por exemplo, a umidade inicial do solo. Neitsch et.al. (2009b) recomenda que este período seja de, no mínimo um ano. Alguns autores como Bonumá et. al. (2011) utilizaram um período de dois anos. Já Salles (2012), Castro (2013) e Ferrigo 2014) utilizaram um período de três anos. Por fim, Sarmento (2010) utilizou um período de aquecimento de quatro anos.
} 


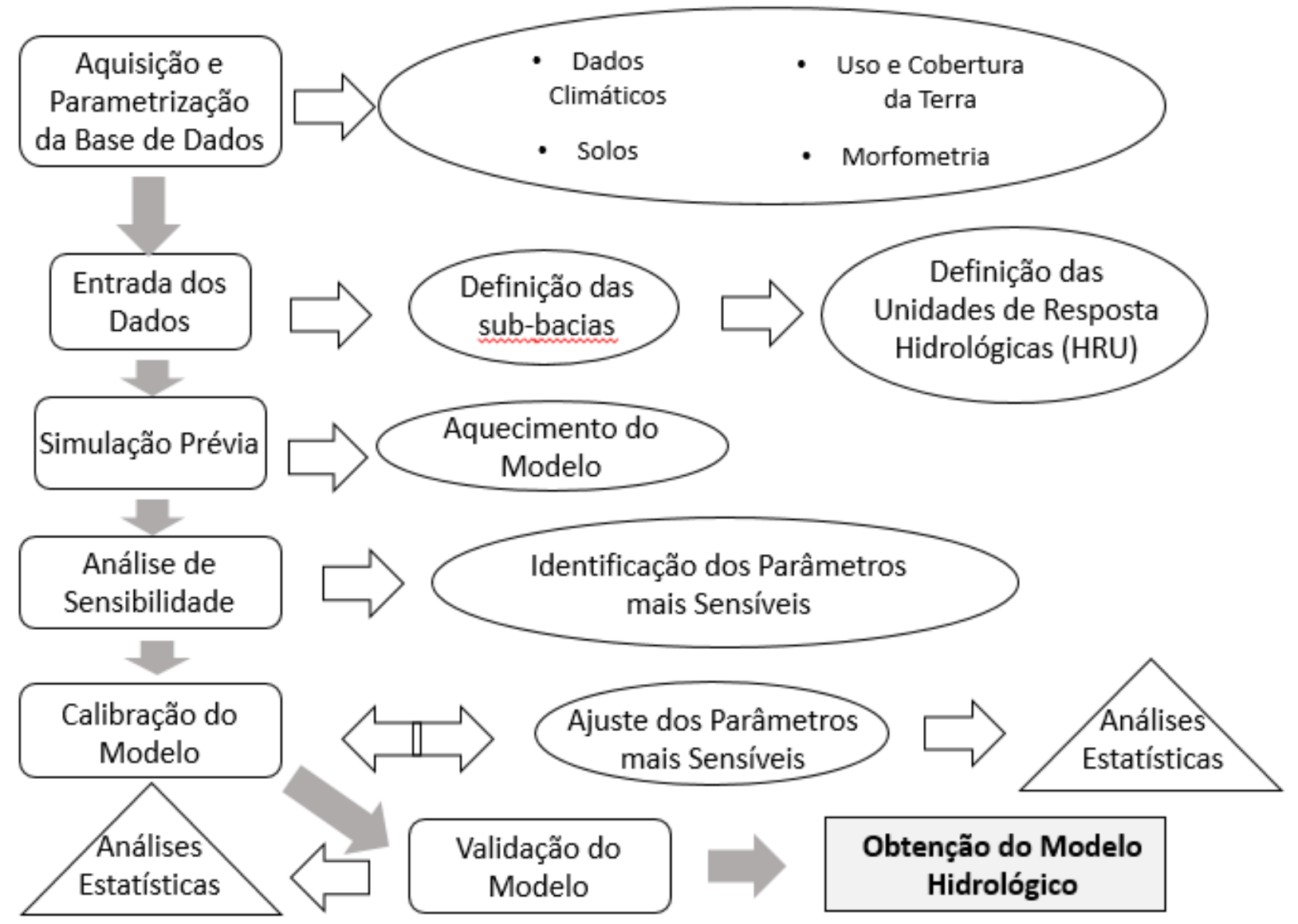

Figura 8 - Fluxograma de aplicação do Modelo SWAT (adaptado de Castro, 2013)

\subsection{1 - DADOS DE ENTRADA DO SWAT}

\subsubsection{1 - Análise Morfométrica}

O MDT foi gerado a partir das cartas topográficas em escala 1:10.000 da TERRACAP. Primeiramente, foi feito a edição das cartas para corrigir eventuais falhas como drenagem mal encaixada, curvas de nível incompletas, pontos cotados com valores errôneos, etc. Após a edição, foi aplicado o modelo TOPOGRID (HUTCHINSON, 1989) para gerar o MDT com resolução espacial de 2 metros. A partir deste, foi gerado a carta de declividade com duas classes, 0 a $20 \%$ (relevo plano a suave e ondulado) e $>20 \%$ (relevo ondulado) para serem utilizados no modelo SWAT, definidas a partir da descrição de IBGE (2007), por apresentarem um critério descritivo com base em características geomorfológicas para a qualificação das classes. 


\subsubsection{2 - Análise do Uso e Cobertura da Terra}

O mapeamento do uso e cobertura da terra foi feito em escala 1:25.000 a partir da generalização, do uso e cobertura da terra em escala 1:5.000 (CHAVES et. al., 2014), elaborado com base na interpretação visual (textura, cor, rugosidade e forma) de ortofotos aéreas, resolução espacial de 1 metro, disponibilizadas pela Companhia Imobiliária de Brasília (TERRACAP, 2010), datadas de 2010. A generalização foi feita com base em interpretação visual, agrupando polígonos que já não podiam mais ser visualizados na escala 1:25.000. Essa etapa foi necessária para facilitar o processo de calibração e verificação do modelo SWAT, uma vez que, com a generalização das classes, o número de HRUs foi reduzido significativamente.

Conforme Neitsch et. al. (2009), as classes de uso e cobertura da terra devem possuir como dados de entrada os valores de CN2. Para inserir estes valores nas classes mapeadas (Tabela 7), foram utilizados os dados de Salles (2012) e Ferrigo (2014), que adaptaram os valores bases do modelo SWAT para áreas de cerrado.

Além disso, a definição das classes foi feita com base nos trabalhos de Salles (2012), Castro (2013), e Ferrigo (2014), que adaptaram os valores bases do modelo SWAT para áreas de cerrado no Distrito Federal. 
Tabela 7 - Valores de CN2 Utilizados

\begin{tabular}{|c|c|c|c|c|}
\hline $\begin{array}{c}\text { Grupo } \\
\text { Hidrológico } \\
\text { Usose de Cobertura } \\
\text { do Solo }\end{array}$ & Grupo A & Grupo B & Grupo C & Grupo D \\
\hline Agricultura de Sequeiro & 67 & 77 & 83 & 87 \\
\hline Agricultura Irrigada & 67 & 78 & 85 & 89 \\
\hline Cultivos Florestais & 45 & 66 & 77 & 83 \\
\hline Edificacoes e Instalacoes & 31 & 59 & 72 & 79 \\
\hline Formacao Campestre & 49 & 69 & 79 & 84 \\
\hline Formacao Florestal & 25 & 30 & 35 & 40 \\
\hline Formação Savânica & 30 & 40 & 45 & 45 \\
\hline Loteamento & 59 & 74 & 82 & 89 \\
\hline Pastagem & 49 & 69 & 79 & 84 \\
\hline Pivo Central & 67 & 78 & 85 & 89 \\
\hline Reservatorios & 92 & 92 & 92 & 92 \\
\hline Solo Exposto & 59 & 74 & 82 & 89 \\
\hline Vegetacao degradada & 77 & 86 & 88 & 89 \\
\hline
\end{tabular}

Fonte: adaptado de Salles (2012) e Ferrigo (2014).

\subsubsection{3 - Base Pedológica}

O modelo SWAT exige, como dado de entrada, um mapa de solos da área de estudo. O mapa utilizado foi elaborado por Lima (2013) em escala 1:30.000 (Figura 9).

Para os parâmetros pedológicos, foram utilizados os valores apresentados por Lima et. al. (2013), que estimou valores médios de diversos parâmetros (condutividade hidráulica, densidade aparente do solo, capacidade de água disponível no solo, granulometria, etc.) para solos situados em ambiente de cerrado. Para isso, o autor utilizou informações coletadas na bacia do Alto Jardim (DF), para serem utilizados como dados de entrada no modelo SWAT, apresentados no Anexo A.

Para o parâmetro albedo do solo úmido - dado de entrada obrigatório nos parâmetros pedológicos -, foi utilizado os dados de Monsalve-Herrera (2013), que apresentou os valores para solos do Distrito Federal a partir de estudo realizado na bacia do ribeirão Riacho Fundo. 


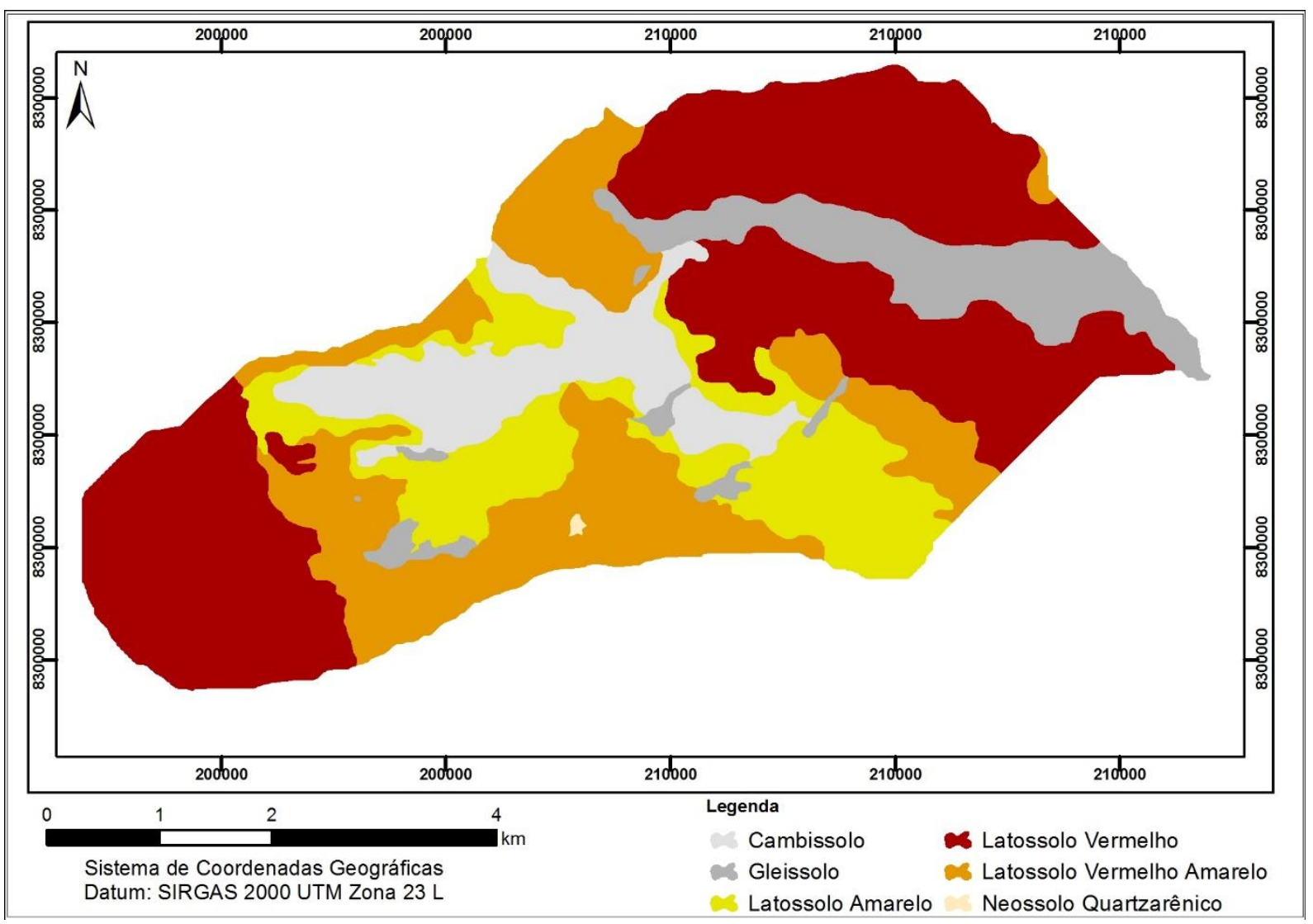

Figura 9 - Mapa de Solo em escala 1:30.000 (LIMA, 2013)

\subsubsection{4 - Dados Climáticos}

O SWAT realiza a distribuição de variáveis climáticas agregando as informações referentes a precipitação, temperatura mínima e máxima, umidade relativa, radiação solar e velocidade do vento considerando a distância entre a estação climatológica e o centróide da bacia (NEITSCH et. al., 2009; SALLES, 2012; CASTRO, 2013; MONSALVE-HERRERA, 2013).

Para os dados climatológicos, foram utilizadas as informações das estações climatológicas da Embrapa CPAC-Principal e CPAC-Chapada, abrangendo o período de jan/2012 a dez/2014. Para o aquecimento do modelo, os dados referentes ao ano de 2012 foram repetidos três vezes, sendo que este período de repetição não é considerado nos resultados.

A Figura 10 apresenta a série de chuva para o período, que possui média de $1326 \mathrm{~mm}$ de precipitação anual para a estação CPAC-Principal e CPAC-Chapada. 

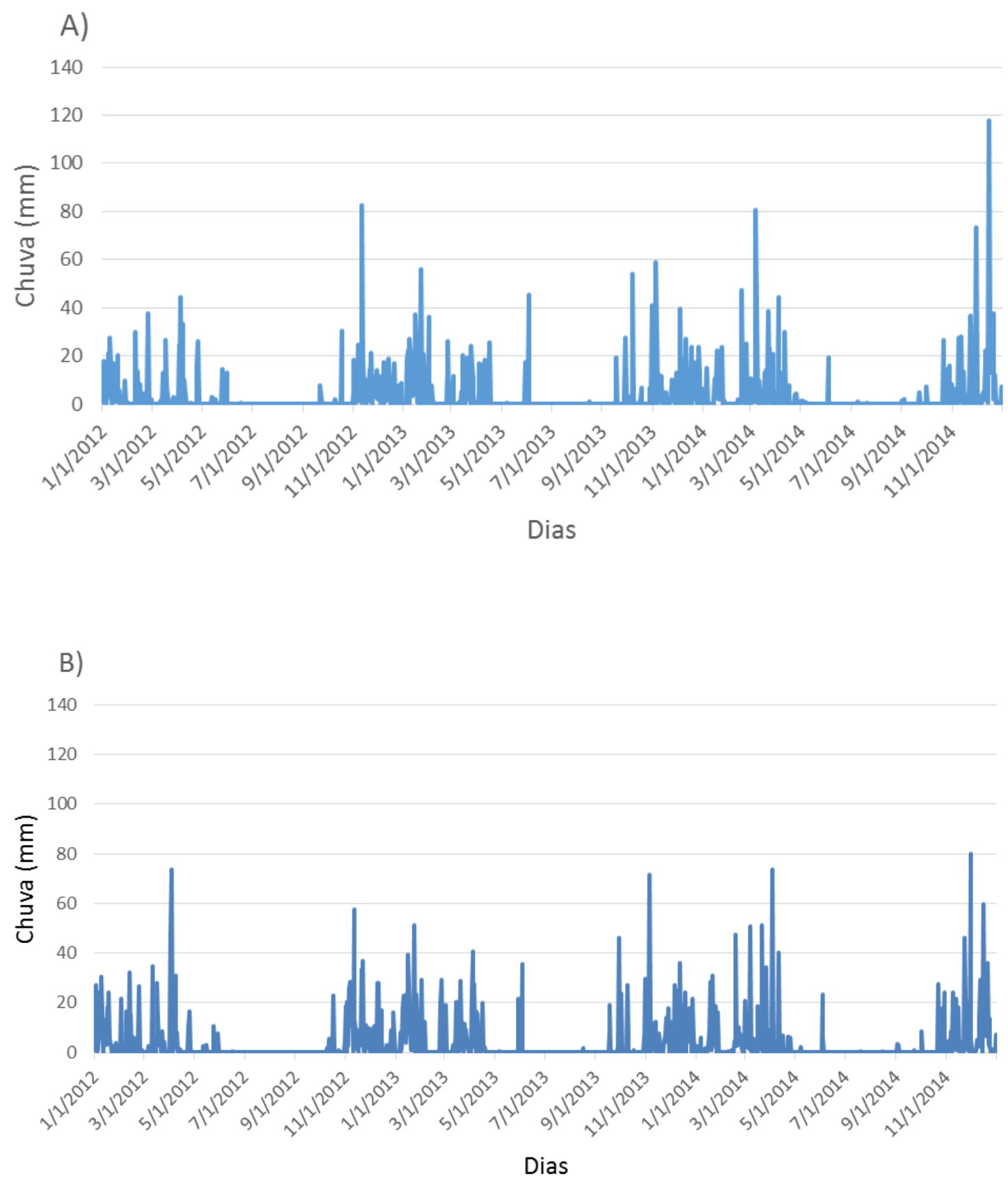

Figura 10 - Série de chuva $(\mathbf{m m})$ entre jan/2012 a dez/2014 provenientes das estações climáticas localizadas na Embrapa Cerrados. A) CPAC_Principal; B) CPAC-Chapada (Dados cedidos pelo Laboratório de Biofísica Ambiental da Embrapa Cerrados) 


\subsubsection{5 - Práticas de Manejo na Área de Estudo}

A produção agrícola na área da fazenda experimental da Embrapa Cerrados, por possuir diversos experimentos de diferentes naturezas, não possui como objetivo final o abastecimento do mercado, mas a produção de ciência e tecnologia agropecuária em ambiente de cerrado. Dessa maneira, para efeitos práticos, a fazenda experimental foi considerada como propriedade normal, com práticas de manejo homogêneas dentro de seus limites. Além disso, como o modelo SWAT trabalha com unidades de resposta hidrológica, as diferentes culturas agrícolas existentes na bacia tiveram que ser agrupadas em classes de uso como Agricultura de Sequeiro, Agricultura Irrigada e Pivô Central ${ }^{6}$. Assim, foi simulado um cenário em que há duas safras por ano (janeiro-julho e agosto-dezembro), onde o principal diferencial entre as atividades agrícolas é a quantidade de fertilizante aplicado e a existência prática de irrigação na HRU.

\subsubsection{1 - Mapeamento da Produção}

Para determinar a área ocupada por cada tipo de cultura foi feito levantamento de campo no período chuvoso e seco dos anos de 2013 e 2014 em toda a bacia, com utilização de GPS, acompanhado de técnicos da Embrapa Cerrados. As informações foram posteriormente plotadas em ambiente de Sistema de Informação Geográfica - SIG. Esta etapa foi feita para determinar a área ocupada por cada cultura agrícola na bacia para que fosse conhecida a quantidade de fertilizantes aplicada nas diferentes HRUs.

\subsubsection{2 - Base de Fertilizantes}

Para a base de fertilizantes, foram utilizados os dados de Sousa et. al. (2002), Andrade (2002), e Vilela et. al. (2002) que apresentaram valores gerais de NPK para culturas perenes e semi-perenes em solos do cerrado, e os dados de Guerra et. al. (2007) que apresentaram valores de NPK para culturas de café na bacia experimental do córrego Sarandi (Tabela 8).

\footnotetext{
6 Para as práticas de fertilização, as áreas de pivô central e de irrigação convencional foram consideradas juntas para não haver uma variação muito grande nos valores de NPK entre as duas classes de uso.
} 
Com base nestas informações, os valores de NPK foram estabelecidos com base na média ponderada entre a quantidade de fertilizante utilizado em determinada cultura (ex: soja, milho, trigo, horticultura, etc.) e a área que ocupa na classe de uso, uma vez que as diferentes culturas agrícolas possuem áreas diferentes dentro das HRUs.

Tabela 8 - Valores de NPK para cada tipo de produção existente na área de estudo

\begin{tabular}{|c|c|c|c|c|c|c|c|}
\hline \multicolumn{8}{|c|}{ AGRICULTURA DE SEQUEIRO } \\
\hline Produção & $\mathbf{N}$ & $\mathbf{P}$ & $\mathbf{K}$ & Produção & $\mathbf{N}$ & $\mathbf{P}$ & $\mathbf{K}$ \\
\hline Fruticultura & 101 & 139 & 120 & Trigo & 90 & 80 & 50 \\
\hline Mandioca & 80 & 80 & 60 & Milho & 30 & 120 & 60 \\
\hline Soja & 6 & 60 & 60 & Horticultura & 0 & 60 & 20 \\
\hline Nativas & 75 & 75 & 50 & \multirow{2}{*}{ Canavial } & \multirow{2}{*}{70} & \multirow{2}{*}{140} & \multirow{2}{*}{120} \\
\hline Pinhao Manso & 70 & 80 & 60 & & & & \\
\hline \multicolumn{8}{|c|}{ AGRICULTURA IRRIGADA E PIVÔ CENTRAL } \\
\hline Produção & $\mathbf{N}$ & $\mathbf{P}$ & $\mathbf{K}$ & Produção & $\mathbf{N}$ & $\mathbf{P}$ & $\mathbf{K}$ \\
\hline Café & 55 & 30 & 55 & Horticultura & 0 & 60 & 20 \\
\hline Canavial & 70 & 140 & 120 & Mandioca & 80 & 80 & 60 \\
\hline Dendê & 180 & 150 & 150 & Milho & 30 & 120 & 60 \\
\hline Feijão & 100 & 120 & 100 & Nativas & 75 & 75 & 50 \\
\hline \multirow{2}{*}{ Fruticultura } & \multirow{2}{*}{101} & \multirow{2}{*}{139} & \multirow{2}{*}{120} & Soja & 6 & 60 & 60 \\
\hline & & & & Trigo & 90 & 80 & 50 \\
\hline
\end{tabular}

Fonte: Adaptado de Sousa et. al. (2002), Andrade (2002); Vilela et. al. (2002), e Guerra et. al.(2007)

\subsubsection{3 - Práticas de Irrigação}

A prática de irrigação é feita em duas etapas: uma primeira operação que é a aplicação inicial da irrigação, onde é determinado uma quantidade inicial de água aplicada na HRU e uma segunda operação, onde a irrigação é feita com base na demanda de água da planta, quando o modelo detectar um nível de stress hídrico de 0,7, é aplicada automaticamente a quantidade de irrigação necessária para atendera estas demandas na HRU. Importante destacar que estes valores são controlados por limites mínimos e máximos para que não haja uma retirada de água da fonte de irrigação maior que o limite de recarga da bacia (NEITSCH et. al.). Estes valores foram fornecidos pela Embrapa Cerrados (Tabela 9). 
Tabela 9 - Quantidade de água aplicada durante as operações de irrigação na área de estudo

\begin{tabular}{|c|c|c|c|c|c|c|}
\hline \multicolumn{7}{|c|}{ MANEJO DA IRRIGAÇÃO - ASPECTOS GERAIS } \\
\hline \multicolumn{3}{|c|}{$\begin{array}{l}\text { Quantidade mínima de água desviada do } \\
\text { canal para irrigação }\left(\mathrm{m}^{3} / \mathrm{s}\right)\end{array}$} & \multicolumn{4}{|c|}{$\begin{array}{l}\text { Fração da quantidade de água disponível máxima a ser } \\
\text { aplicada na HRU }\end{array}$} \\
\hline \multicolumn{3}{|c|}{0,13} & \multicolumn{4}{|c|}{0,7} \\
\hline \multicolumn{3}{|c|}{ 1 $^{\text {a }}$ IRRIGAÇÃ̃O } & \multicolumn{4}{|c|}{ OPERAÇÃO DE AUTO-IRRIGAÇÃO } \\
\hline $\begin{array}{l}\text { Data de } \\
\text { Aplicação }\end{array}$ & \multicolumn{2}{|c|}{$\begin{array}{l}1^{\text {a }} \text { safra: 01/jan } \\
2^{\mathrm{a}} \text { safra: 01/ago }\end{array}$} & $\begin{array}{l}\text { Início da } \\
\text { Operação }\end{array}$ & \multicolumn{3}{|c|}{$\begin{array}{l}1^{\text {a }} \text { safra: } 18 / \text { jan } \\
2^{\mathrm{a}} \text { safra: } 18 / \text { ago }\end{array}$} \\
\hline $\begin{array}{l}\text { Profundidade } \\
\text { da irrigação } \\
\text { aplicada à } \\
\text { HRU (mm) }\end{array}$ & $\begin{array}{c}\text { Fração do } \\
\text { escoamento } \\
\text { superficial }\end{array}$ & $\begin{array}{l}\text { Eficiência } \\
\quad \text { da } \\
\text { irrigação }\end{array}$ & $\begin{array}{c}\text { Quantidade } \\
\text { máxima de } \\
\text { água aplicada } \\
\text { a cada } \\
\text { operação de } \\
\text { auto-irrigação } \\
(\mathrm{mm})\end{array}$ & $\begin{array}{c}\text { Limiar do } \\
\text { stress hídrico } \\
\text { para que o } \\
\text { modelo } \\
\text { acione a } \\
\text { irrigação } \\
\text { automática }\end{array}$ & $\begin{array}{l}\text { Eficiência } \\
\quad \text { da } \\
\text { irrigação }\end{array}$ & $\begin{array}{c}\text { Fração do } \\
\text { escoamento } \\
\text { superficial }\end{array}$ \\
\hline 20 & 0,05 & 0,9 & 20 & 0,7 & 0,9 & 0,05 \\
\hline
\end{tabular}

Fonte: Informações cedidas pela Embrapa Cerrados

\subsection{2 - ANÁLISE DE SENSIBILIDADE}

A identificação dos parâmetros mais sensíveis possui extrema relevância na modelagem hidrológica pois o foco nestes pode levar a uma melhor compreensão e melhor estimativa dos valores simulados, reduzindo, dessa maneira, o nível de incerteza no modelo (LENHART et. $a l ., 2002)$. Esta etapa é importante pois, após a análise de sensibilidade é possível verificar quais parâmetros necessitam de calibração em relação aos dados observados.

Assim, a análise de sensibilidade dos parâmetros, realizada no aplicativo SWAT-CUP (ABBASPOUR, 2015), é feita com base em um sistema linear de regressão múltipla. Com base neste sistema, o programa realiza um teste-t para identificar a relevância relativa de cada um dos parâmetros analisados. A sensibilidade é resultante das variações médias da funçãoobjetivo provocando mudanças em cada parâmetro, ao mesmo tempo que todos os outros parâmetros também sofrem variações (ABBASPOUR, 2015). Utilizando diversas aproximações e faixas de variação de parâmetros do modelo SWAT, Lenhart et. al. (2002) estabeleceu quatro classes de sensibilidade em relação ao teste- $t$ (Tabela 10). 
Castro (2013), Carvalho (2014) e Ferrigo (2014) realizaram extensa revisão bibliográfica sobre o tema, identificando, nos trabalhos com o modelo SWAT no Brasil, os parâmetros com mais sensibilidade no (Tabela 11).

Tabela 10 - Classificação de Sensibilidade dos Parâmetros do Modelo SWAT

\begin{tabular}{|c|c|c|}
\hline Classe & Índice & Sensibilidade \\
\hline I & $0,00 \leq|I|<0,05$ & Baixa a nula \\
\hline II & $0,05 \leq|I|<0,20$ & Média \\
\hline III & $0,20 \leq|I|<1,00$ & Alta \\
\hline IV & $|I| \geq 1,00$ & Muito Alta \\
\hline
\end{tabular}

Fonte: LENHART et. al. (2002) 
Tabela 11 - Parâmetros identificados, por meio de análise de sensibilidade, como os mais importantes na simulação da vazão em diversos trabalhos utilizando o modelo SWAT no Brasil

\begin{tabular}{|c|c|c|}
\hline Parâmetros com maior sensibilidade & Autores & Região \\
\hline $\begin{array}{l}\text { ESCO, ALPHA-BF, SOL-Z, GW-QMN, } \\
\text { GWDELAY, SOL-AWC, REVAPMN, } \\
\text { SURLAG, GWREVAP, CN2 }\end{array}$ & Durães, 2010 & \multirow[t]{4}{*}{ Sudeste } \\
\hline ESCO, SOL-AWC, SLOPE, CN2, SLSUBBSN & Rocha et.al., 2010 & \\
\hline $\begin{array}{l}\text { ESCO, ALPHA-BF, EPCO, SOL-Z, CANMX, } \\
\text { CH-K2, SOL-AWC, SOL-K, CN2 }\end{array}$ & Lelis et. al., 2012 & \\
\hline $\begin{array}{l}\text { CN2, ALPHA-BF, RCHRG-DP,ESCO, SOL- } \\
\text { Z,SOL-AWC, SOL-K }\end{array}$ & Andrade et. al., 2013 & \\
\hline $\begin{array}{l}\text { ESCO, ALPHA-BF, CH-K2, CANMX, } \\
\text { SOLAWC, SOL-K, CN2, SLOPE, BLAI, GW- } \\
\text { QMN }\end{array}$ & Bonumá et.al., 2011 & \multirow[t]{4}{*}{ Sul } \\
\hline $\begin{array}{l}\text { ESCO, ALPHA-BF, SOL-Z, CANMX, SOL- } \\
\text { AWC, CN2, SLOPE, BLAI, GW-QMN, } \\
\text { REVAPMN }\end{array}$ & $\begin{array}{l}\text { Garbossa et. al., } \\
2010\end{array}$ & \\
\hline $\begin{array}{l}\text { ESCO, ALPHA-BF, GW-DELAY, SURLAG, } \\
\text { CN2 }\end{array}$ & Lino et.al., 2009 & \\
\hline $\begin{array}{l}\text { ESCO, ALPHA-BF, SOL-Z, SOL-AWC, BLAI, } \\
\text { GW-QMN, REVAPMN, CH-K2, CN2, } \\
\text { GWREVAP }\end{array}$ & Malutta, 2012 & \\
\hline $\begin{array}{l}\text { SURLAG, GW-REVAP, CN2, GW-REVAP, } \\
\text { RCHRG-DP, SOL-Z }\end{array}$ & Sarmento, 2010 & \multirow[t]{5}{*}{ Centro-Oeste } \\
\hline $\begin{array}{l}\text { CN2, ALPHA-BF, CH-K2, ESCO, GW- } \\
\text { DELAY, CH-N2, GW-QMN, CANMX, } \\
\text { SURLAG }\end{array}$ & Strauch et.al., 2011 & \\
\hline $\begin{array}{l}\text { ALPHA-BF, CN2, GW-DELAY, GW-QMN, } \\
\text { GW-REVAP, ESCO, SLUSUBBSN }\end{array}$ & Ferrigo et. al., 2012 & \\
\hline $\begin{array}{l}\text { ESCO- ALPHA-BF, GW-QMN, SURLAG, } \\
\text { GWREVAP, CN2, CH-K2, RCHRG-DP, CH- } \\
\text { N2, REVAPMN }\end{array}$ & Salles, 2012 & \\
\hline $\begin{array}{l}\text { SURLAG, ALPHA-BF, CN2, GWQMN, SOL- } \\
\text { K, CH-K2, SLOPE, SLUBSN, BLAI, SOL- } \\
\text { ALB }\end{array}$ & Castro, 2013 & \\
\hline
\end{tabular}

Fonte: adaptado de Castro (2013), Carvalho (2014) e Ferrigo (2014) 
Para a variação inicial dos parâmetros de vazão, foram utilizados os intervalos aplicados por Ferrigo (2014) na bacia do Lago Descoberto-DF, e por Salles (2012) na bacia do rio Pipiripau-DF, que também se inserem em ambiente de cerrado, possuindo características de solo e uso parecidos (SALLES, 2012; LIMA, 2013; FERRIGO, 2014). Estes valores encontram-se na Tabela 12.

Para a variação inicial dos parâmetros de sedimentos (Tabela 13), foram utilizado os valores aplicados por Carvalho (2014) na bacia do rio Jardim - DF. Por fim, para a aplicação dos parâmetros de qualidade de água (Tabela 14), foram utilizados os valores aplicados por Monsalve-Herrera (2013) na sub-bacia do Riacho Fundo - DF e Ferrigo (2014) na bacia do Lago Descoberto-DF. 
Tabela 12 - Variação dos parâmetros de vazão para análise de sensibilidade

\begin{tabular}{|c|c|c|c|c|c|}
\hline Parâmetro & Descrição do parâmetro & Unidade & Método & Mínimo & Máximo \\
\hline $\mathrm{CN} 2$ & Curva Número na condição II & Adimensional & Multiplicação & -0.3 & 0.2 \\
\hline ALPHA_BF & $\begin{array}{l}\text { Constante de recessão do fluxo } \\
\text { de base }\end{array}$ & Dias & $\begin{array}{l}\text { Substituição } \\
\text { Direta }\end{array}$ & 0 & 1 \\
\hline GWQMN & $\begin{array}{c}\text { Limiar da profundidade da água } \\
\text { no aquífero superficial } \\
\text { necessária para o fluxo de } \\
\text { retorno ocorrer }\end{array}$ & $\mathrm{mm}$ & $\begin{array}{l}\text { Substituição } \\
\text { Direta }\end{array}$ & -20 & 450 \\
\hline GW_REVAP & $\begin{array}{c}\text { Coeficiente revap, que } \\
\text { determina percolação da água } \\
\text { no aquífero profundo para o } \\
\text { raso }\end{array}$ & Adimensional & $\begin{array}{l}\text { Substituição } \\
\text { Direta }\end{array}$ & 0.02 & 0.1 \\
\hline REVAPMN & $\begin{array}{l}\text { Profundidade do aquífero em } \\
\text { que ocorre o revap }\end{array}$ & $\mathrm{mm}$ & $\begin{array}{l}\text { Substituição } \\
\text { Direta }\end{array}$ & 0 & 500 \\
\hline ESCO & $\begin{array}{l}\text { Fator de compensação de } \\
\text { evaporação do solo }\end{array}$ & Adimensional & $\begin{array}{l}\text { Substituição } \\
\text { Direta }\end{array}$ & 0 & 0.4 \\
\hline GW_DELAY & $\begin{array}{c}\text { Tempo de retardo da água } \\
\text { subterrânea }\end{array}$ & Dias & $\begin{array}{c}\text { Soma dos valores } \\
\text { absolutos }\end{array}$ & 0 & 1228 \\
\hline SHALLST & $\begin{array}{l}\text { Altural inicial da água } \\
\text { subterrânea }\end{array}$ & $\mathrm{mm}$ & $\begin{array}{l}\text { Substituição } \\
\text { Direta }\end{array}$ & 1000 & 5000 \\
\hline DEEPST & $\begin{array}{l}\text { Altura inicial da água no } \\
\text { aquífero profundo }\end{array}$ & $\mathrm{mm}$ & $\begin{array}{l}\text { Substituição } \\
\text { Direta }\end{array}$ & 0 & 3000 \\
\hline CH_K2 & $\begin{array}{c}\text { Condutividade hidráulica } \\
\text { efetiva do canal }\end{array}$ & $\mathrm{mm} \cdot \mathrm{h}^{-1}$ & Multiplicação & -0.2 & 0.2 \\
\hline SOL_AWC & $\begin{array}{l}\text { Capacidade de água disponível } \\
\text { no solo }\end{array}$ & $\mathrm{mm} \cdot \mathrm{mm}^{-1}$ & Multiplicação & 0.2 & 0.5 \\
\hline SOL_K & $\begin{array}{l}\text { Condutividade hidráulica do } \\
\text { solo }\end{array}$ & $\mathrm{mm} \cdot \mathrm{h}^{-1}$ & Multiplicação & -2 & 3 \\
\hline SOL_BD & Densidade aparente do solo & g. $\left(\mathrm{cm}^{3}\right)^{-1}$ & Multiplicação & -0.3 & 0.3 \\
\hline OV_N & $\begin{array}{l}\text { Coeficiente de rugosidade de } \\
\text { Manning do escoamento } \\
\text { superficial }\end{array}$ & Adimensional & Multiplicação & -0.2 & 0.3 \\
\hline
\end{tabular}

Fonte: adaptado de Salles (2012); Lima et. al. (2013); e Ferrigo (2014) 
Tabela 13 - Variação dos parâmetros de sedimentos para análise de sensibilidade

\begin{tabular}{|c|c|c|c|c|c|}
\hline Parâmetro & Descrição do parâmetro & Unidade & Método & Mínimo & Máximo \\
\hline PRF_BSN & $\begin{array}{c}\text { Fator de ajuste de pico de } \\
\text { sedimentos no canal principal }\end{array}$ & Adimensional & Multiplicação & $-0,3$ & 0,3 \\
\hline ADJ_PKR & $\begin{array}{c}\text { Fator de ajuste de pico de } \\
\text { sedimentos nos canais } \\
\text { tributários }\end{array}$ & Adimensional & Multiplicação & $-0,3$ & 0,1 \\
\hline CH_COV1 & Fator de erodibilidade do canal & Adimensional & Substituição direta & 0,5 & 1 \\
\hline CH_COV2 & Fator de cobertura do canal & Adimensional & Substituição direta & 0,9 & 1 \\
\hline SPCON & $\begin{array}{l}\text { Parâmetro linear para cálculo da } \\
\text { quantidade máxima de } \\
\text { sedimento que pode ser } \\
\text { "reentrained" durante o } \\
\text { "routing" do sedimento no canal }\end{array}$ & Adimensional & Substituição direta & 0,0001 & 0,1 \\
\hline SPEXP & $\begin{array}{l}\text { Parâmetro exponencial para } \\
\text { cálculo da quantidade de } \\
\text { sedimento "reentrained" durante } \\
\text { o "routing" do sedimento no } \\
\text { canal }\end{array}$ & Adimensional & Substituição direta & 1 & 2,5 \\
\hline LAT_SED & $\begin{array}{l}\text { Concentração de sedimento no } \\
\text { fluxo lateral e subsuperficial }\end{array}$ & $\mathrm{mg} \cdot \mathrm{L}^{-1}$ & Substituição direta & 0 & 20 \\
\hline SLSUBSN & $\begin{array}{l}\text { Tamanho médio do } \\
\text { comprimento de rampa }\end{array}$ & $\mathrm{m}$ & Substituição direta & 5 & 100 \\
\hline USLE_C & Fator C da MUSLE & Adimensional & Substituição direta & 0 & 0,5 \\
\hline USLE_P & Fator P da MUSLE & Adimensional & Multiplicação & -1 & 1 \\
\hline USLE_K & Fator K da MUSLE & Adimensional & Multiplicação & -1 & 1 \\
\hline
\end{tabular}

Fonte: adaptado de Carvalho (2014) 
Tabela 14- Variação dos parâmetros de nutrientes para análise de sensibilidade

\begin{tabular}{|c|c|c|c|c|c|}
\hline Parâmetro & Descrição do parâmetro & Unidade & Método & Mínimo & Máximo \\
\hline SOL_NO3 & $\begin{array}{c}\text { Concentração inicial de NO3 } \\
\text { nas camadas de solo }\end{array}$ & $\mathrm{mg} \cdot \mathrm{kg}^{-1}$ & Multiplicação & $-0,3$ & $-0,1$ \\
\hline SOL_ORGN & $\begin{array}{c}\text { Concentração inicial de } \mathrm{N} \\
\text { orgânico nas camadas de solo }\end{array}$ & $\mathrm{mg} \cdot \mathrm{kg}^{-1}$ & Multiplicação & $-0,1$ & 0,3 \\
\hline FRT_SURFACE & $\begin{array}{l}\text { Fração de fertilizante aplicado } \\
\text { aos primeiros } 10 \mathrm{~mm} \text { da camada } \\
\text { superior do solo }\end{array}$ & Fração & $\begin{array}{l}\text { Substituição } \\
\text { Direta }\end{array}$ & 0,001 & 0,7 \\
\hline SDNCO & $\begin{array}{l}\text { Limiar de quantidade de água } \\
\text { para denitrificação }\end{array}$ & Adimensional & $\begin{array}{l}\text { Substituição } \\
\text { Direta }\end{array}$ & 0,9 & 1,1 \\
\hline RSDCO & $\begin{array}{l}\text { Coeficiente de decomposição de } \\
\text { resíduos }\end{array}$ & Adimensional & Multiplicação & $-0,2$ & 0,1 \\
\hline NPERCO & $\begin{array}{l}\text { Coeficiente de percolação de } \\
\text { nitrogênio }\end{array}$ & Adimensional & $\begin{array}{l}\text { Substituição } \\
\text { Direta }\end{array}$ & 0,2 & 0,5 \\
\hline BIOMIX & Eficiência de mistura biológica & Adimensional & $\begin{array}{l}\text { Substituição } \\
\text { Direta }\end{array}$ & 0,3 & 1 \\
\hline ANION_EXCL & $\begin{array}{l}\text { Espaço vazio em que ânions são } \\
\text { excluídos }\end{array}$ & Fração & Multiplicação & $-0,2$ & 0,2 \\
\hline SHALLST_N & $\begin{array}{c}\text { Concentração de nitrato } \\
\text { existente na água subsuperficial } \\
\text { contribuindo para a vazão na } \\
\text { sub-bacia }\end{array}$ & $\mathrm{mg} \mathrm{N} \cdot \mathrm{L}^{-1}$ & Multiplicação & $-0,3$ & 0,3 \\
\hline $\mathrm{RCN}$ & Concentração de $\mathrm{N}$ na chuva & $\operatorname{mg~N} \cdot L^{-1}$ & Multiplicação & $-0,3$ & 0,2 \\
\hline $\mathrm{CMN}$ & $\begin{array}{l}\text { Fator de mineralização de } \\
\text { húmus do } \mathrm{N} \text { orgânico }\end{array}$ & Adimensional & Multiplicação & $-0,25$ & 0,25 \\
\hline $\mathrm{CDN}$ & $\begin{array}{c}\text { Coeficiente da taxa exponencial } \\
\text { da denitrificação }\end{array}$ & Adimensional & $\begin{array}{l}\text { Substituição } \\
\text { Direta }\end{array}$ & 0,001 & 0,2 \\
\hline
\end{tabular}

Fonte: adaptado de Monsalve-Herrera (2013); Lima et. al.(2013); e Ferrigo (2014) 


\subsection{3 - CALIBRAÇÃO, VERIFICAÇÃO DO MODELO, E ANÁLISE ESTATÍSTICA}

A calibração do modelo hidrológico é feita para ajustar os valores simulados na bacia com base em dados observados em determinados pontos da bacia, podendo ser calibrado pela vazão, sedimentos, qualidade da água, etc. (ABBASPOUR, 2015). Conforme Arnold et. al. (2000), o primeiro passo para a calibração é separar o recorte temporal da série de dados observados em período de calibração e validação, sendo que no primeiro, os dados podem variar na bacia de estudo para que os dados simulados se aproximem dos dados observados. Uma vez determinados os parâmetros que permitem esta aproximação, o modelo é aplicado no segundo período para validar estes resultados.

Nesse contexto, calibração do modelo é feita em etapas ou iterações, em que diferentes faixas de variação de cada parâmetro é inserido para atender os valores de referência do balanço hídrico na área de estudo, associado à análise de sensibilidade onde são identificados os parâmetros que estão influenciando mais os resultados do modelo. Cada iteração consiste de um determinado número de simulações onde o modelo testa, para cada simulação um valor diferente para cada parâmetro utilizado. Abbaspour (2015) aponta que 500 simulações para cada iteração é, em geral, suficiente para calibrar o modelo.

Após a calibração, é feita uma análise estatística para determinar a eficiência do modelo. Para tal, foram utilizados quatro índices: o p-factor, que representa o quanto os dados observados se encontram dentro da curva de incerteza; o $r$-factor, que representa a espessura da curva de incerteza - se o valor de $p$-factor for igual a 1 , e de $r$-factor for igual a 0 , então a simulação corresponderia exatamente aos dados observados (JAJARMIZADEH et. al., 2012; ABBASPOUR et. al., 2015); e, para estimar o erro existente entre os dados observados e simulados, foram utilizadas as funções objetivo $\mathrm{R}^{2}$ e o coeficiente de Nash-Sutcliffe (NASH e SUTCLIFFE, 1970; ABBASPOR, 2005; NEITSCH et. al., 2009; ABBASPOUR, 2014; ABBASPOUR et. al., 2015), conforme demonstrado, respectivamente, nas Equações 5 e 6. Tendo como base a comparação com outros trabalhos, Green e van Griensven (2008) atribuiram os valores de ENS $\geq 0,4$ e $\mathrm{R}^{2} \geq 0,5$ como sendo satisfatórios.

$$
R^{2}=\frac{\left[\sum_{i}\left(Q_{m, i}-\bar{Q}_{m}\right)\left(Q_{s, i}-\bar{Q}_{s}\right)\right]^{2}}{\sum_{i}\left(Q_{m, i}-\bar{Q}_{m}\right)^{2} \sum_{i}\left(Q_{s, i}-\bar{Q}_{s}\right)^{2}}
$$


Onde $\mathrm{R}^{2}$ é o coeficiente de determinação; Q é a variável analisada (vazão, quantidade de sedimentos ou quantidade de NO3), e m e s são, respectivamente, os dados medidos $i$ e simulados $s$.

$$
E N S=1-\frac{\sum_{i}\left(Q_{m}-Q_{s}\right)^{2}}{\sum_{i}\left(Q_{m, i}-\bar{Q}_{m}\right)^{2}}
$$

Onde ENS é o coeficiente de Nash-Sutcliffe; Q é a variável analisada (vazão, quantidade de sedimentos ou quantidade de NO3), e m e s são, respectivamente, os dados medidos $i$ e simulados $s$.

Os dados de vazão utilizados para a calibração foram dados cedidos pelo Laboratório de Hidrometria da Embrapa Cerrados. A estação de monitoramento, localizada próximo à jusante da bacia, encontra-se nas coordenadas 209.894 X/8.277.283Y (Figura 7).

\subsubsection{1 - Calibração e Verificação pela Vazão}

Na Figura 11, é possível verificar a série de vazão utilizada, que abrange o período entre jan/2012 e dez/2014 (dados cedidos pelo Laboratório de Hidrometria da Embrapa Cerrados). Os dois primeiros anos se referem à calibração e o último à verificação. Tanto a calibração quanto a análise de sensibilidade foram realizadas no aplicativo SWAT-CUP, versão 5.1.6. Para o processo de calibração, com base em dados diários, foram feitas 5 iterações com 500 simulações cada. 


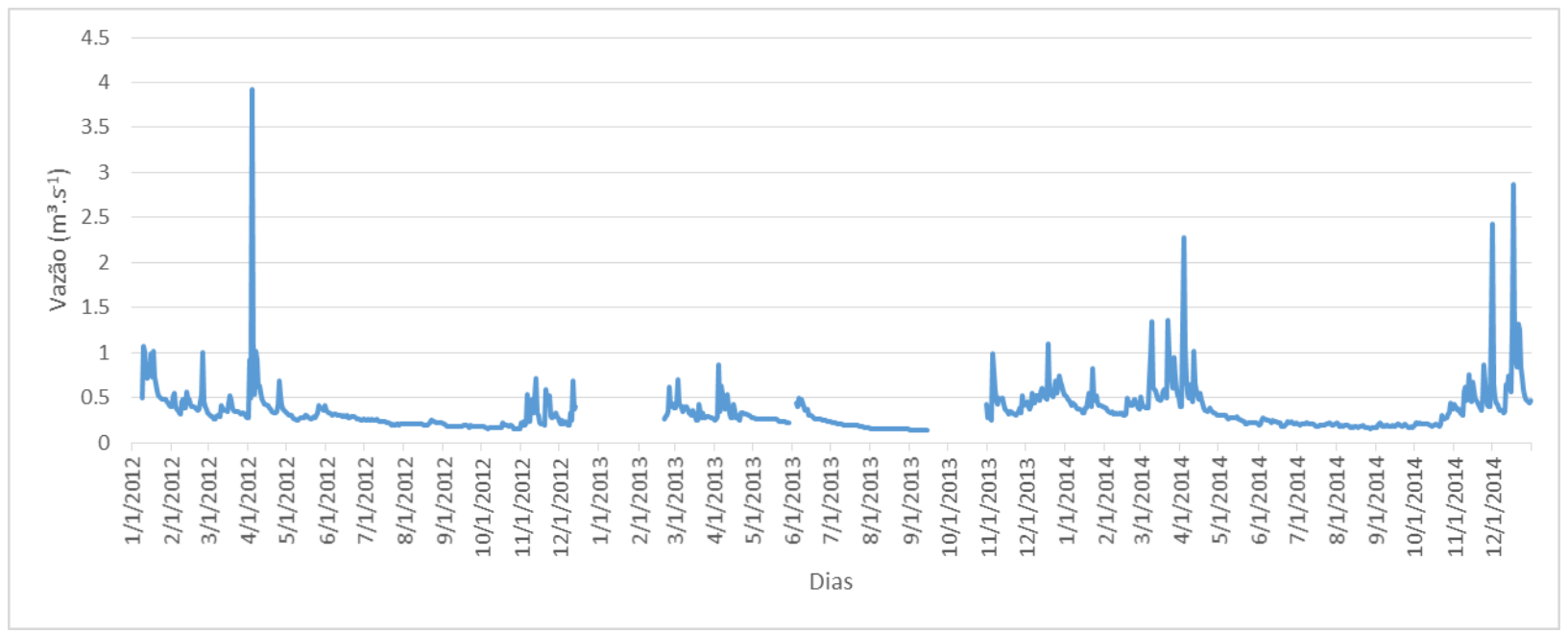

Figura 11 - Série de vazão na Estação Jusante (Dados cedidos pelo Laboratório de Hidrometria da Embrapa Cerrados)

\subsubsection{2 - Calibração e Verificação pela Qualidade da Água}

\subsubsection{1 - Sedimentos}

Na Figura 12, é possível verificar a série de sedimentos utilizada, que abrange o período entre jan/2012 e dez/2014. Os dois primeiros anos se referem à calibração e o último à verificação. Tanto a calibração quanto a análise de sensibilidade foram realizadas no aplicativo SWAT-CUP, versão 5.1.6.

Para gerar a série, foi utilizada a curva-chave de sedimentos (dados cedidos pelo Laboratório de Hidrometria da Embrapa Cerrados), que apresentou índice de correlação $\left(\mathrm{R}^{2}\right)$ de 0,68 com os dados de vazão.

O processo de calibração, com base em dados mensais, de sedimentos foi feito com 2 iterações de 500 simulações cada. Os resultados foram levados para o ARCSWAT para a elaboração dos mapas de perda de solos, $\mathrm{K}$ e $\mathrm{Ca}+\mathrm{Mg}$. 


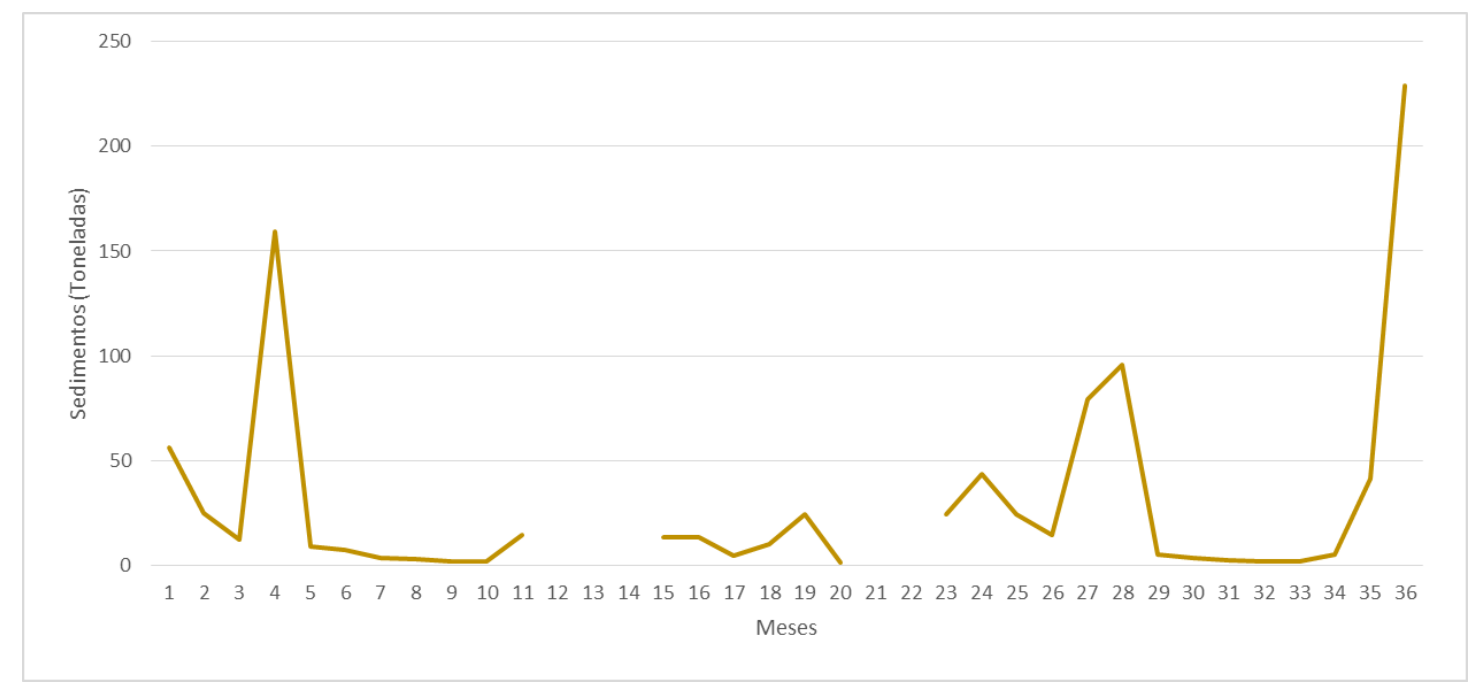

Figura 12 - Série de sedimentos na Estação Jusante (Dados cedidos pelo Laboratório de Hidrometria da Embrapa Cerrados)

\subsubsection{2 - Nutrientes}

Na Figura 13, é possível verificar a série de nitrato (NO3) utilizada, que abrange o período entre jan/2012 e dez/2014. Os dois primeiros anos se referem à calibração e o último à verificação. Tanto a calibração quanto a análise de sensibilidade foram realizadas no aplicativo SWAT-CUP, versão 5.1.6.

Para gerar a série, foi utilizada a curva-chave de NO3 (dados cedidos pelo Laboratório de Química de Água da Embrapa Cerrados), que apresentou índice de correlação ( $\left.\mathrm{R}^{2}\right)$ de 0,69 com os dados diários de vazão. Os dados foram convertidos de concentração de NO3 (mg.L $\left.\mathrm{L}^{-1}\right)$ para carga de NO3 utilizando a Equação 7 (NEISCH et.al., 2005; AKHAVAN et.al., 2010):

$$
N_{\text {Load }}=570,24 \cdot N O_{3}^{-} \cdot Q \cdot d^{-1}
$$

Onde $\mathrm{N}_{\text {Load }}$ é a quantidade de NO3 carreado pelo escoamento superficial (kg N.dia ${ }^{-1}$ ); 570,24 é um fator de conversão; $\mathrm{NO}_{3}^{-}$é a concentração de nitrato $\left(\mathrm{mg} \cdot \mathrm{L}^{-1}\right)$; Q é a vazão $\left(\mathrm{m}^{3} \cdot \mathrm{s}^{-}\right.$ ${ }^{1}$ ); e $d$ é a quantidade de dias no mês.

Para o processo de calibração com base em dados diários de NO3, foi necessária apenas 1 iteração de 500 simulações. Importante destacar que os dados de fósforos não foram 
calibrados uma vez que a variação da quantidade de Fósforo Total observados é praticamente nula, apresentando valores próximos a $0,02 \mathrm{mg} . \mathrm{L}^{-1}$, não apresentando correlação com os dados de vazão. Os resultados foram levados para o ARCSWAT para geração dos mapas de perdas de nitrogênio e fósforo.

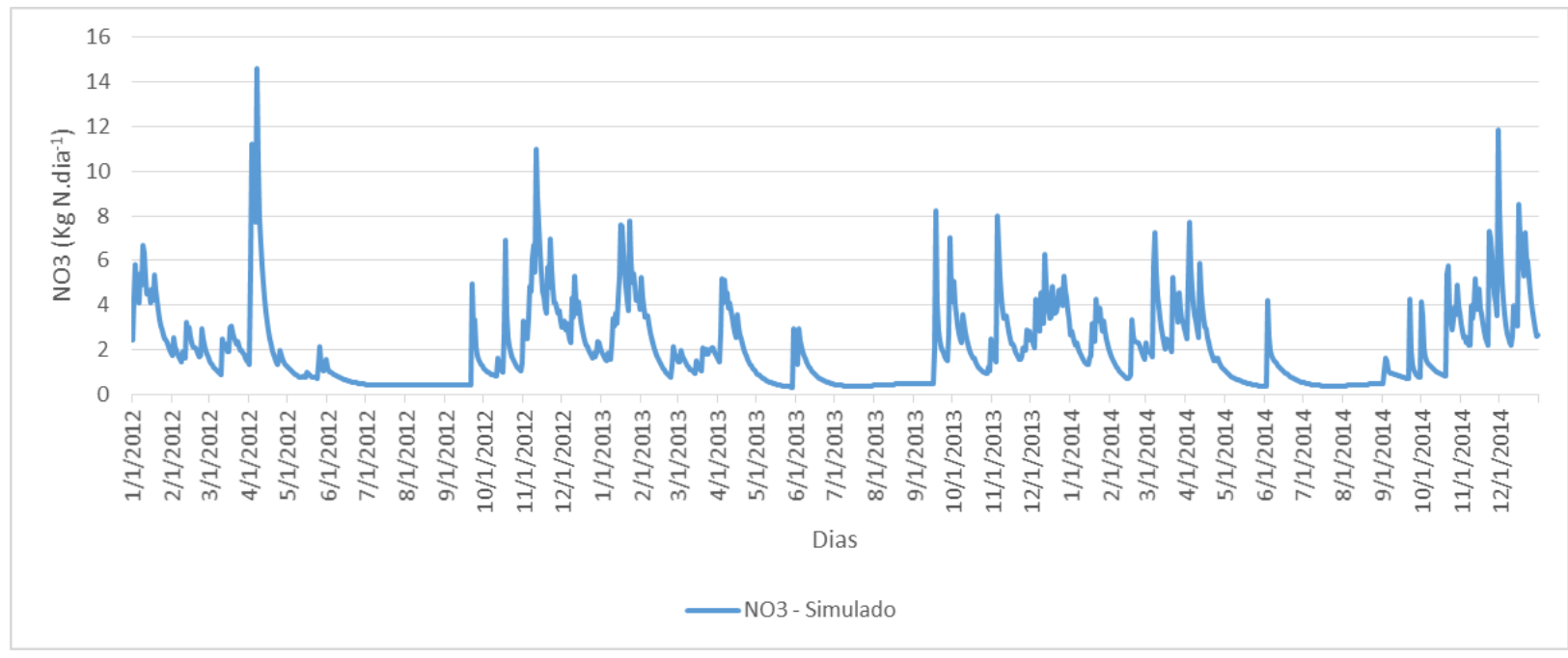

Figura 13 - Série de NO3 (kg) na Estação Jusante (Dados cedidos pelo Laboratório de Química de Água da Embrapa Cerrados)

\subsection{4 - ANÁLISE DA PERDA DE SOLOS E PRODUÇÃO DE SEDIMENTOS}

Em relação aos processos de perda de solos, o modelo SWAT utiliza a MUSLE (Modified Universal Soil Loss Equation), que se difere da USLE ao substituir a erosividade da chuva pelo fator de escoamento superficial (Equação 8). Essa modificação permite uma melhor análise das taxas de sedimentação, pois o escoamento superficial ocorre em função tanto da precipitação como de umidade anterior ao evento de chuva (WILLIAMS, 1975; NEITSCH et. al., 2009).

$$
\text { Sed }=11,8 \cdot\left(Q_{L} \times q_{p} \times A_{h r u}\right)^{0,56} \cdot \text { K.C.P.L.S.CFRG }
$$

Onde: Sed é a produção de sedimentos diária (toneladas); $\mathrm{Q}_{\mathrm{L}}$ é a lâmina escoamento superficial $\left(\mathrm{mm} \cdot \mathrm{ha}^{-1}\right) ; \mathrm{q}_{\mathrm{p}}$ é a vazão de pico $\left(\mathrm{m}^{3} \cdot \mathrm{s}^{-1}\right) ; \mathrm{A}_{\mathrm{hru}}$ é a área da unidade de resposta 
hidrológica - HRU (ha); Ké a erodibilidade do solo (ton.ha.h.hs ${ }^{-1}$.(MJ.mm) ${ }^{-1}$ ); Lé comprimento de rampa (adimensional); $\mathrm{S}$ é o gradiente de declividade (\%); $\mathrm{C}$ representa a cobertura superficial ou uso/manejo (adimensional); $\mathrm{P}$ representa as práticas conservacionistas (adimensional), e CFRG representa o fator fragmentos grosseiros.

Para os valores de CP (Equação 1) foram utilizados os valores aplicados por Lima e Lopes (2009) ao estimar os valores de perda de solos no Estado de Tocantins (Tabela 15).

Tabela 15 - Valores Iniciais de C e P utilizados

\begin{tabular}{|c|c|c|}
\hline Classe de Uso e Ocupação do Solo & C & 0,2 \\
\hline $\begin{array}{c}\text { Agricultura de Sequeiro, Agricultura } \\
\text { Irrigada e Pivô Central }\end{array}$ & 0,18 & 0,2 \\
\hline Pastagem & 0,025 & 0,1 \\
\hline Cultivos Florestais & 0,012 & 0,1 \\
\hline $\begin{array}{c}\text { Formação Savânica, Formação Campestre e } \\
\text { Vegetação Degradada }\end{array}$ & 0,042 & 0,1 \\
\hline Formação Florestal & 0,012 & 0 \\
\hline
\end{tabular}

Fonte: adaptado de Lima e Lopes (2009)

A partir do modelo calibrado pela quantidade de sedimentos, foram gerados mapas para cada um dos anos de 2012, 2013 e 2014 mostrando a perda de solos por HRU. Os resultados foram agrupados em 3 classes de susceptibilidade, conforme Lima et. al. (2012), demonstrado na Tabela 16.

Tabela 16 - Classes de Perda de Solos

\begin{tabular}{|c|c|}
\hline Classificação & $\begin{array}{c}\text { Perda de Solos } \\
\left(\mathbf{t}^{\text {.ha }} \mathbf{~}^{\mathbf{1}} \text {.ano }^{-\mathbf{1}}\right)\end{array}$ \\
\hline Baixa & $<10$ \\
\hline Média & $10-20$ \\
\hline Alta & $>20$ \\
\hline
\end{tabular}

Fonte: LIMA et. al. (2012)

Por fim, foi gerado um gráfico apresentando a quantidade de sedimentos no canal principal em comparação com os dados de vazão observados e simulados, e com os dados de chuva da Estação Climática CPAC-Principal - por estar mais próxima da Estação Jusante (Figura 7). 


\subsection{5 - ANÁLISE DA PERDA DE NUTRIENTES}

\subsubsection{1 - Perdas de $\mathbf{N}$ e $P$}

Para a análise e mapeamento da perda de nutrientes, foram utilizados os resultados simulados pelo SWAT, que calcula as perdas de $\mathrm{N}$ e $\mathrm{P}$ - provocadas exclusivamente pela erosão do solo - com base nas seguintes informações (NEITSCH et, al., 2011):

- Perdas de Nitrogênio

- Quantidade de nitrogênio orgânico transportado para fora da HRU no período analisado ( $\mathrm{kg} \mathrm{N} / \mathrm{ha})$;

○ NO3 presente no escoamento superficial ( $\mathrm{kg} \mathrm{N} / \mathrm{ha}$ );

- NO3 presente no escoamento lateral ( $\mathrm{kg} \mathrm{N} / \mathrm{ha})$;

○ Quantidade de NO3 lixiviado no perfil de solo ( $\mathrm{kg} \mathrm{N} / \mathrm{ha})$;

- Quantidade de NO3 transportado para o canal principal por meio do fluxo de base;

- Perdas de Fósforo

- Quantidade de fósforo orgânico transportado para fora da HRU no período analisado (kg P/ha);

○ Fósforo mineral absorvido pelo sedimento transportado para o canal durante o período analisado (kg P/ha);

- Níveis de fósforo solúvel transportado pelo escoamento superficial para o canal principal ( $\mathrm{kg} \mathrm{P} / \mathrm{ha})$;

- Níveis de fósforo solúvel transportado pelo fluxo de base para o canal principal (kg P/ha);

A partir da soma desses parâmetros, foi gerado um mapa de perdas de nutrientes para os anos 2012, 2013 e 2014. Importante destacar que, mesmo que estes nutrientes carreados para os corpos de água da bacia impliquem em custos externos à produção (TELLES, 2011), foram considerados apenas os custos internos à produção dado a dificuldade em determinar se estes custos serão internalizados nos diversos módulos produtivos existentes em uma bacia hidrográfica ocupada por agricultura. 


\subsubsection{2 -Perdas de K e Ca+Mg}

Para o cálculo das perdas de $\mathrm{K}$ foi utilizado o valor apresentado por Pimentel et. al. (1995), em que 1 tonelada de camada superior de solo fértil apresenta, em média $16 \mathrm{~kg}$ de potássio $^{7}$. Já para as perdas de cálcio e magnésio foi utilizado o valor utilizado por Tosto et. al. (2010), em que 1 tonelada de solo possui, em média, $1 \mathrm{~kg}$ de $\mathrm{Ca}+\mathrm{Mg}^{8}$. A partir destes valores em conjunto com o mapa de perda de solos, foram gerados os mapas de perdas de $\mathrm{K}$ e $\mathrm{Ca}+\mathrm{Mg}$ para os anos 2012, 2013 e 2014. Estes valores médios se aplicam para diversos tipos de solo, uma vez que não há dados experimentais disponíveis na bibliografia para que seja feita uma especificação das perdas de potássio e corretivos para cada tipo de solo.

Essa aproximação foi necessária uma vez que o SWAT trabalha apenas com as perdas de $\mathrm{N}$ e $\mathrm{P}$.

\section{4 - ANÁLISE DO CUSTO DE REPOSIÇÃO}

Um dos métodos mais utilizados para valorar os custos provocados pela erosão é o custo de reposição (HUFSCHMIDT et. al. 1983; BARBIER, 1998; PUGLIESI et. al., 2011), em que se estima os custos relacionados à reposição de nutrientes perdidos no decorrer de diversos processos dinâmicos. Neste trabalho, foca-se nas perdas provocadas por erosão laminar e lixiviação de Nitrogênio e Fósforo, utilizando a formulação aplicada por Rodrigues (2005), Dantas e Monteiro (2007) e Pugliesi et. al. (2011), demonstrado abaixo:

$$
C I=(Q n \cdot P n)+C a
$$

Onde $C I$ é o custo de reposição de nutrientes $\left(\mathrm{R} \$ . \mathrm{ha}^{-1}\right) ; Q n$ é a quantidade de fertilizantes carreados por processos erosivos $\left(\mathrm{kg} \cdot \mathrm{ha}^{-1}\right)$; Pn é o preço dos fertilizantes $\left(\mathrm{R} \$ \mathrm{~kg}^{-1}\right)$; e $C a$ é o custo de aplicação dos fertilizantes $\left(\mathrm{R} \$ \cdot \mathrm{ha}^{-1}\right)$.

\footnotetext{
7 Pimentel et. al. (1995) realizou estudo sobre o impacto econômico da erosão em nível global.

${ }^{8}$ Tosto et. al. (2010) realizou estudo do custo de reposição de fertilizantes no espaço rural do município de Araras-SP
} 
Para os valores de Pn e Ca para os anos de 2012, 2013 e 2014, foram utilizados as informações de EMATER-DF (2015), FAEG (2015), Silva Júnior et. al. (2010), e Rocha et. al. (2007), apresentados na Tabela 17. Importante destacar que o ano de 2012 foi considerado como ano de implantação das culturas perenes e semi-perenes, e, quando necessário, os anos de 2013 e 2014 foram considerados como anos de manutenção da cultura.

Para a obtenção de $Q n$, foi utilizado o fator de conversão dos valores referentes à perda de nutrientes para a quantidade de fertilizante apresentado por Belinazzi Júnior et. al. (1981), demonstrado na Tabela 18. 
Tabela 17 - Custos de Aplicação e Preços dos Fertilizantes

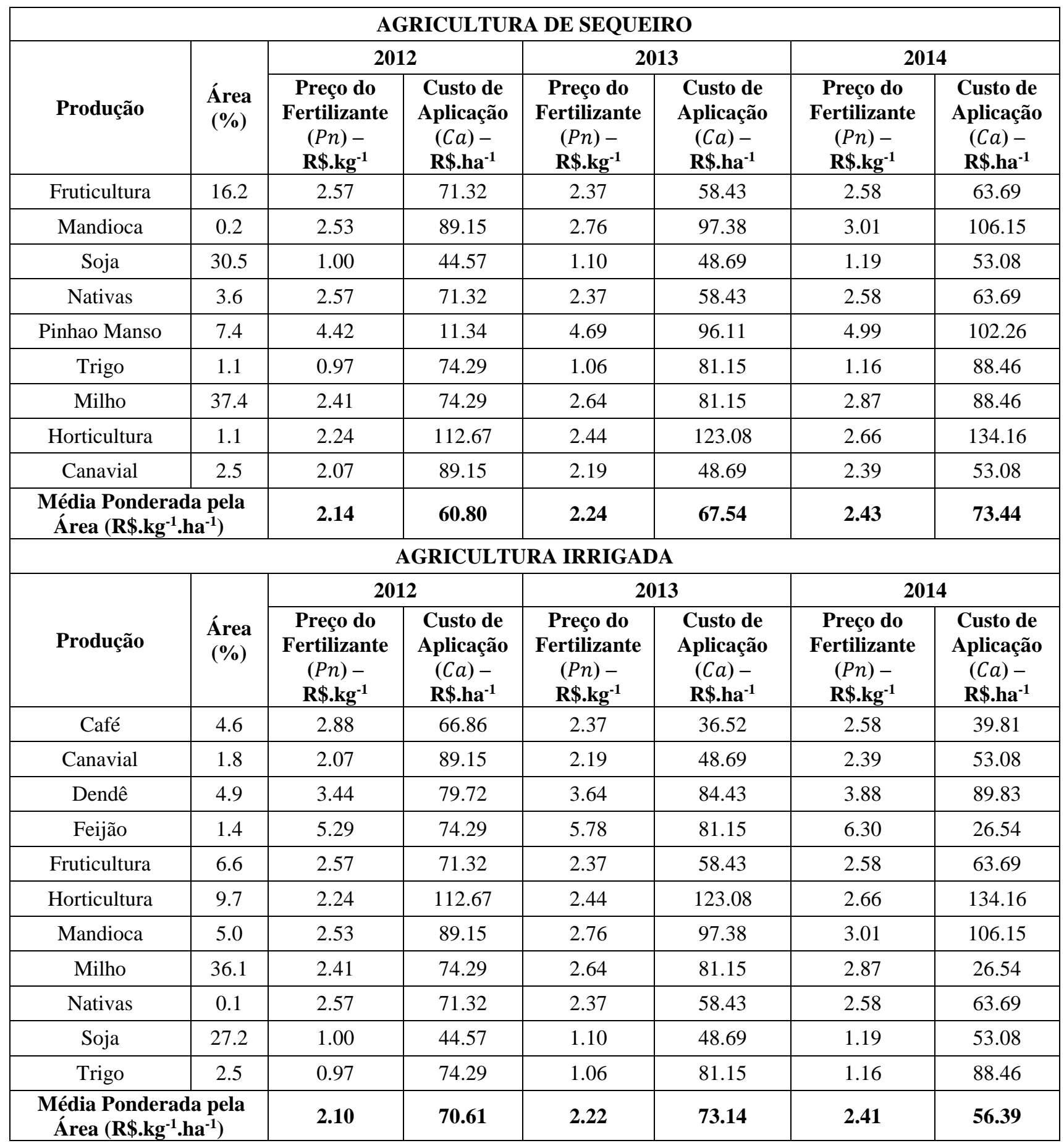

Fonte: Adaptado de EMATER-DF (2015), FAEG (2015), Silva Júnior et. al. (2010), e Rocha et. al. (2007) 
Tabela 18 - Coeficientes técnicos de conversão de nutrientes em fertilizantes

\begin{tabular}{|c|c|c|c|}
\hline Elementos & Fertilizantes & $\begin{array}{c}\text { Teor médio } \\
\text { de nutrientes } \\
(\boldsymbol{\%})\end{array}$ & $\begin{array}{c}\text { Relação Kg nutrientes / } \\
\text { Kg de fertlizantes }\end{array}$ \\
\hline $\mathrm{N}$ & Sulfato de amônio & 20 & 5 \\
\hline $\mathrm{P}$ & Superfosfato simples & 18 & 5,56 \\
\hline $\mathrm{K}$ & Cloreto de Potássio & 58 & 1,72 \\
\hline $\mathrm{Ca}+\mathrm{Mg}$ & Calcário Dolomítico & 38 & 2,63 \\
\hline
\end{tabular}

Fonte: BELINAZZI JÚNIOR et. al. (1981)

\section{5- ANÁLISE DO IMPACTO ECONÔMICO DA REPOSIÇÃO DE NUTRIENTES NA PRODUÇÃO}

\subsection{1 - CÁLCULO DA PRODUTIVIDADE}

O modelo SWAT utiliza para o cálculo da produtividade uma versão simplificada do modelo EPIC, em que desenvolvimento fenológico da planta é baseado em unidades de calor (Heat Units) acumulados diariamente. Nesse sentido, a planta possui uma temperatura mínima de crescimento em que, a partir desta, a planta começa a crescer conforme a temperatura aumenta até atingir uma temperatura ideal de crescimento que, quando excedida, a taxa de crescimento é reduzida até ser interrompida quando atingir uma temperatura máxima (WILLIAMS, 1990). Além da temperatura, o crescimento vegetal pode ser interrompido por stress hídrico, stress de nitrogênio e stress de fósforo (NEITSCH et. al., 2011).

\subsection{2 - CÁLCULO DO VALOR DA PRODUÇÃO}

Os impactos econômicos provocados pela erosão na agricultura devem ser considerados como custo de oportunidade (HUFSCHMIDT ET AL.,1983; BARBIER 1990, 1994 E 1998); MCCONELL e BURGER, 2011; ENGLISH et. al., 2013; LIENHARD et.al., 2014; e MITTER et. al., 2014), onde o produtor, como agente econômico racional, irá estabelecer o investimento necessário em práticas de manejo para que a produção agrícola seja sustentável no longo prazo.

Assim, foi calculado o valor presente líquido (Equação 10) para estimar o valor da produção na bacia do córrego Sarandi: 


$$
V P L=-C_{0}+\sum_{t=1}^{n} \frac{\left[R-\left(C_{m}+C_{r}\right)\right]}{(1+r)^{t}}
$$

Onde VPL é o valor presente líquido; $\mathrm{C}_{0}$ é o investimento inicial do empreendimento; $\mathrm{r}$ é a taxa de juros privado ${ }^{9}$; t é o ano do empreendimento (Ano 1 - implantação, referente a 2012; Anos 2 e 3 - manutenção, referentes a 2013 e 2014); R é o valor de mercado do produto final; $\mathrm{C}_{\mathrm{m}}$ é o custo de manutenção ou replantio da cultura e $\mathrm{C}_{\mathrm{r}}$ é o custo de reposição da HRU.

Para os custos de implantação, manutenção e receitas geradas por cultura foram utilizadas as informações de EMATER-DF (2015), FAEG (2015), Silva Júnior et. al. (2010), e Rocha et. al. (2007). A Tabela 19 apresenta os valores de implantação ${ }^{10}\left(\mathrm{C}_{0}\right)$ das diversas culturas para o ano 2012 e os valores de manutenção ou replantio são referentes aos anos 2013 e 2014 com e sem manejo. Já a Tabela 20 apresenta os valores de receita ${ }^{10}$ gerados por hectare para cada tipo de cultura existente na bacia, tendo como base as unidades de comercialização de cada produção fornecidas por EMATER-DF (2015), FAEG (2015), Silva Júnior et. al. (2010), e Rocha et. al. (2007) para cada ano da série analisada. Importante destacar que, na bibliografia, algumas culturas como dendê e pinhão-manso não apresentavam a receita gerada pela unidade de comercialização (ex: saca de milho é vendida a $\mathrm{R} \$ 11,88$, conforme dados da EMATER-DF, 2015), a unidade de todos os valores de receita gerados foram convertidos para $\mathrm{R} \$ \cdot \mathrm{ha}^{-1}$.

Por fim, foi gerado o mapa do custo relativo das perdas provocadas pela erosão para cada HRU com base na porcentagem dos custos gerados para a reposição de nutrientes em relação ao VPL da produção.

\footnotetext{
${ }^{9}$ Para este trabalho, foi utilizado a taxa de juros de 8,75\% a.a. adotado pelo Banco Central (set/2015) para financiamento rural. Este valor foi considerado para todas as HRUs, incluindo as possíveis propriedades inseridas no PRONAF (Programa Nacional de Fortalecimento da Agricultura Familiar), pois não foi realizado levantamento das propriedades inseridas no programa.

${ }^{10}$ Valores monetários corrigidos pelo Índice Geral de Preços ao Consumidor Amplo (IPCA) - IBGE
} 
Tabela 19 - Custo de Implantação e Manutenção para Agricultura Irrigada, Pivô Central e Agricultura de Sequeiro

\begin{tabular}{|c|c|c|c|c|c|}
\hline \multirow[b]{2}{*}{ Classe } & \multirow[b]{2}{*}{ Cultura } & \multirow{2}{*}{$\begin{array}{c}\text { Área } \\
\text { Ocupada } \\
(\%)\end{array}$} & \multicolumn{3}{|c|}{ Custos de Implantação e Manutenção $\left(\mathbf{R} \$ . h^{-1}\right)$} \\
\hline & & & 2012 & 2013 & 2014 \\
\hline \multirow{12}{*}{$\begin{array}{l}\text { Agricultura } \\
\text { Irrigada }\end{array}$} & Café & 4.6 & $11,185.28$ & $4,422.44$ & $7,894.52$ \\
\hline & Canavial & 1.8 & $6,419.55$ & $2,036.62$ & $2,220.08$ \\
\hline & Dendê & 4.9 & $5,398.10$ & 480.79 & 875.57 \\
\hline & Feijão & 1.4 & $2,815.43$ & $3,075.41$ & $3,352.45$ \\
\hline & Fruticultura & 6.6 & $13,029.86$ & $8,172.58$ & $10,360.55$ \\
\hline & Horticultura & 9.7 & $17,494.47$ & $19,109.92$ & $20,831.35$ \\
\hline & Mandioca & 5.0 & $5,526.84$ & $6,037.19$ & $6,581.03$ \\
\hline & Milho & 36.1 & $1,959.63$ & $2,140.58$ & $2,333.41$ \\
\hline & Nativas & 0.1 & $7,802.72$ & $8,523.23$ & $9,291.00$ \\
\hline & Soja & 27.2 & $1,704.29$ & $1,861.67$ & $2,029.37$ \\
\hline & Trigo & 2.5 & $1,714.23$ & $1,872.52$ & $2,041.20$ \\
\hline & \multicolumn{2}{|c|}{$\begin{array}{c}\text { Média Ponderada pela } \\
\text { Área }\end{array}$} & 4,993.04 & 4,336.07 & 4,981.92 \\
\hline \multirow{4}{*}{ Pivô Central } & Café & 18.9 & $13,584.85$ & $7,043.58$ & $10,751.77$ \\
\hline & Milho & 38.3 & $4,359.20$ & $4,761.73$ & $5,190.66$ \\
\hline & Soja & 42.7 & $4,103.86$ & $4,482.82$ & $4,886.63$ \\
\hline & \multicolumn{2}{|c|}{$\begin{array}{c}\text { Média Ponderada pela } \\
\text { Área }\end{array}$} & $5,994.04$ & $5,073.85$ & $6,111.95$ \\
\hline \multirow{10}{*}{$\begin{array}{l}\text { Agricultura } \\
\text { de Sequeiro }\end{array}$} & Fruticultura & 16.2 & $12,521.72$ & $7,644.29$ & $9,699.75$ \\
\hline & Mandioca & 0.2 & $5,155.39$ & $5,631.44$ & $6,138.73$ \\
\hline & Soja & 30.5 & $1,332.84$ & $1,455.92$ & $1,587.07$ \\
\hline & Nativas & 3.6 & 7802.716 & 8523.225 & 9290.998 \\
\hline & $\begin{array}{l}\text { Pinhao } \\
\text { Manso }\end{array}$ & 7.4 & $2,221.33$ & $1,301.83$ & $1,479.33$ \\
\hline & Trigo & 1.1 & $1,714.23$ & $1,872.52$ & $2,041.20$ \\
\hline & Milho & 37.4 & $1,588.18$ & $1,734.83$ & $1,891.11$ \\
\hline & Horticultura & 1.1 & $16,964.12$ & $18,530.60$ & $20,199.83$ \\
\hline & Canavial & 2.5 & $6,048.10$ & $1,630.87$ & $1,777.78$ \\
\hline & \multicolumn{2}{|c|}{$\begin{array}{c}\text { Média Ponderada pela } \\
\text { Área }\end{array}$} & $3,847.48$ & $3,016.90$ & $3,514.45$ \\
\hline
\end{tabular}

Fonte: adaptado de EMATER-DF (2015), FAEG (2015), Silva Júnior et. al. (2010), e Rocha et. al. (2007) 
Tabela 20 - Receitas geradas na Agricultura Irrigada, Pivô Central e Agricultura de Sequeiro

\begin{tabular}{|c|c|c|c|c|c|}
\hline \multirow{2}{*}{ Classe } & \multirow{2}{*}{ Cultura } & \multirow{2}{*}{$\begin{array}{c}\text { Área } \\
\text { Ocupada } \\
(\%)\end{array}$} & \multicolumn{3}{|c|}{ Receita Safra (R\$.ha $\left.{ }^{-1}\right)$} \\
\hline & & & 2012 & 2013 & 2014 \\
\hline \multirow{12}{*}{ Agricultura Irrigada } & Café & 4.6 & $6,258.6$ & $6,836.5$ & $7,452.3$ \\
\hline & Canavial & 1.8 & $5,943.2$ & $6,492.0$ & $7,076.8$ \\
\hline & Dendê & 4.9 & $2,290.6$ & $2,426.0$ & $2,581.3$ \\
\hline & Feijão Irrigado & 1.4 & $2,815.6$ & $3,075.6$ & $3,352.6$ \\
\hline & Fruticultura & 6.6 & $9,615.5$ & $10,503.4$ & $11,449.5$ \\
\hline & Horticultura & 9.7 & $15,165.2$ & $16,565.6$ & $18,057.8$ \\
\hline & Mandioca & 5.0 & $5,152.8$ & $5,628.6$ & $6,135.6$ \\
\hline & Milho & 36.1 & $1,588.6$ & $1,735.3$ & $1,891.6$ \\
\hline & Nativas & 0.1 & 530.2 & 579.1 & 631.3 \\
\hline & Soja & 27.2 & $1,332.8$ & $1,455.9$ & $1,587.1$ \\
\hline & Trigo & 2.5 & 530.2 & 579.1 & 631.3 \\
\hline & \multicolumn{2}{|c|}{ Média Ponderada pela Área } & $3,861.56$ & $4,214.41$ & $4,590.95$ \\
\hline \multirow{4}{*}{ Pivô Central } & Café & 18.9 & $6,258.6$ & $6,836.5$ & $7,452.3$ \\
\hline & Milho & 38.3 & $1,588.6$ & $1,735.3$ & $1,891.6$ \\
\hline & Soja & 42.7 & $1,332.8$ & $1,455.9$ & $1,587.1$ \\
\hline & \multicolumn{2}{|c|}{ Média Ponderada pela Área } & $2,362.07$ & $2,580.19$ & $2,812.61$ \\
\hline \multirow{10}{*}{ Agricultura de Sequeiro } & Canavial & 2.5 & $5,943.2$ & $6,492.0$ & $7,076.8$ \\
\hline & Fruticultura & 16.2 & $9,615.48$ & $10,503.38$ & $11,449.53$ \\
\hline & Horticultura & 1.1 & $15,165.2$ & $16,565.6$ & $18,057.8$ \\
\hline & Mandioca & 0.2 & $5,152.8$ & $5,628.6$ & $6,135.6$ \\
\hline & Milho & 37.4 & $1,588.6$ & $1,735.3$ & $1,891.6$ \\
\hline & Trigo & 1.1 & 530.2 & 579.1 & 631.3 \\
\hline & Nativas & 3.6 & 453.2 & 495.0 & 539.6 \\
\hline & Pinhão Manso & 7.4 & $1,315.8$ & $1,393.6$ & $1,482.8$ \\
\hline & Soja & 30.5 & $1,332.8$ & $1,455.9$ & $1,587.1$ \\
\hline & \multicolumn{2}{|c|}{ Média Ponderada pela Área } & $3,003.58$ & $3,277.71$ & $3,570.27$ \\
\hline
\end{tabular}

Fonte: adaptado de EMATER-DF (2015), FAEG (2015), Silva Júnior et. al. (2010), e Rocha et. al. (2007) 


\section{0 - RESULTADOS}

\section{1 - ANÁLISE MORFOMÉTRICA}

A partir da interpolação dos dados topográficos, foi gerado o modelo digital de terreno com resolução espacial de 2 metros, com altitude variando entre 920 e 1253 metros de altitude (Figura 14), sendo que as menores altitudes se encontram na parte leste e nordeste da área de estudo e as maiores altitudes encontram-se na parte oeste e sudoeste. A partir do MDT, foi gerada a carta de declividade (Figura 15). A maior parte da bacia encontra-se na classe de 0 a $20 \%$ de declividade, enquanto as maiores declividades ocorrem nos canais de drenagem que dividem a região de chapada e a região dissecada de vale (CHAVES et.al., 2014).

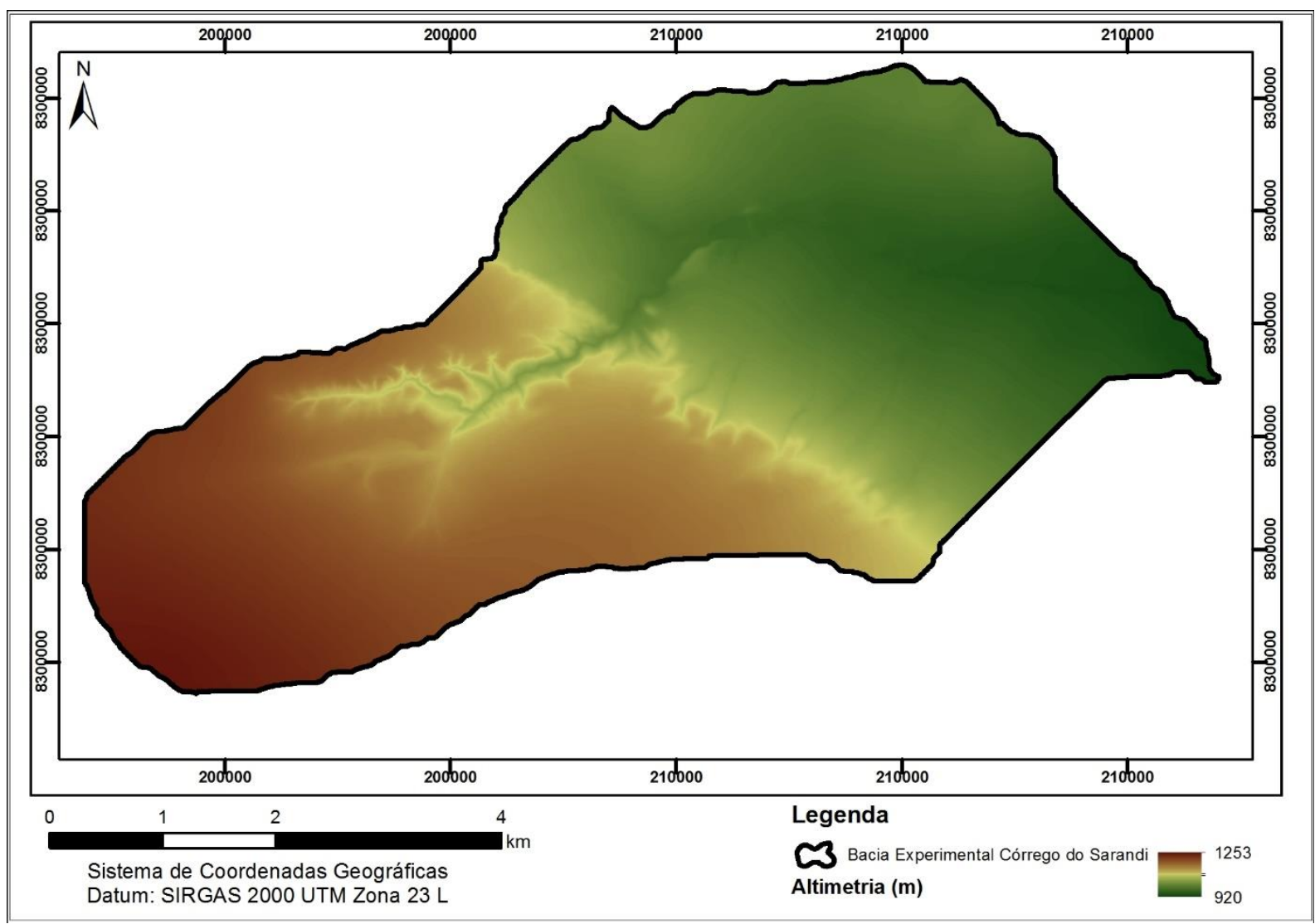

Figura 14 - Modelo Digital de Terreno da Área de Estudo 


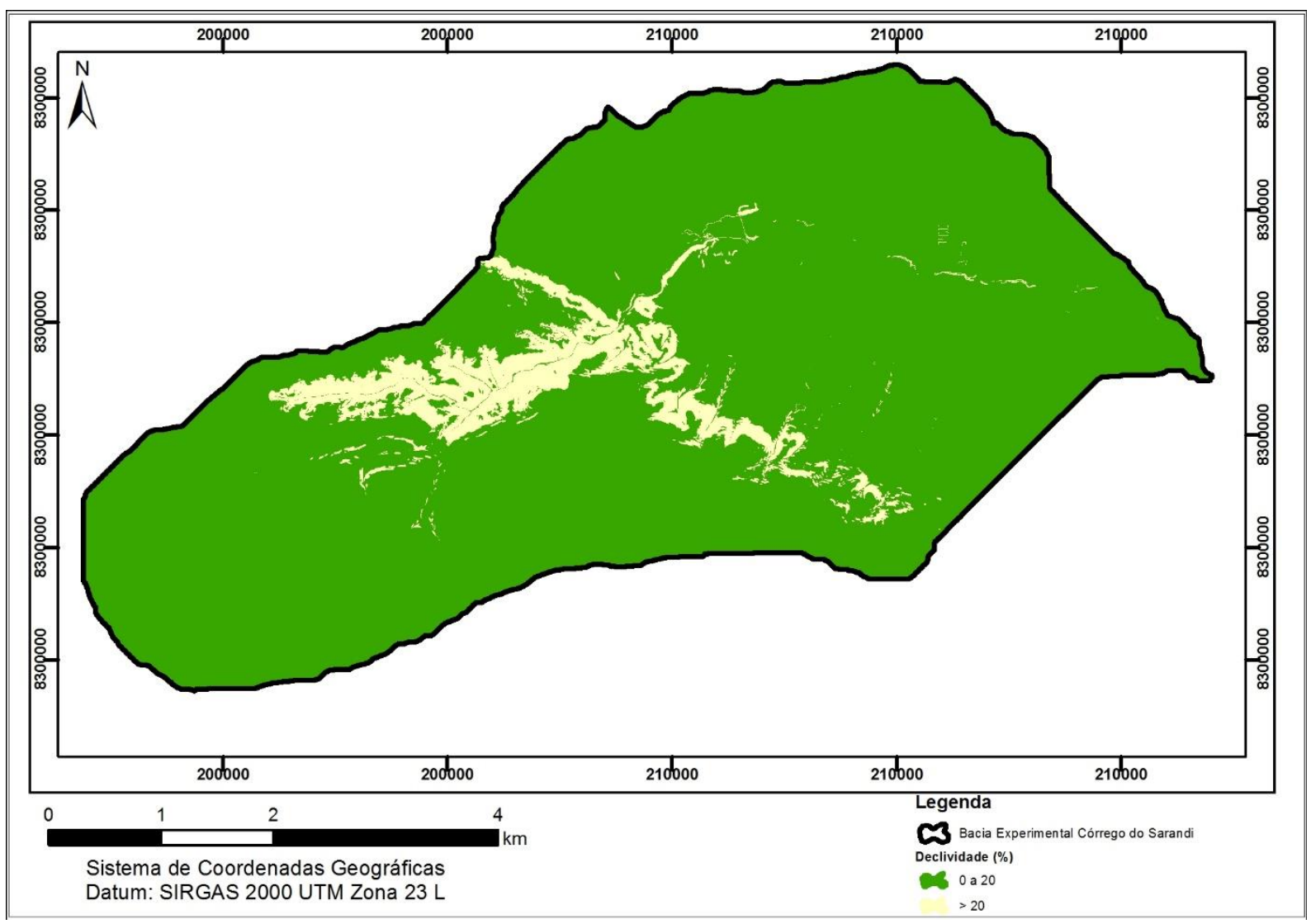

Figura 15 - Declividade da Área de Estudo

\section{2 - MAPA DE USO E COBERTURA DA TERRA}

Ao fim do processo de mapeamento, foram delimitadas as seguintes classes de uso e cobertura da terra, apresentadas na Figura 16:

1) Agricultura Irrigada: áreas destinadas à produção agrícola em que há utilização de um conjunto de técnicas e equipamentos destinados à irrigação, no caso deste trabalho, com exceção do pivô central.

2) Agricultura de Sequeiro: áreas destinadas à produção agrícola sem a utilização de sistema de irrigação.

3) Cultivos Florestais: áreas destinadas à produção florestal, como os plantios homogêneos de eucalipto.

4) Edificações/Instalações: áreas com a presença de obras civis. 
5) Formação Campestre: formação vegetal com predominância de vegetação herbácea e raros indivíduos arbóreos e arbustivos esparsos conforme Ribeiro e Walter (2008).

6) Formação Florestal: tipos de vegetação com predominância de espécies arbóreas, com dossel praticamente contínuo, como as Matas de Galeria e o Cerradão conforme Ribeiro e Walter (2008).

7) Formação Savânica: agrupa locais com árvores e arbustos espalhados sobre o estrato graminoso, sem formação de dossel contínuo, como no caso do Cerrado sentido restrito conforme Ribeiro e Walter (2008).

8) Loteamento: Área bem delimitada para comercialização de lotes.

9) Pastagem: áreas com vegetação herbácea plantada pelo homem para a alimentação animal (bovinos), como o caso dos campos de braquiária.

10) Pivô Central: áreas destinadas à produção agrícola com utilização de um sistema de irrigação do tipo pivô central.

11) Reservatórios: onde há acumulação de água por meio de barragens artificiais ao longo do rio ou de canais.

12) Solo Exposto: áreas onde a cobertura vegetal foi removida deixando aparente quaisquer dos horizontes do solo.

13) Vegetação Degradada: área em que houve alteração antrópica da vegetação original e que se encontra em processo lento de regeneração. 


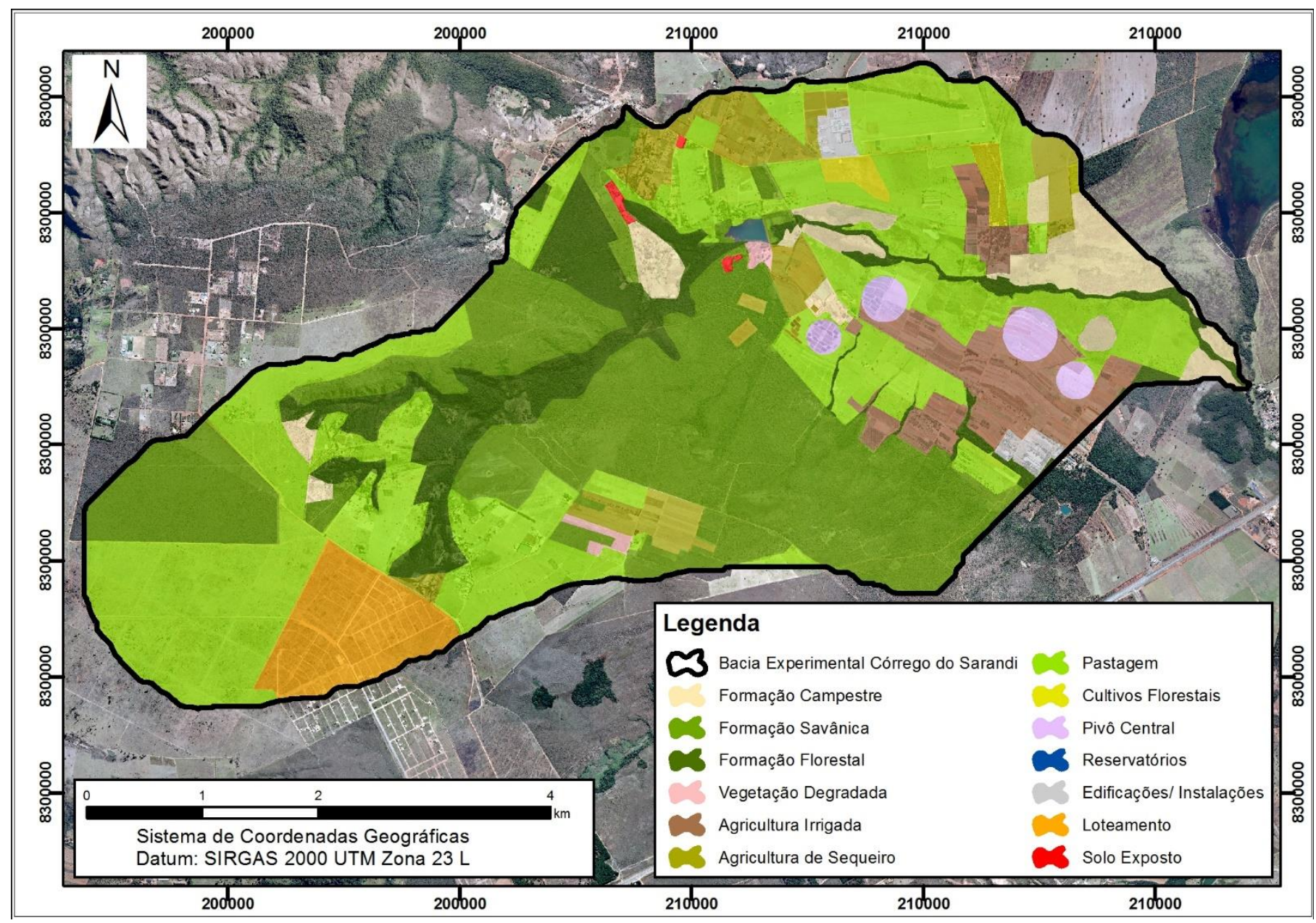

Figura 16 - Mapa de Uso e Ocupação da Terra na Bacia do Sarandi em escala 1:25.000 (adaptado de Chaves et. al., 2014)

\section{3 - MAPEAMENTO DA PRODUÇÃO AGRÍCOLA NA ÁREA DE ESTUDO}

O mapeamento da produção agrícola na bacia experimental do córrego Sarandi (Figura 17, Tabela 21) demonstra que, na área de agricultura irrigada - incluindo as áreas de pivô central - a maior parte da produção é composta por milho $(36,1 \%)$ soja $(27,2 \%)$. Ganham destaque também a horticultura, fruticultura, mandioca, dendê e café que representam, respectivamente, $9,7 \%, 6,6 \%, 5,0 \%, 4,9 \%$, e 4,6\% da área cultivada. As demais culturas representam 5,9\% da área cultivada. 
Já na área de agricultura de sequeiro, o milho é a cultura mais representativa $(37,4 \%)$ seguida da soja (30,5\%). Em terceiro, a fruticultura ocupa $16,2 \%$ da área e a área de pinhão manso ocupa $7,4 \%$. As demais produções ocupam juntas $8,6 \%$ da área total de agricultura de sequeiro.

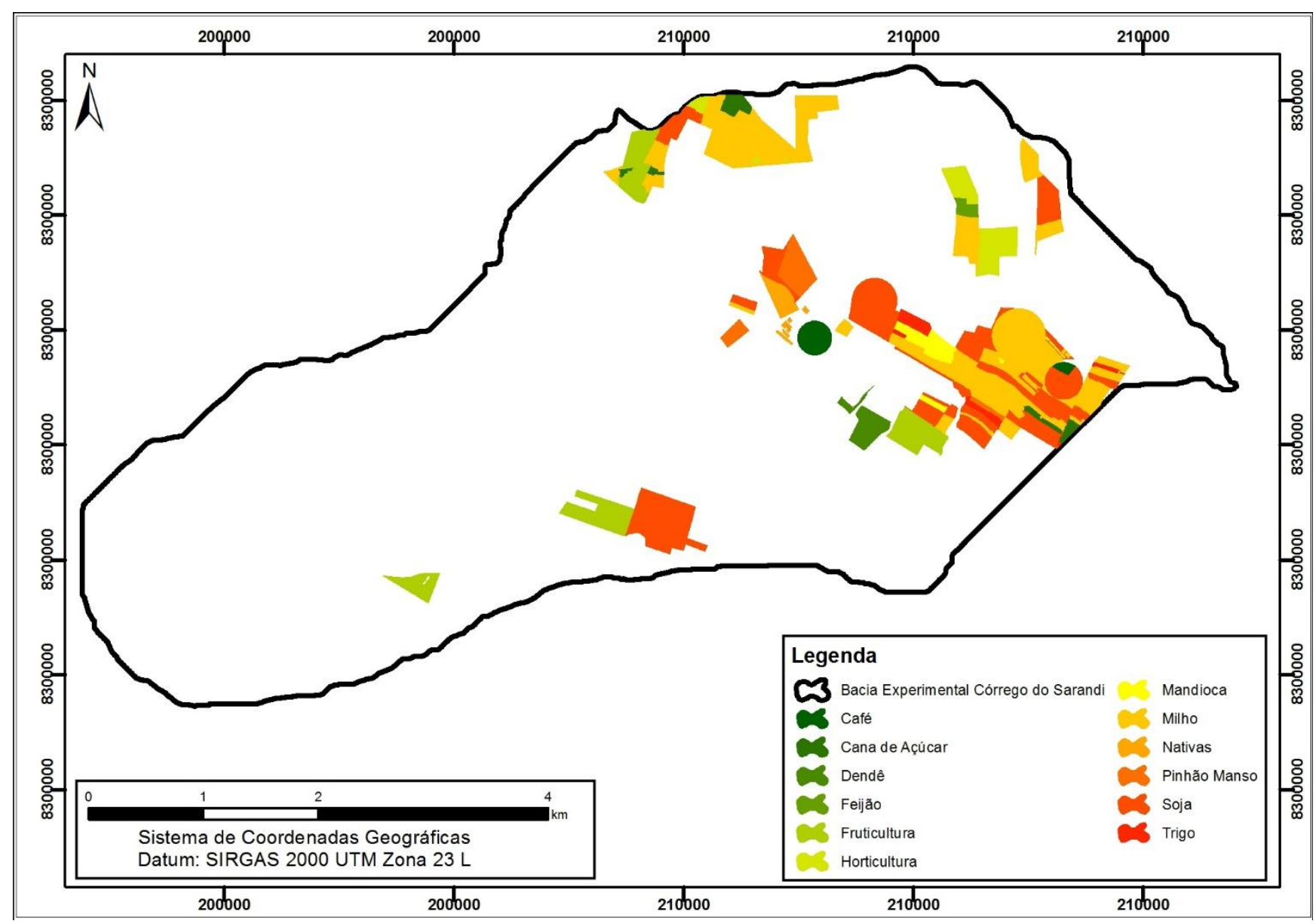

Figura 17 - Mapa de Produção Agrícola na bacia do córrego Sarandi 
Tabela 21 - Área ocupada pelas diversas culturas produzidas na bacia

\begin{tabular}{|c|c|c|c|c|c|}
\hline \multicolumn{6}{|c|}{ AGRICULTURA DE SEQUEIRO } \\
\hline Produção & Área (ha) & $\begin{array}{c}\text { Área } \\
(\%)\end{array}$ & Produção & $\begin{array}{c}\text { Área } \\
\text { (ha) }\end{array}$ & $\begin{array}{c}\begin{array}{c}\text { Área } \\
(\%)\end{array} \\
\end{array}$ \\
\hline Fruticultura & 30.8 & 16.2 & Trigo & 2.0 & 1.1 \\
\hline Mandioca & 0.4 & 0.2 & Milho & 71.2 & 37.4 \\
\hline Soja & 58.0 & 30.5 & Horticultura & 2.1 & 1.1 \\
\hline Nativas & 6.9 & 3.6 & \multirow[b]{2}{*}{ Canavial } & \multirow[b]{2}{*}{4.8} & \multirow[b]{2}{*}{2.5} \\
\hline $\begin{array}{l}\text { Pinhao } \\
\text { Manso }\end{array}$ & 14.1 & 7.4 & & & \\
\hline \multicolumn{6}{|c|}{ AGRICULTURA IRRIGADA } \\
\hline Produção & Área (ha) & $\begin{array}{c}\text { Área } \\
(\%)\end{array}$ & Produção & $\begin{array}{c}\text { Área } \\
\text { (ha) }\end{array}$ & $\begin{array}{c}\text { Área } \\
(\%)\end{array}$ \\
\hline Café & 8.6 & 4.6 & Mandioca & 9.3 & 5.0 \\
\hline Canavial & 3.4 & 1.8 & Milho & 67.0 & 36.1 \\
\hline Dendê & 9.1 & 4.9 & Nativas & 0.3 & 0.1 \\
\hline Feijão & 2.6 & 1.4 & Soja & 50.5 & 27.2 \\
\hline Fruticultura & 12.3 & 6.6 & \multirow{2}{*}{ Trigo } & \multirow{2}{*}{4.7} & \multirow{2}{*}{2.5} \\
\hline Horticultura & 17.9 & 9.7 & & & \\
\hline
\end{tabular}

\section{4 - VALOR DE NPK APLICADO NAS UNIDADES DE RESPOSTA HIDROLÓGICA DA ÁREA DE ESTUDO}

A partir da média ponderada do valor de NPK da cultura em relação à área que a cultura ocupa na HRU, foram estabelecido os valores de NPK aplicados nas operações de fertilização. $\mathrm{Na}$ área de agricultura de sequeiro fertilizante com NPK 40-97-69 (Tabela 22). Já nas áreas de agricultura irrigada e pivô central serão aplicados fertilizantes com NPK 39-87-66 (Tabela 21). 
Tabela 22 - Valores médios de NPK aplicados às operações de fertilização

\begin{tabular}{|c|c|c|c|c|c|c|c|c|c|c|c|}
\hline \multicolumn{12}{|c|}{ AGRICULTURA DE SEQUEIRO } \\
\hline Produção & Área (ha) & $\begin{array}{c}\text { Área } \\
(\%)\end{array}$ & $\mathbf{N}$ & $\mathbf{P}$ & $\mathbf{K}$ & Produção & $\begin{array}{c}\text { Área } \\
\text { (ha) }\end{array}$ & $\begin{array}{l}\text { Área } \\
(\%)\end{array}$ & $\mathbf{N}$ & $\mathbf{P}$ & $\mathbf{K}$ \\
\hline Fruticultura & 30.8 & 16.2 & 101 & 139 & 120 & Trigo & 2.0 & 1.1 & 90 & 80 & 50 \\
\hline Mandioca & 0.4 & 0.2 & 80 & 80 & 60 & Milho & 71.2 & 37.4 & 30 & 120 & 60 \\
\hline Soja & 58.0 & 30.5 & 6 & 60 & 60 & Horticultura & 2.1 & 1.1 & 0 & 60 & 20 \\
\hline Nativas & 6.9 & 3.6 & 75 & 75 & 50 & \multirow[b]{2}{*}{ Canavial } & \multirow[b]{2}{*}{4.8} & \multirow[b]{2}{*}{2.5} & & & \\
\hline $\begin{array}{l}\text { Pinhao } \\
\text { Manso }\end{array}$ & 14.1 & 7.4 & 70 & 80 & 60 & & & & 70 & 140 & 120 \\
\hline \multicolumn{9}{|c|}{ Média Ponderada NPK em relação à área ocupada } & 40 & 97 & 69 \\
\hline \multicolumn{12}{|c|}{$\begin{array}{l}\text { AGRICULTURA IRRIGADA } \\
\end{array}$} \\
\hline Produção & Área (ha) & $\begin{array}{c}\text { Área } \\
(\%)\end{array}$ & $\mathbf{N}$ & $\mathbf{P}$ & $\mathbf{K}$ & Produção & $\begin{array}{c}\text { Área } \\
\text { (ha) }\end{array}$ & $\begin{array}{c}\text { Área } \\
(\%)\end{array}$ & $\mathbf{N}$ & $\mathbf{P}$ & $\mathbf{K}$ \\
\hline Café & 8.6 & 4.6 & 55 & 30 & 55 & Mandioca & 9.3 & 5.0 & 80 & 80 & 60 \\
\hline Canavial & 3.4 & 1.8 & 70 & 140 & 120 & Milho & 67.0 & 36.1 & 30 & 120 & 60 \\
\hline Dendê & 9.1 & 4.9 & 180 & 150 & 150 & Nativas & 0.3 & 0.1 & 75 & 75 & 50 \\
\hline Feijão & 2.6 & 1.4 & 100 & 120 & 100 & Soja & 50.5 & 27.2 & 6 & 60 & 60 \\
\hline Fruticultura & 12.3 & 6.6 & 101 & 139 & 120 & \multirow[b]{2}{*}{ Trigo } & \multirow[b]{2}{*}{4.7} & \multirow{3}{*}{2.5} & & \multirow[b]{2}{*}{80} & \multirow[b]{2}{*}{50} \\
\hline Horticultura & 17.9 & 9.7 & 0 & 60 & 20 & & & & 90 & & \\
\hline & & 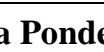 & & II & çao & ea ocupada & & & 39 & 87 & 60 \\
\hline
\end{tabular}

Fonte: Adaptado de Sousa et. al. (2002), Andrade (2002); Vilela et. al. (2002), e Guerra et. al.(2007)

\section{5 - DEFINIÇÃO DAS UNIDADES DE RESPOSTAS HIDROLÓGICAS (HRUS)}

A partir do cruzamento dos mapas de declividade, solos, e uso e cobertura da terra, foram definidas 261 unidades de respostas hidrológicas (HRU) por meio da interface ArcSWAT. Na Figura 18 pode-se observar que diferentes polígonos compõem uma mesma HRU. Isso ocorre, pois, o modelo SWAT não considera os limites físicos da HRU, mas a porcentagem que ela ocupa dentro de uma sub-bacia.

Observa-se que na parte alta da bacia, a oeste, as HRUs apresentam uma área maior que as HRUs localizadas na parte baixa, a oeste. Isso ocorre devido a diversificação do uso e dos tipos de solo na parte baixa da bacia. 


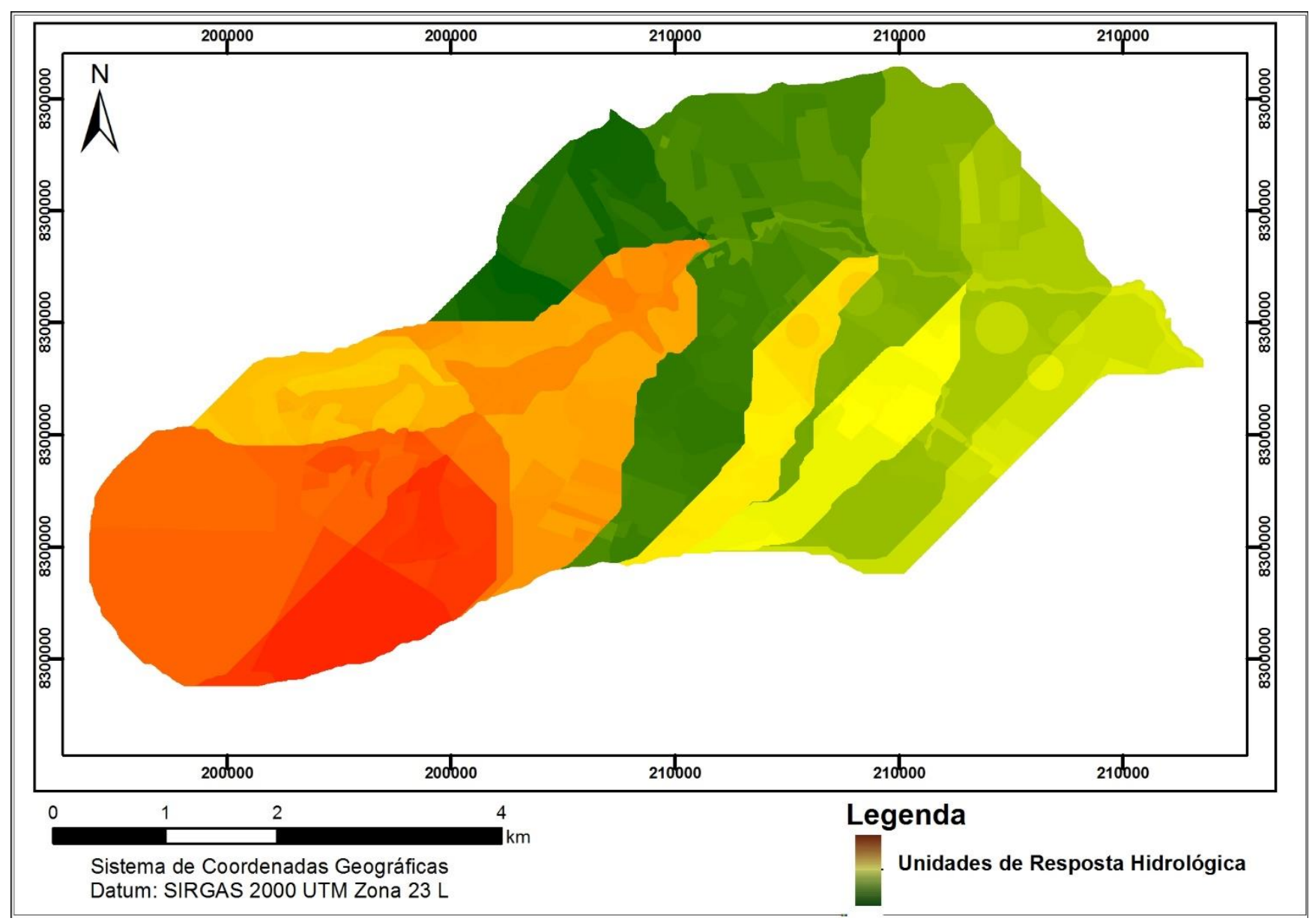

Figura 18 - Mapa de HRUs geradas na interface ArcSWAT

\section{6 - ANÁLISE DE SENSIBILIDADE}

\subsection{1 - VAZÃO}

Com os resultados da análise de sensibilidade dos parâmetros relacionados à vazão, observa-se que, de acordo com as classes de sensibilidade definidas por Lenhart et. al. (2002) na Tabela 10, somente o parâmetro GWQMN encontra-se na classe de sensibilidade média. Os parâmetros ESCO, REVAPMN, SHALLST e DEEPST tiveram sensibilidade alta no modelo. Os demais parâmetros encontram-se na classe muito alta, sendo que os parâmetros mais sensíveis foram SOL_K (condutividade hidráulica do solo), SOL_BD (densidade aparente do solo, e CN2 (Curva-número). A Figura 19 apresenta os valores do t-stat e p-value dos parâmetros analisados. 

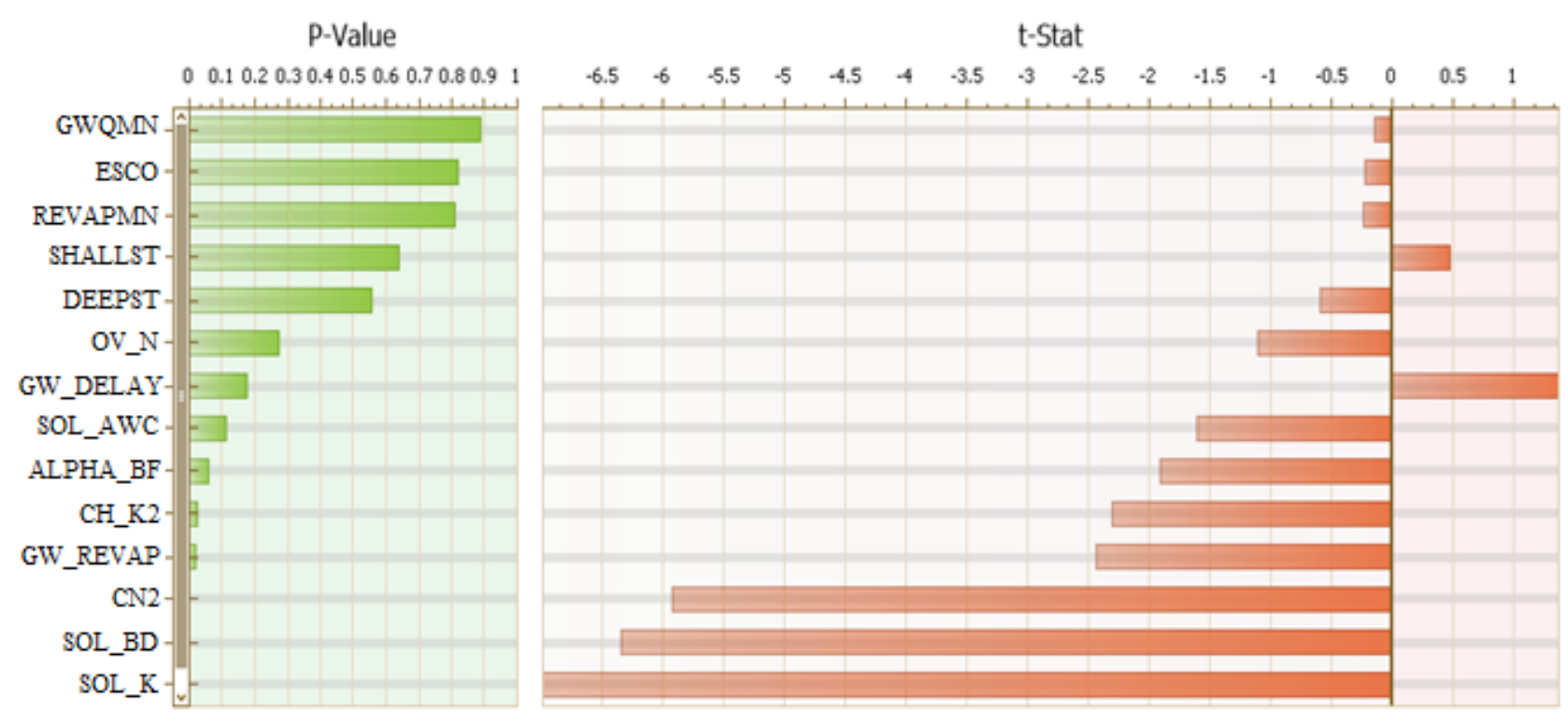

Figura 19 - Valores de t-stat e p-value dos parâmetros relacionados à vazão

Os resultados obtidos corroboram com a análise feita por Salles (2012), Castro (2013), e Ferrigo (2014) acerca dos parâmetros mais sensíveis identificados em trabalhos envolvendo o modelo SWAT no Brasil, demonstrando que, em geral, bacias na área do cerrado apresentam os parâmetros SOL_K, CN2, ALPHA_BF e SOL_AWC entre os parâmetros mais sensíveis do modelo (Tabela 11).

Além disso, Lima et. al. (2014) demonstraram, a partir de aplicações do modelo em duas bacias localizadas na caatinga e duas bacias localizadas no cerrado brasileiro, que existe uma relação direta entre parâmetros como o Curva Número (CN2) - que determina o escoamento superficial e fluxo de base - e a condutividade hidráulica do solo (SOL_K), motivo pelo qual estes dois parâmetros geralmente aparecem como mais sensíveis em trabalhos com o SWAT em áreas do cerrado (Tabela 11).

\subsection{2 - SEDIMENTOS}

Com os resultados na análise de sensibilidade dos parâmetros relacionados aos sedimentos, observa-se que, de acordo com as classes de sensibilidade definidas por Lenhart $e t$. al. (2002) na Tabela 10, os parâmetros USLE_C (Formação Savânica), LAT_SED, USLE_C (Formação Campestre), e USLE_C (Agricultura de Sequeiro) encontram-se na classe de 
sensibilidade média. Os parâmetros USLE_C (Agricultura Irrigada), USLE_P, USLE_K, USLE_C (Pastagem), USLE_C (Formação Florestal), USLE_C (Pivô Central), SPCON, ADJ_PKR, e USLE_C (Cultivos Florestais) tiveram sensibilidade alta no modelo. Os demais parâmetros encontram-se na classe muito alta, sendo que os parâmetros mais sensíveis foram PRF_BSN (Fator de ajuste de pico de sedimentos no canal principal), SPEXP (Parâmetro exponencial para cálculo da quantidade de sedimento em resuspensão no canal), e SLSUBBSN (Tamanho médio do comprimento de rampa). A Figura 20 apresenta os valores do $t$-stat e $p$ value dos parâmetros analisados.

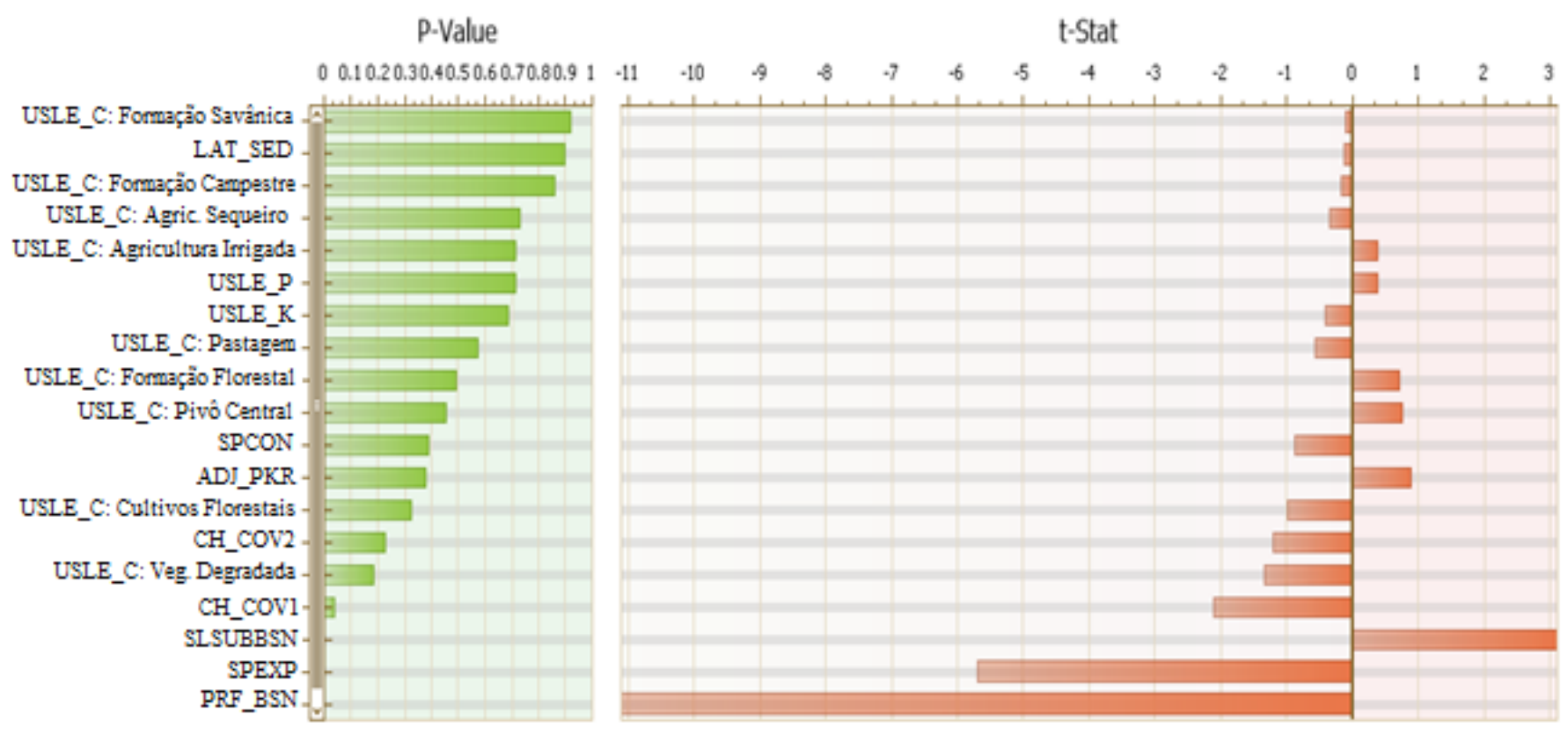

Figura 20 - Valores de t-stat e p-value dos parâmetros relacionados aos sedimentos

Strauch (2012) e Carvalho (2014), identificaram, respectivamente, nas bacias do ribeirão Pipiripau e rio Jardim, ambas localizadas no Distrito Federal, os parâmetros referentes ao fator de ajuste de pico (PRF_BSN e ADJ_PKR) e o tamanho do comprimento de rampa (SLSUBBSN) possuem maior sensibilidade no modelo SWAT. No caso do Sarandi, a sensibilidade desses parâmetros também se mostrou muito alta. Isso ocorre dado o peso que estes parâmetros possuem na formulação da MUSLE (Equação 8). 


\subsection{3 - NUTRIENTES}

Com os resultados na análise de sensibilidade dos parâmetros relacionados à qualidade de água, observa-se que, de acordo com as classes de sensibilidade definidas por Lenhart et. al. (2002) na Tabela 10, os parâmetros CMN, RSDCO, SOL_ORGN, e SOL_NO3 tiveram sensibilidade alta no modelo. Os demais parâmetros encontram-se na classe muito alta, sendo que os parâmetros mais sensíveis foram ANION_EXCL (Fração de da porosidade em que os ânions são excluídos), CDN (Coeficiente da taxa exponencial da denitrificação), e SDNCO (Coeficiente de decomposição de resíduos). A Figura 21 apresenta os valores do $t$-stat e $p$-value dos parâmetros analisados.

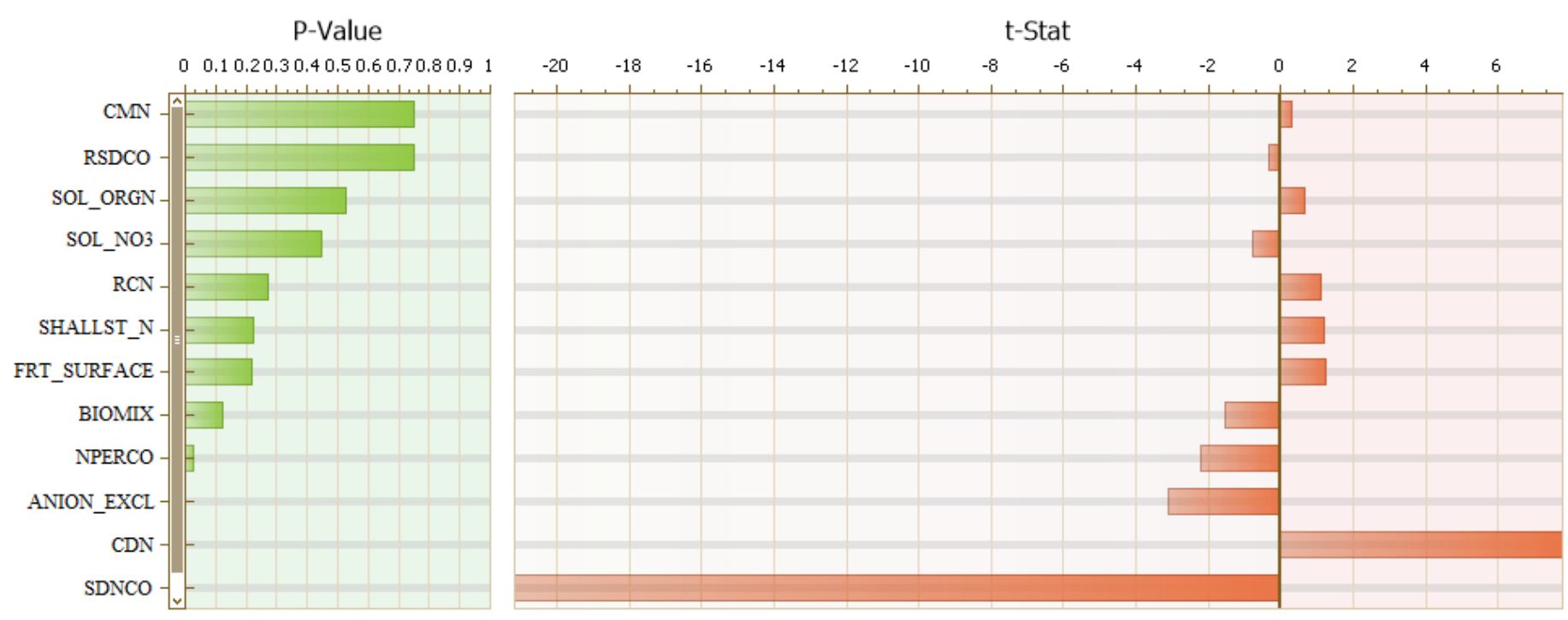

Figura 21 - Valores de t-stat e p-value dos parâmetros relacionados aos nutrientes

Os resultados obtidos na análise de sensibilidade dos parâmetros relacionados à qualidade de água estão semelhantes com o trabalho de Akhavan et. al. (2010) - que aplicou o SWAT para analisar a lixiviação de nitrato em uma bacia monitorada ocupada por agricultura no Irã - do que os resultados obtido por Monsalve-Herrera (2013) que aplicou o modelo SWAT em uma bacia urbana monitorada no DF.

No primeiro, utilizando uma base de dados observados de nitrato, os parâmetros mais sensíveis foram o CDN, SDNCO, RCN e NPERCO. Já no segundo trabalho, utilizando uma base de dados de nitrogênio total, os parâmetros mais sensíveis foram o NPERCO e o BIOMIX. 
Essa diferença ressalta a importância da escolha, organização dos dados de entrada e dados para a calibração no SWAT, evidenciando que este modelo, caso seja aplicado em uma bacia não monitorada, poderá apresentar resultados com alto grau de incerteza no modelo.

\section{7 - CALIBRAÇÃO E VERIFICAÇÃO DO MODELO SWAT 4.7.1 - SIMULAÇÃO DA VAZÃO}

Na Figura 22 é possível observar os resultados obtidos na simulação prévia em comparação com os dados observados de vazão e com os dados de chuva. Pode-se observar que a maior parte dos picos simulados estão superestimados em relação aos picos observados. Além disso, o fluxo de base simulado está muito abaixo do fluxo de base observado.

Estas observações mostram que os parâmetros identificados como mais sensíveis (Figura 19) são justamente aqueles que precisam de um ajuste maior, uma vez que estes parâmetros estão associados ao escoamento superficial (CN2; SOL_BD e CH_K2) e fluxo de base (SOL_K; SOL_BD; CN2; GW_REVAP; e ALPHA_BF). A Tabela 23 mostra os valores iniciais do modelo e os valores obtidos após o processo de calibração.

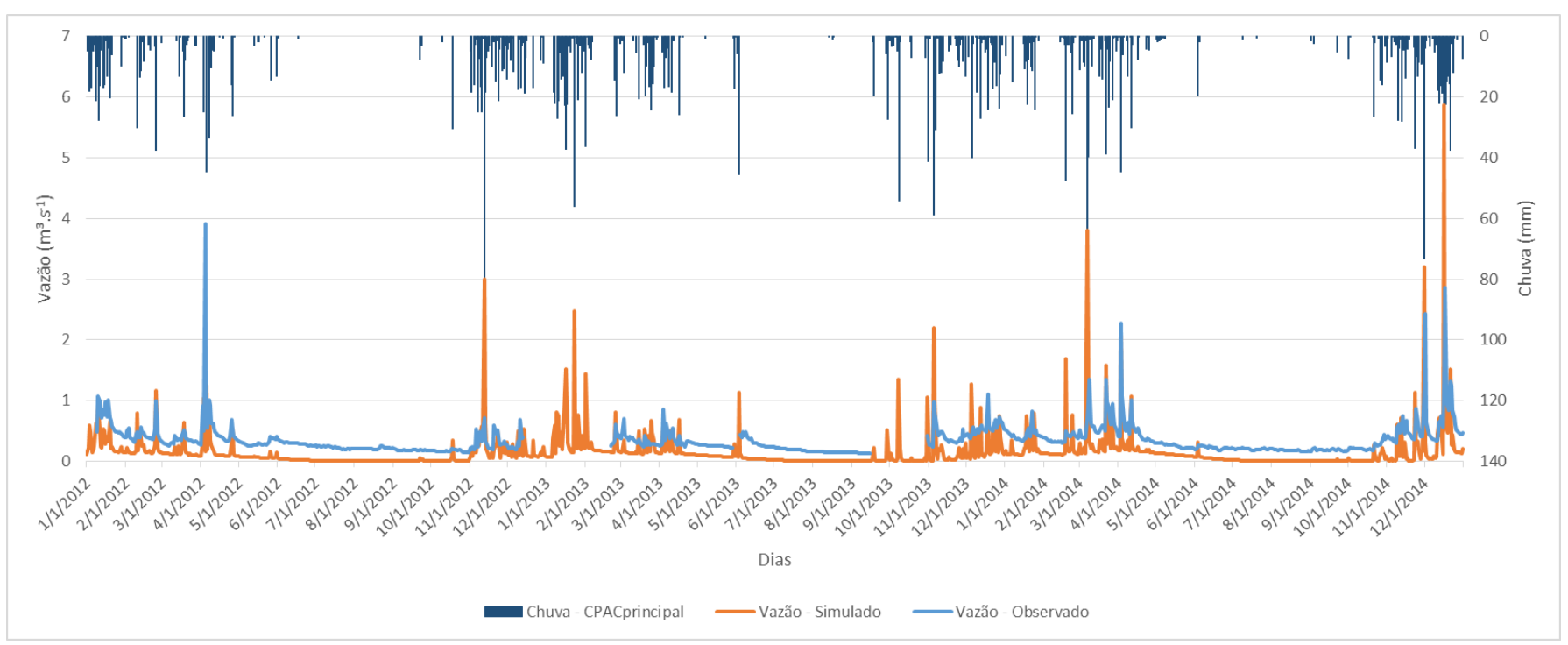

Figura 22 - Comparação entre dados simulados com dados observados de vazão e de chuva sem calibração 
Tabela 23 - Comparação entre a variação de valores inicial e final utilizada no modelo SWAT para parâmetros de vazão

\begin{tabular}{|c|c|c|}
\hline Parâmetros & Variação Inicial* & Variação Final** $^{*}$ \\
\hline GWQMN & $0-5.000$ & $295-507$ \\
\hline ESCO & $0-1$ & $0-0,150791$ \\
\hline REVAPMN & $0-1.000$ & $287-570$ \\
\hline SHALLST & $0-5.000$ & $2.091-3.678$ \\
\hline DEEPST & $0-10.000$ & $1.842-3.678$ \\
\hline OV_N & $0,01-30$ & $0-400$ \\
\hline GW_DELAY & $0-500$ & $0,100718-0,326069$ \\
\hline SOL_AWC & $0-1$ & $0,45-1,05$ \\
\hline ALPHA_BF & $0-1$ & $0-0,1$ \\
\hline CH_K2 & $-0,01-500$ & $0,061316-0,091784$ \\
\hline GW_REVAP & $0,02-0,2$ & $26-40$ \\
\hline CN2 & $35-98$ & $0,33-1,02$ \\
\hline SOL_BD & $0,7-2,5$ & $0-2,848$ \\
\hline SOL_K & $0-3.000$ & \\
\hline
\end{tabular}

* Valores padrões do modelo SWAT (NEITSCH et. al., 2011)

** Valores obtidos após a calibração

A Figura 23 apresenta os resultados da calibração e verificação comparando os dados simulados de vazão com os dados observados na Estação Jusante e com os dados de chuva. A calibração da vazão por dados diários apresentou resultados satisfatórios (MORIASI et. al., 2007; GREEN e VAN GRIENSVEN, 2008; ABBASPOUR et. al. 2015) com p-factor de 0,65, r-factor de 1,38, $\mathrm{R}^{2}$ de 0,50 e ENS de 0,44. Tanto o fluxo de base como o escoamento superficial apresentaram picos e depressões condizentes com os dados de chuva da estação CPACPrincipal.

Os resultados da verificação também se apresentaram satisfatórios com $p$-factor de 0,48, $r$-factor de 1,13 $\mathrm{R}^{2}$ de 0,73 e ENS de 0,67. Importante destacar que os índices estatísticos poderiam apresentar melhores resultados com uma série de dados maior com um número significativo de picos, dado que os índices utilizados no SWAT apresentam melhores respostas quando há uma maior presença de picos na série analisada (SALLES, 2012).

Comparando o ENS obtido com outros trabalhos realizados no Distrito Federal (Tabela 24), observa-se que os resultados para a calibração de vazão estão satisfatórios. 
Tabela 24 - Valores de ENS obtidos em simulações de vazão com o modelo SWAT no Distrito Federal

\begin{tabular}{|c|c|c|c|c|}
\hline Referência & $\begin{array}{c}\text { Bacia } \\
\text { Hidrográfica }\end{array}$ & $\begin{array}{c}\text { ENS obtido no } \\
\text { processo de } \\
\text { calibração }\end{array}$ & $\begin{array}{c}\text { ENS obtido no } \\
\text { processo de } \\
\text { verificação }\end{array}$ & $\begin{array}{c}\text { Formato dos } \\
\text { dados utilizados } \\
\text { na série de vazão }\end{array}$ \\
\hline Sarmento (2010) & Descoberto & 0,62 & 0,34 & Diário \\
\hline Strauch et. al. (2012) & Pipiripau & 0,78 & 0,65 & Diário \\
\hline Salles (2012) & Pipiripau & 0,67 & 0,79 & Mensal \\
\hline Castro (2013) & Jardim & 0,60 & $-0,84$ & Diário \\
\hline Monsalve-Herrera (2013) & Paranoá & 0,79 & $-1,02$ & Mensal \\
\hline \multirow{2}{*}{ Ferrigo (2014) } & \multirow{2}{*}{ Descoberto } & 0,40 & 0,48 & Diário \\
\cline { 3 - 5 } & \multirow{2}{*}{ Carvalho (2014) } & 0,65 & 0,24 & Mensal \\
\hline Este trabalho & \multirow{2}{*}{ Sarandi } & 0,52 & 0,49 & Diário \\
\cline { 3 - 5 } & & 0,71 & 0,54 & Mensal \\
\hline
\end{tabular}

Após a calibração, observa-se uma melhora no fluxo de base, principalmente no período seco que apresentou, na simulação prévia, valores próximos de zero. Com a calibração, a vazão mínima simulada passou de $0,002 \mathrm{~m}^{3} \cdot \mathrm{s}^{-1}$ para $0,105 \mathrm{~m}^{3} \cdot \mathrm{s}^{-1}$, sendo que a vazão mínima observada é de $0,138 \mathrm{~m}^{3} \cdot \mathrm{s}^{-1}$.

Os valores de pico também passaram por ajuste, sendo que os valores máximos simulados foram reduzidos após o processo de calibração. Os valores de vazão máxima simulados passaram de $5,879 \mathrm{~m}^{3} \cdot \mathrm{s}^{-1}$ para $2,396 \mathrm{~m}^{3} \cdot \mathrm{s}^{-1}$ após a calibração, sendo que a vazão máxima observada é de $3,918 \mathrm{~m}^{3} \cdot \mathrm{s}^{-1}$.

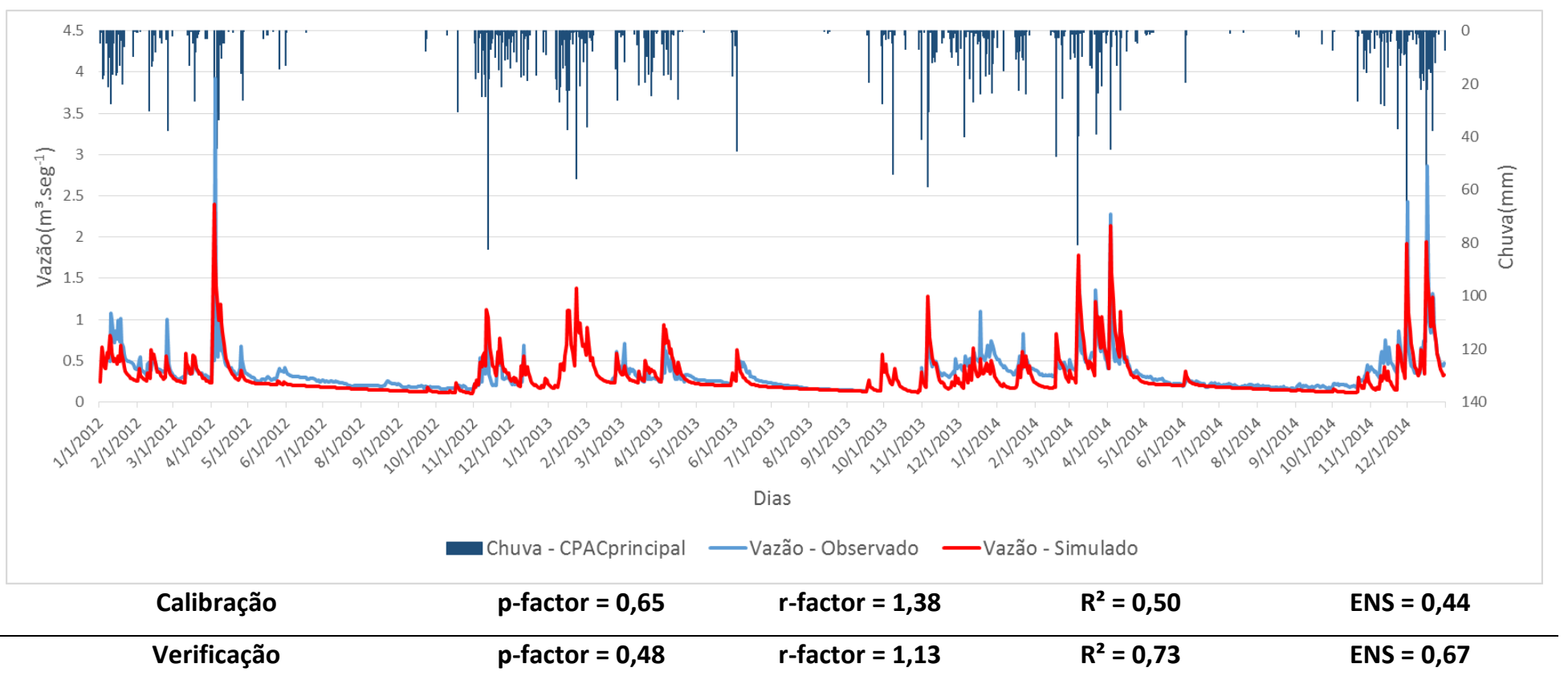

Figura 23 - Comparação entre dados simulados com dados observados de vazão e de chuva após a calibração 
As Figuras 24 e 25 apresentam uma comparação dos dados observados e simulados sem calibração e após a calibração para todo o período analisado (2012 a 2014). Observa-se que, após a calibração, houve uma melhora significativa na distribuição dos dados. Além disso, os valores de pico de vazão foram consideravelmente reduzidos e os valores de vazão mínima também apresentaram um aumento, afastando-se da origem do gráfico, indicando um aumento do fluxo de base. Por fim, observa-se uma melhora significativa na correlação dos dados, em que o R2 passou de 0,27 na calibração prévia para 0,61 após a calibração, com maior coerência dos dados em relação à linha de tendência.

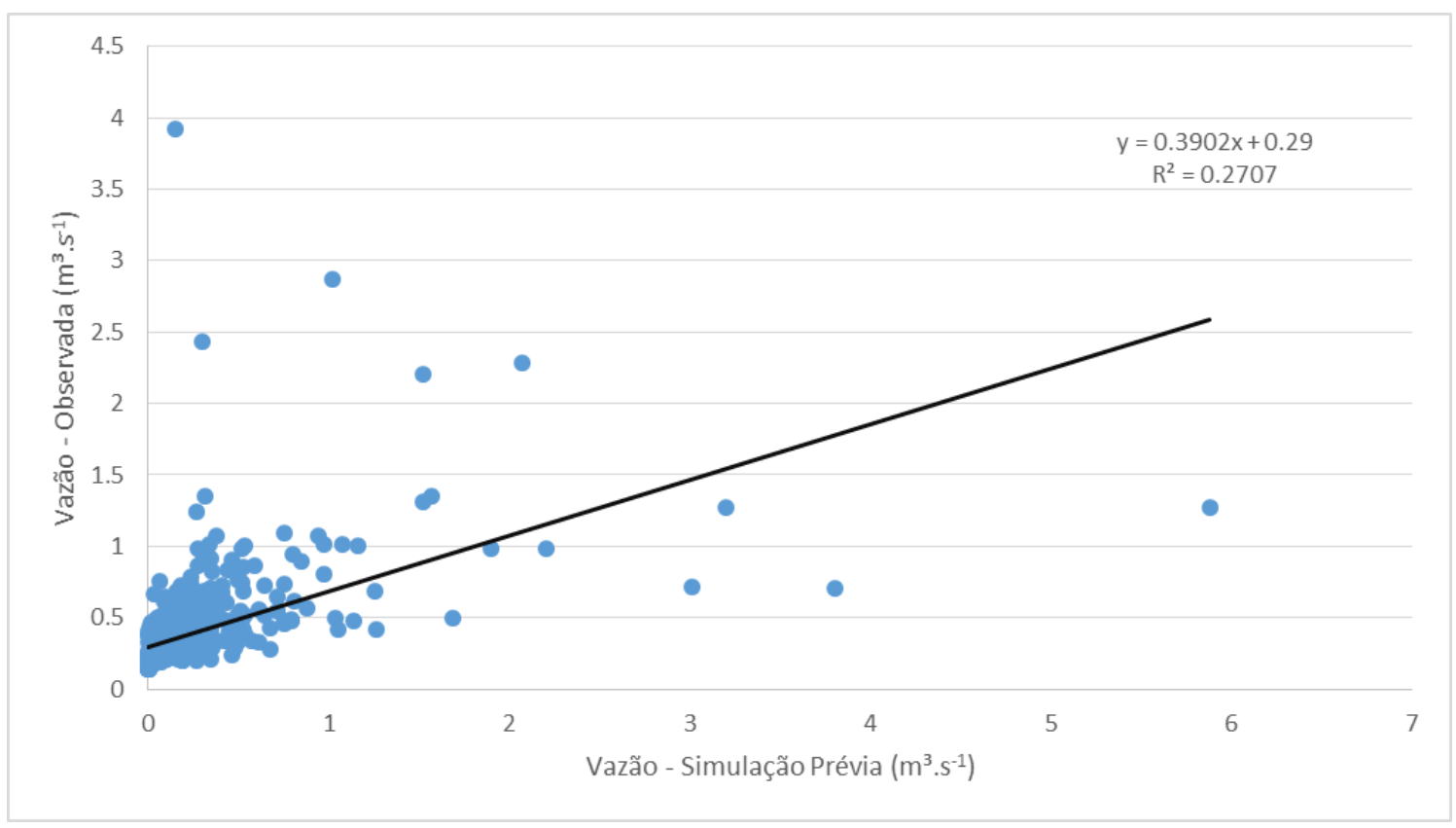

Figura 24 - Gráfico de dispersão dos dados de vazão observados e simulados no período de 2012 a 2014 sem calibração 


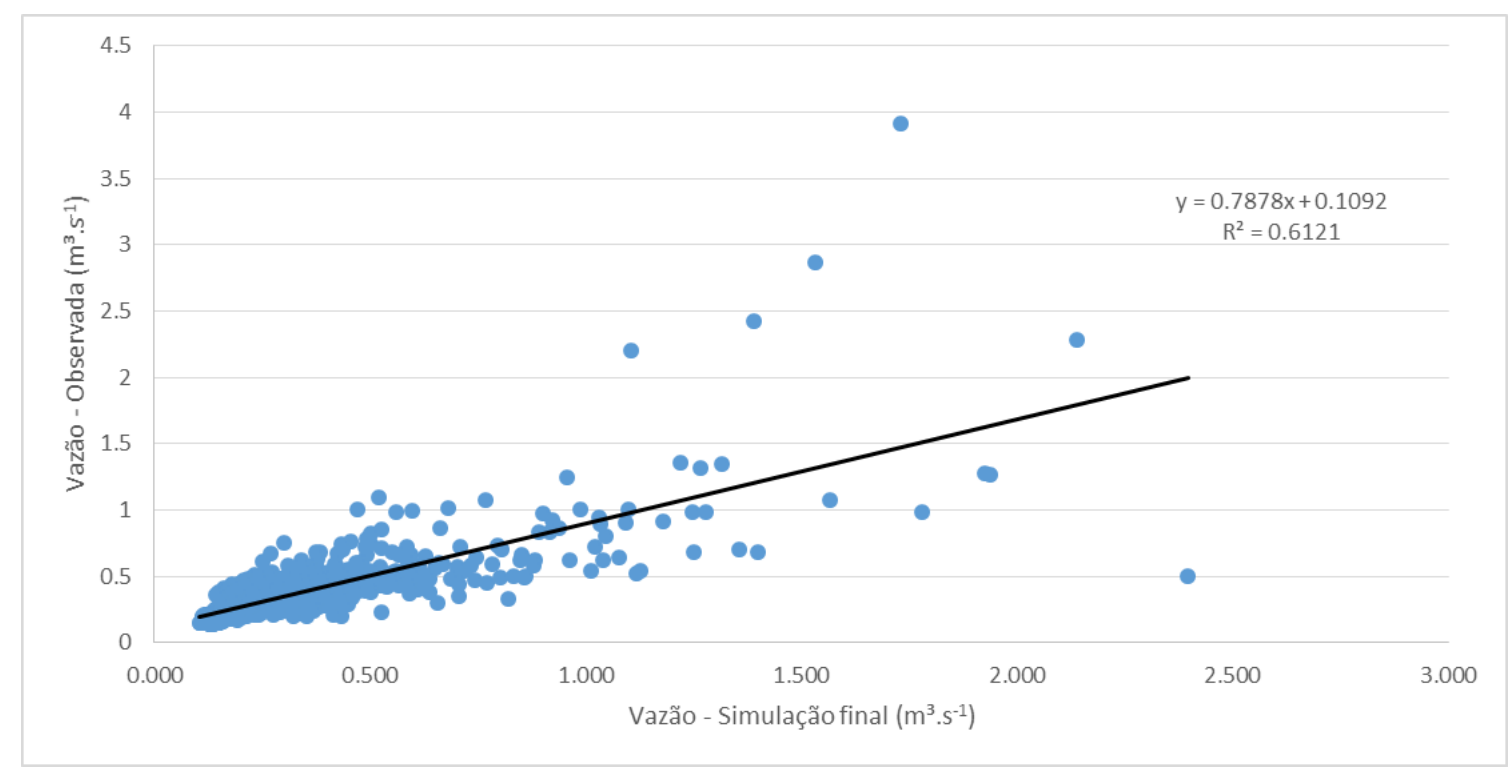

Figura 25 - Gráfico de dispersão dos dados de vazão observados e simulados no período de 2012 a 2014 após a calibração

\subsubsection{1 - Simulação do Balanço Hídrico na Bacia}

O ciclo hidrológico da bacia simulada pelo SWAT apresentou os seguintes resultados: A evapotranspiração e transpiração foram equivalentes a $819,8 \mathrm{~mm}$; evapotranspiração potencial de $1465 \mathrm{~mm}$; precipitação de $1326 \mathrm{~mm}$; CN médio de 37,88; Escoamento superficial de 51,35 mm; fluxo lateral de 393,55 mm; coeficiente Revap do aquífero raso foi equivalente a $89,85 \mathrm{~mm}$; percolação para os aquíferos rasos de $57,31 \mathrm{~mm}$; a recarga do aquífero profundo foi de 2,87 mm; e o fluxo de retorno foi de 54,44 mm (Figura 26).

Na simulação, o fluxo de base representa $72 \%$ do fluxo total. Já o escoamento superficial representa $28 \%$ do fluxo total, estes resultados são coerentes com o valor de CN2 simulado. A evapotranspiração representa $66 \%$ do total precipitado, enquanto a água proveniente de cursos de água representa $34 \%$ do total precipitado. Estes resultados quando comparados com as observações feitas por Lima (2010) - Tabela 5 - mostram-se satisfatórios. 


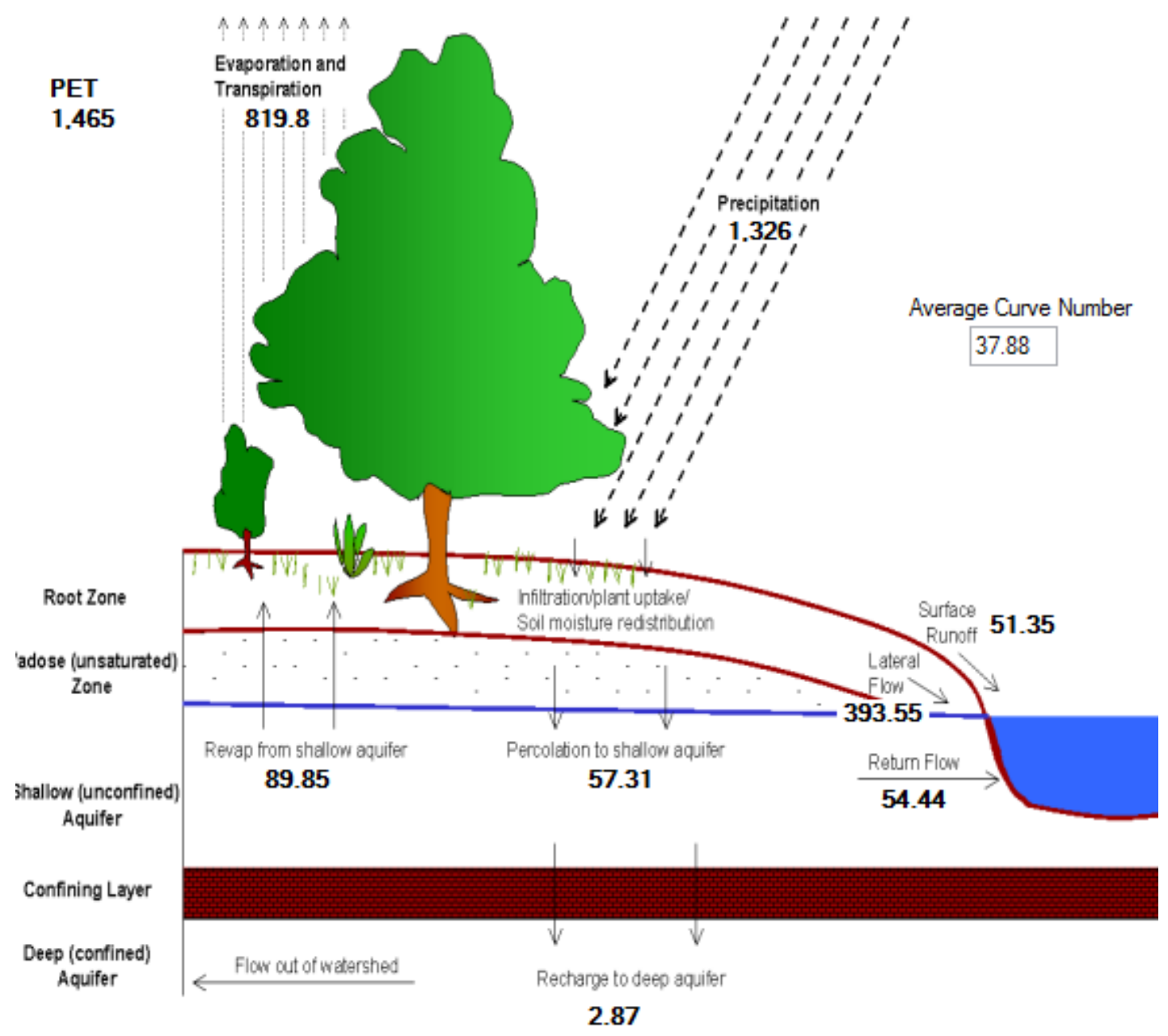

Figura 26 - Ciclo Hidrológico Simulado pelo SWAT - todas as unidades em mm (Figura gerada pelo aplicativo SWAT-Check)

\subsection{2 - CALIBRAÇÃO E VERIFICAÇÃO DO MODELO SWAT PELO SEDIMENTO}

Na Figura 27 é possível observar os resultados obtidos na simulação prévia em comparação com os dados observados de sedimentos e com os dados de chuva. Pode-se observar que a maior parte dos picos simulados estão superestimados em relação aos picos observados.

Estas observações mostram que os parâmetros identificados como mais sensíveis (Figura 20) são justamente aqueles que precisam de um ajuste maior, uma vez que estes parâmetros estão associados à quantidade de sedimentos no canal principal (PRF_BSN e SPEXP) e comprimento de rampa (SLSUBBSN). A Tabela 25 mostra os valores iniciais do modelo e os valores obtidos após o processo de calibração. 


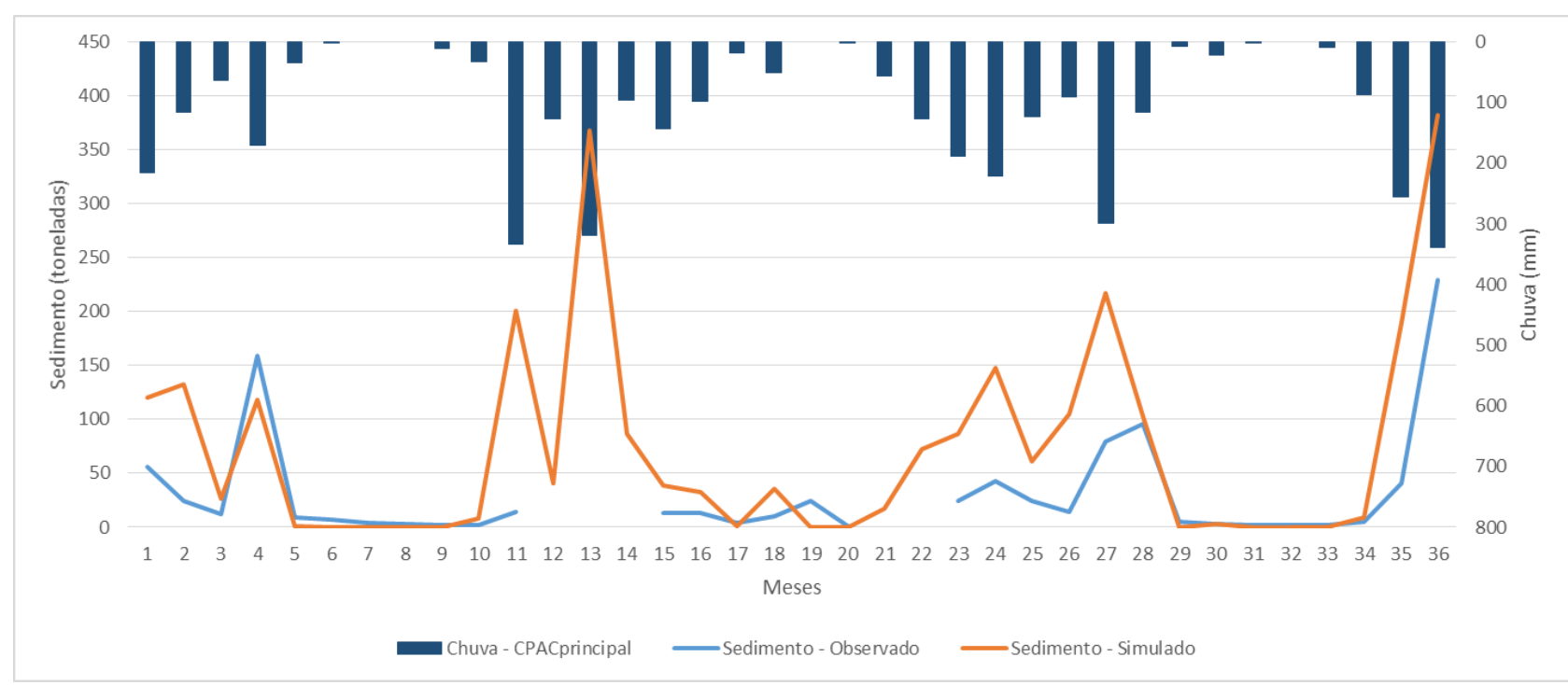

Figura 27 - Comparação entre dados simulados com dados observados de sedimentos e de chuva sem calibração

Tabela 25 - Comparação entre a variação de valores inicial e final utilizada no modelo SWAT para parâmetros de sedimentos

\begin{tabular}{|c|c|c|}
\hline Parâmetros & Variação Inicial & Variação Final*** \\
\hline USLE_C: Formação Savânica** & 0,042 & 0,3795 \\
\hline USLE_C: Formação Campestre** & 0,042 & 0,2335 \\
\hline USLE_C: Formação Florestal** & 0,012 & 0,0715 \\
\hline USLE_C: Agricultura de Sequeiro** & 0,18 & 0,4465 \\
\hline USLE_C: Agricultura Irrigada** & 0,18 & 0,1615 \\
\hline USLE_C: Pivô Central** & 0,18 & 0,0665 \\
\hline USLE_C: Cultivos Florestais*** & 0,012 & 0,0425 \\
\hline USLE_C: Pastagem** & 0,025 & 0,3165 \\
\hline USLE_C: Vegetação Degradada** & 0,042 & $0,00-14,98$ \\
\hline LAT_SED* & $0-5.000$ & Variação por classe de \\
\hline USLE_P** & & de manejo \\
\hline USLE_K* & $0-1$ & $0-0,6$ \\
\hline SPCON* & & $0,25-0,29$ \\
\hline ADJ_PKR* & $0-0,65$ & $0,38-1,53$ \\
\hline CH_COV1* & $0,0001-0,1$ & $0,43-0,56$ \\
\hline CH_COV2* & $0,5-2$ & $0,92-0,95$ \\
\hline SLSUBBSN* & $0,05-0,6$ & $18,54-278,12$ \\
\hline SPEXP* & $0,001-1$ & $1,79-2,03$ \\
\hline PRF_BSN* & $10-150$ & $0-1,20$ \\
\hline CHEidicas
\end{tabular}

* Valores padrões do modelo SWAT (NEITSCH et. al., 2011)

* Valores baseados de Lima e Lopes (2009)

*** Valores obtidos após a calibração 
A Figura 28 apresenta os resultados da calibração e verificação comparando os dados simulados de sedimentos com os dados observados na Estação Jusante e com os dados de chuva. A calibração dos sedimentos por dados mensais apresentou resultados insatisfatórios (MORIASI et. al., 2007; GREEN e VAN GRIENSVEN, 2008; ABBASPOUR et. al. 2015) com p-factor de 0,00, r-factor de 0,14, $\mathrm{R}^{2}$ de 0,51 e ENS de -0,14. Os dados simulados apresentaram picos e depressões condizentes com os dados de chuva da estação CPACPrincipal. Por outro lado, os resultados da verificação se apresentaram satisfatórios com com p-factor de 0,00, r-factor de 0,08, $\mathrm{R}^{2}$ de 0,81 e ENS de 0,66. Importante destacar que a falta de picos na série de calibração contribuiu significativamente para os índices insatisfatórios, além disso, os dados simulados estão superestimados em relação aos dados observados, contribuindo para um alto nível de incerteza no modelo - representado pelos baixos valores de $p$-factor e $r$ factor (AKHAVAN et. al., 2010) -, tanto na calibração quanto na verificação.

Comparando os resultados obtidos com outros trabalhos realizados no Distrito Federal (Tabela 26), observa-se que os resultados do período de calibração apresentam-se insatisfatórios enquanto os resultados do período de verificação apresentam-se satisfatórios, mas com alto nível de incerteza.

Tabela 26 - Valores de ENS obtidos em simulações de sedimentos com o modelo SWAT no Distrito Federal

\begin{tabular}{|c|c|c|c|c|}
\hline Referência & $\begin{array}{c}\text { Bacia } \\
\text { Hidrográfica }\end{array}$ & $\begin{array}{c}\text { ENS obtido no } \\
\text { processo de } \\
\text { calibração }\end{array}$ & $\begin{array}{c}\text { ENS obtido no } \\
\text { processo de } \\
\text { verificação }\end{array}$ & $\begin{array}{c}\text { Formato dos } \\
\text { dados utilizados } \\
\text { na série de vazão }\end{array}$ \\
\hline Strauch et. al. (2012) & Pipiripau & 0,37 & $-2,10$ & Diário \\
\hline Carvalho $(2014)^{*}$ & Jardim & $-0,06$ & - & Diário \\
\cline { 3 - 5 } & Sarandi & 0,26 & - & Mensal \\
\hline Este trabalho & $\mathbf{- 0 , 1 4}$ & $\mathbf{0 , 6 6}$ & Mensal \\
\hline
\end{tabular}

* O autor realizou a análise estatística do período de calibração e verificação de forma conjunta

Após a calibração, observa-se uma redução significativa nos picos de sedimento. Com a calibração, a menor quantidade de sedimentos simulada de 0 toneladas.mês ${ }^{-1}$ para 21,92 toneladas.mês ${ }^{-1}$, sendo que a quantidade mínima de sedimentos observada é de 1,05 toneladas.mês ${ }^{-1}$, demonstrando que os valores mínimos ficaram superestimados. Em relação aos picos, apesar dos resultados estarem superestimados em relação aos dados observados, houve uma redução significativa após o processo de calibração, sendo que a quantidade máxima de sedimento passou de 381,8 toneladas.mês ${ }^{-1}$ para 229,05 toneladas.mês ${ }^{-1}$, sendo que a maior quantidade de sedimentos observada é de 143,9 toneladas.mês ${ }^{-1}$. 


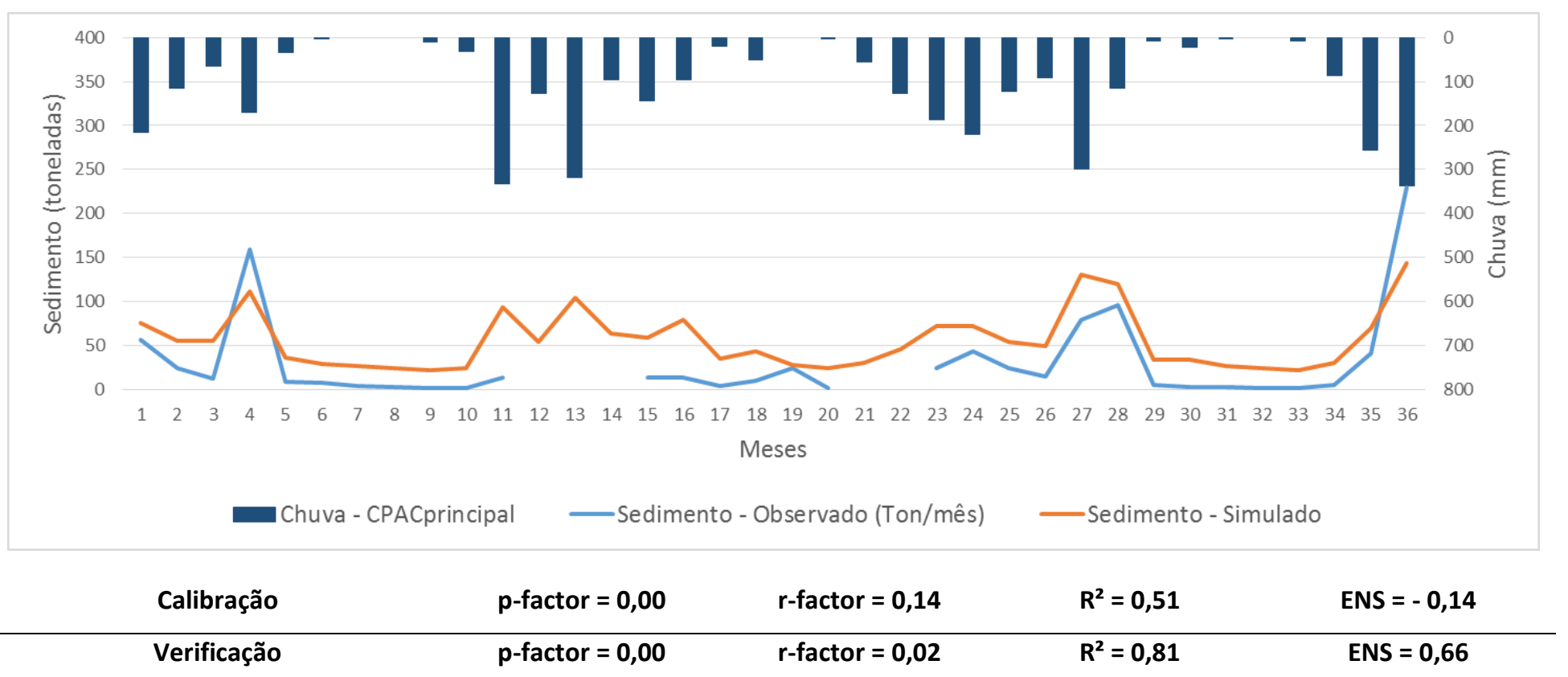

Figura 28 - Comparação entre dados simulados com dados observados de sedimentos e de chuva após a calibração

As Figuras 29 e 30 apresentam uma comparação dos dados observados e simulados sem calibração e após a calibração para todo o período analisado (2012 a 2014). Observa-se que, após a calibração, houve uma pequena melhora na distribuição dos dados. Além disso, os valores de pico de sedimentos foram consideravelmente reduzidos e os valores mínimos também apresentaram um aumento, afastando-se da origem do gráfico. Por fim, observa-se uma pequena melhora na correlação dos dados, em que o R2 passou de 0,62 na calibração prévia para 0,69 após a calibração, com menor dispersão dos dados em relação à linha de tendência. 


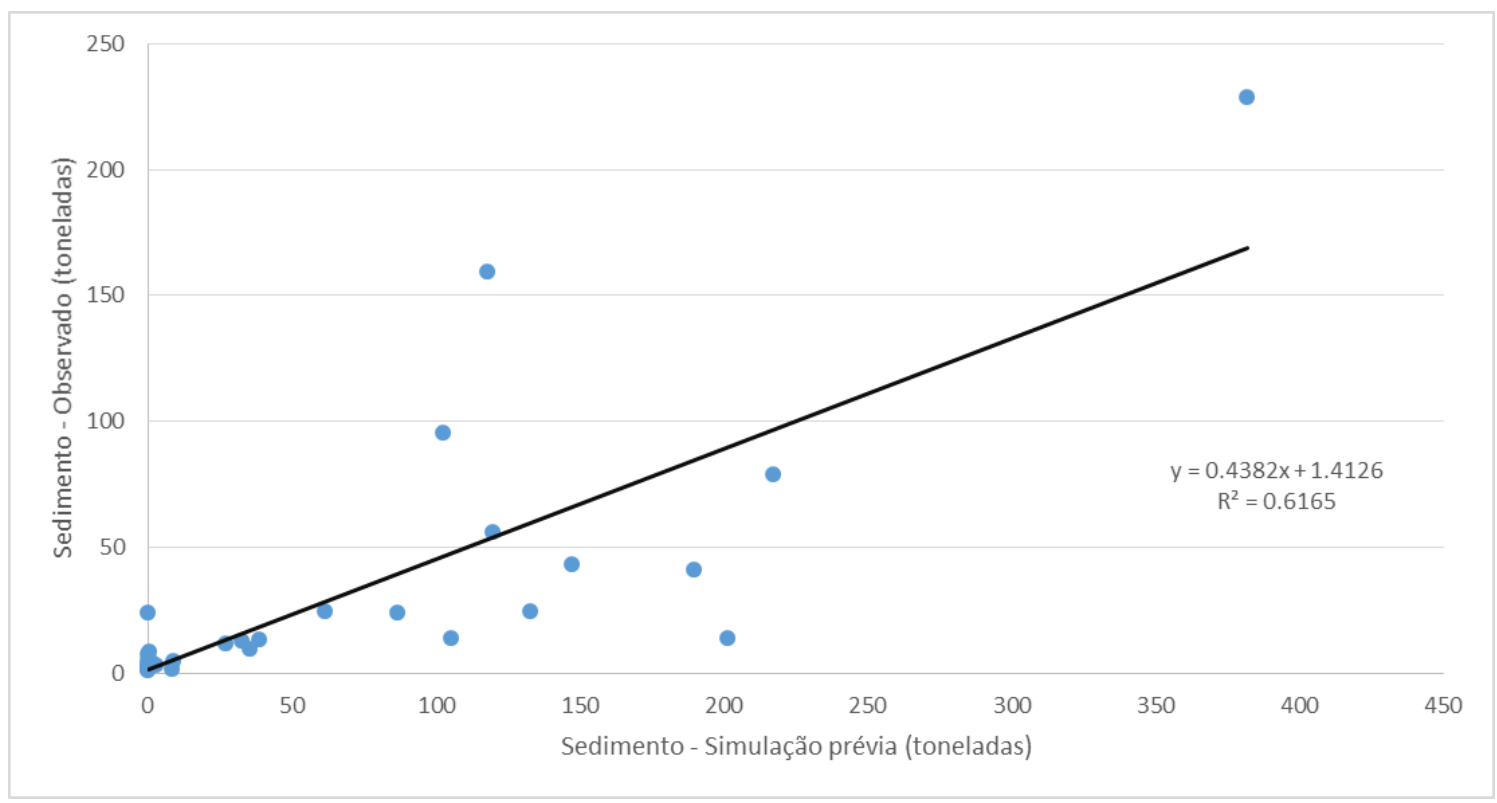

Figura 29 - Gráfico de dispersão dos dados de sedimentos observados e simulados no período de 2012 a 2014 sem calibração

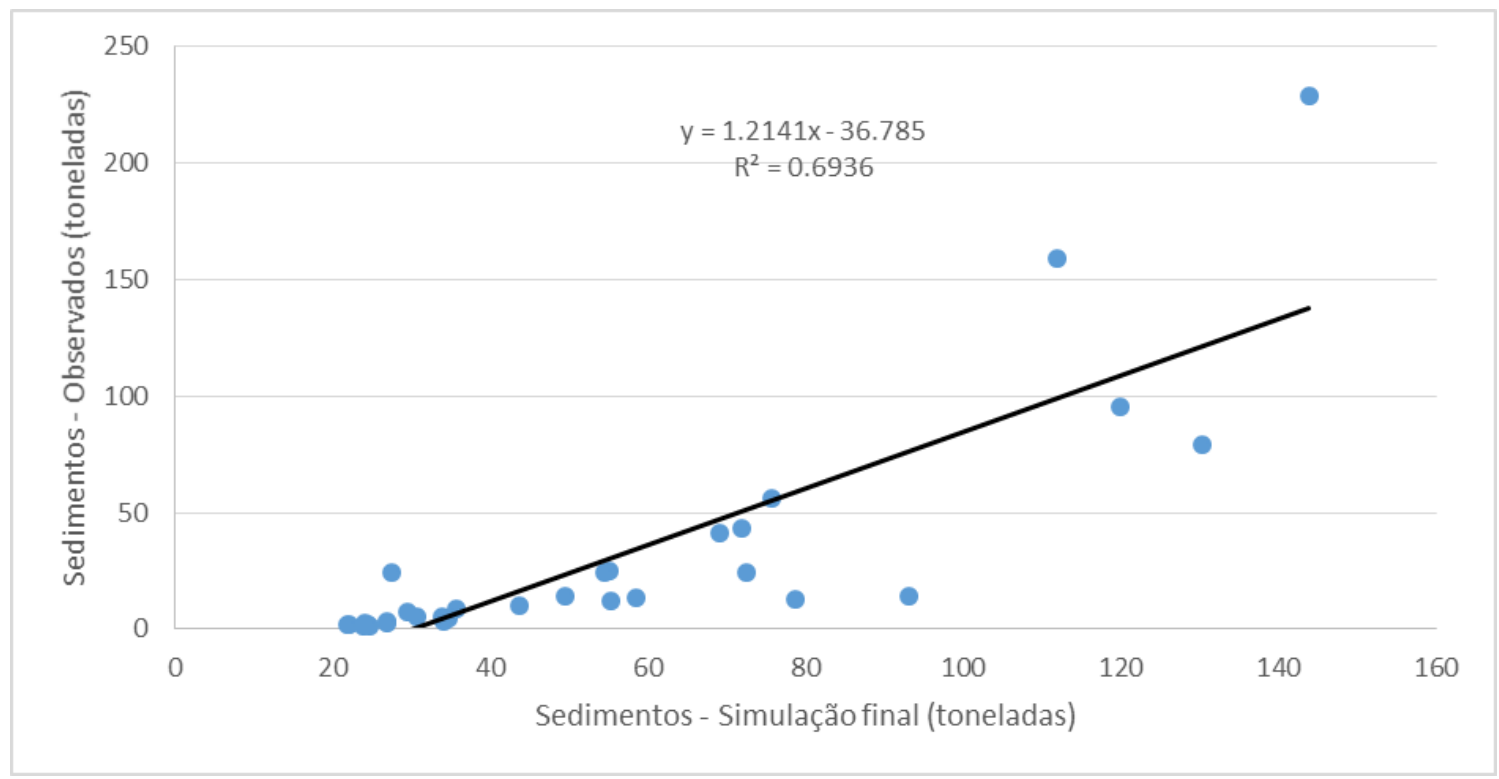

Figura 30 - Gráfico de dispersão dos dados de sedimentos observados e simulados no período de 2012 a 2014 após a calibração 


\subsection{3 - CALIBRAÇÃO E VERIFICAÇÂO DO MODELO SWAT PELOS NUTRIENTES}

Na Figura 31 é possível observar os resultados obtidos na simulação prévia em comparação com os dados observados de NO3 e com os dados de chuva. Pode-se observar que a maior parte dos picos simulados estão superestimados em relação aos picos observados.

Estas observações mostram que os parâmetros identificados como mais sensíveis (Figura 21) são justamente aqueles que precisam de um ajuste maior, uma vez que estes parâmetros estão associados às perdas de nitrogênio (SDCNO; CDN; ANION_EXCL; e NPERCO). A Tabela 27 mostra os valores iniciais do modelo e os valores obtidos após o processo de calibração.

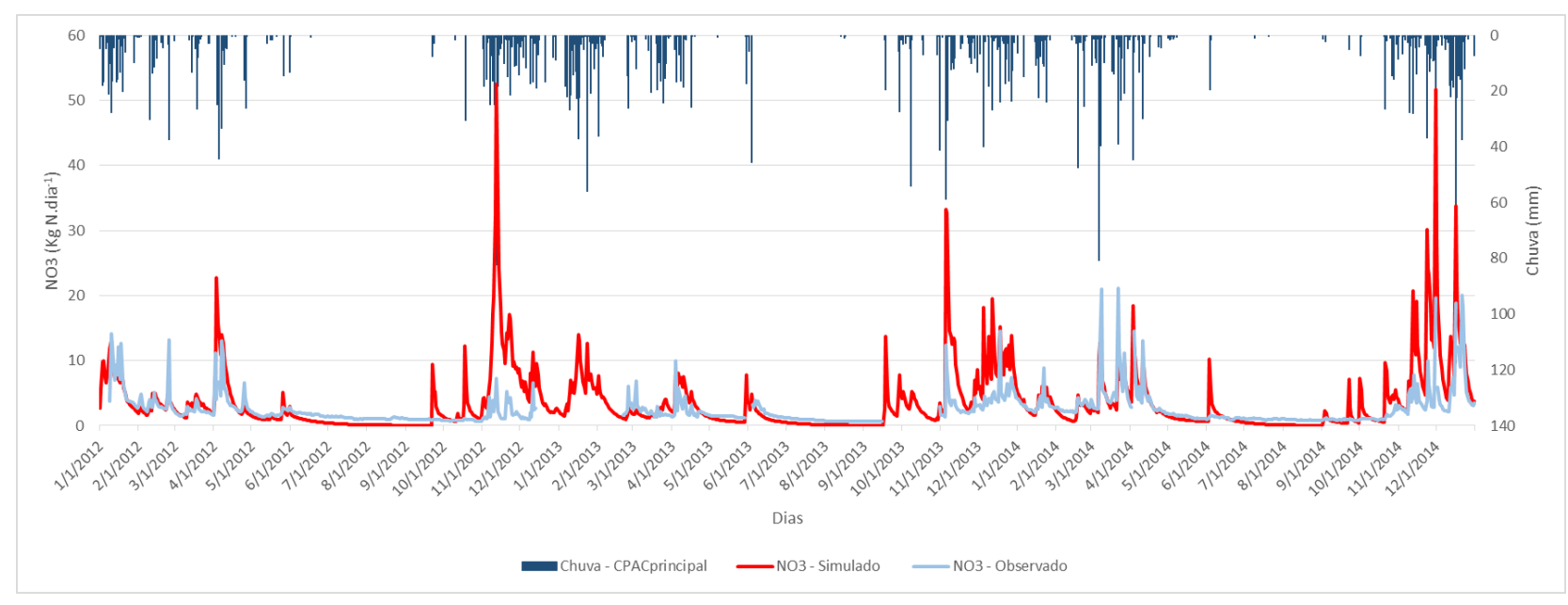

Figura 31 - Comparação entre dados simulados com dados observados de NO3 e de chuva sem calibração 
Tabela 27 - Comparação entre a variação de valores inicial e final utilizada no modelo SWAT para parâmetros de qualidade da água

\begin{tabular}{|c|c|c|}
\hline Parâmetros & Variação Inicial* & Variação Final** $^{* *}$ \\
\hline CMN & $0,001-0,003$ & $0,001-0,003^{* * *}$ \\
\hline RSDCO & $0,02-0,1$ & $0,019-0,09$ \\
\hline SOL_ORGN & $0-100$ & $0-91,14$ \\
\hline SOL_NO3 & $0-100$ & $0-120,48$ \\
\hline RCN & $0-15$ & $0-15,19$ \\
\hline SHALLST_N & $0-1.000$ & $0-633,45$ \\
\hline FRT_SURFACE & $0-1$ & $0,07-0,2$ \\
\hline BIOMIX & $0-1$ & $0,75-1,00$ \\
\hline NPERCO & $0-1$ & $0,057-0,35$ \\
\hline ANION_EXCL & $0,01-1$ & $0,011-1,14$ \\
\hline CDN & $0-3$ & $0,066-0,20$ \\
\hline SDNCO & $0-1$ & $0,8-1$ \\
\hline
\end{tabular}

* Valores padrões do modelo SWAT (NEITSCH et. al., 2011)

** Valores obtidos após a calibração

*** Valor não alterado pelo processo de calibração

A Figura 32 apresenta os resultados da calibração e verificação comparando os dados simulados de NO3 com os dados observados na Estação Jusante e com os dados de chuva. A calibração da vazão por dados diários apresentou resultados satisfatórios (MORIASI et. al., 2007; GREEN e VAN GRIENSVEN, 2008; ABBASPOUR et. al. 2015) com $p$-factor de 0,42, r-factor de 2,02, $\mathrm{R}^{2}$ de 0,47 e ENS de 0,38. Os dados simulados apresentaram picos e depressões condizentes com os dados de chuva da estação CPAC-Principal. Por outro lado, os resultados da verificação se apresentaram insatisfatórios com com $p$-factor de $0,57, r$-factor de $1,28 \mathrm{R}^{2} \mathrm{de}$ 0,73 e ENS de 0,58. Assim como na série de vazão, os resultados poderiam apresentar um menor nível de incerteza com uma série de dados maior, desde que apresentasse um maior número de picos (SALLES, 2012).

Os resultados obtidos quando comparados com outros trabalhos no Distrito Federal mostrou-se satisfatório (Tabela 28).

Tabela 28 - Valores de ENS obtidos em simulações de qualidade de água com o modelo SWAT no Distrito Federal

\begin{tabular}{|c|c|c|c|c|c|}
\hline \multirow{2}{*}{ Referência } & $\begin{array}{c}\text { Bacia } \\
\text { Hidrográfica }\end{array}$ & $\begin{array}{c}\text { Parâmetro de } \\
\text { Calibração }\end{array}$ & $\begin{array}{c}\text { ENS obtido } \\
\text { no processo } \\
\text { de calibração }\end{array}$ & $\begin{array}{c}\text { ENS obtido no } \\
\text { processo de } \\
\text { verificação }\end{array}$ & $\begin{array}{c}\text { Formato dos } \\
\text { dados } \\
\text { utilizados na } \\
\text { série de vazão }\end{array}$ \\
\hline \multirow{2}{*}{ Monsalve-Herrera (2013) } & Riacho Fundo & $\begin{array}{c}\text { Nitrogênio } \\
\text { Total }\end{array}$ & 0,45 & $-0,85$ & Mensal \\
\cline { 3 - 6 } & Fósforo Total & $-3,43$ & $-7,31$ & Mensal \\
\hline Este trabalho & Sarandi & Nitrato (NO3) & $\mathbf{0 , 3 8}$ & $\mathbf{0 , 5 8}$ & Diário \\
\hline
\end{tabular}


Após a calibração, observa-se um aumento nos valores mínimos de NO3. Com a calibração, a menor quantidade de simulada passa de $0,03 \mathrm{~kg} \mathrm{~N} \mathrm{dia}^{-1}$ para 0,328 Kg N.dia ${ }^{-1}$, sendo que a quantidade mínima de NO3 observada é de $0,634 \mathrm{Kg} \mathrm{N}$. dia $^{-1}$, demonstrando que os valores mínimos simulados ficaram mais próximos dos valores observados.

Em relação aos picos, houve uma redução significativa após o processo de calibração, sendo que a quantidade máxima de NO3 passou de 52,43 Kg N.dia ${ }^{-1}$ para 14,58 Kg N.dia ${ }^{-1}$, sendo que a maior quantidade de NO3 observada é de $14,51 \mathrm{Kg} \mathrm{N} \cdot \mathrm{dia}^{-1}$.

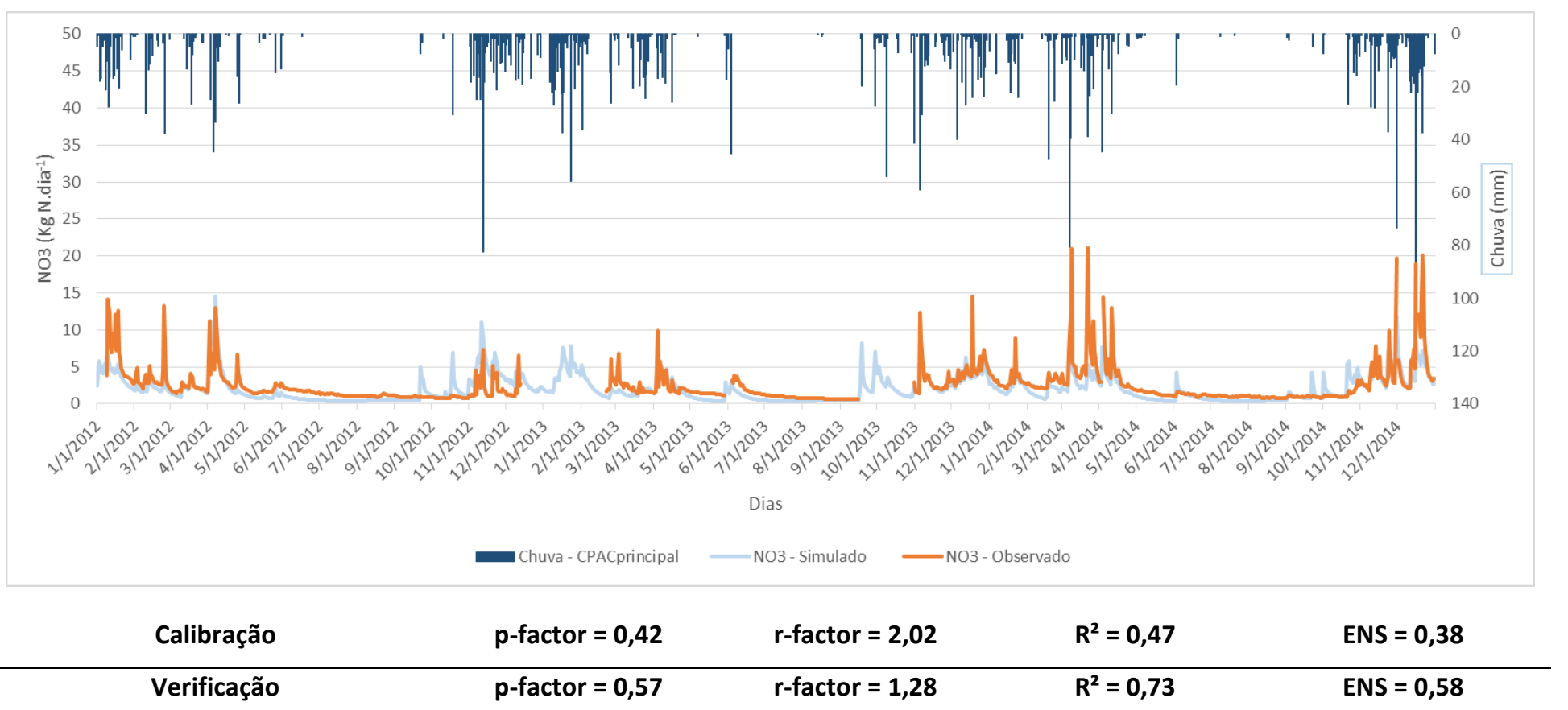

Figura 32 - Comparação entre dados simulados com dados observados de NO3 e de chuva após a calibração

As Figuras 33 e 34 apresentam uma comparação dos dados observados e simulados sem calibração e após a calibração para todo o período analisado (2012 a 2014). Observa-se que, após a calibração, houve uma melhora significativa na distribuição dos dados. Além disso, os valores de pico de NO3 foram consideravelmente reduzidos e a quantidade mínima também apresentou um aumento, afastando-se da origem do gráfico. Por fim, observa-se uma melhora significativa na correlação dos dados, em que o R2 passou de 0,37 na calibração prévia para 0,50 após a calibração, com maior coerência dos dados em relação à linha de tendência. 


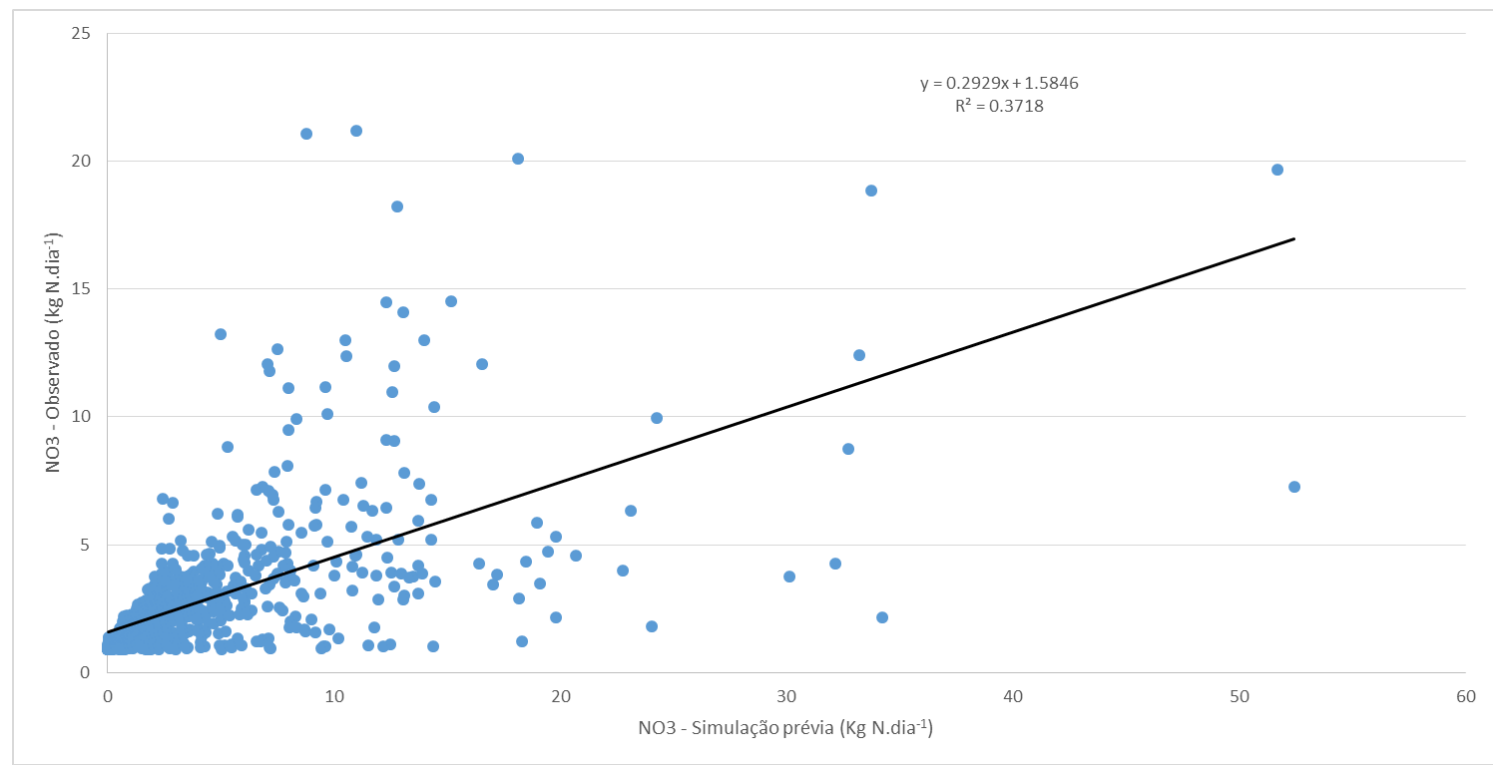

Figura 33 - Gráfico de dispersão dos dados de NO3 observados e simulados no período de 2012 a 2014 sem calibração

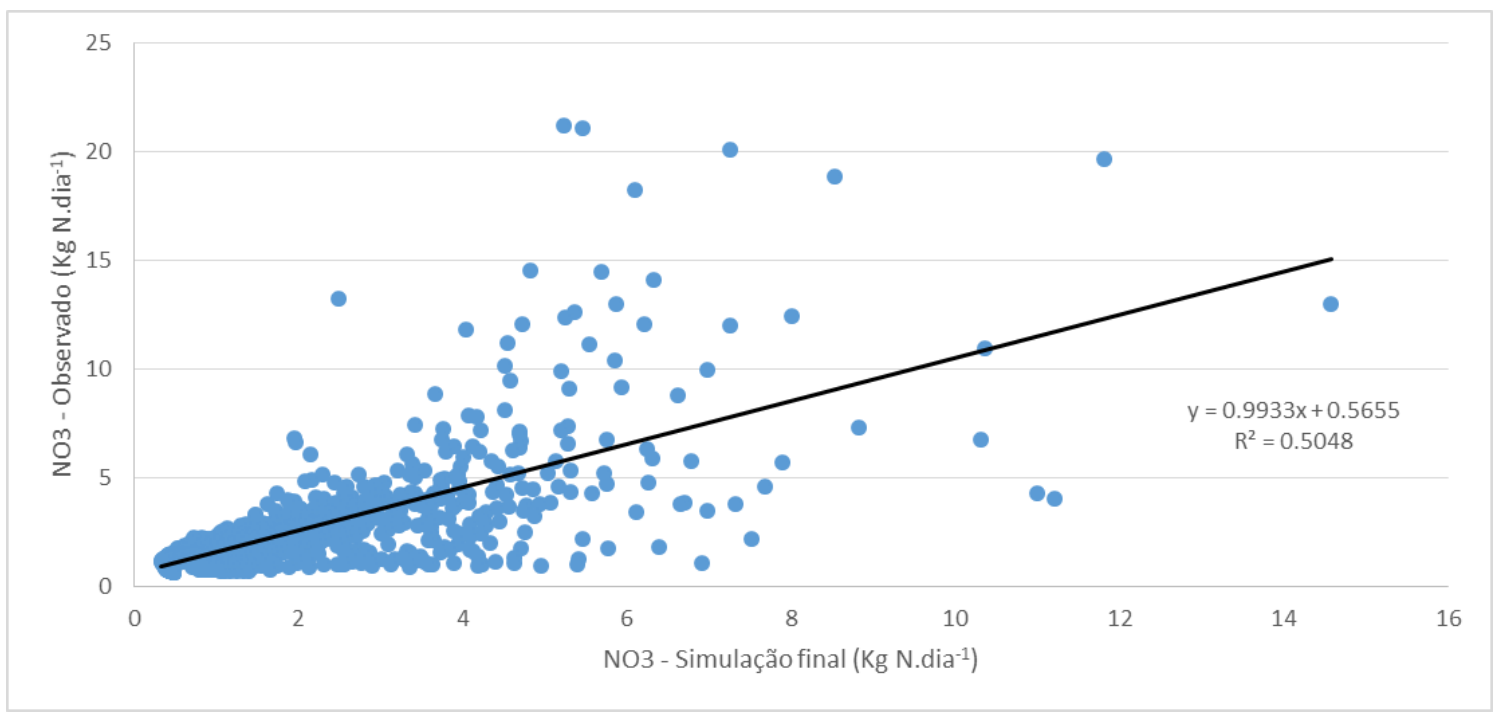

Figura 34 - Gráfico de dispersão dos dados de NO3 observados e simulados no período de 2012 a 2014 após a calibração

\section{8 - ANÁLISE DA PERDA DE SOLOS}

Os resultados apresentados são compatíveis com os resultados obtidos por Lima et. al. (2012) ao aplicar a USLE na bacia do córrego Sarandi para estimar o potencial erosivo da área (Tabela 29). O autor aplicou a Equação Universal de Perda de Solos (USLE) para estimar a 
susceptibilidade à erosão e dar suporte a análise de serviços ecossistêmicos na bacia do Sarandi (DF), demonstrando que a maior parte da bacia possui baixa susceptibilidade à erosão e que um programa para controle de erosão na bacia não seria uma prioridade imediata. Os autores aplicaram o modelo considerando um cenário onde não há práticas conservacionistas na bacia, ou seja, o valor dos fatores C e P é 1.

Nos três anos do período analisado, 99,98\% da bacia encontram-se na classe baixa de erosão, apresentando menos de 10 ton.ha ${ }^{-1} \cdot$ ano $^{-1}$ em perdas de solo (Tabela 26 e Figura 35). Somente em uma pequena área de solo exposto com aproximadamente 0,5 ha em área de cambissolo em relevo ondulado apresentou, nos anos de 2012 e 2013 perdas de aproximadamente 15,5 e 14,5 ton.ha ${ }^{-1}$. no $^{-1}$ respectivamente. Já no ano de 2014, esta área de solo exposto apresentou perdas de solo de aproximadamente 27 ton.ha ${ }^{-1} \cdot$ ano $^{-1}$.

Os baixos níveis de perda de solos podem ser explicado pelo fato de que, $47 \%$ da bacia encontra-se preservada, incluindo as áreas de maior declividade e bordas de chapada (CHAVES et. al., 2014).

Tabela 29 - Comparação dos resultados obtidos com os de Lima et. al. (2012) para o período analisado

\begin{tabular}{|c|c|c|c|c|c|}
\hline \multirow{2}{*}{ Classificação } & \multicolumn{2}{|c|}{ Potencial Erosivo (Fator CP =1) } & \multicolumn{3}{|c|}{ Erosão Atual } \\
\cline { 2 - 6 } & \multicolumn{2}{|c|}{ Referência (LIMA et.al. 2012) } & $\mathbf{2 0 1 2}$ & $\mathbf{2 0 1 3}$ & $\mathbf{2 0 1 4}$ \\
\cline { 2 - 6 } & $\begin{array}{c}\text { Perda de Solos } \\
\left(\mathbf{t . h a}^{-\mathbf{1}} \cdot \mathbf{a n o}^{-\mathbf{1}}\right)\end{array}$ & $\begin{array}{c}\text { Área da } \\
\text { Bacia (\%) }\end{array}$ & $\begin{array}{c}\text { Área da } \\
\text { Bacia (\%) }\end{array}$ & $\begin{array}{c}\text { Área da } \\
\text { Bacia (\%) }\end{array}$ & $\begin{array}{c}\text { Área da } \\
\text { Bacia (\%) }\end{array}$ \\
\hline Baixa & $<10$ & 89,3 & 99,98 & 99,98 & 99,98 \\
\hline Média & $10-20$ & 5,5 & 0,018 & 0,018 & 0,00 \\
\hline Alta & $>20$ & 5,2 & 0,003 & 0,003 & 0,019 \\
\hline
\end{tabular}




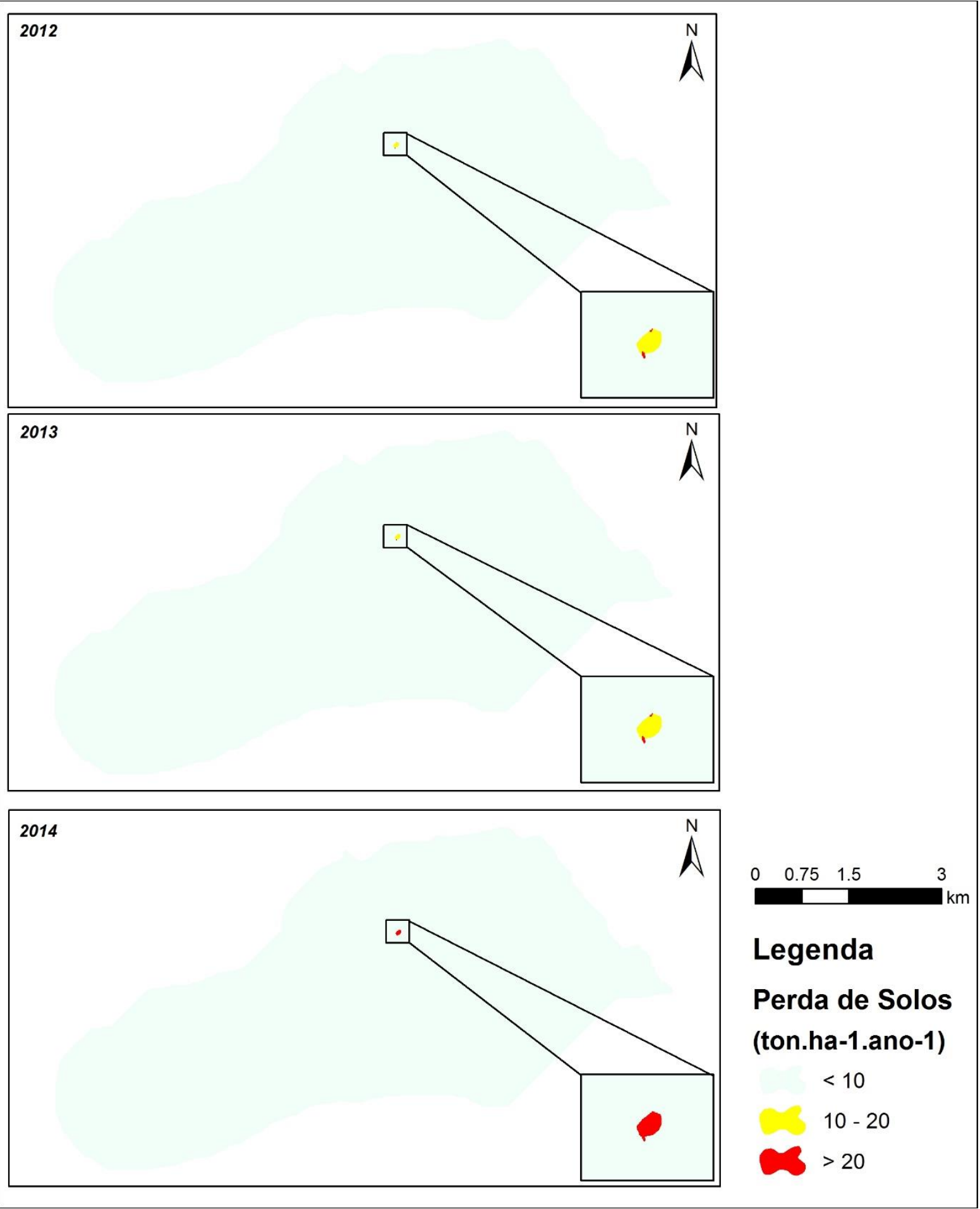

Figura 35 - Erosão anual durante o período de jan/2012 a dez/2014 na área de estudo 
Em relação à quantidade de sedimentos no canal principal, a Figura 36 apresenta que durante os três anos analisados, foram contabilizados: 382 dias com produção inferior a 1 tonelada, com produção de sedimentos de 255,8 toneladas, ou $13,2 \%$ da produção total de sedimentos; 397 dias com produção de sedimentos entre 1 e 2 toneladas, representando $28,1 \%$ do total de sedimentos; 260 dias com produção de sedimentos entre 2 e 5 toneladas, representando 39,1\% dos sedimentos no canal; foram 54 dias com produção entre 5 e 10 toneladas, representando $17,8 \%$ da produção de sedimentos; e, por fim, somente em 3 dias houveram produção entre 10 e 20 toneladas de sedimento, representando 35,3 toneladas, ou $1,8 \%$ da produção de sedimentos. A quantidade de sedimentos transportados para o canal totaliza aproximadamente 1945,5 toneladas.

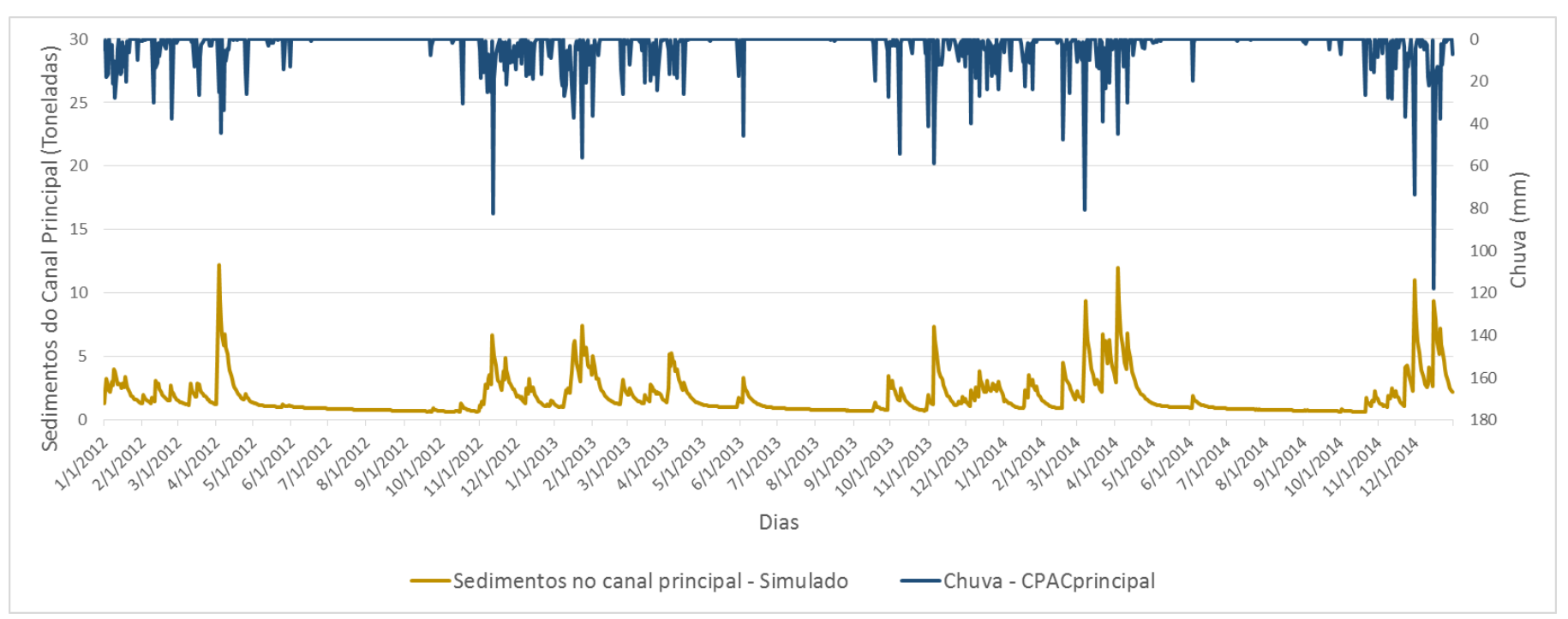

Figura 36 - Total de sedimento transportado no canal principal no período de 2012-2014 (toneladas.dia ${ }^{-1}$ ) comparados com os dados de precipitação registrado na Estação CPAC-Principal (mm) 


\section{9 - ANÁLISE DA PERDA DE NUTRIENTES NA BACIA}

\subsection{1 - PERDAS DE N E P}

A Figura 37 apresenta que, na maior parte da bacia, as perdas são abaixo de 10 kg.ha${ }^{1}$. ano ${ }^{-1}$. As perdas que variam de 10 a $20 \mathrm{~kg} \cdot \mathrm{ha}^{-1} \cdot \mathrm{ano}^{-1}$ se localizam na parte nordeste da bacia área de produção de milho e horticultura; na parte central da bacia - área de produção de milho e soja; na parte sul da fazenda experimental da Embrapa - área de produção de dendê próxima ao curso de água-, todas em ambiente de gleissolos. Este padrão se repete nos dois primeiros anos da série analisada.

Já no ano de 2014, as perdas de nitrogênio chegam a 23,4 kg.ha-1 na parte sul da fazenda experimental da Embrapa Cerrados -área de produção de dendê em ambiente de latossolo vermelho. Nesta área, durante os meses de março de dezembro houve um acúmulo de nitrogênio orgânico causado principalmente pela concentração de resíduo vegetal e fixação de NO3 pelas plantas. Como durante estes meses houve, nesta HRU, um maior escoamento superficial devido a um aumento na precipitação, este acúmulo de $\mathrm{N}$ orgânico foi então carreado para o canal principal, contribuindo, assim, para uma maior perda total de nitrogênio na área de produção de dendê em ambiente de latossolo vermelho.

As baixas perdas de $\mathrm{N}$ ocorrem devido ao fato de que a maior parte da produção agrícola da área de estudo encontra-se em locais com um nível muito baixo de perda de solos e escoamento superficial, uma vez que $47 \%$ da bacia, incluindo as bordas de chapada e áreas de maiores declividades, encontram-se preservadas (CHAVES et. al., 2014).

Em relação aos valores médios na bacia durante o período analisado, a perda de nitrogênio total foi de $1,79 \mathrm{~kg} \cdot \mathrm{ha}^{-1}$; com perda de nitrogênio orgânico de 1,22 kg.ha-1 . Em relação ao nitrato, $0,17 \mathrm{~kg} \cdot \mathrm{ha}^{-1}$ foram perdidos por meio do escoamento superficial, $0,31 \mathrm{~kg} \cdot \mathrm{ha}^{-}$ ${ }^{1}$ foram lixiviados, $0,09 \mathrm{~kg} \cdot \mathrm{ha}^{-1}$ foram perdidos por meio de escoamento lateral. Os níveis de nitrato no fluxo subsuperficial foi de $0,002 \mathrm{~kg} \cdot \mathrm{ha}^{-1}$ com taxa de solubilidade de $0,124 \%$.

Em relação às perdas de fósforo na bacia, a perda de fósforo total foi de $0,4 \mathrm{~kg}_{\text {gha }}{ }^{-1}$; com perda de fósforo orgânico de $0,18 \mathrm{~kg} \cdot \mathrm{ha}^{-1}$. A quantidade de fósforo solúvel no escoamento superficial é de $0,22 \mathrm{~kg} \cdot \mathrm{ha}^{-1}$, apresentando taxa de solubilidade de $0,56 \%$. As perdas de fósforo simuladas foram similares aos valores dos dados observados disponibilizados pela Embrapa Cerrados e estão demonstradas na Figura 38. 


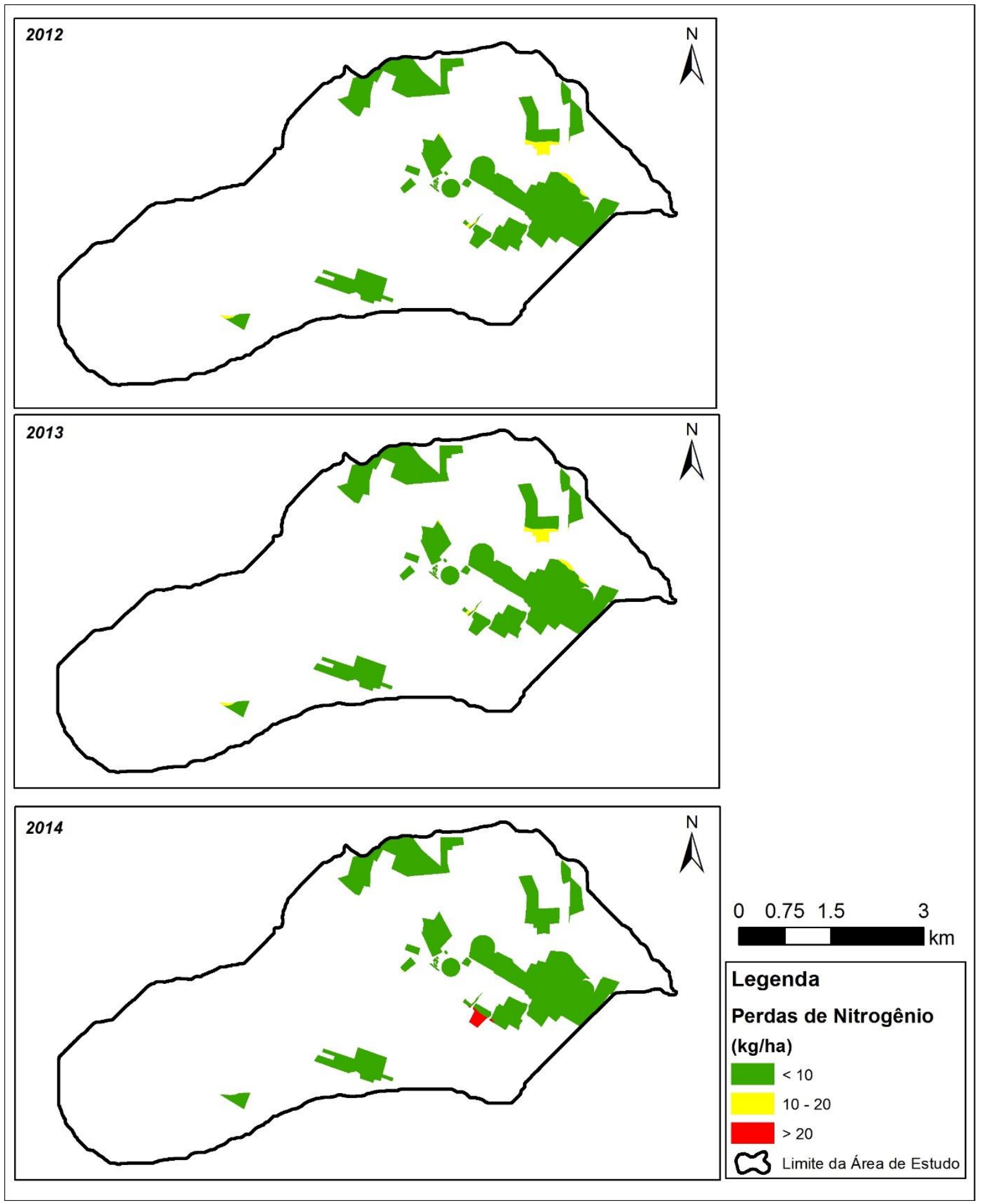

Figura 37 - Perdas de N simulados pelo SWAT na área de produção agrícola da bacia experimental do córrego Sarandi 


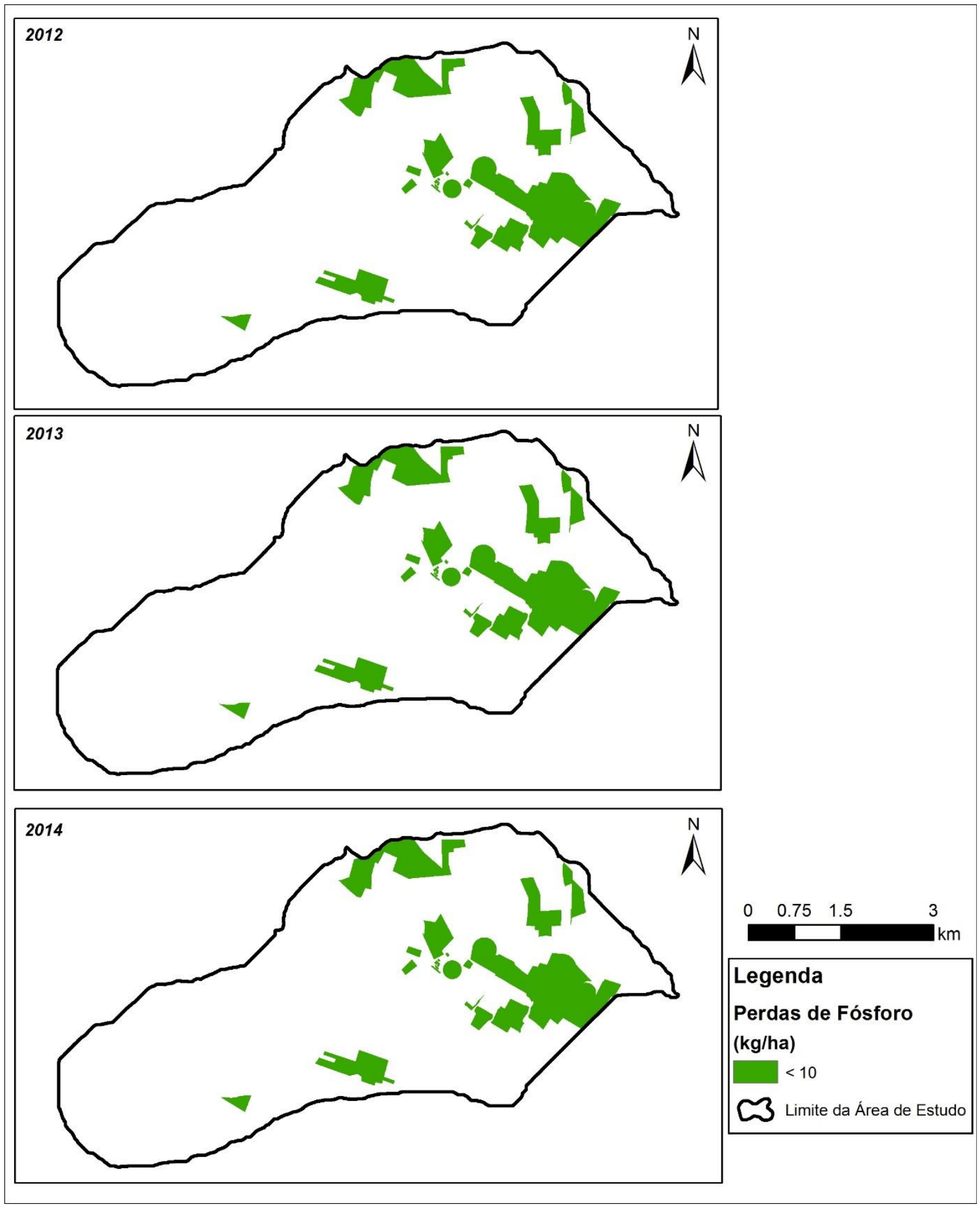

Figura 38 - Perdas de P simulados pelo SWAT na área de produção agrícola da bacia experimental do córrego Sarandi 


\subsection{2 - PERDAS DE K E Ca+Mg}

As perdas de potássio (Figura 39) são baixas, chegando a, no máximo, em 2014, 19 kg.ha-1 em uma HRU onde há produção de soja na parte mais oeste da fazenda experimental da Embrapa. No mesmo ano, a produção de fruticultura e dendê apresentam perdas entre 10 e 12,5 kg.ha-1. Estes valores ocorrem devido a um aumento do escoamento superficial nestas áreas ocorridas em razão de uma quantidade maior de chuva precipitada nos meses de março e dezembro deste ano.

Já as perdas de $\mathrm{Ca}+\mathrm{Mg}$ (Figura 40) também apresentaram baixos valores, com, no máximo 1,3 kg.ha- ${ }^{-1}$ na mesma HRU descrita anteriormente. 


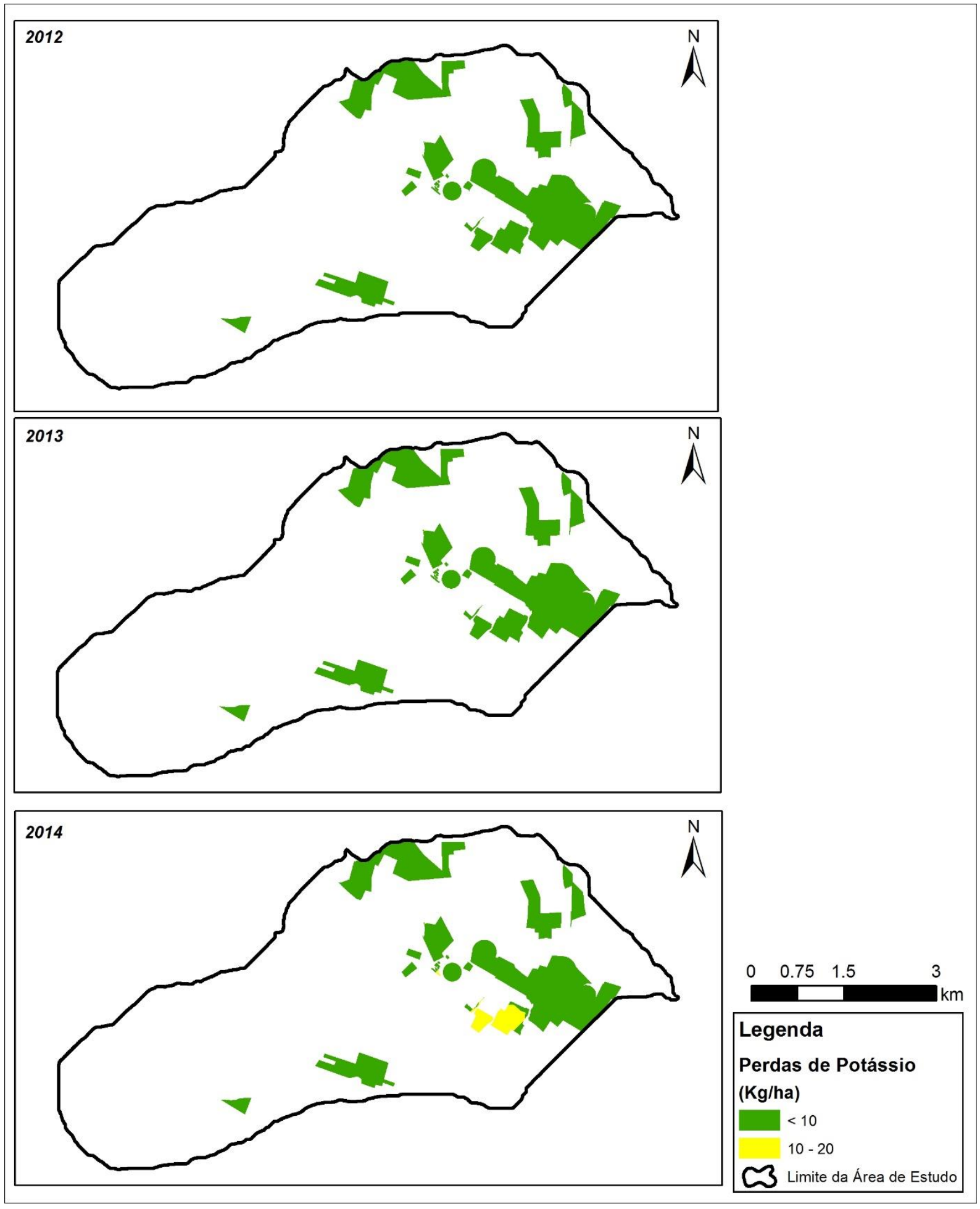

Figura 39 - Perdas de K estimadas a partir das taxas de erosão laminar na área de produção agrícola da bacia experimental do córrego Sarandi 


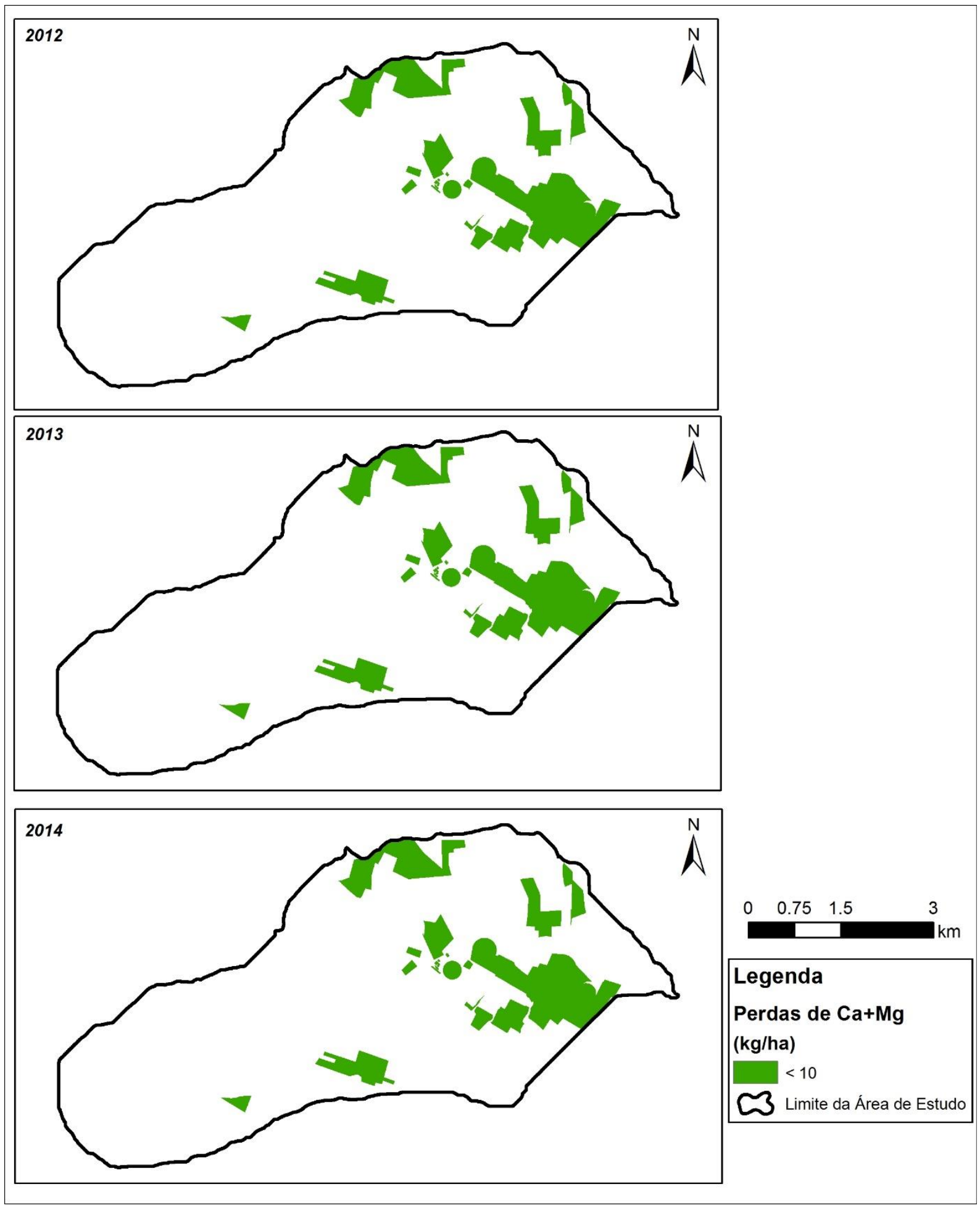

Figura 40 - Perdas de Ca+Mg estimadas a partir das taxas de erosão laminar na área de produção agrícola da bacia experimental do córrego Sarandi 


\subsection{0 - ANÁLISE DO CUSTO DE REPOSIÇÃO DE FERTILIZANTES}

No ano de 2012, os custos de reposição variam entre 75,97 a 240,87 R \$.ha ${ }^{-1}$; no ano de 2013, os custos variaram entre 86,51 e 212,81 R\$.ha-1; já o ano de 2014 apresentou custos variando entre 87,81 e $447,05 \mathrm{R} \$ . \mathrm{ha}^{-1}$ (Figura 41).

A parte alta da bacia ocupada principalmente por Agricultura de Sequeiro, apresentou o mesmo padrão em todos os anos do período analisado, com custos de reposição variando entre 100 e $200 \mathrm{R} \$ \cdot \mathrm{ha}^{-1}$.

Uma porção da fazenda experimental da Embrapa, apresentou, durante todo o período, custos abaixo de $100 \mathrm{R}$.ha ${ }^{-1}$. As áreas de Pivô Central apresentaram o mesmo padrão durante os três anos analisados, com exceção de uma pequena área localizada em ambiente de gleissolo, que apresentou, em 2013, custos acima de $200 \mathrm{R} \$ . \mathrm{ha}^{-1}$.

Neste mesmo ano, todas as áreas produtivas em ambiente de gleissolo apresentaram custos acima de $200 \mathrm{R} \$ \cdot \mathrm{ha}^{-1}$.

Por fim, a área de produção de dendê, está em ambiente de latossolo vermelho, localizada na parte sul da fazenda da Embrapa, apresentou os maiores custos de reposição 447,05 R \$.ha ${ }^{-1}$; as áreas de produção em ambiente de gleissolo descritas anteriormente também apresentaram custos acima de $200 \mathrm{R} \$ . \mathrm{ha}^{-1}$. Todas estas áreas possuem menos de 5 ha.

Os resultados mostram que, em geral, os custos de reposição na bacia são baixos quando comparados com outros trabalhos que utilizaram o método de custo de reposição de nutrientes para calcular os custos internos provocados pela erosão na agricultura (RODRIGUES, 2005; TOSTO et.al., 2010; PUGLIESI et.al., 2011; entre outros). 


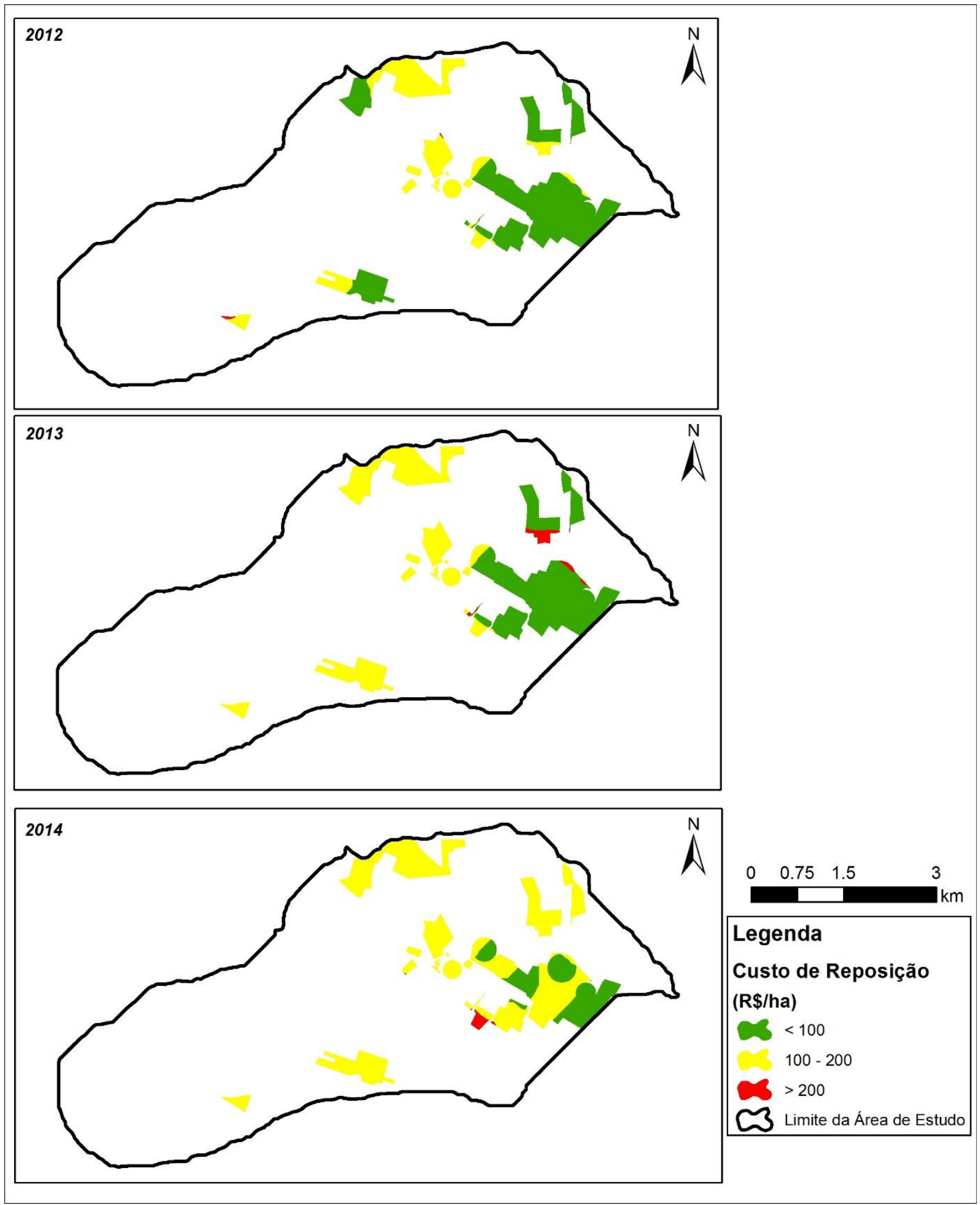

Figura 41 - Custos de reposição de fertilizantes na área de produção agrícola da bacia experimental do córrego Sarandi 


\subsection{1 - IMPACTOS DA PERDA DE NUTRIENTES NO VALOR DA PRODUÇÃO}

Na simulação da produtividade da cultura agrícola é possível observar que, no primeiro ano da série, a maior parte da agricultura de sequeiro teve uma produção menor que 5 ton.ha ${ }^{-1}$, e o restante da área produtiva da bacia teve produção que variou entre 5 e 10 ton.ha $^{-1}$. Nos demais anos da série, a área produtiva da bacia apresentou uma produção que variou de 5 a 10 ton.ha ${ }^{-1}$, com exceção da área de produção de dendê na parte sul da fazenda da Embrapa, onde a produção chegou a aproximadamente 16 ton.ha- ${ }^{-1}$ (Figura 42).

Com a produtividade da bacia simulada, foi possível calcular o Valor Presente Líquido das HRUs (Equação 10) ocupadas por agricultura de sequeiro, agricultura irrigada, e pivô central. É possível observar na Figura 43 que 2012 - considerado na simulação como ano de implantação da cultura - apresentou os menores ganhos, dado que nesse ano os custos de implantação foram maiores e a receita gerada foi menor que nos demais anos, gerando renda inferior a $50.10^{3} \mathrm{R} \$ \cdot \mathrm{ha}^{-1}$. No ano de 2013 somente a área de produção de dendê localizada na parte sul da fazenda da Embrapa apresentou aumento de valor, chegando a aproximadamente $79.10^{3} \mathrm{R} \$ . \mathrm{ha}^{-1}$. Já no ano de 2014, somente a área de agricultura irrigada encontra-se na faixa de valor entre $50.10^{3}$ e $100.10^{3} \mathrm{R} \$ . \mathrm{ha}^{-1}$, com exceção das áreas de pivô central que apresentam VPL menor que $50.10^{3} \mathrm{R} \$ . \mathrm{ha}^{-1}$, e a área de produção de dendê localizada na parte sul da fazenda da Embrapa, que apresentou um VPL de aproximadamente $132.10^{3} \mathrm{R} \$ . \mathrm{ha}^{-1}$.

Importante destacar que, dada a natureza heterogênea da fazenda experimental da Embrapa, não foi feita a calibração da produtividade na bacia, permitindo que o SWAT obtivesse os maiores valores possíveis com o banco de dados utilizado, podendo, assim, haver resultados superestimados quando comparados com a realidade da bacia.

Por fim, foi feita a análise do custo relativo da reposição de nutrientes (Figura 44) verificando qual o impacto dos custos internos no VPL da produção agrícola na área de estudo para cada HRU. Na maior parte da bacia, no ano de 2012, a reposição de nutrientes foi menos de $2 \%$ do VPL. Na parte norte da bacia -área de produção de milho e horticultura em ambiente de gleissolo -, os custos representam aproximadamente 11,1\% do VPL da produção. Na parte alta da bacia, a oeste -área de fruticultura em ambiente de gleissolo -, os custos representam $11,6 \%$ do VPL da HRU. O maior custo relativo foi observado na pequena faixa de pivô central que se localiza em ambiente de gleissolo, representando 19,85\% do VPL. Já nos demais anos 
da série, os custos relativos foram muito baixos, representando, no máximo, 2,08\% do VPL em 2013 e $0,74 \%$ do VPL em 2014.

Estes resultados demonstram a importância do conhecimento da paisagem para identificação dos pontos mais críticos e os motivos que levam algumas áreas agricultáveis apresentarem, como consequência da erosão, maiores custos internos do que outras.

Retomando a ideia da Figura 1, em que as paisagens se formam por meio de processos diversos em tempos diversos, pode-se afirmar, perante o exposto, que as atividades econômicas contribuem significativamente para a alteração e criação de novas paisagens, contribuindo para a formação da totalidade do espaço. Em contrapartida, os elementos que compõem a paisagem e consequentemente, a totalidade do espaço, conforme demonstrado, são variáveis importantes na composição do valor econômico ambiental, que devem ser considerados em seus diferentes contextos espaciais para que a valoração seja mais próxima da realidade. Além disso, verificase que os diversos autores analisados seguem tanto a vertente da economia ambiental neoclássica como a vertente da economia ecológica e que os conceitos geográficos apresentados têm a contribuir para a ciência econômica ambiental como um todo, independente da vertente escolhida para a análise.

Assim, pode-se concluir que os conceitos geográficos fornecem uma gama de ferramentas teóricas e práticas a serem incorporadas aos modelos da economia ambiental, uma vez que, ao se ter um conhecimento maior dos processos que envolvem as transformações da paisagem provocadas pelas atividades econômicas, é possível desenvolver estes modelos, incorporando novas variáveis e reduzindo o grau de incerteza, tanto do ponto de vista quantitativo como do ponto de vista qualitativo. 


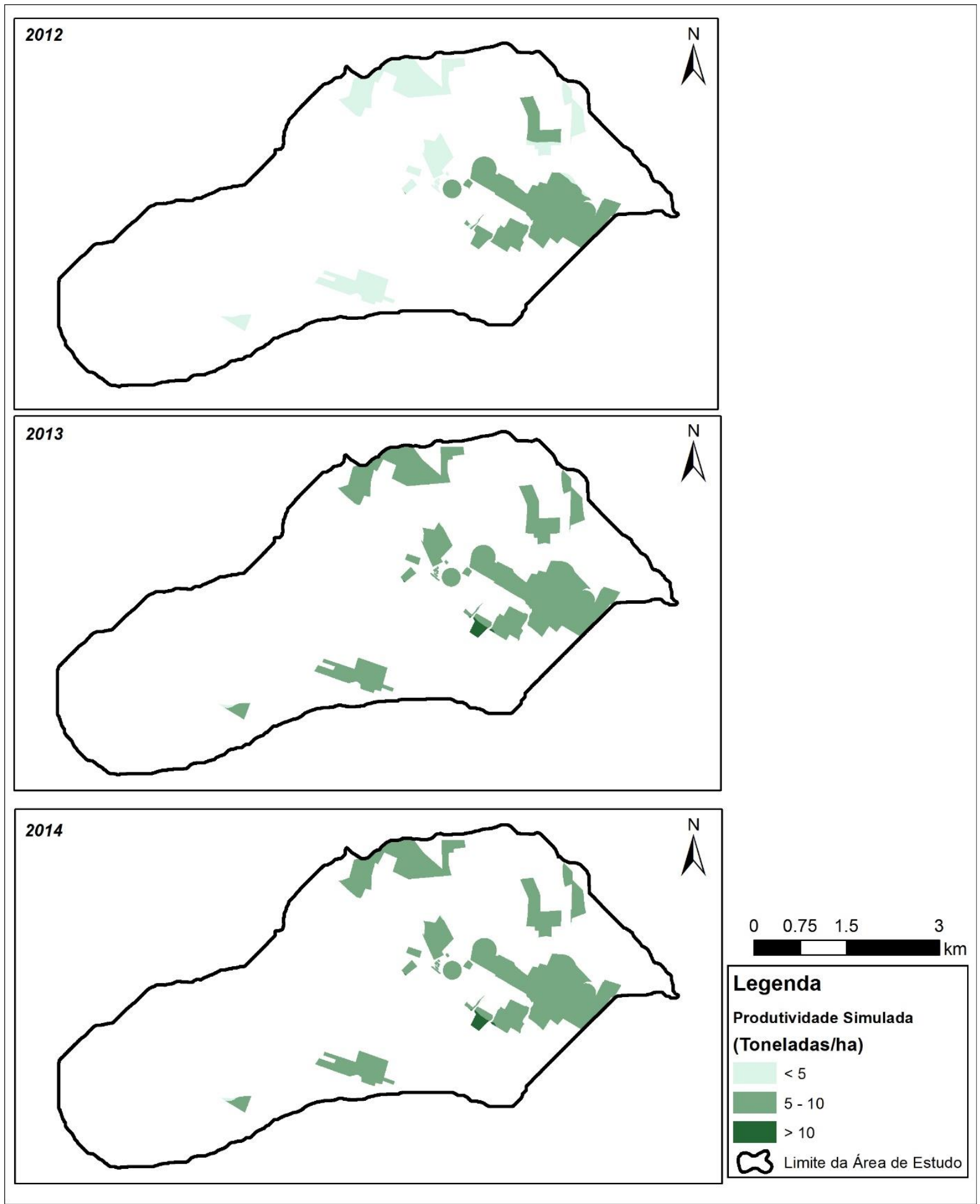

Figura 42 - Produtividade agrícola simulada pelo SWAT 


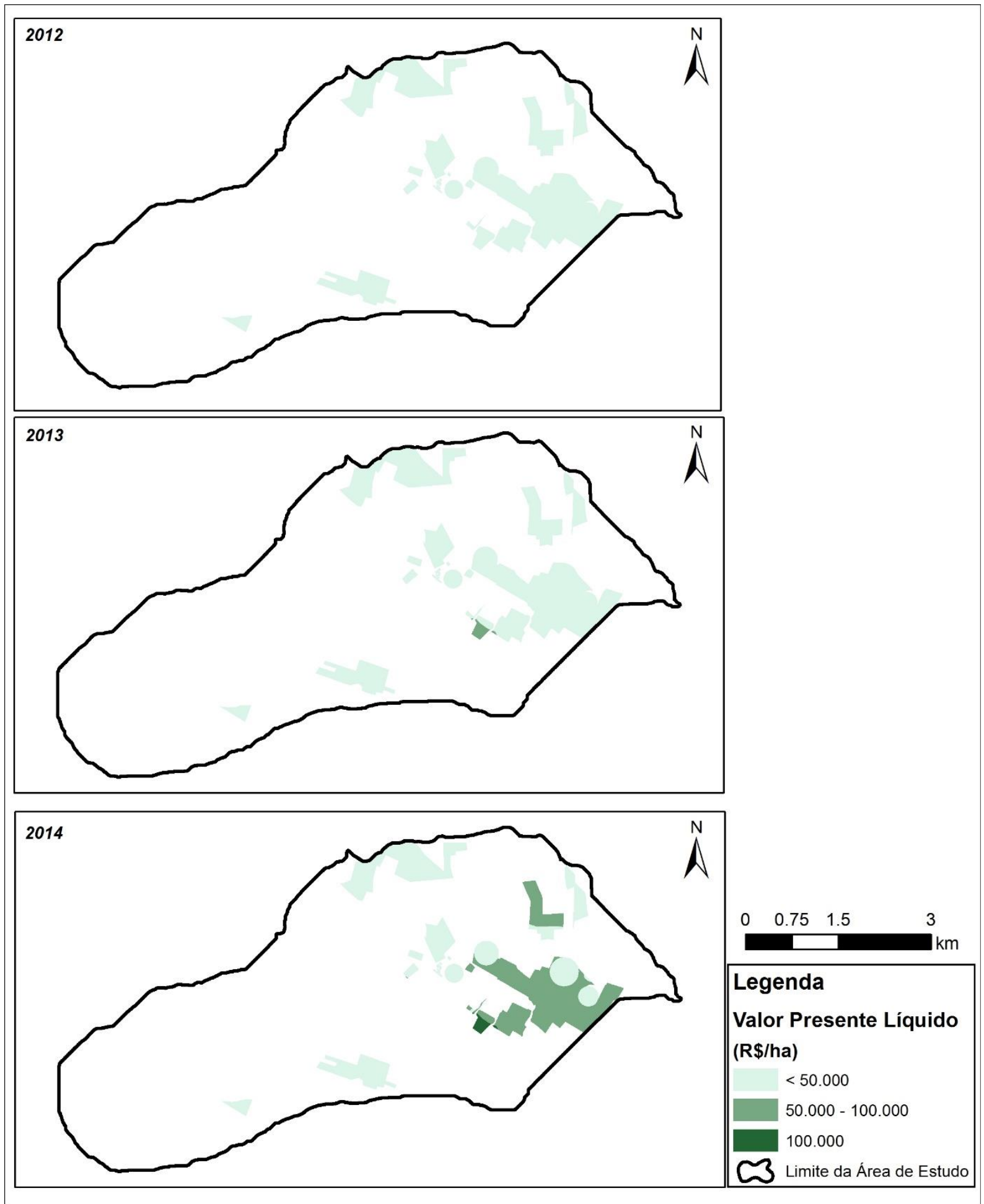

Figura 43 - Valor Presente Líquido da produção (R\$.ha-1) na área de estudo 


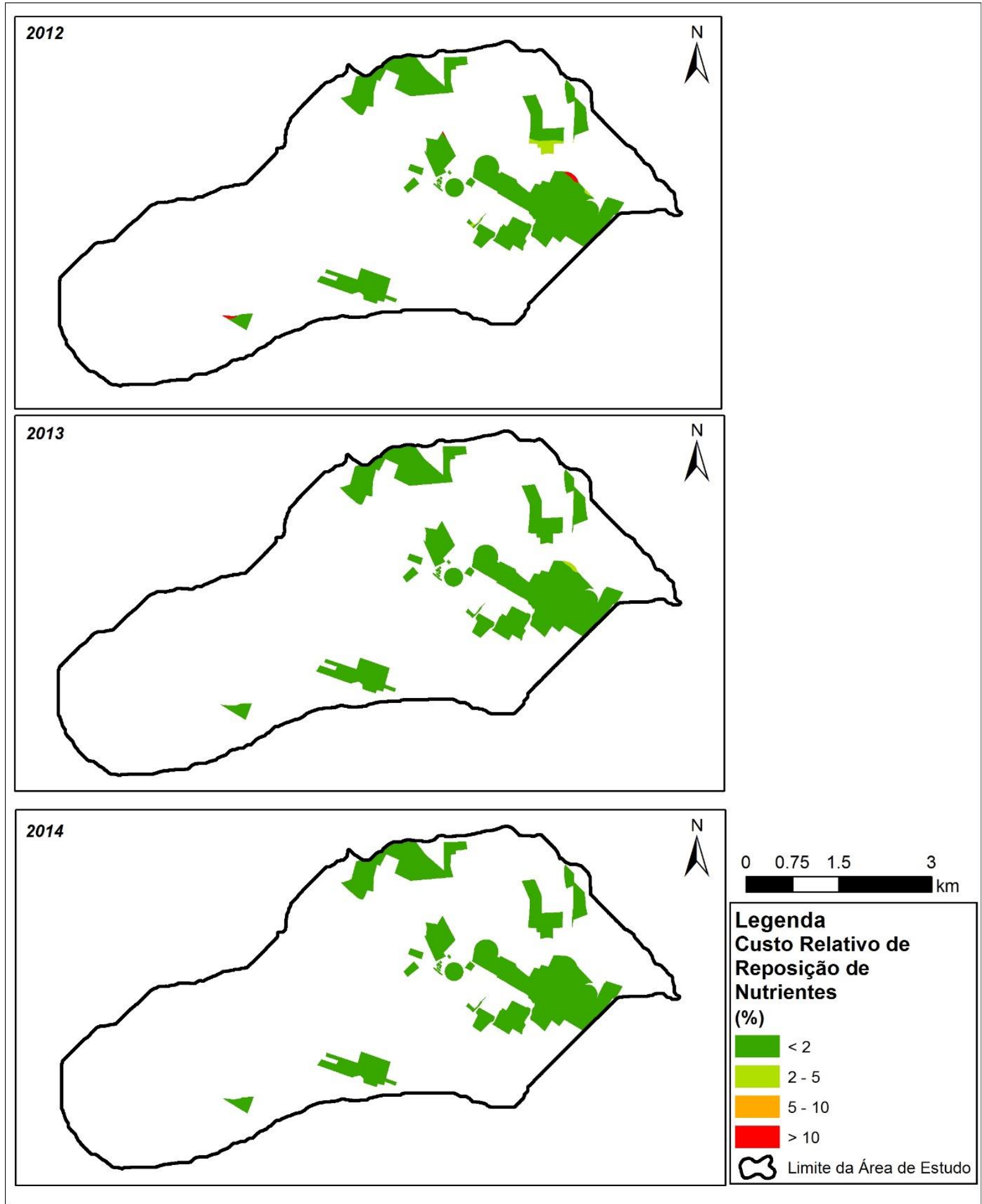

Figura 44 - Custos relativos da reposição de nutrientes em relação ao VPL da produção 


\section{0 - CONSIDERAÇÕES FINAIS}

Os resultados deste trabalho indicam que:

a) Foi possível a integração de modelos hidrológico e econômico para avaliar os custos internos provocados pela erosão em uma bacia hidrográfica ocupada por agricultura, com geração de resultados plausíveis e passíveis de serem utilizados para gestão do espaço geográfico;

b) A aplicação do SWAT foi capaz de simular a vazão e o fluxo de nutrientes, em escala temporal diária, de forma satisfatória, no entanto, a simulação de sedimentos, mesmo em escala temporal mensal, mostrou-se insatisfatória, com resultados superestimados em relação aos dados observados;

c) Com a aplicação do modelo SWAT, foi possível qualificar e quantificar as perdas de solo, de nutrientes e custos associados de forma espacialmente distribuída dentro de bacias hidrográfica.

d) Esta abordagem metodológica possui grande potencial como ferramenta de gestão do espaço geográfico, tanto em escala de propriedade como em escala de bacia hidrográfica, reduzindo o grau de subjetividade e incertezas no processo de tomadas de decisão.

e) Verificou-se que os custos internos da erosão foram baixos $(<2 \%$ do valor da produção) em grande parte da bacia de estudo, exceto onde se desenvolve agricultura em áreas com baixa aptidão agrícola, como o caso de cultivos implantados em ambiente de gleissolo, em que os custos foram acima de $10 \%$ do valor da produção, chegando a aproximadamente $20 \%$.

f) Estes resultados demonstram a importância do conhecimento da paisagem para identificação dos pontos mais críticos e os motivos que levam algumas áreas agricultáveis apresentarem, como consequência da erosão, maiores custos internos do que outras;

g) Os conceitos geográficos fornecem uma gama de ferramentas teóricas e práticas a serem incorporadas aos modelos da economia ambiental, uma vez que, ao se ter um conhecimento maior dos processos que envolvem as transformações da paisagem provocadas pelas atividades econômicas, é possível desenvolver estes 
modelos, incorporando novas variáveis e reduzindo o grau de incerteza, tanto do ponto de vista quantitativo como do ponto de vista qualitativo;

h) Por fim, recomenda-se que a metodologia utilizada seja aplicada em outras bacias, tanto no cerrado como em outros biomas, para que haja uma verificação de sua eficiência para a valoração dos custos internos da erosão em diferentes áreas de agricultura. 


\section{REFERÊNCIAS BIBLIOGRÁFICAS}

AB'SÁBER, A. (1989) Zoneamento Ecológico e Econômico da Amazônia: Questões de Escala e Método. Estudo Avançados, São Paulo, 3, pp. 4-20.

ABBASPOUR, K.C. Swat-Cup: SWAT Calibration and Uncertainty Programs. Department of Systems Analisys, Integrated Assessment and Modelling (SIAM), Eawag, Swiss federal Institute of Aquatic Science and Technology, Duenbendorf, Switzerland, 100p., 2015.

ABBASPOUR, K.C.; ROUHOLAHNEJAD, E; VAGHEFI, S.; SRIVINASAN, R.; YANG, H.; KLOVE, B. A continental-scale hydrology and water quality model for Europe: Calibration and uncertainty of a high-resolution large-scale SWAT model. In: Journal of Hydrology, 524, p. 733-752, 2015.

ACSELRAD, H. Zoneamento Ecológico-econômico- entre a ordem visual e o mercado-mundo. In: XII Encontro Nacional de Estudos Populacionais, 2000, Caxambu-MG. XII Encontro Nacional de Estudos Populacionais, 2000, pp. 1-28. Disponível em: <http://www.abep.nepo.unicamp.br/docs/anais/pdf/2000/todos/ambt25_2.pdf >. Acessado em: 09/08/2015.

AKHAVAN, S.; JAHANGIR, A.K.; MOUSAVI, S.F.; AFYUNI, M.; ESLAMIAN, S.S.; ABBASPOUR, K.C. Application of SWAT model to investigate nitrate leaching in HamadanBahar Watershed, Iran. In: Agriculture, Ecosystems and Environment, vol. 139, 2010, p. 675688.

ANDRADE, L.R.M. Corretivos e fertilizantes para culturas perenes e semiperenes. In: SOUSA, D.M.G.; LOBATO, E. (Orgs.) Cerrado: correção do solo e adubação, Planaltina, DF, Embrapa Cerrados, p. 317-366, 2002.

ANDRADE, M. A.; MELLO, C.R.; BESKOW, S. Simulação hidrológica em uma bacia hidrográfica representativa dos Latossolos na região Alto Rio Grande, MG. Revista Brasileira de Engenharia Agrícola e Ambiental (Online), v. 17, 2013, 69-76.

ANDRADE, D.C.; ROMEIRO, A.R. Valoração de serviços ecossistêmicos: por que e como avançar? In: Sustentabilidade em debate, Brasília, v. 4, nº 1, p. 43-58, 2013.

ARNOLD, J.G.; ALLEN, P.M. Estimating hydrologic budgets for three Illinois watersheds. In: Journal of Hydrology, no 176, p. 57-77, 1996.

ARNOLD, J.G. MUTTIAH, R.S.; SRINIVASAN, R.; ALLEN, P.M. Regional estimation of base flow and groundwater recharge in the Upper Mississippi river basin. In: Journal of Hydrology, 227, 21-40, 2000.

ARNOLD, J.G; MORIASI, D.N.; GASSMAN, P.W.; ABBASPOUR, K.C.; WHITE, M.J.; SRINIVASAN, R.; SANTHI, C.; HARMEL, R.D.; VAN GRIENSVEN, A.; VAN LIEW, M.W.; KANNAN, N.; JHA, M.K. SWAT: Model use, calibration and validation. In: Transactions of the ASABE - American Society of Agricultural nad Biological Engineering, vol. 55(4), pp. 1491-1508, 2012.

ARNOLD, J.G.; HARMEL, D.; JOHNSON, M.V.V.; BINGNER, R.; STRICKLAND, T.C.; WALBRIDGE, M.; CHINNASAMY, S.; DILUZIO, M.; WANG, X. Impacts of the Agricultural Service Research Service Watershed Assessment studies on the conservation 
effects assessment Project Cropland National Assessment. In: Journal of Soil and Water Conservation, 69 (5), 2014, 137A-144A.

BARBIER, E.B. The farm-level economics of soil conservation: the uplands of Java. In: Land Economics, vol. 66, no 2, p. 199-211, 1990.

Valuing Environmental Functions: Tropical Wetlands. In: Land Economics, Vol. 70, n 2., pp. 155-173, 1994. Disponível em: http://www.jstor.org/stable/3146319 . Acessado em: $24 / 09 / 2012$

The Economics of Soil Erosion: Theory, Methodology and Examples. In: BARBIER, E.B. (org.) The Economics of Environment and Development: Selected Essays, Edward Elgar, Cheltenham, UK, pp. 281-307. 1998.

BEASLEY, D.B.; HUGGINS, L.F. ANSWERS User's Manual. Chicago: U.S. Environmental Protection Agency. Report n ${ }^{\circ}$ 905/9-82-001, 1982.

BELINAZZI JR., R.; BERTOLINI, D.; LOMBARDI NETTO, F. A ocorrência de erosão rural no Estado de São Paulo. In: Simpósio sobre o controle da erosão, n. 2 São Paulo, 1981. anais: ABGE, 1981.

BENDER, O.; BOEHMER, H.J.; JENS, D.; SCHUMACHER, K.P. Using GIS to analyse longterm cultural landscape change in Southern Germany. In: Landscape and Urban Planning, Elsevier, no 70, p. 111-125. 2005.

BENNET, H.H. Some neglected soil investigations. Soil Science Society of American Journal, v. B4, n.1, p.63-72, 1923.

. Some Aspects of Soil Erosion as a National Problem. Soil Science Society of American Journal, v. B10, n. 1-2, p. 55-74, 1929.

The cost of soil erosion. The Ohio Journal of Science, v.33, n.4, 271-279, 1933.

BOLLINGER, J. Simulating complex landscapes with a generic model: Sensitivity to qualitative and quantitative classifications. Ecological Complexity, nº 2, 2005, p. 131-149.

BONUMÁ, N. B., REICHERT, J. M., MINELLA, J. P., BARROS, C. A. P., RODRIGUES, M. F., BUARQUE, D. C. Balanço hídrico e sua relação com a modelagem da produção de sedimentos em uma pequena bacia hidrográfica rural. In: IX Encontro Nacional de Engenharia de Sedimentos. Brasília, Distrito Federal. Brasil, 2010.

CARLOS, A.F.A. A condição espacial. São Paulo. Contexto, 2011, 157p.

CARVALHO, F.H. Uso do modelo SWAT na estimativa de vazão e da produção de sedimentos em bacia agrícola do Cerrado Brasileiro. Dissertação de Mestrado, Universidade de Brasília Faculdade de Agronomia e Medicina Veterinária, 2014, 154p.

CASTRO, K.B. Avaliação do modelo SWAT na simulação da vazão em bacia agrícola do cerrado intensamente monitorada. Dissertação de Mestrado, Universidade de Brasília, Instituto de Geociências, 122p., 2013.

CHAVES, T.A. Análise do Custo Econômico da Erosão em uma Bacia Hidrográfica Ocupada por Agricultura - Um Estudo de Caso na Bacia do Rio Jardim-DF. Dissertação de Mestrado 
em Geografia, Universidade de Brasília, Instituto de Ciências Humanas, Departamento de Geografia, 86p., 2011.

CHAVES, T.A.; LIMA, J.E.F.W.; AQUINO, F.G.; VILELA, M.F.; GOMES, R.A.T.; CARVALHO JÚNIOR, O.A.; GUIMARÃES, R.F. Mapeamento do uso e cobertura da terra na bacia experimental do córrego Sarandi-DF em escala 1:5.000. Em: Boletim de Pesquisa e Desenvolvimento (Embrapa Cerrados), v. 320, pp. 1-25, 2014.

CHRISTOFOLETTI, A. L. H. Sistemas Dinâmicos: As abordagens da Teoria do Caos e da Geometria Fractal em Geografia. In: VITTE, A.C. \& GUERRA, A.J.T. Reflexões sobre a geografia física no Brasil. Rio de Janeiro, Bertrand Brasil, 2004, p. 89-110.

COHEN, M.J.; BROWN, M.T.; SHEPERD, K.D. Estimating the environmental costs of soil erosion at multiple scales in Kenya using emergy synthesis. In: Agriculture, Ecosystems \& Environment, $\mathrm{n}^{\circ}$ 114, p. 249-269, 2006.

CORREIA, E.F.G.; RIBEIRO, G.P.; BAPTISTA, A.C. Modelagem hidrológica da bacia hidrográfica do rio Bengalas, Nova Friburgo, RJ, utilizando o potencial de geotecnologias na definição de áreas de risco à inundação. In: Revista Brasileira de Cartografia, nº 67/6, 2015, 1183-1202.

CONSTANZA, R.; D’ARGE, R.; DE GROOT, R.; FARBER, S.; GRASSO, M. HANNON, B.; LIMBURG, K. NAEEM, S.; O’NEILL, R.V.; PARUELO, J.; RASKIN, R.G.; SUTTON, P. VAN DEN BELT, M. The value of the world's ecosystem services and natural capital. In: Nature, 387, 253 - 260. 1997.

CREPANI, E.; MEDEIROS, J.S.; HERNANDEZ FILHO, P.; FLORENZANO, T. G.; DUARTE, V. BARBOSA, C.C.F. Sensoriamento Remoto e Geoprocessamento Aplicados ao Zoneamento Ecológico-Econômico e ao Ordenamento Territorial. São José dos Campos, INPE, Ministério da Ciência e Tecnologia, junho de 2001, 103.p.. Disponível em: <www.dsr.inpe.br/laf/sap/artigos/CrepaneEtAl.pdf>. Acessado em: 09/08/2015.

DANTAS, K.P.; MONTEIRO, M.S.L. Valoração econômica dos efeitos internos da erosão: impactos da produção de soja no cerrado piauiense. In: RESR, Piracicaba, SP, vol. 48, $\mathrm{n}^{\circ} 4$, 2010, p. 619-633.

DRAKE, L. The Swedish agricultural landscape - economic characteristics, valuations and policy options. In: International Journal of Social Economics, vol. 26, nº7-9, 1999, pp. 10421062.

DE GROOT, R.S.; ALKEMADE, R.; BRAAT, L.; HEIN, L.; WILLEMEN, L. (2010) Challenges in integrating the concept of ecosystem services and values in landscape planning, management and decision making. In: Ecological Complexity, n ${ }^{\circ}$ 7, p. 260-272.

DURÃES, M. F. Caracterização e avaliação do estresse hidrológico da bacia do Rio Paraopeba, por meio de simulação chuva-vazão de cenários atuais e prospectivos de ocupação e uso do solo utilizando um modelo hidrológico distribuído. Dissertação de Mestrado, Instituto de Meio Ambiente e Recursos Hídricos, Universidade Federal de Minas Gerais, Belo Horizonte, 2010, 134p 
EMATER-DF - Empresa de Assistência Técnica e Extensão Rural do Distrito Federal. Custos de produção. 2015. Disponível em: <http://www.emater.df.gov.br/>. Acesso em: 15/09/2015.

EMBRAPA. Pesquisa, Desenvolvimento, e Inovação para o Agronegócio Brasileiro: Cenários 2002-2012. Brasília, Embrapa Informação Tecnológica, 2003, 91p.

ENGLISH, A.; TYNER,W.E.; SESMERO, J. OWENS, P.; MUTH JUNIOR, D.J.; Environmental tradeoffs of stover removal and erosion in Indiana. In: Biofuels, Bioproducts, and Biorefining, volume 7, $\mathrm{n}^{\circ} 1, \mathrm{p} .78-88,2013$.

FAEG - FEDERAÇÂO DA AGRICULTURA E PECUÁRIA DE GOIÁS. Estimativa do Custo de Produção do Trigo, junho de 2015, 2015. Disponível em:<www.sistemafaeg.com.br/custode-producao-trigo>. Acessado em: 23/09/2015

FAISSOL, S. Problemas Geográficos brasileiros: análises quantitativas. IBGE, 1973, 271p.

FAN, M.; SHIBATA, H.; WANG, Q. Optimal conservation planning of multiple hydrological ecosystem services under land use and climate chances in Teshio river watershed, northernmost of Japan. In: Ecological Indicators, vol. 62, 2016, p. 1-13.

FERRIGO, S. Análise de consistência dos parâmetros do modelo SWAT obtidos por calibração automática - Estudo de caso da bacia do lago Descoberto - DF. Dissertação de Mestrado ENC/FT/Universidade de Brasília, Tecnologia Ambiental e Recursos Hídricos, 164p. 2014.

FISHER, B.; TURNER, R.K.; MORLING, P. Defining and classifying ecosystem services for decision making. In: Ecological Economics, nº 68, p. 643-653. 2009.

FERRIGO, S. Análise de consistência dos parâmetros do modelo SWAT obtidos por calibração automática - Estudo de caso da bacia do lago Descoberto - DF. Dissertação de Mestrado ENC/FT/Universidade de Brasília, Tecnologia Ambiental e Recursos Hídricos, 164p. 2014.

FORTES, M.Z.; BARBOSA, M.V.; NASCIMENTO, R.C.; CARVALHO, J.T.; ALBUQUERQUE, C.J. Análise de Viabilidade Técnico-Econômica para Erradicação de Árvores sob Linhas de Distribuição. In: Revista Brasileira de Energia, vol. 16, nº1, 2010, pp. 93-106.

GARBOSSA, L. H. P.; BLAINSKI, E.; JUSTEN, J. G K.; VASCONCELOS, L. R.. Potencial de uso de modelo hidrológico de base física na avaliação da legislação florestal e seus impactos nos cenários hidrológicos. In X Simpósio de Recursos Hídricos do Nordeste. Fortaleza - Ceará. Brasil, 2010.

GÓMEZ-BAGGETHUN, E; DE GROOT, R.; LOMAS, P. L.; MONTES, C. (2010) The history of ecosystem services in economic theory and practice: From early notions to markets and payment schemes. In: Econolical Economics, n $^{\circ}$ 69. P. 1209-1218.

GREEN, C.H.; VAN GRIENSVEN, A. Autocalibration in hydrologic modelling: Using SWAT2005 in small-scale watersheds. In: Environmental Modelling \& Software, 23, p. 422434, 2008.

GUERRA, A.F.; ROCHA, O.C.; RODRIGUES, G.C.; SANZONOWICZ, C.; RIBEIRO FILHO, G.C. TOLEDO, P.M.R.; RIBEIRO, L.F. Sistema de produção de café irrigado: um novo enfoque. In: ITEM, $\mathrm{n}^{\circ} 73,1^{\circ}$ trimestre de 2007, p. 52-61, 2007. 
HAMMOND, A.; ADRIAANSE, A.; RODENBURG, E.; BRYANT, D.; WOODWARD, R. Enviromental Indicators: A systematic approach to measuring and reporting on environmental policy performance in the context of sustainable development. World Resources Institutes. May, 1995.

HARTSHORNE, R. Perspective on the Nature of Geography. Association of American Geographers, Monograph Series, No. 1. Chicago: Rand McNally. 1959, 201p.

HARVEY, D. O enigma do capital e as crises do capitalismo. São Paulo: Boitempo, 2011, 240p.

HEIDE, C.M. van der; BLAEIJ, A.T.; HEIJMAN, W.J.M. Economic aspects in landscape decision making: a participatory planning tool based on a representative approach. In: 12th Congress of the European Association Economists - EAAE, 2008, p. 1-10.

HEINZE, B.C.L. A importância da agricultura irrigada para o desenvolvimento da Região Nordeste. Monografia, MBA - Gestão Sustentável da Agricultura Irrigada. Fundação Getúlio Vargas, Brasília, 70p. 2002.

HOLZER, W. Paisagem, imaginário, identidade: alternativas para o estudo geográfico. In: ROSENDAHL, Zeny; CORRÊA, Roberto Lobato (Org.). Manifestações da cultura no espaço. Rio de Janeiro: Ed. UERJ, 1999, pp. 149-168.

HUFSCHMIDT, M.M.; JAMES, E.; MEISTER, A.D.; BOWER, B.T.; DIXON, J.A. Environment, Natural Systems and Development: An economic Valuation Guide. Baltimore, The Johns Hopkins University Press, 1983, 338p

HUTCHINSON, M.F. A new procedure for gridding elevation and stream line data with automatic removal of spurious pits. In: Journal of Hydrology, 106: 211-232. 1989.

IBGE - INSTITUTO BRASILEIRO DE GEOGRAFIA E ESTATÍSTICA. Manual Técnico de Pedologia. $2^{a}$ Edição, IBGE, Rio de Janeiro, RJ, 316p., 2007.

JAJARMIZADEH, M.; HARUN, S.; GHAHRAMAN, B.; MOKHTARI, M.H. Modeling daily stream flow using plant evapotranspiration method. In: International Journal of Water Resources and Environmental Engineering, vol. 4(6), pp. 218-226, 2012.

KOUA, T.J.J.; JOURDA, J.P.; KOUAME, K.J.; KOUAUO, A.A.; N’DRI, W.K.C.; LAZAR, G.; LANE, S. Effectiveness of Soil and Water Assessment Tool model to simulate water flow in a large agricultural complex watershed: case of Buyo Lake basin, westof Côte D'Ivoire. In: Environmental Engineering and Management Journal, vol. 13, nº 7, 2014, p. 1735-1742.

LA BLACHE, V. Os Gêneros de Vida na Geografia Humana. Nossos Clássicos: Geografia Geral. GEOgraphia, Ano 7, n 13, 2005, pp. 113-130.

Princípios de Geografia Humana. Lisboa, Cosmos, 1954, 241p.

LELIS, T. A. ; CALIJURI, M. L. ; SANTIAGO, A. da F. ; LIMA, D. C. de ; ROCHA, E. de O. Análise de sensibilidade e calibração do modelo SWAT aplicado em bacia hidrográfica da região sudeste do Brasil. Revista Brasileira de Ciência do Solo (Impresso). v. 36, 2012, 623634 
LENHART, T.; ECKHARDT, K.; FOHRER, N.; FREDE, -G. Comparison of two different approaches of sensitivity analysis. In: Physics and Chemistry of the Earth, 27, p. 645-654, 2002.

LIENHARD, P.; PANYASIRI, K.; SAYPHOUMMIE, S.; LEUDPHANANE, B.; LESTRELIN, G.; SÉGUY, L.; TYVET, F.; Profitability and opportunity of conservation agriculture in acid savannah grasslands of Laos. In: International Journal of Agricultural Sustainability, vol. 12, nº, p. 391-406, 2014.

LIMA, J.E.F.W. Determinação e simulação da evapotranspiração de uma bacia hidrográfica do Cerrado. Dissertação de Mestrado, Universidade de Brasília, Faculdade de Agronomia e Medicina Veterinária, 2000, 75p.

LIMA, J. E. F. W.; LOPES, W. T. A. Estimativa da erosão no Estado do Tocantins utilizando a Equação Universal de Perda de Solo. In: IDE, C.N.; VAL, L.A.A.; RIBEIRO, M.L. (Org.). Produção de sedimentos e seus impactos ambientais, sociais e econômicos. 1 ed. Campo Grande: Ed. Oeste, 2009, v. 1, p. 499-518.

LIMA, J.E.F.W. Modelagem numérica do fluxo da água no solo e do escoamento de base em uma bacia experimental em área experimental do cerrado. Tese de doutorado, publicação PETHAR.TD - 08/10, Departamento de Engenharia Civil e Ambiental, Universidade de Brasília, DF, 2010, 312p.

LIMA, J.E.F.W. ; LOPES, W. T. A. ; AQUINO, F.G. ; OLIVEIRA-FILHO, E. C. ; SANO, E. E. ; SILVA, F. D. M. . Modelagem do potencial de erosão como suporte a programas de pagamento por serviços ambientais: o caso da bacia experimental do Córrego Sarandi - DF. In: CRISTIANO POLETO; ADELMO LOWE PLETSCH; ELOY LEMOS MELLO; NEWTON DE OLIVEIRA CARVALHO. (Org.). X ENES - Encontro Nacional de Engenharia de Sedimentos: artigos selecionados. 1ed.Porto Alegre: ABRH, 2012, v. 1, p. 396-410.

LIMA, J.E.F.W.; SILVA, E.M.; STRAUCH, M.; LORZ, C. Development of a soil database for applying SWAT model in a catchment of the Brazilian Savanna. In: SWAT Conference 2013. Toulouse, Book of Abstracts, v.1, 2013.

LIMA, J.E.F.W.; MONTENEGRO, S.M.G.L; MONTENEGRO, A.A.A.; KOIDE, S. Comparative hydrology: relationships among physical characteristics, hydrological behavior, and results of the SWAT model in diferente regions of Brazil. In: Revista Brasileira de Geografia Física, vol. 7, nº, pp. 1187-1195, 2014

LIMA, L.A.S. Aplicação dos métodos semiautomático e lógica fuzzy para o mapeamento de solos da bacia do Sarandi. Dissertação de Mestrado, Universidade de Brasília, Instituto de Geociências, 124p., 2013.

LINO, J. F. L., CORSEUIL, C. W., KOBIYAMA, M., MALUTTA, S., UDA, K., BORTOLOTTO, N. L., SANTOS, I. Análise da vazão da bacia hidrográfica do rio Preto com o modelo SWAT. In: XVIII Simpósio Brasileiro de Recursos Hídricos. Campo Grande, Mato Grosso do Sul. Brasil, 2009.

MACHADO, R.E.; VETORAZZI, C.A.; XAVIER, A.C. Simulação de cenários alternativos de uso da terra em uma microbacia utilizando técnicas de modelagem e geoprocessamento. In: Revista Brasileira de Ciências do Solo, vol. 27, n 4, 2003, p. 727-733. 
MALUTTA, S. Estudo hidrossedimentológico da bacia hidrográfica do rio negrinho - SC com o modelo SWAT. Dissertação de Mestrado, Instituto de Engenharia Ambiental, Universidade Federal de Santa Catarina, 2012, 126p

MARCHIORO, E.; FERNANDES, N.F.; MACEDO, J. R.; BHERING, S.B.; GONÇALVES, A.O.; CAIADO, M. A. C. Modelagem da produção de sedimentos no Noroeste Fluminense como subsídio ao planejamento ambiental: um estudo de caso da bacia do Córrego Santa Maria. In: Revista Brasileira de Geomorfologia, vol. 12, nº1, p. 29-38, 2011.

MARTINELLI, M. e PEDROTTI, F. (2001) A Cartografia das Unidades de Paisagem: Questões Metodológicas. In: Revista Do Departamento de Geografia, USP, 14, p. 39-46.

MARTINS, E.S.; REATTO, A.; CARVALHO JR., O.A.; GUIMARÃES, R.F. (2004) Ecologia da Paisagem: Conceitos e Aplicações Potenciais no Brasil. In: Documentos Embrapa, $\mathrm{n}^{\mathbf{o}}$ 121, $35 \mathrm{p}$.

MAXIMIANO, L. A. Considerações sobre o conceito de paisagem. Revista RA'e GA, Curitiba, $\mathrm{n}^{\mathrm{o}}$ 8, 2004, p. 83-91, Editora UFPR.

MAY, P.H.; LUSTOSA, M.C.; VINHA, V. (2003) Economia do Meio Ambiente: Teoria e prática. Rio de janeiro: Elsevier, $5^{\mathrm{a}}$ impressão, $318 \mathrm{p}$

MCCONNELL, M.; BURGER, L.W. Precision conservation: a geospatial decision support tool for optimizing conservation and profitability in agricultural landscapes. In: Journal of Soil and Water Conservation, vol. 66, nº 4, p. 347-354, 2011.

MELLO, C. R.; VIOLA, M. R.; NORTON, L. D.; SILVA, A. M.; ACERBI JÚNIOR, F. W. Development and application of a simple hydrologic model simulation for a Brazilian head water basin. In: Catena, v.75, 2008, p.235-247.

MENKE, A.B. Análise de grupos para classificação de bacias hidrográficas do estado de Goiás, utilizando parâmetros morfométricos. Dissertação de Mestrado, Universidade de Brasília, Instituto de Ciências Humanas, Departamento de Geografia, 2012, 86p.

MINOTI, R.T. Abordagens qualitativa e quantitativa de micro-bacias hidrográficas e áreas alagáveis de um compartimento do médio Mogi-Superior/SP. Tese de Doutorado, Universidade de São Paulo, Escola de Engenharia de São Carlos, 247p., 2006.

MITSCH, W.J.; GOSSELINK, J.G.. The value of wetlands: importance of scale and landscape setting. In: Ecological Economics, nº 35, 2000, p. 25-33.

MITTER, H.; KIRCHNER, M.; SCHMID, E.; SCHONHART, M. The participation of agricultural stakeholders in assessing regional vulnerability of cropland to soil water erosion in Austria. In: Reg. Environmental Change, v.14, p.385-400, 2014.

MONSALVE HERRERA, D.J. Integração de modelos de quantidade e qualidade da água para avaliação de cargas contaminantes em afluentes de mananciais de abastecimento. Dissertação de Mestrado, Universidade de Brasília, Faculdade de Tecnologia, Tecnologia Ambiental e Recursos Hídricos, 120 p. 2013.

MONTGOMERY, D.R. Soil Erosion and Agricultural Sustainability. In: Proceedings of the National Academy of Sciences, vol. 104, n 33, august, 2007, pp. 13268-13272. 
MORIASI D. N; ARNOLD J. G; VAN LIEW M. W; BINGER R. L; HARMEL R. D; VEITH T. Model evaluation guidelines for systematic quantification of accuracy in watershed simulations. Trans ASABE, v. 50, p. 885-900, 2007.

MUELLER, C. C. Os economistas e as relações entre o sistema econômico e o meio ambiente. Brasília: Editora Universidade de Brasília, Finatec, 2007, 562p.

NASH, J.E. e SUTCLIFFE, J.E. River flow forecasting through conceptual models: Part I. A discussion of principles. In: Journal of Hydrology, 10(3), pp. 282-290, 1970.

NEITSCH, S.L.; ARNOLD, J.G.; KINIRY, J.R.. WILLIAMS, J.R. Soil and Water Assessment Tool Theoretical Documentation: Version 2009. Texas Water Resources Institute Technical Report, $\mathrm{n}^{\circ}$ 406, 618p., 2011.

NELSON, E.; MENDONZA, G.; REGETZ, J.; POLASKY, S.; TALLIS, H.; CAMERON, D.R.; CHAN, K.M.; DAILY, G. C.; GOLDSTEIN, J.; KEREIVA, P.M.; LOSDORF, E.; NAIDOO, R.; RICKETS, T.H.; SHAW, M. R. (2009). Modelling multiple ecosystem services, biodiversity conservation, commodity production, and tradeoffs at landscape scales. In: Front Ecol Environ, v. 7, no 1, p. 4-11.

NETO, R. O.; PETTER, C.O. (2005) A abordagem econômica no contexto da mineração. REM: E. Esc. Minas, Ouro Preto, vol. 58, n 1, p. 71-75.

OLIVEIRA, S.N. Metodologia para delimitação e análise multivariada de atributos morfométricos de bacia de drenagem usando modelo digital de elevação hidrologicamente corrigido. Dissertação de Mestrado, Universidade de Brasília, Instituto de Ciências Humanas, Departamento de Geografia, 2008, 74p.

ORTIZ, R.A. Valoração Econômica Ambiental. In: MAY, P.H.; LUSTOSA, M.C.; VINHA, V.

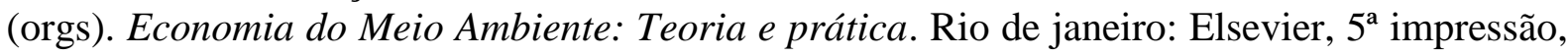
318 p. 2003.

PEREIRA, D.R.; ALMEIDA, A.Q.; MARTINEZ, M.A.; ROSA, D.R.Q. Impacts of deforestation on water balance components of a watershed on the Brazilian east coast. In: Revista Brasileira de Ciências do Solo, vol. 38, n 4, 2014, p. 1350-1358.

PIMENTEL, D.; HARVEY, C.; RESOSUDARMO, P.; SINCLAIR, K.; KURZ, D.; MCNAIR, M.; CRIST, S.; SHPRITZ, L.; FITTON, L.; SAFFOURI, R.; BLAIR, R. Environmental and economic costs of soil erosion and conservation benefits. In: Science, New Series, Vol. 267, $\mathrm{n}^{\circ}$ 5201, 1995, pp. 1117-1123.

PUGLIESI, A.C.V.; MARINHO, M.A.; MARQUES, J.F.; LUCARELLI, J.R.F. Valoração econômica do efeito da erosão em sistemas de manejo do solo empregando o método custo de reposição. In: Bragantia, Campinas, v. 70, n¹, 2011, p. 113-121.

RIBEIRO, J.F.; WALTER, B.M.T. As principais fitofisionomias do Bioma Cerrado. In: SANO, S.M.; ALMEIDA, S.P.; RIBEIRO, J.F. (Org.). Cerrado: ecologia e flora. Embrapa Cerrados, Planaltina. p.151 -212.

ROCHA, R.N.C.; RODRIGUES, M. R. L. ;TEIXEIRA, P. C.;LOPES, R.;CUNHA, R. N. V.; MACEDO, J. L. M.V . Rentabilidade econômica comparativa entre o custo de produção do dendezeiro (Elaeis guineensis Jacq.) em monocultivo e intercalado com mandioca em áreas degradadas na amazônia Ocidental.. In: $4^{o}$ Congresso Brasileiro de Plantas Oleaginosas, óleos, 
gorduras e biodiesel, 2007, Varginha. $4^{\circ}$ Congresso Brasileiro de Plantas Oleaginosas, óleos, gorduras e biodiesel, $2007 . \quad$ Disponível em: <http://www.redebiodiesel.com.br/arquivos/download/27.pdf>. Acessado em: 18/09/2013.

ROCHA, S. A. Geografia Humanista: História, conceitos e o Uso da paisagem percebida como Perspectiva de Estudo. In: Revista RA'EGA, Curitiba, n. 13, Editora UFPR, 2007, pp. 19-27.

ROCHA, E. O.; CALIJURI. M. L.; CARVALHO, I. de C.; SILVA, M. D. F. M. Utilização do modelo SWAT no monitoramento de impactos ambientais decorrentes de alterações climáticas. In: XXIV Congresso Brasileiro de Cartografia. Aracaju - SE - Brasil., 2010, 1256-1264.

RODRIGUES, W. Valoração econômica dos impactos ambientais de tecnologias de plantio em região de Cerrados. In: Rev. Econ. Sociol. Rural [online]. 2005, vol.43, n.1, pp. 135-153.

ROMEIRO, A.R. (2003) Economia ou Economia Política da Sustentabilidade. In: MAY, P.H.; LUSTOSA, M.C.; VINHA, V. (ORGS). Economia do Meio Ambiente: Teoria e prática. Rio de janeiro: Elsevier, $5^{\mathrm{a}}$ impressão, 318 p.

SALLES, L.A. Calibração e validação do modelo SWAT para a predição de vazões na bacia do ribeirão Pipiripau. Dissertação de Mestrado, Universidade de Brasília, Faculdade de Tecnologia, Departamento de Engenharia Florestal, 114p., 2012.

SANTOS, M. A natureza do Espaço. Técnica e tempo. Razão e emoção. São Paulo: HUCITEC, $4^{\mathrm{a}}$ edição, 384p. 1996.

SARCINELLI, O.; MARQUES, J.F.; ROMEIRO, A.R. Custos e benefícios da adoção de práticas e medidas para conservação do solo agrícola: um estudo de caso na microbacia hidrográfica do córrego Oriçanguinha. In: Informações Econômicas, v. 39, nº 4, 2009, p. 5-16.

SARMENTO, L. Análise de incertezas e avaliação dos fatores influentes no desempenho de modelos de simulação de bacias hidrográficas. Tese de Doutorado, Faculdade de Tecnologia, Universidade de Brasília., 2010, 241p.

SARTORI, A.; GENOVEZ, A. M.; LOMBARDI NETO, F. Classificação Hidrológica de Solos Brasileiros para a Estimativa da Chuva Excedente com o Método do Serviço de Conservação do Solo dos Estados Unidos. Parte 1: Classificação. In: Revista Brasileira de Recursos Hídricos, v. 10, 2005, p. 19-29.

SCHICK, J.; BERTOL, I.; BALBINOT JÚNIOR, A.A.; BATISTELA, O. Erosão Hídrica em Cambissolo Húmico Alimínico submetido a diferentes sistemas de preparo e cultivo do solo: II. Perdas de Nutrientes e Carbono Orgânico. Revista Brasileira de Ciências do Solo, 24: 437447, 2000.

SILVA, C.L.; OLIVEIRA, C.A.S. Runoff measurement and prediction for a watershed under natural vegetation in central Brazil. In: Revista Brasileira de Ciência do Solo, 23(3), 1999, p. 695-701.

SILVA,V.C. Estimativa da erosão atual da bacia do rio Paracatu (MG/GO/DF). In: Pesquisa Agropecuária Tropical, 34(3), 147-159, 2004.

SILVA JÚNIOR, A.G.; PEREZ, R.; MOTTA, R.A.; ERVILHA, J.C.C.; LEITE, M.A.V. Viabilidade Econômico Financeira da Produção e Industrialização do Pinhão Manso. In: 
BioEnergia UFV, s/n, 2010. Disponível em: http://www.bioenergiaufv.com.br/ . Acessado em: 16/09/2013.

SOUSA, D.M.G.; LOBATO, E.;Calagem e adubação para culturas anuais e semiperenes. In: SOUSA, D.M.G.; LOBATO, E. (Orgs.) Cerrado: correção do solo e adubação, Planaltina, DF, Embrapa Cerrados, p. 283-316, 2002

STEINBERGER, M. Território, Ambiente e Políticas Públicas Espaciais. Brasília, Paralelo 15 e LGE Editora, 2006, 406p.

STIGLIANO, B. V.; RIBEIRO, H.; CESAR, P. A. B. (2011) Paisagem Cultural e Sustentabilidade: Possíveis Conexões e Subsídios para Políticas Públicas e Planejamento do Turismo. Revista Turismo em Análise, vol. 22, nº 3, p. 632-650.

STRAUCH, M.; BERNHOFER, C.; KOIDE, S.; VOLK, M.; LORZ, C.; MAKESCHIN, F. Using precipitation data ensemble for uncertainty analysis in SWAT streamflow simulation. In: Journal of Hydrology. Amsterdam. v. 414-415, 2012, 413-424

STRAUCH, M.; LIMA, J.E.F.W.; VOLK, M.; LORZ, C.; MAKESHIN, F. The impact of best management practices on simulated streamflow and sediment load in a Central Brazilian catchment. In: Journal of Environmental Management, vol. 127, Supplement, 2013, p. S24S36.

TAPPEINER, U.; TASSER, E.; TAPPEINER, G. Modelling vegetation patterns using natural and anthropogenic influence factors: preliminary experience with a GIS based model applied to an Alpine area. In: Ecological Modelling, n 113, 1998, pp. 225-237.

TELLES, T.A.; GUIMARÃES, M.F.; DECHEN, S.C.F. The costs of soil erosion. In: Revista Brasileira de Ciência do Solo. V. 35, p. 287-298, 2011

TERRACAP - COMPANHIA IMOBILIÁRIA DE BRASÍlLIA. Novo Mapeamento 1:10.000 do DF. Brasília, TERRACAP, Formato Digital, 2010.

TOLEDO, L.B.; ROLIM, P.A.M.; NEVES, D.G.; BRAGA, A.P.; NASCIMENTO, M.J.C.; SANTOS, D.N.; LIMA, K.C. Balanço hídrico de Altamira - PA. In: XII Congresso de Meteorologia, Foz do Iguaçu, pp. 486-490, 2002.

TOSTO, S.G.; PEREIRA, L.C.; ROMEIRO, A.R.; SOBRINHO, R.P.; ANDRADE, D.C.; VALLADARES, G.S. Valoração da erosão do e a sustentabilidade ambiental no espaço rural do município de Araras, SP. In: Anais do $5^{\circ}$ seminário sobre sustentabilidade: Artigos Selecionados, Curitiba, 2010, p. 309-321.

VEIGA, J.E.; EHLERS, E. Diversidade Biológica e Dinamismo Econômico no Meio Rural. IN: MAY, P.H.; LUSTOSA. M.C.; VINHA, V. (ORGS). Economia do Meio Ambiente: Teoria e prática. Rio de janeiro: Elsevier, 5a impressão, 318 p., 2003.

VIANA, J.A.S. Agronegócio Baiano: História recente de uma evolução silenciosa. In: Bahia Análise de Dados, vol. 13, nº 4, 2004, p. 851-867.

VILELA, L.; SOARES, W.V.; SOUSA, D.M.G.; MACEDO, M.C. Calagem e adubação para pastagens. In: SOUSA, D.M.G.; LOBATO, E. (Orgs.) Cerrado: correção do solo e adubação, Planaltina, DF, Embrapa Cerrados, p. 367-384, 2002. 
WATHERN, P.; YOUNG, S.N.; BROWN, I.W.; ROBERTS, D.A (1986). Ecological Evaluation Techniques. In: Landscape Planning, $n^{\circ} 12$, pp. 403-420.

WILLIAMS, J.R. Sediment - yield prediction with universal equation using runoff energy factor. in: Present and prospective technology for predicting sediment yield and sources: Proceedings of the sediment-yield workshop. USDA Sedimentation Lab., Oxford, Mississippi, p. 244-252, 1975.

WILLIAMS, J.R. The erosion-productivity impact calculator (EPIC) model - A case history. In: Philosofical Transactions of the Royal Society of London Series B-Biological Sciences, 329 (1255); 421-428. 1990.

WISHMEIER, W.H. Storms and soil conservation. In: Journal of Soil and Water Conservation, 17, pp. 55-59, 1962.

WISHMEIER, W.H. Use and misuse of the soil loss equation. In: Journal of soil and water conservation. 31, pp. 5-9, 1976.

YOUNG, R.A.; ONSTAD, C.A.; BOSH, D.D.; ANDERSON, P. AGNPS A nonpoint-source pollution model: a watershed analysis. U.S. Department of Agriculture, Conservation Research Report, 35, 80p. 1987.

ZHANG, L.; NAN, Z.; YU, W.; GE, Y. Modelling land-use and land cover change and hydrological responses under consistent climate change scenarios in the Heihe river basin, China. In: Water Resources Management, vol. 29, n 13, 2015, pp. 4701-4717. 
ANEXOS 
ANEXO A - Valores médios dos parâmetros por camada e classe de solo

\begin{tabular}{|c|c|c|c|c|c|c|c|c|c|c|c|c|c|c|}
\hline \multicolumn{15}{|c|}{ Camada 1} \\
\hline Classe de Solo & SNAM & NLAYERS & HYDGRP & SOL_ZMX & SOL_Z & SOL_BD & SOL_AW & SOL_K & SOL_CBN & CLAY & SILT & SAND & ROCK & USLE_K \\
\hline $\begin{array}{l}\text { Latossolos } \\
\text { Vermelhos }\end{array}$ & LV & 3 & A & $8.000,00$ & 300,00 & 0,90 & 0,12 & 612,20 & 1,67 & 55,93 & 29,37 & 14,70 & 0,00 & 0,018 \\
\hline $\begin{array}{c}\text { Latossolos } \\
\text { Vermelho-Amarelos }\end{array}$ & LVA & 3 & A & $8.000,00$ & 300,00 & 0,94 & 0,11 & $1.112,85$ & 1,69 & 57,36 & 24,61 & 18,03 & 0,00 & 0,019 \\
\hline Cambissolos & $\mathrm{CX}$ & 2 & $\mathrm{C}$ & $1.000,00$ & 300,00 & 0,99 & 0,11 & 874,33 & 1,58 & 49,84 & 32,95 & 17,21 & 0,00 & 0,023 \\
\hline Gleissolos & GX & 2 & $\mathrm{D}$ & $1.000,00$ & 300,00 & 0,87 & 0,01 & 494,44 & 2,56 & 51,59 & 28,54 & 19,87 & 0,00 & 0,021 \\
\hline Plintossolos & $\mathrm{FX}$ & 2 & $\mathrm{D}$ & $1.000,00$ & 300,00 & 1,09 & 0,14 & 553,78 & 1,14 & 37,97 & 21,91 & 40,12 & 0,00 & 0,030 \\
\hline \multicolumn{15}{|c|}{ Camada 2} \\
\hline Classe de Solo & SNAM & NLAYERS & HYDGRP & SOL_ZMX & SOL_Z & SOL_BD & SOL_AW & SOL_K & SOL_CBN & CLAY & SILT & SAND & ROCK & USLE_K \\
\hline $\begin{array}{l}\text { Latossolos } \\
\text { Vermelhos }\end{array}$ & LV & 3 & A & $8.000,00$ & $1.000,00$ & 0,94 & 0,14 & 461,07 & 1,01 & 66,28 & 22,93 & 10,79 & 0,00 & 0,015 \\
\hline $\begin{array}{c}\text { Latossolos } \\
\text { Vermelho-Amarelos }\end{array}$ & LVA & 3 & A & $8.000,00$ & $1.000,00$ & 0,96 & 0,13 & 401,26 & 0,95 & 64,37 & 20,54 & 15,09 & 0,00 & 0,017 \\
\hline Cambissolos & $\mathrm{CX}$ & 2 & $\mathrm{C}$ & $1.000,00$ & $1.000,00$ & 1,00 & 0,16 & 262,52 & 0,72 & 49,16 & 34,31 & 16,53 & 0,00 & 0,023 \\
\hline Gleissolos & GX & 2 & $\mathrm{D}$ & $1.000,00$ & $1.000,00$ & 0,87 & 0,13 & 494,44 & 2,56 & 51,59 & 28,54 & 19,87 & 0,00 & 0,021 \\
\hline Plintossolos & FX & 2 & $\mathrm{D}$ & $1.000,00$ & $1.000,00$ & 1,09 & 0,14 & 553,78 & 1,14 & 37,97 & 21,91 & 40,13 & 0,00 & 0,030 \\
\hline \multicolumn{15}{|c|}{ Camada 3} \\
\hline Classe de Solo & SNAM & NLAYERS & HYDGRP & SOL_ZMX & SOL_Z & SOL_BD & SOL_AW & SOL_K & SOL_CBN & CLAY & SILT & SAND & ROCK & USLE_K \\
\hline $\begin{array}{l}\text { Latossolos } \\
\text { Vermelhos }\end{array}$ & LV & 3 & A & $8.000,00$ & $8.000,00$ & 0,94 & 0,14 & 142,32 & 1,01 & 66,28 & 22,93 & 10,79 & 0,00 & 0,015 \\
\hline $\begin{array}{c}\text { Latossolos } \\
\text { Vermelho-Amarelos }\end{array}$ & LVA & 3 & A & $8.000,00$ & $8.000,00$ & 0,96 & 0,13 & 230,05 & 0,95 & 64,37 & 20,54 & 15,09 & 0,00 & 0,017 \\
\hline
\end{tabular}

Fonte: Lima et. al. (2013) 
